\title{
Insights into the Rheology of Rocks under Brittle-Ductile Deformation Conditions from an Exhumed Shear Array in the Southern Alps, New Zealand
}

\section{Susanne Grigull}

\author{
A thesis \\ submitted to the Victoria University of Wellington \\ in fulfilment of the requirements for \\ the degree of \\ Doctor of Philosophy \\ in Geology
}

Victoria University of Wellington

2011 


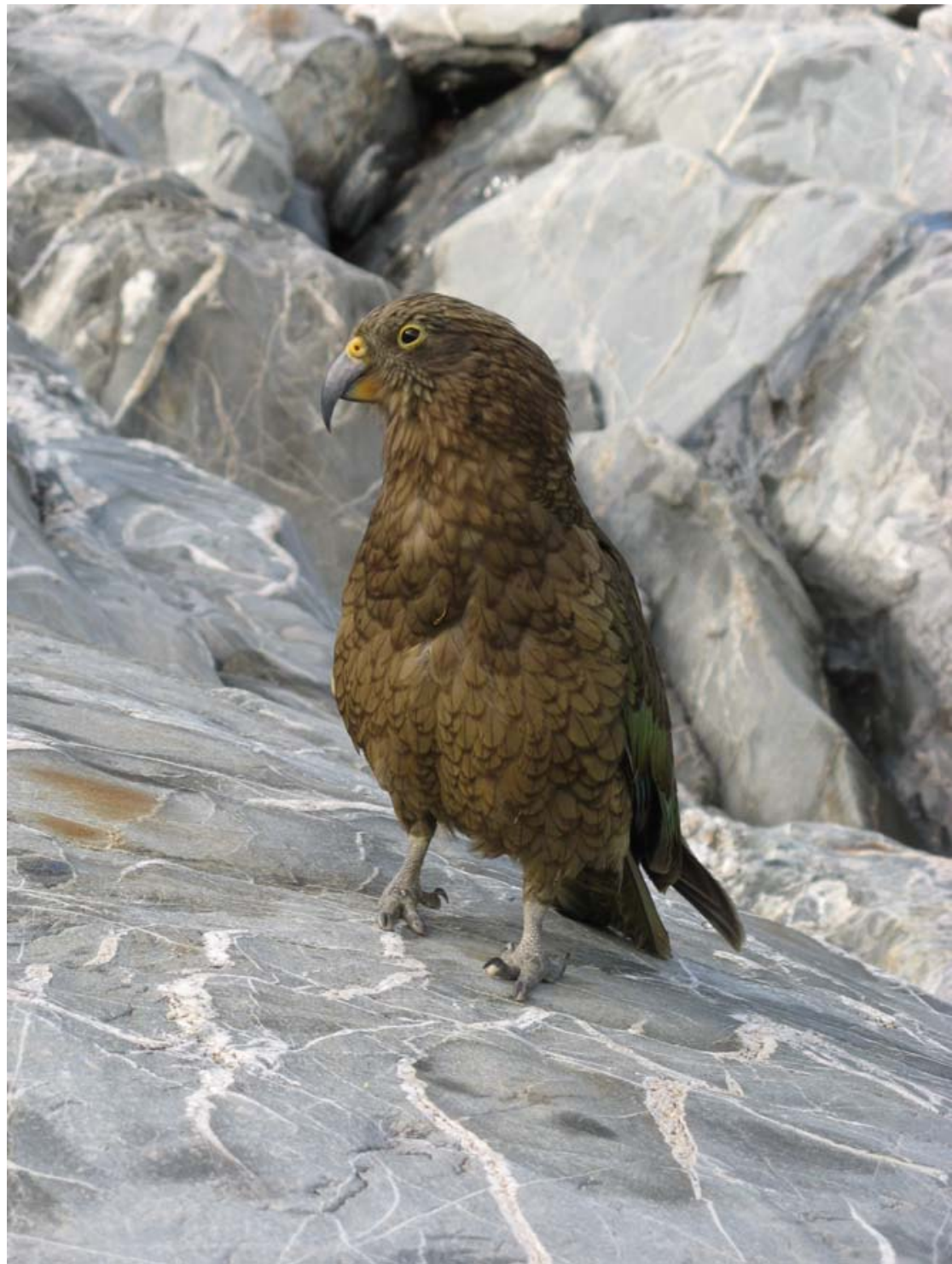

Kea, observing rocks that host brittle-ductile shear zones 


\begin{abstract}
A suite of brittle-ductile faults in the central Southern Alps, New Zealand is used as a natural laboratory into the rheology of quartz rocks. The fault array is $\sim 2 \mathrm{~km}$ wide and formed in the hanging-wall of the SE-dipping Alpine Fault during the late Cenozoic at $\geq$ $25 \mathrm{~km}$ depth. It was exhumed in the past few Myr and is now exposed 5-7 km east of the Alpine Fault. The faults are near-vertical, extend laterally and vertically over tens of metres, and strike sub-parallel to the Alpine Fault. They displace quartzofeldspathic Alpine Schist (metagreywacke) in a predominantly brittle way. The faults impinge upon and displace abundant centimetre-thick quartz veins that are discordant to the dominant schist foliation. These quartz veins exhibit a full range of slip from fully brittle to fully ductile. In most quartz veins, a ductile component of slip and a 1-3 cm $(n=72)$ wide ductile shear zone are present. The mean total slip measured in the veins is $7.2 \pm 5.8 \mathrm{~cm}$ $(n=72)$.
\end{abstract}

This study first develops a method to determine the true shape and displacement of a geological marker from any outcrop orientation. It then uses a set of geometrical scaling relationships exhibited by the ductilely-to-brittlely sheared quartz veins, and the observed interaction between brittle faults and ductilely deforming quartz veins to develop a series of finite-element models that reproduce the field observations. A flow law of the form $\dot{\varepsilon}=A \cdot f_{\mathrm{H}_{2} \mathrm{O}}^{m} \cdot \sigma_{d}^{n} \cdot \exp (-Q / R T)$ is used to model the behaviour of the quartz veins. Flow law parameters for the quartz veins and viscous and frictional strength ratios between quartz and schist are determined from these models. For $Q=$ $135 \mathrm{~kJ} \mathrm{~mol}^{-1}, f_{\mathrm{H}_{2} \mathrm{O}}=200 \mathrm{MPa}$ and $m=1.0$, the results show that the scaling relationships in the quartz veins are successfully reproduced for $A=10^{-10 \pm 2} \mathrm{MPa}^{-\mathrm{n}} \mathrm{s}^{-1}$, and $n \approx 4$.

The ratio between ductile-to-total slip $(D)$ were measured for 72 veins throughout the brittle-ductile shear array and are highly variable. In order to understand what has led to this variability, we investigate the following parameters: original vein thickness, deformation temperature, water content, microfracturing, calcite fraction, and total slip. $D$-ratios appear to scale with original vein thickness, however, significant scattering of the $D$-values indicates that other factors also control $D$. The temperature resolution (from Titanium-in-Quartz geothermometry and oxygen isotopy) is not high enough to 
determine whether temperature influenced the $D$-values. Fourier Transform Infrared Spectroscopy (FTIR), and optical microscopy reveal that water content, microfracturing, and calcite fraction were very similar from one vein to another and therefore did not control the $D$-ratios either. Detailed outcrop maps of the brittle-ductile shears and displacement-length profiles along five individual faults indicate that the total slip varied rapidly and on short distances (cm- to m-scale) along the faults. We infer that these varying slip rates led to different flow strain rates in the deforming quartz veins and therefore can explain the variations in $D$-values.

Optical microscopy reveals abundant fluid inclusions in both the deformed and undeformed parts of the veins. These inclusions indicate that the quartz was 'wet' and the veins were weakened with respect to the surrounding schist. We therefore infer that the location of the shear zones was predetermined by the position of the brittle faults propagating through the stronger schist and impinging on the weaker quartz veins. 


\section{Acknowledgements}

My greatest thanks go to my supervisors Tim Little and Susan Ellis. Thank you for giving me the opportunity to experience New Zealand geology and to work on this interesting, challenging and important project. Thank you, Susan for guiding me through the world of numerical modelling. Thank you both for proofreading endless numbers of drafts, and your great support and patience throughout the years. I have learned a lot from you.

My research was financially supported by a Vice Chancellor's Strategic Research scholarship, a PhD submission scholarship, 'the Tectonics fund' and by my parents for which I am extremely grateful. GNS Science is thanked for enabling me to take part in the AGU Fall meeting, 2006 in San Francisco. I am thankful to have received a New Zealand Postgraduate Study Abroad Award that enabled me to participate in the ISES Summer School on the Rheology of Earth material, 2006 in Colorado Springs. For organising this summer school, I thank Christine Siddoway, Jan Tullis, Holger Stünitz, and Basil Tikoff. Thank you for inviting me to a highly enlightening week of rheology.

I thank Matt Hill and Katie Peters for being the best fieldies anyone can wish for. Thank you for great times in the field and for making cold nights and rainy days bearable up in the Southern Alps. Long live whiskey-and-tea! Special thanks to Matt for counting calcite grains in my samples. Thank you also to Tim and Susan, and to Ruth Wightman, Liz Schermer, and Julia Onnecken for being a fun group on the first field trip to the Southern Alps in 2006.

The Department of Conservation (DOC) is gratefully acknowledged for signing helicopter landing permits and allowing us to take samples in the area. A big thank you to the pilots from Fox and Franz heliservices for repeatedly dropping us of in the remote study area and especially for picking us up again after several days of field work.

Ralph Wahrlich is thanked for managing the Abaqus license server throughout the first three years of my research. Stewart Bush is especially thanked for preparing thin sections and sample mounts. A big Thank You to John Paterson and Kate Saunders for 
helping me work with the microprobe. Joel Baker and Marc-Alban Millet are thanked for their great support with the "laser"-analyses and for helping me understand geochemistry a little bit better. I would like to extend special thanks to Bernhard Stöckhert, Klaus Röller, Rita Seifert from Ruhr-University Bochum for the preparation of thin and thick sections from my samples and for running the FTIR-analyses. Thank you Rita, for coming all the way to New Zealand and introducing me to the FTIR technique. I would like to thank Julie Vry for patiently answering my questions on fluid inclusions and always being open for interesting discussions on the brittle-ductile shears.

I wish to thank my recent office mates and friends Dee Ninis, Rachel Carne, and Megan Korchinski. Special thanks to Rach for being my late night buddy. Former $4^{\text {th }}$ and $5^{\text {th }}$ floor inhabitants and people that I have not yet mentioned above but that I would like to thank and that I am grateful to have met are: Aidan, Julene, Nettie, Caell, Dave K., Monica, Richard, Dave M., Martin, Kate S., Kate W., Anya, Erik, Sonja, Jess, and Rosie. Without you guys, this journey would have been only half as much fun. My warmest thanks go out to Katrina Jacobs for being so patient and for being the best support one can wish for when writing up a $\mathrm{PhD}$ thesis.

Gillian Ruthven is thanked for leading such an excellent library and always being able to help finding the odd article. Thank you to the 'office girls' (Shannon, Hayley, Lin, Suzanne) for always being able to help. Shona DeSain is thanked for being so understanding.

Although living on the other side of the world during most of my $\mathrm{PhD}$, my family always believed in me and supported me. Thank you so much for that. 


\section{Table of contents}

Title page $\quad$ i

Frontispiece $\quad$ ii

Abstract iii

Acknowledgements $\quad \mathrm{v}$

Table of contents vii

List of figures xii

List of tables $\quad \mathrm{xV}$

Chapter 1 - Inroduction and thesis outline 1

1.1 Motivation and scope of the thesis 1

1.2 Theoretical background - Quartz rheometry by means of experiments compared to naturally deformed rocks 3

1.3 Theoretical background - depth of brittle-ductile coupling in the crust 6

1.4 Tectonic setting of the South Island of New Zealand 9

$\begin{array}{lll}1.5 & \text { Study area: a brittle-ductile shear array } & 12\end{array}$

$\begin{array}{lll}1.6 & \text { Thesis outline and organisation } & 17\end{array}$

Chapter 2 - A Graphical-Algebraic Method for Analysing Shear Zone Displacements from Observations on Arbitrarily Oriented Outcrop Surfaces 20

$\begin{array}{lll}2.1 & \text { Introduction } & 21\end{array}$

2.2 Assumptions 22

2.3 Preparing x-y-z data from photographs (Step 1) 23

$\begin{array}{lll}2.3 .1 & \text { Coordinate systems } & 23\end{array}$

$\begin{array}{lll}2.3 .2 & \text { Digitising } & 24\end{array}$

$\begin{array}{lll}\text { 2.3.3 Geographical coordinates of points } & 24\end{array}$

2.4 Projection into the movement plane (Step 2) 26

2.4.1 The movement plane (m-plane) in point-normal form 26

2.4.2 The projection vector and projection line 26

$\begin{array}{lll}\text { 2.4.3 The projection process } & 28\end{array}$

2.5 Plan view of the m-plane (Step 3) 29 
2.6 Examples 31

2.6.1 Example A 33

2.6.2 Example B 33

2.7 Discussion and conclusions 33

Appendix 2.A - Glossary

2.A.1 Denotation 35

2.A.2 Subscripts and Superscripts 35

2.A.3 Key 35

Appendix 2.B - Conversions 36

2.B.1 Conversion from geological attitudes to Cartesian coordinates 36

2.B.2 Conversion from Cartesian coordinates to geological attitudes 36

Chapter 3 - Rheological constraints on quartz derived from scaling relationships and numerical models of sheared brittle-ductile quartz veins, central Southern Alps, New Zealand 39

3.1 Introduction 40

3.2 Tectonic setting and outcrop scale studies 43

3.2.1 The Southern Alps of New Zealand and the Alpine Fault 43

3.2.2 Study area: An array of brittle-ductile faults 44

3.3 Summary of geological and physical constraints on vein deformation 50

3.3.1 Time available for ductile deformation and subsequent static recrystallisation of the quartz veins $\quad 50$

$\begin{array}{lll}3.3 .2 & \text { Temperature } & 50\end{array}$

3.3.3 Deformation depth and stress state $\quad 51$

3.3.4 Fault slip rates 53

3.4 Field data - Fault-shear zone scaling relationships 56

3.5 Numerical experiments $\quad 59$

3.5.1 Experimental framework - Rheological end-members 59

$\begin{array}{lll}\text { 3.5.2 Description of numerical technique } & 61\end{array}$

3.5.3 Model setup $\quad 62$

3.5.3.1 Initial geometry and boundary conditions 62

3.5.3.2 Choice of material parameters used in model series 1 to $4 \quad 64$ 
3.5.4 Results - model series 1: Influence of the viscous-to-frictional (quartz-toschist) strength contrast $R^{q s}$ and of the flow law stress exponent (n) on the propagation behaviour of the brittle fault $\quad 66$

3.5.5 Results - model series 2: brittle-ductile transition in the quartz veins $\quad 70$

3.5.5.1 Vein thickness th ${ }_{\text {orig }}$ and $\mathrm{A}_{\mathrm{M}}$-values 71

3.5.5.2 Total vein displacement $y_{\text {tot }} \quad 73$

3.5.6 Results - model series 3: influence of stress exponent $n_{\mathrm{q}}$ on deformed quartz vein shape

3.5.7 Results - model series 4: influence of the quartz-to-schist viscous-viscous strength ratio $V^{q s}=\tau_{v}^{q} / \tau_{v}^{s}$ on the deformed vein shape 76

3.6 Discussion

3.6.1 Shear bifurcation, energy dissipation, and frictional-viscous coupling between schist and quartz

3.6.2 Brittle-ductile transition in quartz veins

3.6.3 Stress exponent in the quartz veins

3.6.4 Viscosity contrast between schist and quartz

3.6.5 Estimation of quartz flow parameters constrained by modelling 84

3.7 Conclusions 86

$\begin{array}{ll}\text { Glossary } & 88\end{array}$

Appendix 3.A - The choice of initial flow law for the quartz veins 89

Appendix 3.B - Strain softening used in models 92

Appendix 3.C - Conversion of triaxial laboratory experiments to plane strain numerical experiments 94

Appendix 3.D - Strain rate conventions in our code 97

Appendix 3.E - Frictional yield parameters in our code 97

Appendix 3.F - Creep flow parameters in our code 98

Chapter 4 - Controls on shear zone formation in brittlely to ductilely deformed rocks from the central Southern Alps of New Zealand 99

$\begin{array}{lll}4.1 & \text { Introduction } & 100\end{array}$

$\begin{array}{lll}4.2 & \text { Geological and tectonic setting } & 103\end{array}$

4.3 Study area and field description of brittle-ductile shears 107 
4.4 Microstructures and CPOs of the deforming quartz veins and the fault-infilling quartz-carbonate veins

4.5 Field data documenting brittle-ductile deformation of quartz veins

4.5.1 Detailed maps showing brittle-ductile shear geometry

4.5.2 Geometrical scaling relationship between ductile displacement (d) of the quartz veins and ductile shear zone width (dsw) - Does it indicate shear zone hardening or softening?

4.6 Variations in D-values - Do they hold information on rheological (pre)conditions of the quartz veins prior to shear zone localisation?

4.6.1 Preface - Which factors can cause different D-values?

4.6.2 Variability of D with original vein thickness ( $\mathrm{th}_{\text {orig }}$ ) and total slip ( $\left.\mathrm{y}_{\text {tot }}\right) \quad 123$

$\begin{array}{ll}\text { 4.6.3 Indicators of spatially variable fault slip rates } & 128\end{array}$

4.6.4 Indicators of variable shear strain rates in regions of fault overlaps 129

4.6.5 Effect of varying calcite fraction in the quartz veins on D

4.6.6 Influence of precursory embrittlement, water-content and water-species in the quartz veins on the deformation type

4.6.6.1 Optical microscopic evidence for precursory embrittlement in the sheared quartz veins

4.6.6.2 Determination of water species and water content in the quartz veins

4.6.6.2.1 FTIR - Sampling philosophy and analysis

4.6.6.2.2 FTIR - Results

4.6.7 Influence of locally variable conditions of deformation on the vein ductility $D$

4.6.7.1 Temperature

4.6.7.1.1 Quartz-calcite oxygen isotope exchange thermometry on shearinfilling veins

4.6.7.1.2 Titanium-in-Quartz geothermometry ("TitaniQ")

4.6.7.2 Depth and differential stress during shearing

4.7 Discussion

4.7.1 Was precursory brittle deformation necessary for the localisation of the ductile shear zones? 
4.7.2 Was local softening or hardening of the quartz veins necessary to form the ductile shear zones?

4.7.3 What has caused the different degrees of ductility in the quartz veins? 156

4.8 Conclusions

Appendix 4.A - Analytical details of quartz-calcite ${ }^{18} \mathrm{O} /{ }^{16} \mathrm{O}$ exchange thermometry

Appendix 4.B - Analytical details of Titanium-in-Quartz geothermometry

Appendix 4.C - Fluid inclusions analyses on shear-infilling quartz-calcite veins 164

Chapter 5 - Summary of results and conclusions

5.1 Summary of results

5.1.1 Geometry of the brittle-ductile shears and slip rate estimates

5.1.2 Deformation conditions during shear zone formation in the quartz veins 167

5.1.3 Can laboratory-derived flow laws be extrapolated to natural conditions? 168

5.1.4 Reasons for differences in ductility of the quartz veins and implications for shear zone localisation

5.2 Conclusions

References

Appendix A - MATLAB ${ }^{\circledR}$ script for Chapter 2 


\section{List of Figures}

\section{Chapter 1}

1.1 Temperature-strength plots

$\begin{array}{lll}1.2 & \text { Synoptic cross-section through shear zone } & 8\end{array}$

$\begin{array}{lll}1.3 & \text { Plot of stress versus temperature and depth } & 8\end{array}$

1.4 Tectonic setting of the South Island, New Zealand 9

1.5 Digital elevation model of the central Southern Alps 14

$\begin{array}{lll}1.6 & \text { Overview photograph of brittle-ductile shears } & 15\end{array}$

$\begin{array}{lll}1.7 & \text { Photographs of brittle-ductile shears } & 16\end{array}$

\section{Chapter 2}

2.1 Outcrop photograph of brittle-ductile shears 22

2.2 Block diagram of spatial relationship between outcrop and fault surfaces 25

2.3 Block diagram illustrating movement plane and projection vector 27

2.4 Plan view of movement plane after two rotations 31

2.5 Flow diagram of two example veins being projected into the m-plane 32

\section{Chapter 3}

3.1 Geological setting of central Southern Alps 45

3.2 Rocks and structures in the brittle-ductile fault array 46

3.3 Escalator model of formation and exhumation of the shear array 49

3.4 Microphotographs of ductilely sheared quartz vein 49

3.5 Calculation of minimum and maximum slip rates in the shear array 55

3.6 Geometrical scaling relationships derived from deformed quartz veins 58

3.7 Ductile deformation of Alpine Schist in step-over zone 60

3.8 Possible modelling combinations of frictional and viscous end-members 61

$\begin{array}{lll}3.9 & \text { Initial model setup } & 63\end{array}$

3.10 Photograph of fault bending around quartz vein 64

3.11 Results of model series 1

3.12 Results of model series $2-D$ versus $t h_{\text {orig }} \quad 72$

3.13 Results of model series $2-D$ versus $y_{\text {tot }} \quad 74$

3.14 Plot illustrating how to determine pre-exponential factor $A_{M} \quad 75$

3.15 Results of model series 3 - influence of stress exponent on vein shape 76 
3.16 Results of model series 4 - influence of viscosity ratio on $d s w \quad 78$

3.17 Results of model series $4-d s w$ versus $t h_{\text {orig }} \quad 79$

3.18 Schematic plot of viscous energy dissipation $\quad 81$

3.19 Temperature-strength plots with determined flow law parameters $\quad 85$

3.A-1 Comparison of strain accumulation via GSI versus GSS creep 91

3.B-1 Results of strain softening tests 93

\section{Chapter 4}

4.1 Flow diagram illustrating two different ways of shear zone formation 101

4.2 Geometrical measurements taken in brittle-ductile shears 102

4.3 Tectonic setting of South Island, New Zealand 105

4.4 Cross-section through the central Southern Alps 106

$\begin{array}{ll}\text { 4.5 Maps of sampling locations } & 109\end{array}$

$\begin{array}{lll}4.6 & \text { Field photographs of brittle-ductile shears } & 110\end{array}$

4.7 Microphotograph of ductilely sheared quartz vein 112

$\begin{array}{ll}\text { 4.8 Microphotographs of fault-infilling vein } & 113\end{array}$

4.9 Detailed map of Crawford Knob outcrops 115

4.10 Detailed map of Crawford Knob outcrops 116

4.11 Detailed outcrop map of shear CK-A and displacement-length plot 119

4.12 Detailed outcrop map of shears CK-B, CK-C displacement-length plot 120

4.13 Plot of ductile shear zone width versus ductile component of slip 121

4.14 Overview of factors that may influence ductility $D$ of a vein 123

$\begin{array}{ll}4.15 \text { Plots of } D \text { versus } t h_{\text {orig }} \text { and } y_{\text {tot }} & 124\end{array}$

4.16 Plots of $D, t h_{\text {orig }}$, and $y_{\text {tot }}$ along individual shears $\quad 125$

4.17 Photographs of one ductilely and one brittlely deformed quartz vein 128

4.18 Ductile flow of Alpine schist in overlap region between faults 130

$\begin{array}{ll}4.19 \text { Calcite content in quartz veins } & 132\end{array}$

4.20 Fluid inclusions in the quartz veins 136

$\begin{array}{ll}4.21 \text { FTIR spectra for vein } \mathrm{CH} 326 & 139\end{array}$

4.22 FTIR results - molecular water content in the quartz veins 141

4.23 Backscatter and cathodoluminescence photographs of the deformed veins 145

$\begin{array}{ll}4.24 \text { Plot of temperature results versus paleodepth } & 148\end{array}$

4.25 PT-diagram to determine pore fluid pressure 151

4.26 Mohr-Coulomb analysis of stress state at $25 \mathrm{~km}$ depth 152 
4.27 Proposed model for shear zone formation in the quartz veins

4.A1 Plot of oxygen isotopes in calcite versus quartz from infilling vein

\section{Chapter 5}

5.1 Temperature-strength plots of published flow laws in comparison to flow law derived in this study

\section{Appendix B}

B1 Benchmark results of our modelling code versus Abaqus 


\section{List of tables}

\section{Chapter 1}

1.1 Parameters for experimentally derived flow laws

\section{Chapter 3}

3.1 Field-based maximum slip rate estimates

3.2 Material parameters used in model series 1

3.3 Model parameters used to test the brittle-ductile transition in quartz veins 71

3.4 Model parameters for model series 4

\section{Chapter 4}

4.1 Mean attitudes of structural features at Crawford Knob 117

4.2 Original thicknesses and total displacement of veins for FTIR analysis 138

$\begin{array}{lll}4.3 & \text { Titanium-in-Quartz analyses results } & 146\end{array}$

4.A Oxygen isotope composition of fault-infilling veins 161

$\begin{array}{lll}\text { 4.B Fluid inclusion data from infilling veins } & 165\end{array}$ 


\section{Chapter 1}

\section{Introduction and thesis outline}

\subsection{Motivation and scope of the thesis}

Crustal deformation and the strength of the Earth's crust vary with the tectonic environment, lithology and mineralogy, availability and type of fluids, temperature, and time (e.g., Bürgmann and Dresen, 2008). Since quartz is one of the major constituents of the Earth's crust, its rheology exerts a major control on crustal strength and the depth of the brittle-to-ductile transition, and on the maximum depth for the nucleation of large earthquakes. The brittle-ductile transition is the region in the crust where normal stressdependent, pressure-sensitive, frictional deformation of rocks is replaced by strain ratedependent, temperature-sensitive viscous flow of rocks (e.g., Evans and Kohlstedt, 1995). Whilst the strength of the upper crust is well described by brittle-elastic friction laws (e.g., Byerlee, 1978), most of our knowledge about the viscous flow behaviour of quartz in the mid- to lower crust is based on deformation experiments conducted in laboratories at strain rates (and temperatures) that are several orders of magnitudes higher than those reasonable for nature. It is important to know whether one can extrapolate laboratory-derived flow laws to natural conditions, because many studies that model crustal scale deformation (including GPS-based velocities), stress transfer in the crust, and earthquake nucleation use the experimentally derived flow laws in their rheological setup (e.g., Ellis et al., 2006a, b). Geological studies testing those flow laws against the observations of naturally deformed rocks are rare. This study tries to gain rheological information by an evaluation of naturally sheared quartz veins, both brittle and ductile, and the quartzofeldspathic rocks that host these veins. The study tries to contribute to the understanding of quartz rheology, the localisation of shear zones, and to improve our knowledge of deformation mechanisms operating at the brittle-ductile transition in the crust.

The rocks that are investigated in this study were exhumed in the hanging wall of the Alpine Fault, near Fox and Franz Josef glaciers in the central Southern Alps of New Zealand. The dextral-reverse Alpine Fault is the major plate boundary between the Australian and the Pacific plates on South Island, New Zealand. Here, Pacific Plate rocks are upramped obliquely onto the underlying Australian Plate. In the central 
Southern Alps, high uplift rates along the Alpine Fault have accompanied mountain building that began after the onset of Pacific-Australian plate convergence at 5-8 Ma, and that accomplished the exhumation of crustal rocks from depths greater than $20 \mathrm{~km}$ (Tippet and Kamp, 1993; Sutherland, 1996; Batt, 2001; Batt et al., 2004; Little et al., 2005). The brittle-ductile shear array studied here is approximately $2 \mathrm{~km}$ wide and lies 5-7 km to the southeast of the Alpine Fault. The rock type that occurs in the study area is predominantly biotite-zone, greenschist-facies quartzofeldspathic metagreywacke (Alpine Schist). These rocks include intercalated metapsammites and metapelites. The Alpine Schist hosts quartz veins of variable thicknesses and orientations, most of them discordant to the foliation. Both the schist and the quartz veins that are embedded in the schist have been transected by and neotectonically sheared across a sub-parallel array of small, near-vertical faults. Whilst the displacement of the schist is generally fully brittle, the displacement of the veins embedded in that host is variably brittle to ductile.

This study attempts to extract information about the rheology of quartzose rocks from field observations such as the deformed macroscopic shape of the veins, systematic scaling relationships between various geometric properties of the veins, as well as from the microstructure of the sheared quartz veins. Detailed surveying and geological mapping on the outcrop scale of the brittle-to-ductile shears as well as finite element modelling of the sheared quartz veins was used to test laboratory derived flow laws against the naturally deformed quartz veins. These data were also used to investigate whether the deformed shape and geometrical scaling relationships in the sheared quartz veins contain information on strength ratios between pure quartz and quartzofeldspathic schist or on flow law parameters that may have been operative during shearing of the pure quartz veins. Laboratory analyses (e.g. Fourier-transform infrared spectroscopy, Titanium-in-Quartz geothermometry, quartz-calcite oxygen isotope thermometry) of the variably brittlely and ductilely sheared quartz veins were conducted in order to determine factors that may have controlled the degree of ductile versus brittle deformation in a quartz vein and the localisation of ductile shear zones in these veins.

The Southern Alps of New Zealand have been subject to numerous geoscientific studies. A comprehensive collection of papers on the geological and tectonic development and setting of the Southern Alps has recently been published in a monograph by the American Geophysical Union (eds. D. Okaya, T. Stern, F. Davey, 2007). Decades of research in the Southern Alps have led to a good understanding of 
the kinematics and deformation conditions prevailing in the crust of that young orogen. The Southern Alps of New Zealand therefore provide an exceptionally valuable natural laboratory into the rheology of quartz and quartzose rocks under brittle-ductile deformation conditions.

\subsection{Theoretical background - Quartz rheometry by means of experiments compared to} naturally deformed rocks

Experimentally derived flow laws for steady-state creep of quartz usually relate strain rate and differential stress in the form of an Arrhenius equation:

$$
\dot{\varepsilon}=A \cdot \sigma_{d}^{n} \cdot f_{H_{2} O}^{m} \cdot d^{-r} \cdot \exp \left(-\frac{Q}{R T}\right)
$$

(e.g. Twiss and Moores, 2007, pp. 477) where $\dot{\varepsilon}$ is uniaxial strain rate $\left(\mathrm{s}^{-1}\right), A$ is a preexponential factor $\left(\mathrm{MPa}^{-\mathrm{n}} \mathrm{s}^{-1}\right), f_{\mathrm{H}_{2} \mathrm{O}}$ is water fugacity (MPa), $m$ is the fugacity exponent, $d$ is grain size $(\mu \mathrm{m}), r$ is the grain size exponent, $\sigma_{d}$ is the differential stress (MPa), $n$ is the stress exponent, $Q$ is activation enthalpy $\left(\mathrm{J} \mathrm{mol}^{-1}\right), R$ is the universal gas constant (8.314 $\mathrm{J} \mathrm{mol}^{-1} \mathrm{~K}^{-1}$ ), and $T$ is temperature (K). For $m=0$, and $n>1$, eq. 1.1 follows a power-law and describes grain-size insensitive (GSI) dislocation creep. For $m=2-3$ and $n=1$, eq. 1.1 becomes a grain-size sensitive (GSS) diffusion creep law, linearly relating strain rate and flow stress (Newtonian viscosity).

A range of experimentally derived flow laws exists describing the steady-state creep behaviour of quartz or quartzite (e.g., Kronenberg and Tullis, 1984; Paterson and Luan, 1990; Luan and Paterson, 1992; Hirth and Tullis, 1992, Gleason and Tullis, 1995; Brodie and Rutter, 2000; Rutter and Brodie, 2004a, b). To derive these flow laws, uniaxial or triaxial experiments were conducted under high temperatures $\left(>700^{\circ} \mathrm{C}\right)$, and at strain rates of $10^{-7} \mathrm{~s}^{-1}$ or higher. Such experimental deformation temperatures are higher than typical mid-crustal temperatures $\left(300-500^{\circ} \mathrm{C}\right)$. Laboratory strain rates exceed common geological strain rates $\left(10^{-11}\right.$ to $\left.10^{-16} \mathrm{~s}^{-1}\right)$ by at least four orders of magnitude (Twiss and Moores, 2007, p. 488). It is questionable whether laboratoryderived flow laws for quartz can be extrapolated to low natural strain rates. Experimental uncertainties may arise from poor stress resolution during the experiments, imprecise determination of the water content and water fugacity during the experiment, or uncertainty in whether steady state creep was achieved during the experiment (e.g., Stipp and Tullis, 2003). The type of deformation apparatus (e.g., gas 
or solid medium) may also play a role when comparing the established flow laws. These uncertainties may result in erroneous conclusions about crustal strength and the brittleductile transition at depth. This is especially critical when working with crustal scale models that impose a rheological layering in the model crust. Most studies that involve crustal scale deformation, assume a 'wet quartz' rheology for the mid-crust (e.g., Montési, 2004; Ellis et al., 2006a, b). Flow law parameters of several published flow laws for dry and wet quartz are summarised in Table 1.1 and the range of flow strengths that are predicted by those flow laws for a natural strain rate of $\dot{\varepsilon}=10^{-14} \mathrm{~s}^{-1}$ is plotted in Fig. 1.1. As can be seen from the experimental results (Table 1.1), the stress exponent is predicted to be greater than 1.0 in all experiments except those of Brodie and Rutter (2000) and Rutter and Brodie (2004). This experimental result indicates that the relationship between applied differential stress and resulting creep strain rate is nonlinear, and that quartz flows with a power-law viscosity rather than a Newtonian one. An implication is that dislocation creep might be the dominant deformation mechanism in quartz rather than diffusional processes or dissolution-precipitation creep.

Despite the range of predicted strengths, the laboratory-derived flow laws provide valuable information on the microstructural evolution of quartz and quartzose rocks during their ductile and/or brittle deformation. Hirth and Tullis (1992) have performed experiments on quartz aggregates in the molten-salt cell and have derived three regimes of dislocation creep in quartz. In regime 1 (low temperature, high strain rate) quartz flows through bulging recrystallisation $(\mathrm{BLG})$; in regime 2 (medium temperature, medium strain rate) the main deformation mechanism is subgrain rotation recrystallisation (SGR); in regime 3 (high temperature; low strain rate) grain boundary migration (GBM) is a dominant mechanism of recrystallisation and recovery. In nature, these dislocation creep regimes have been inferred in several studies (e.g., Dunlap et al., 1997; Hirth et al., 2001; Stipp et al., 2002), which indicates that the flow laws that were produced in laboratories may represent deformation processes that occur naturally in the Earth (e.g. Stöckhert et al., 1999; Hirth et al., 2001). Recently, a numerical modelling software called ELLE has been developed that can be used to model rock microstructures on the grain-scale (e.g. Bons et al., 2000; Jessell et al., 2001; Piazolo et al., 2001; Piazolo et al., 2002). The ELLE modelling results also reproduce microstructures that are similar to those found in many naturally deformed rocks. 
Table 1.1: Parameters for experimentally derived flow laws for quartz. SQT: Simpson quartzite, HQT: Heavitree quartzite, NOV: novaculite, BHQ: Black Hills quartzite, BZQ: hot-pressed Brazilian quartzite, RGD: Ruby Gap Duplex quartzite; GSI: grain-size insensitive creep, GSS: grain size sensitive creep.

\begin{tabular}{|c|c|c|c|c|c|c|}
\hline source & $\begin{array}{l}\log _{10} \mathrm{~A} \\
\left(\mathrm{MPa}^{-\mathbf{n}} \mathrm{s}^{-1}\right)\end{array}$ & $\mathbf{n}$ & $\begin{array}{l}Q \\
\left(\mathbf{k J ~ m o l} \mathbf{~}^{-1}\right)\end{array}$ & m & rock & remarks \\
\hline Heard and Carter 1968 & -10.1 & 5.7 & 243 & 0 & SQT & dry \\
\hline Hansen and Carter 1982 & -4.5 & 1.9 & 123 & 0 & HQT & dry \\
\hline Jaoul et al. 1984 (A) & -5 & 2.4 & 163 & 0 & HQT & $\begin{array}{l}\text { dry, } \alpha \text {-qtz, NaCl- } \\
\text { medium }\end{array}$ \\
\hline Jaoul et al. 1984 (B) & -3.51 & 2.3 & 171 & 0 & HQT & dry, $\mathrm{CaCO}_{3}$-medium \\
\hline Jaoul et al. 1984 (C) & -5.46 & 2.8 & 184 & 0 & HQT & $\begin{array}{l}\text { vacuum-dried, } \\
\mathrm{CaCO}_{3}\end{array}$ \\
\hline $\begin{array}{l}\text { Kronenberg and Tullis } \\
1984 \text { (A) }\end{array}$ & -5.3 & 2.9 & 170 & 0 & NOV & as-is \\
\hline $\begin{array}{l}\text { Kronenberg and Tullis } \\
1984 \text { (B) }\end{array}$ & -5.398 & 4.0 & 300 & 0 & HQT & vacuum-dried \\
\hline Koch et al. 1989 (A) & -6.936 & 2.72 & 134 & 0 & SQT & dry \\
\hline $\begin{array}{l}\text { Kronenberg and Tullis } \\
1984 \text { (C) }\end{array}$ & -5.66 & 2.7 & 120 & 0 & HQT & $\begin{array}{l}0.4 \text { wt } \% \text { water } \\
\text { added }\end{array}$ \\
\hline Jaoul et al. 1984 (D) & -2.28 & 1.4 & 146 & 0 & HQT & $\begin{array}{l}0.28 \text { wt } \% \text { water } \\
\text { added }\end{array}$ \\
\hline Jaoul et al. 1984 (E) & -2.54 & 1.8 & 151 & 0 & HQT & $\begin{array}{l}0.39 \text { wt } \% \text { water } \\
\text { added }\end{array}$ \\
\hline Koch et al. 1989 (B) & -5.3 & 2.61 & 145 & 0 & SQT & wet \\
\hline $\begin{array}{l}\text { Paterson and Luan } 1990 \\
\text { (A) }\end{array}$ & -7.18 & 3.1 & 135 & 0 & Gel prec. & best estimate \\
\hline $\begin{array}{l}\text { Paterson and Luan } 1990 \\
\text { (B) }\end{array}$ & -9.4 & 4.0 & 135 & 0 & $\begin{array}{l}\text { Silicic } \\
\text { acid }\end{array}$ & best estimate \\
\hline Gleason and Tullis 1995 & -3.96 & 4.0 & 223 & 0 & BHQ & no melt, molten salt \\
\hline Brodie and Rutter 2000 & -3.3 & 3.0 & 220 & 0 & BZQ & GSI \\
\hline Hirth et al. 2001 & -11.2 & 4.0 & 135 & 0 & RGD & $\begin{array}{l}\text { geological study, } \\
f_{\mathrm{H}_{2} \mathrm{O}}=37 \mathrm{MPa}\end{array}$ \\
\hline $\begin{array}{l}\text { Rutter and Brodie } 2004 \\
\text { (GSI) }\end{array}$ & -4.93 & 2.97 & 242 & 0 & BZQ & GSI, fine-grained \\
\hline Brodie and Rutter 2000 & -0.2 & 1.0 & 220 & 2.0 & BZQ & GSS \\
\hline Rutter and Brodie 2004 & -0.4 & 1.0 & 220 & 2.0 & BZQ & $\begin{array}{l}\text { GSS, ultrafine- } \\
\text { grained }\end{array}$ \\
\hline
\end{tabular}

There are not many outcrop-scale geological examples of naturally deformed quartzose rocks, against which these flow laws have been quantitatively tested. Lan and Hudleston (1995) compared the shape of experimentally, numerically, and naturally folded rocks and predicted that it may, under certain assumptions, be possible to use folds to make inferences about the rheological properties of rocks using lab-derived flow laws. Kenis et al. (2004) and Kenis et al. (2005) have used structural observations in combination with numerical modelling of deformed mullions in order to test the effect of varying flow law parameters and of varying pre-deformational geometries on the deformed shape of the mullions. Their mullion models incorporated three lithologies: psammite, pelite, and quartz. They inferred a power law viscosity for quartz 
and a linear viscous rheology for psammites and pelites. They also inferred a greater strength for quartz than for the surrounding psammites and pelites. In a similar way, the present study will combine outcrop observations with numerical modelling to test existing experimental flow laws against naturally deformed quartz rocks, especially with respect to the pre-exponential factor and the stress exponent ( $n$, in Eq. 1.1).

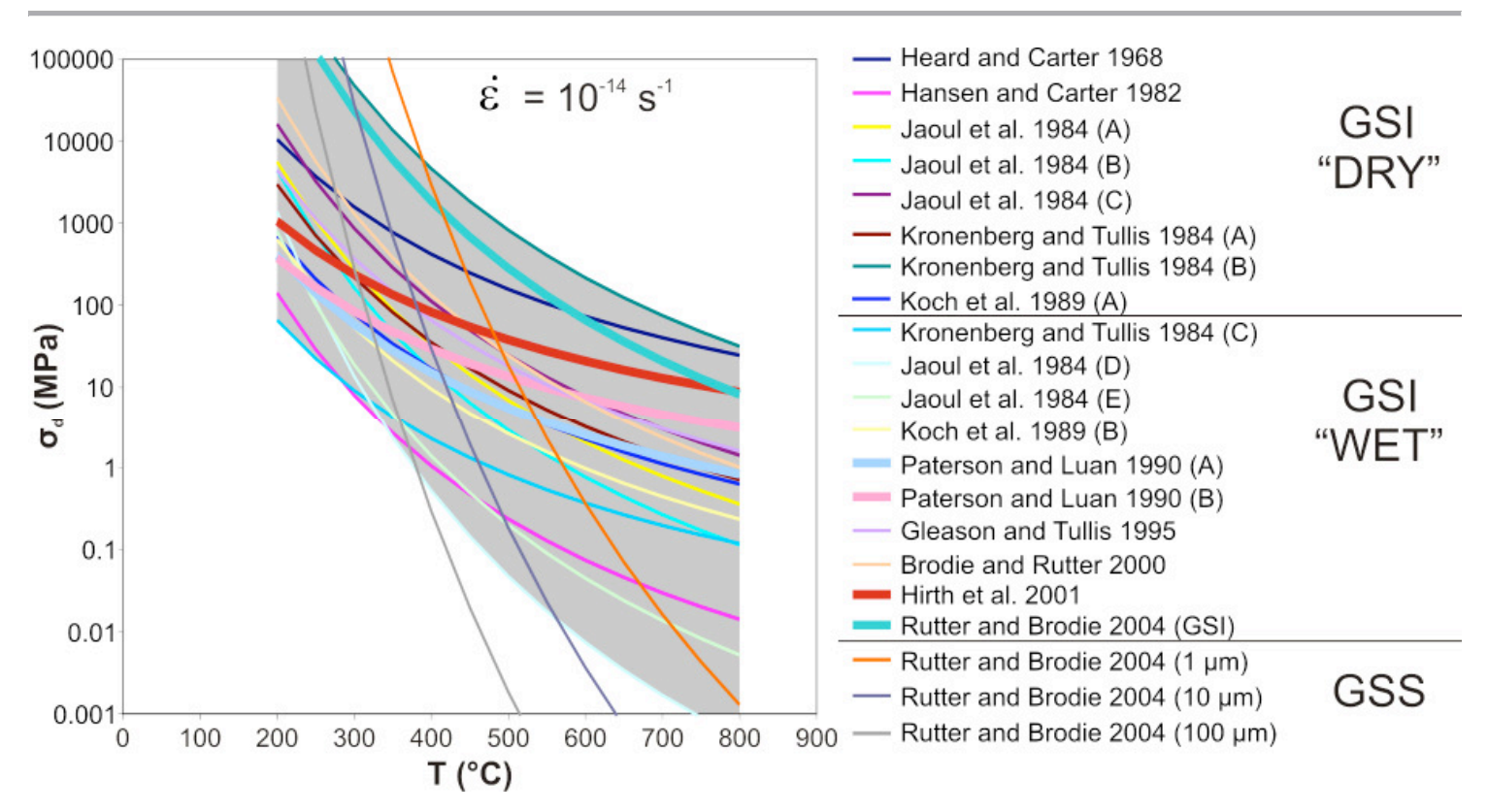

Fig. 1.1: Temperature-strength graphs illustrating range of differential stresses predicted by published flow laws for quartz at a fixed strain rate of $10^{-14} \mathrm{~s}^{-1}$. GSI: grain-size insensitive creep; GSS: grain-size sensitive creep. The grey shaded area covers the existing range of laboratory-derived dislocation creep (GSI) flow laws for quartz.

\subsection{Theoretical background - depth of brittle-ductile coupling in the crust}

The Earth's crust has often been approximated as a simplified two layer model with a brittle-elastic upper part and a ductile ${ }^{1}$ or viscoelastic lower part (e.g., Brace and Kohlstedt, 1980; Kirby, 1980). The change from brittle-elastic fracturing of rocks to the ductile-viscous flow of rocks is usually called "the brittle-ductile transition" (Paterson, 2005). Other studies refer to it as the "brittle-plastic transition" (Rutter, 1986; Scholz, 1988), or "frictional-viscous transition" (Schmid and Handy, 1991). In a typical twolayer model, the brittle strength of the upper part of the crust is calculated via a frictional law (e.g., Byerlee, 1978) and the viscous strength of the lower part is

\footnotetext{
${ }^{1}$ In this thesis, the term "ductile" is used as an equivalent to "viscous", being fully aware that ductility is not a mechanism-specific concept but simply a description of macroscopically coherent-looking deformation, which may at a smaller or larger scale be brittle (e.g. Rutter, 1986; Schmid and Handy, 1991; Schrank et al., 2008).
} 
described by a steady-state flow law for wet quartz (Eq. 1.1). The transition from frictional sliding to crystal-plastic creep in quartz occurs at approximately $300^{\circ} \mathrm{C}$ (Voll, 1976; Kerrich et al., 1977). In feldspar, this transition occurs at $\sim 450^{\circ} \mathrm{C}$ (Voll, 1976; White, 1976), so that the temperature range embracing the brittle-ductile transition in quartzofeldspathic rocks is commonly thought to span $\sim 300-450^{\circ} \mathrm{C}$ (Scholz, 1988).

Fig. 1.2a schematically depicts the development of the lithospheric strength with depth. This is a synoptic view of the varying character of a single shear zone as a function of depth (Fig. 1.2b). Fig. 1.2a shows that the maximum strength of the crust is reached at the brittle-ductile transition zone, which is conceptualised as a sharp intersection of a linear frictional law with an exponential ductile creep law. The depth of the nominal brittle-ductile transition zone is also thought to approximate the maximum depth for the nucleation of shallow earthquakes. This depth lies at about $\sim 15 \mathrm{~km}$, depending mainly on the geothermal gradient (Sibson, 1982; Tse and Rice, 1986; Scholz, 1988).

Since the lower part of the two-layer model is described by Eq. 1.1, the depth of the brittle-ductile transition must also strongly depend on changes in strain rate and temperature, and on the ratio $\lambda$ of pore-fluid pressure $P_{f}$ to lithostatic pressure $P_{\text {lithos }}$ (Fig. 1.3). The depth of the brittle ductile transition increases with both pore fluid pressure and increasing strain rate (Fig. 1.3). During an earthquake; i.e., at high strain rates, this depth might be deflected downward, so that transient brittle deformation is possible well below the steady-state brittle-ductile transition at temperatures that are higher than $\sim 300^{\circ} \mathrm{C}$ (the temperature at which quartz ceases to deform by crystalplasticity). In the post- and inter-seismic periods of the seismic cycle, differential stresses and strain rates are waning. Ductile creep of the previously coseismically fractured rocks is then possible during the post-seismic period of relaxed stresses (e.g., Trepmann and Stöckhert, 2003; Ellis and Stöckhert, 2004a, b; Montési, 2004; Nüchter and Stöckhert, 2007).

The depth of the brittle-ductile transition can also depend on the complex compositions of polymineralic rocks that may be deformed by a combination of deformation mechanisms leading to a composite flow law for e.g., quartzofeldspathic rocks as they occur in the Alpine Schist (e.g. Handy, 1990, 1994; Ji and Zhao, 1993; Saha, 1997; Ji and Xia, 2002). For these reasons, the expression "the brittle-ductile transition" should be avoided or only be used when referring to crustal steady-state or to a monomineralic rock. 


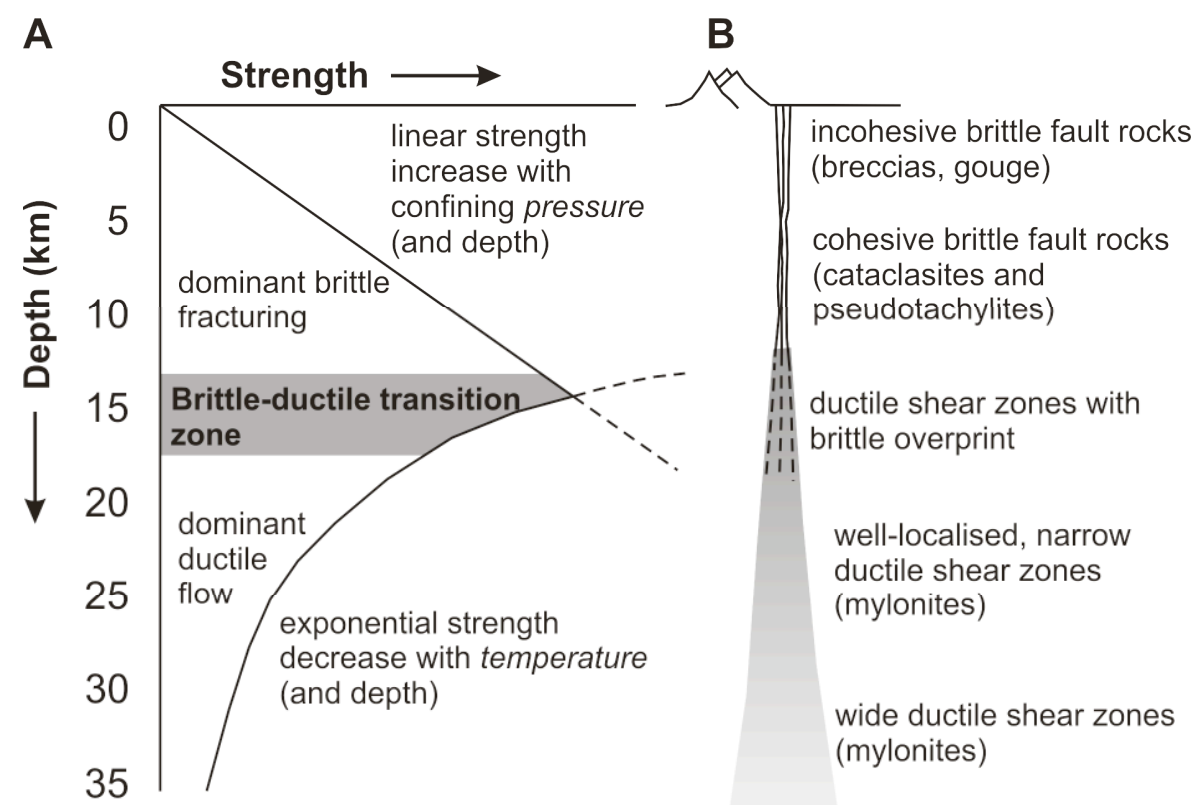

Fig. 1.2 a) "Christmas-tree" diagram of strength development of the lithosphere with depth. The brittleductile transition zone marks the transition of pressure-dependent to temperature-dependent deformation. b) Schematic cross-section through a transcurrent shear zone after Passchier and Trouw (2005, p. 114). Dominant types of fault rocks are listed on the right. The rock types in the shear zone change with increasing depth and metamorphic grade.

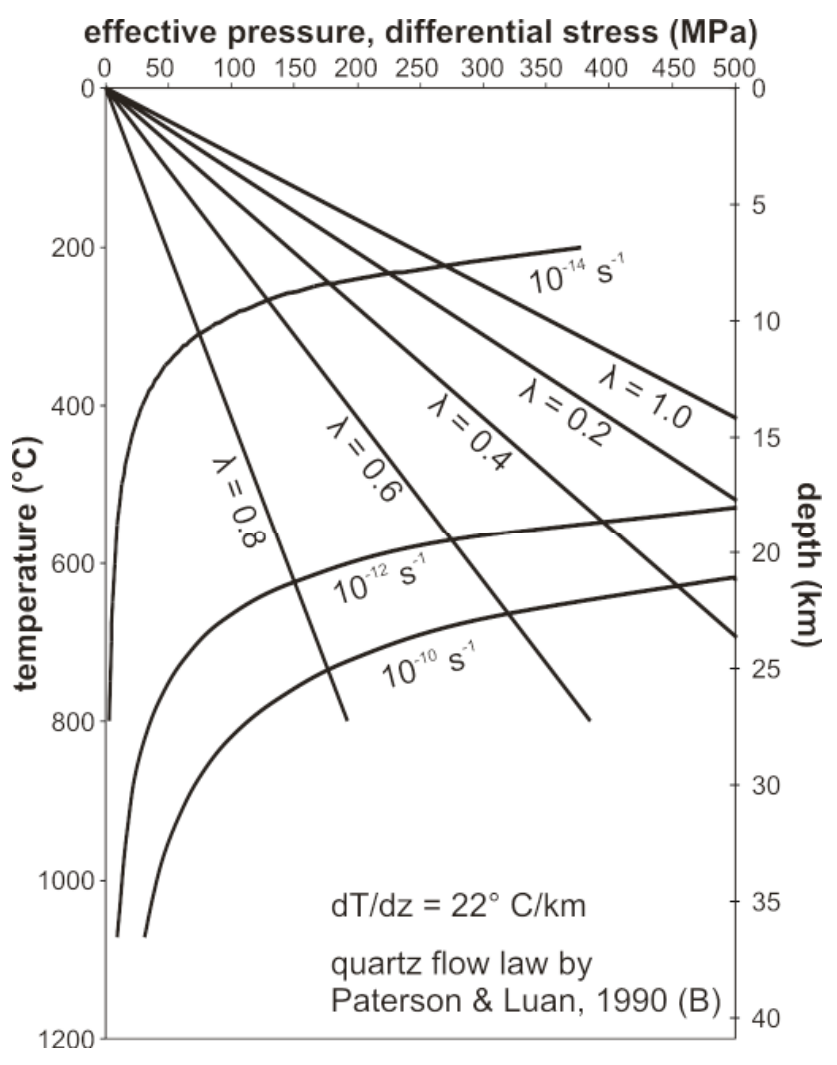

Fig. 1.3: Plot of stress versus temperature and depth at variable strain rates and pore fluid pressure. At high strain rates, the depth of the brittle-ductile transition will be deflected downward. 


\subsection{Tectonic setting of the South Island of New Zealand}

New Zealand sits on the active Australian-Pacific plate boundary (Fig. 1.4a). Geomorphological expressions of that plate boundary are the Hikurangi Trough to the east of the North Island, the Puysegur Trench to the southwest of the South Island, and the dextral-reverse, NE-SW-striking, SE-dipping Alpine Fault and adjacent Southern Alps of New Zealand. The Hikurangi Trough and the Puysegur Trench mark the westward subduction of the Pacific plate under the continental Australian plate, and the eastward subduction of oceanic Australian plate under the continental Pacific plate, respectively. The Alpine Fault connects the two opposite-dipping subduction zones and accommodates that transition with a dextral-reverse, top-to-the-NW movement (Figs. $1.4 \mathrm{a}, \mathrm{b})$.

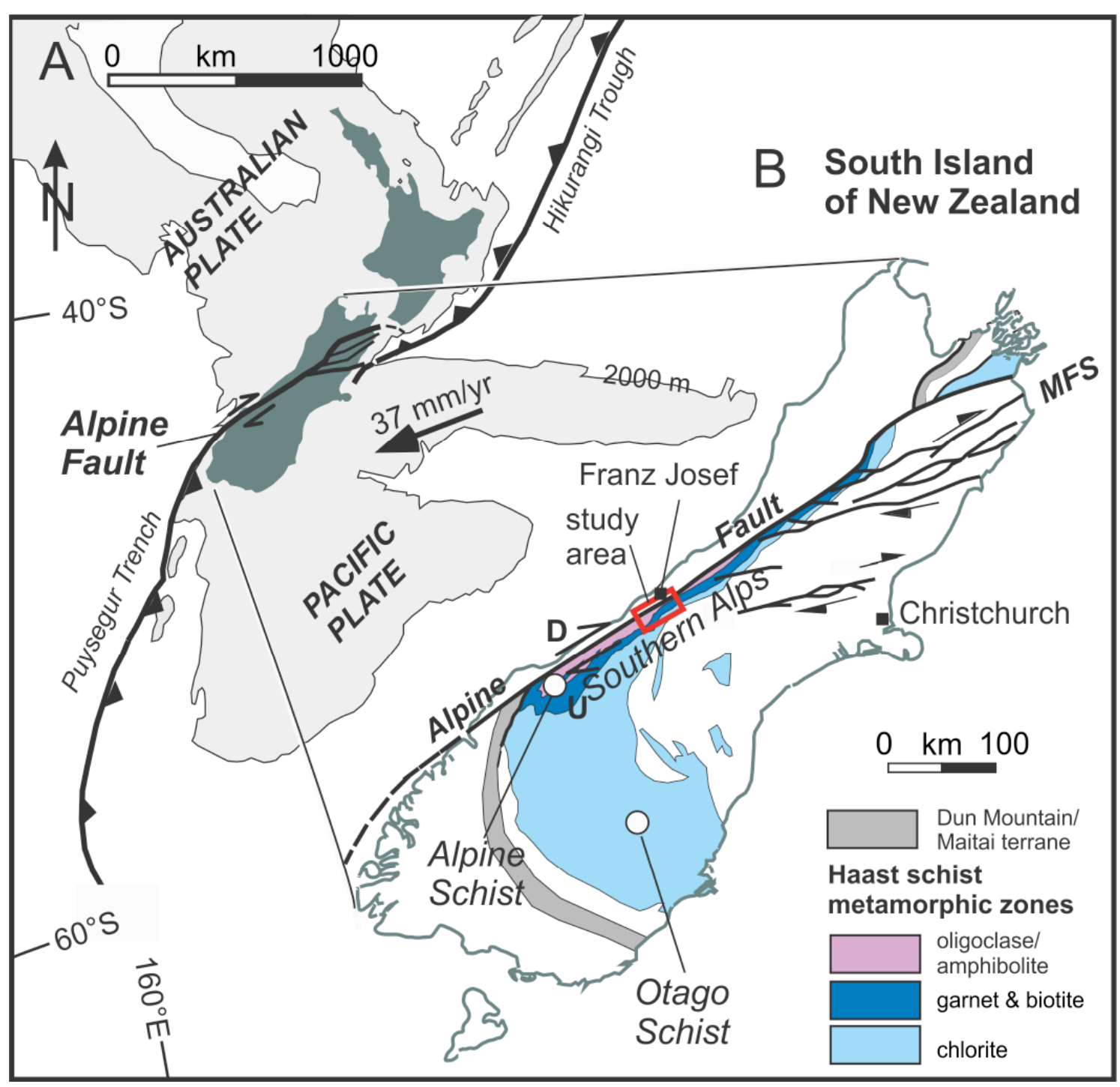


Fig. 1.4 (previous page): a) The New Zealand continent (green) straddling the plate boundary between the Australian and Pacific plate. The $2000 \mathrm{~m}$ isobath is indicated by the grey-shaded area. The plate convergence vector is from the NUVEL-1A global plate convergence model (DeMets et al., 1990, 1994). b) Geologic map of South Island, showing the dextral-reverse Alpine Fault and the Marlborough Fault System (MFS) as well as major units of basement rocks (Dun Mountain/Maitai terrane, Haast Schist). The Haast Schist is divided into the Alpine Schist and the Otago Schist (Sutherland, 1999). Isograds in the Haast Schist are shown by metamorphic index minerals. The study area is indicated by the red rectangle.

Since the onset of strike-slip movement on the Alpine Fault in the late Oligocene (29-24 Ma; Cox and Sutherland, 2007), the fault has dextrally offset basement rocks by at least $470 \mathrm{~km}$ (Wellman, 1955; Norris and Cooper, 2001, 2007; Sutherland et al., 2006; Cox and Sutherland, 2007, and references therein; Fig. 1.4b). This apparent offset is expressed by the dextral separation of a distinctive suite of Permian volcaniclastics, volcanics, and ophiolites (Dun Mountain Ophiolite Belt and overlying Maitai terrane, Fig. 1.4b; Wellman, 1955). Australian-Pacific plate convergence averaged over the past $\sim 3 \mathrm{~m}$.y. has been oblique at $37 \pm 2 \mathrm{~mm} / \mathrm{yr}$ at an azimuth of $071 \pm 2^{\circ}$ (NUVEL-1A global plate motion model of DeMets et al., 1990, 1994). This is approximately $16^{\circ}$ clockwise from the average Alpine Fault strike $\left(055^{\circ}\right)$. The NUVEL-1A plate motion vector consists of a margin-parallel dextral component of $35.7 \pm 1.9 \mathrm{~mm} / \mathrm{yr}$ and a marginnormal component of $9.5 \pm 2.0 \mathrm{~mm} / \mathrm{yr}$. Beavan et al. (2002) have averaged 12 years of continuous and campaign GPS data of surface velocities of the Pacific, Australian, and North American plates. Their present-day GPS velocity estimations are $38.9 \pm 1.0$ $\mathrm{mm} / \mathrm{yr}$ and $9.1 \pm 1.5 \mathrm{~mm} / \mathrm{yr}$ for the dextral and the convergent movement on the central part of the Alpine Fault respectively. Cande and Stock (2004) have included motion since $\sim 6 \mathrm{Ma}$ of the previously-unrecognised Macquarie plate in their velocity model (see also Beavan et al., 2007). Cande and Stock's (2004) Euler pole lies $250 \mathrm{~km}$ northeast of the NUVEL-1A pole. Their model results in slower plate motion rates than the models by DeMets et al. (1994) and Beavan et al. (2002). Cande and Stock (2004) derive a dextral velocity of $35.5 \pm 1.6 \mathrm{~mm} / \mathrm{yr}$ and a plate-normal velocity of $6.5 \pm 1.8$ $\mathrm{mm} / \mathrm{yr}$ averaged over the past 2.58 Myrs. Geologically determined late Quaternary strike-slip rates on the central Alpine Fault are $27 \pm 5 \mathrm{~mm} / \mathrm{yr}$ (Berryman et al., 1992; Norris and Cooper, 2001). This is approximately three quarters of the total PacificAustralian plate motion. Late Quaternary dip-slip rates on the central section of the Alpine Fault are 8-12 mm/yr and decrease to almost zero to the NE and SW along the fault (Norris and Cooper, 2001; Sutherland et al., 2006). Since the transition from 
mainly strike-slip motion on the fault to transpressive tectonics at 6-8 Ma (e.g., Batt et al., 2004), the Alpine Fault has accumulated $90 \pm 20 \mathrm{~km}$ plate-normal shortening (e.g., Walcott, 1998). When using the GPS velocities from Cande and Stock (2004), this shortening may only have been $40 \pm 15 \mathrm{~km}$. The shortening is accommodated by crustal thickening and erosion in the central South Island.

Exhumation rates along the central part of the Alpine Fault are as high as $\sim 10$ mm/yr (Wellman, 1979; Bull and Cooper, 1986; Tippet and Kamp, 1993; Beavan et al., 2007). Here, rocks from depths of $>20 \mathrm{~km}$ have been exhumed (Little et al., 2005). The exhumation rates are approximately counter-balanced by high erosion rates west of the Main Divide, a situation that may have led to a near-steady state of the topography in the central part of the Southern Alps (Adams, 1980, 1981; Little et al., 2005; Herman et al., 2007). The high exhumation rates are predicted to have resulted in an upward deflection of isotherms and increase in the geothermal gradient in the central Southern Alps, of up to $60-90^{\circ} \mathrm{C} / \mathrm{km}$ close to the surface (e.g. Shi et al., 1996).

The lower limit of historically observed seismicity is reported to be at $10-14 \mathrm{~km}$ under most of the South Island, but to be shallower at 8-10 km closer to the Alpine Fault (Leitner et al., 2001). The base of seismicity in an active orogen is usually equated to the depth of the brittle-ductile transition in quartz at the $300-350^{\circ} \mathrm{C}$ isotherm in an active orogen (e.g., Scholz, 2002). Closer to the Alpine Fault, due to the local high uplift rates, rocks are uplifted faster than they can cool, thereby advecting the $300^{\circ} \mathrm{C}$ isotherm upwards (Koons, 1987; Holm et al., 1988; Craw, 1997; Leitner et al., 2001; Craw and Campbell, 2004). The shallower $300^{\circ} \mathrm{C}$ isotherm may be the reason for the shallower base of seismicity adjacent to the Alpine Fault (Leitner et al., 2001).

Seismic imaging across the central Southern Alps indicates a listric shape at depth for the Alpine Fault, dipping $\sim 60^{\circ}$ to the SE in the upper $15 \mathrm{~km}$ of the crust and $\leq 45^{\circ}$ to the $\mathrm{SE}$ to $\geq 30 \mathrm{~km}$ depth, where it transitions into a subhorizontal décollement (Kleffmann et al., 1998; Stern et al., 2001, 2007). The existence of a décollement at $\geq$ $30 \mathrm{~km}$ depth is supported by the absence of exposed rocks that are higher-grade than amphibolite facies to the east of the Alpine Fault (e.g. Grapes and Watanabe, 1992; Vry et al., 2004; Cox and Barrell, 2007). The geophysical data is in good agreement with geological studies suggesting an Alpine Fault dip of $40-60^{\circ} \mathrm{SE}$. This fault dip estimate was inferred from the mean foliation attitude of Alpine Fault mylonites in the region around Fox and Franz Josef glaciers (Sibson et al., 1981; Cooper and Norris, 1994; Little et al. 2002b). 
Stern et al. (2001, 2007) imaged a $~ 30 \mathrm{~km}$ thick low-velocity zone above the Alpine Fault that extends from 5-8 km depth to $35 \mathrm{~km}$ depth. They interpreted this low velocity zone as representing a volume of interconnected metamorphic fluids that have been released during shearing and during neometamorphism of the rocks above the décollement. This interpretation is supported by a magnetotelluric study in that area (Wannamaker et al., 2002), which showed a high conductivity region coinciding approximately with the seismically imaged low-velocity zone. The top of the lowvelocity zone is roughly coincident with the maximum depth $(\sim 8 \mathrm{~km})$ of earthquakes beneath the central Southern Alps (Leitner et al., 2001; Stern et al., 2001).

A 1-2 km wide mylonite zone directly to the east of the Alpine Fault indicates ductile strain localisation and shearing at depth, along the fault. The mylonite is overprinted by a $\sim 10 \mathrm{~m}$ thick cataclasite zone immediately east of the active trace of the Alpine Fault, indicating an upward narrowing of shear across a mid-crustal brittle regime as the Pacific Plate rocks were exhumed (Toy et al., 2008 and references therein). Near Fox and Franz Josef glaciers, the mean attitude of the mylonitic foliation indicates that the Alpine Fault dips $40-60^{\circ} \mathrm{SE}$ in the central section of the Southern Alps (Sibson et al., 1981; Norris and Cooper, 1995; Little et al., 2002b). Toy (2007) reports that deformation temperatures and pressures in the Alpine Fault mylonites did not exceed $\sim 650^{\circ} \mathrm{C}$ and $\geq 700-850 \pm 150 \mathrm{MPa}$ respectively; i.e., the mylonitisation took place at 26-33 km depth. These P-T values are based on feldspar thermobarometry, Tiin-Biotite thermometry, and the absence of prism<c>-slip quartz CPO fabrics in the Alpine Fault mylonites. In and to the east of the mylonite zone, rocks of up to amphibolite facies (garnet-oligoclase zone) grade are exposed (but no higher) despite $\sim 90 \mathrm{~km}$ of late Cenozoic shortening. The metamorphic grade decreases to the East of the Alpine Fault to prehnite-pumpellyite facies at the Main Divide of the Southern Alps. The Mesozoic predominantly quartzofeldspathic rocks that were exhumed along the central part of the Alpine Fault are termed Alpine Schist and are a sub-division of the so-called Haast Schist group that also includes the Otago Schist (Grapes and Watanabe, 1992; Grapes, 1995; Sutherland, 1999; Fig. 1.4b). The protolith of the Alpine Schist is chiefly Torlesse terrane greywacke and argillite.

\subsection{Study area: a brittle-ductile shear array}

The study area is located in the central Southern Alps, New Zealand, near the Fox and Franz Josef glaciers (Fig. 1.5). Within that area, $5-7 \mathrm{~km}$ to the southeast of the 
Alpine Fault (and structurally above that SE-dipping fault), a 1-2 km wide array of closely spaced $(30-60 \mathrm{~cm})$, near-vertical faults is exposed in the uplifted and exhumed hanging wall of the Alpine Fault (green-shaded area in Fig. 1.5). The fault array is 20 $\mathrm{km}$ long and the average strike of these faults is NE-SW, subparallel to the trace of the Alpine Fault. The enveloping trace of this zone deflects across the topography, indicating a SE-ward dip of the entire tabular zone that encloses the array of faults. The occurrence of these faults is restricted to the described area in the central Southern Alps. None of these faults have been detected north of the Callary River or south of Balfour Glacier (Fig. 1.5). The field data for this thesis was collected during three New Zealand summers $(2006,2007,2008)$ at two locations in the shear array: Chancellor Ridge and Crawford Knob (Fig. 1.5). At these sites, the faults are exposed in superb glaciated outcrops where they could be studied in detail and in 3D (Fig. 1.6).

The faults cut and offset the dominant foliation in the Alpine Schist in an acute angle and truncate all other pre-existing structures such as older quartz veins (Fig. 1.7a, b). They extend both laterally and vertically over up to tens of metres (Fig. 1.7a). Throughout the array, the faults consistently show both dextral and NW-up senses of slip. Where the faults intersect older quartz veins embedded within the brittlely deformed Alpine Schist host, the quartz veins are typically ductilely sheared rather than brittlely displaced (Fig. 1.7b). Other quartz marker veins show both brittle and ductile slip components. The majority of quartz veins embedded in that schist form an acute angle with the dominant foliation and have been folded about a foliation-parallel axial plane prior to being sheared by the brittle faults. In this study, the expression "brittleductile shear" describes our main field observation: a fault that brittlely offsets the quartzofeldspathic Alpine Schist, and usually blunts into discordant quartz veins, that are smoothly displaced across cm-wide ductile shear zones in those quartz veins (Fig. 1.7b). The field work consisted mainly of detailed surveying and outcrop mapping of the brittle-ductile shears, as well as sampling of some of the deformed quartz veins.

The shears are interpreted to have been activated sequentially, similar to the steps of an escalator, during passing of Pacific Plate rocks across the Alpine Fault foot ramp (Little et al., 2002b; Little, 2004). The deep embrittlement is seen as a transient process that took place under elevated fluid pressure and enhanced strain rates at the foot of the Alpine Fault (Little et al., 2002 a, b; Little, 2005; Wightman et al., 2006). As a result of rapid uplift in the hanging wall of the Alpine Fault and high erosion rates, the brittle- 
ductile shears have been exhumed from $>20 \mathrm{~km}$ depth during the past $\sim 3$ Myrs (Little et al., 2002a).

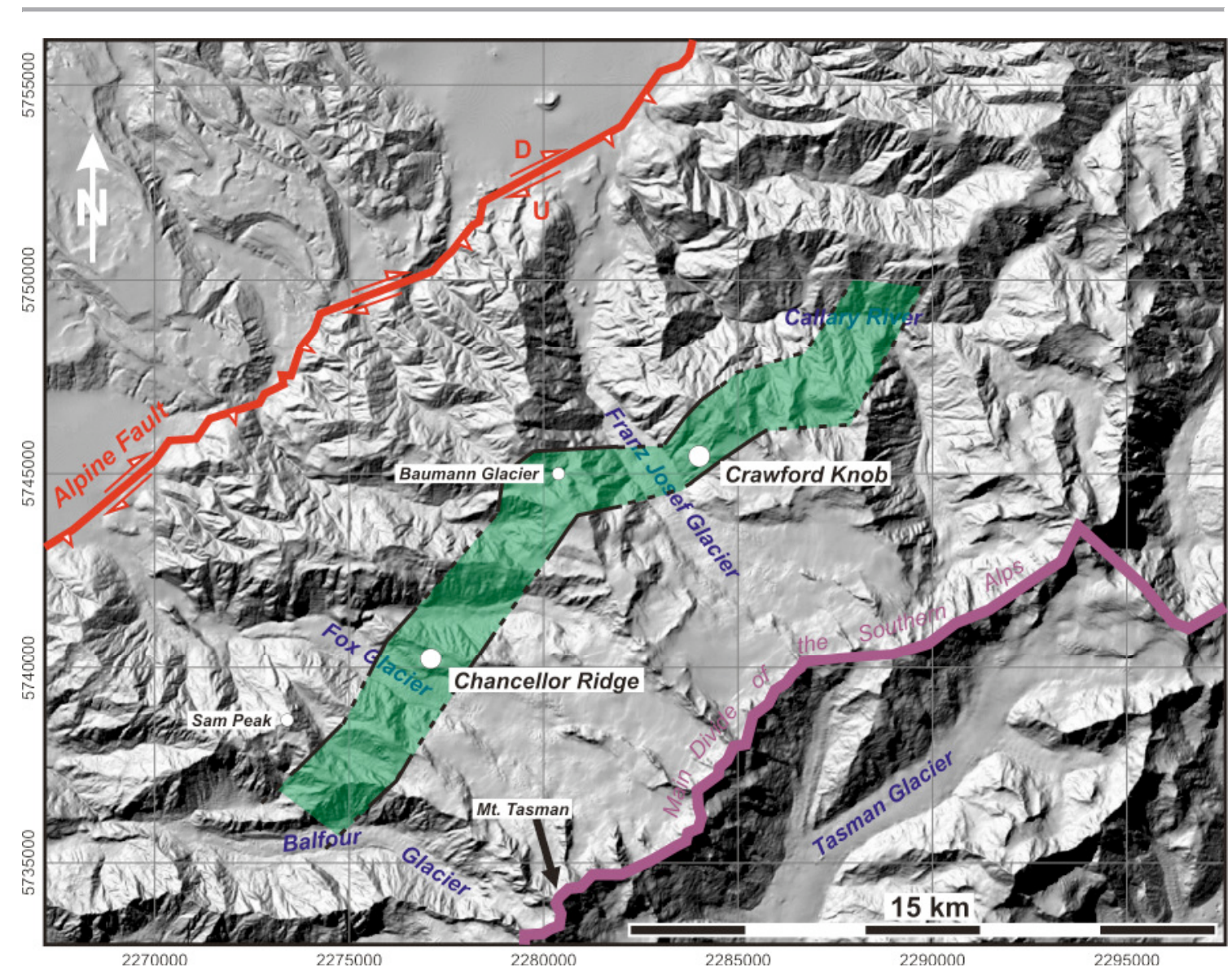

Fig. 1.5: Digital elevation model of the central Southern Alps of New Zealand. The green shaded area marks the approximate extent of the brittle-ductile shear array. Note the parallelism between Alpine Fault (red), brittle-ductile shear array (green), and Main Divide of the Southern Alps (purple). Chancellor Ridge and Crawford Knob are the two major surveying and sampling sites for this study.

The brittle-ductile shear array has been the subject of several studies on different aspects of rock deformation under transient brittle-ductile deformation conditions (e.g., Little et al., 2002a, b; PhD thesis by Wightman, 2005; MSc thesis by Hill, 2005; Wightman et al., 2006; Wightman and Little, 2007). These studies gave insight into the formation, and the deformation conditions of the brittle-ductile shear array, and on the microstructural evolution of the ductilely to brittlely sheared quartz veins. The present study builds on this foundational research by advancing in the following new directions: quantitative rheology modelling, investigation of the interaction between brittle and ductile deformation, and investigation of controls on ductile shear zone localisation in the quartz veins. 


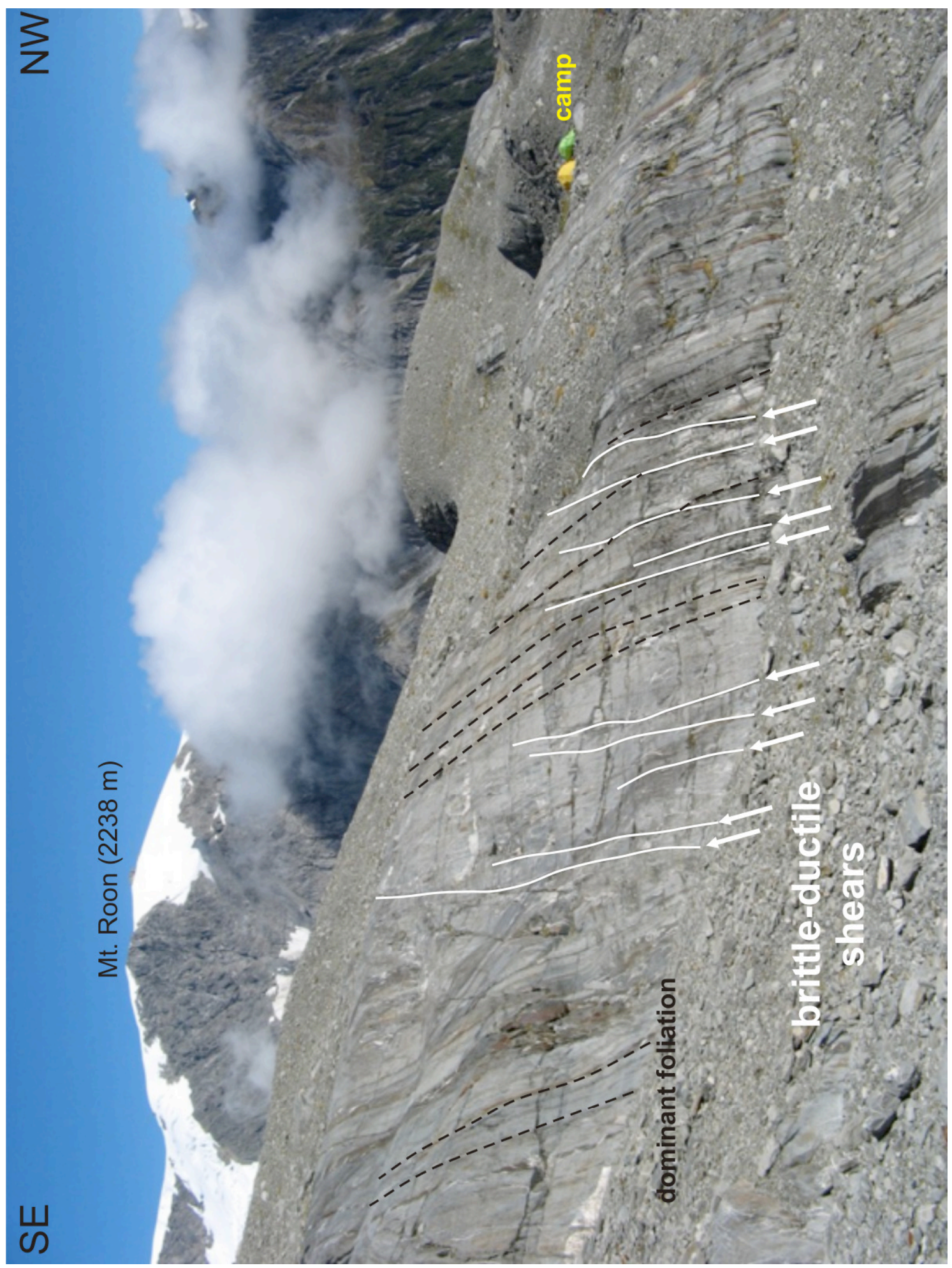

Fig. 1.6: Glacier-polished outcrops of brittle-ductile shears at Craford Knob. Facing SW towards the Franz Josef Glacier valley (Waiho river). The dominant foliation is traced with black stippled lines. The white arrows indicate the approximate trend of the shear/outcrop intersections. 

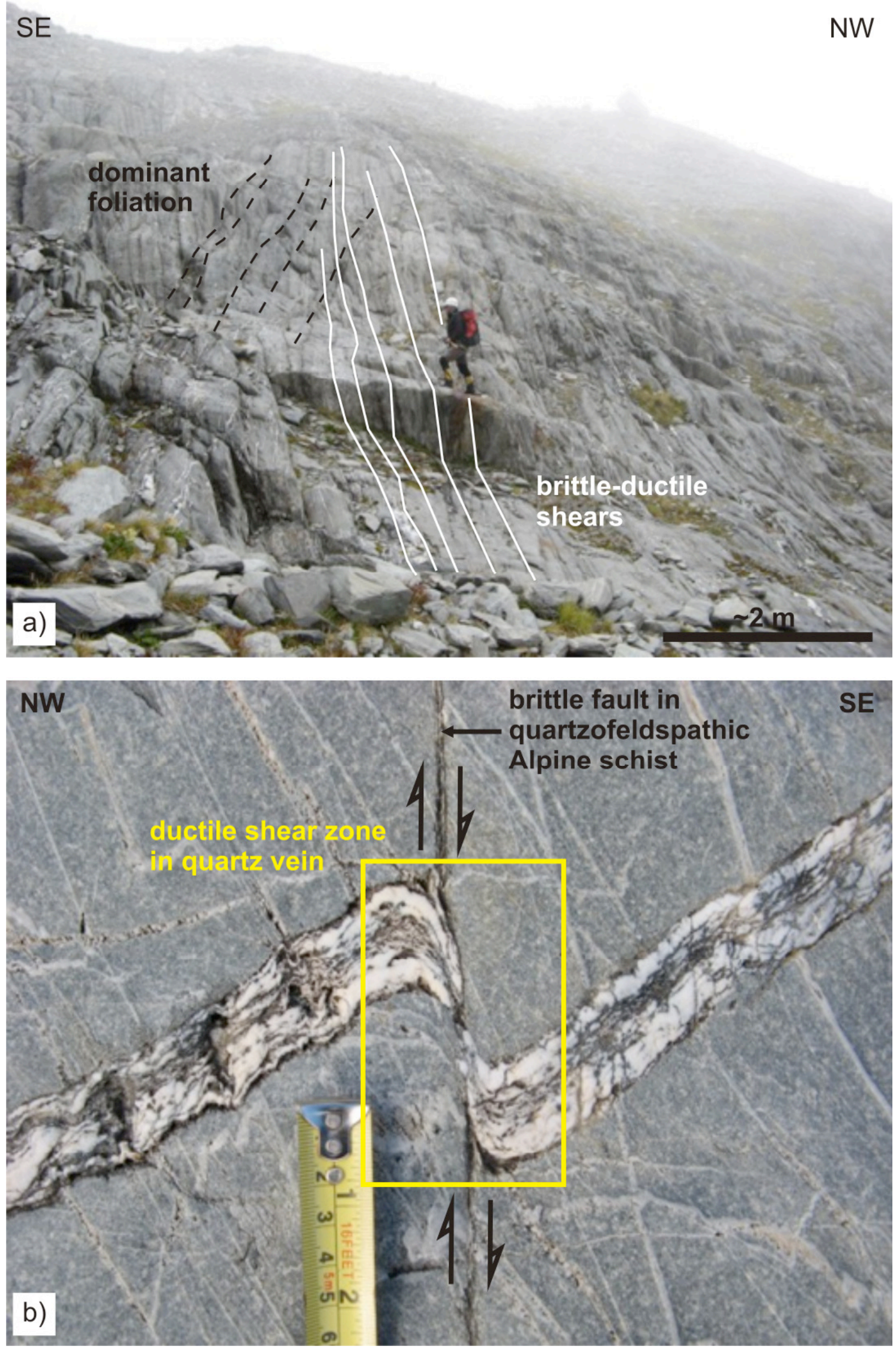
Fig. 1.7 (previous page): a) Glaciated outcrops of brittle-ductile shears at Chancellor Ridge. The nearvertical shears extend over tens of meters and are sub-parallel to each other. b) Close-up of a "brittleductile shear" as defined in the main text: a narrow, brittle fault offsets the Alpine schist in a dextral, NW-up sense; where the fault encounters a discordant quartz vein, the style of deformation changes from brittle to mostly ductile in that quartz vein.

\subsection{Thesis outline and organisation}

This thesis is written in five chapters of which Chapter 2 has been published in Journal of Structural Geology (Grigull and Little, 2008; JSG, v. 30, p. 868-875) and chapters 3 and 4 are intended for publication as stand-alone papers. There is some unavoidable repetition of exposition material between the chapters such as the geological and tectonic setting of the study area, the outcrop description of the brittleductile shear array, and some references. Contributions to the thesis by co-authors of the individual papers are clearly indicated in the text.

In Chapter 2, we address a common problem in structural geology: How can we extract the true displacement and the true shape of a displaced geological marker from an arbitrarily oriented outcrop surface; "true" meaning the plan view of the movement plane. Some measurements of the displacements and the shapes of the brittlely-toductilely sheared quartz veins were taken on outcrop surfaces that were not oriented parallel to the movement plane of the shears. The difference in orientation between the measurement plane (outcrop surface) and the movement plane might have induced unsystematic scattering of geometrical scaling relationships measured in the deformed quartz veins. In this paper, we describe what sequence of graphical and mathematical steps are necessary to project the outline of a deformed quartz vein and of the brittle fault directly from the outcrop surface into the movement plane of that fault. These algebraic operations can be used on any actual faulted or sheared geological marker provided it has a cylindrical symmetry about the marker's cut-off line. For the implementation of those mathematical operations, we have developed a Matlab ${ }^{\circledR} \operatorname{code}$ The numerical input for this code consists of the attitudes of the outcrop surface, the fault plane, the marker vein, and the trend and plunge of the slip vector. The program enables one to rotate and project the trace of the veins that was directly taken from the outcrop onto the movement plane. The MATLAB ${ }^{\circledR}$ code can be found in Appendix A. 
In Chapter 3, we use a set of geometrical scaling relationships relating to the sheared quartz veins to establish flow law parameters that could have been operative during deformation of the quartz veins. We also address the question whether or not laboratory-derived flow laws are applicable to the deformed quartz veins in the Southern Alps. In this chapter, after projecting the trace of the sheared quartz veins into the movement plane, we perform numerical modelling of schist and quartz vein deformation to test whether we can reproduce the observed scaling relationships as well as the observed interaction between brittle faults and ductilely deforming quartz veins by using published flow laws for quartz within the well constrained deformation conditions of the shear array. The scaling relationships include e.g. ductile shear zone width vs. original vein thickness or total displacement. By changing flow law parameters in the numerical models, and comparing the modelling results with our field observations, we try to bracket values for the pre-exponential factor and the stress exponent for the quartz veins in the Southern Alps within certain boundary conditions (e.g., frictional yield stress). Numerical modelling for Chapter 3 was first conducted with the commercial finite element code ABAQUS (Simulia). We encountered considerable difficulty in modelling localised shear zones to high finite strain with the ABAQUS software, so after two years, we decided to switch to a Lagrangian-Eulerian finite-element code, SULEC, developed by S. Ellis and S. Buiter. SULEC was benchmarked against the early stages of deformation predicted by ABAQUS. SULEC uses a tracer-in-cell approach, which enabled us to simulate extremely narrow faults and shear zones without the subsequent distortion of the initial finite element grid and its necessary remeshing.

In Chapter 4, we focus on the variability of ductile to brittle deformation observed in the naturally sheared quartz veins. We try to identify rheological factors that could have led to fully brittle deformation of some veins and fully ductile deformation of other veins, despite those veins having similar original thicknesses and final displacements. We also investigate if changes in quartz vein rheology or deformation conditions could have been mandatory for shear zone localisation in those quartz veins. In order to find out in what way the "ductility" of the quartz veins varied spatially (i.e., along- or across-strike of the shears), we mapped several square meters of outcrop in the shear array at Crawford Knob. To evaluate the chief controlling factor(s) on the "ductility" of the deformed quartz veins, we sampled a representative suite for 
laboratory testing. Using an optical microscope, we quantitatively determined the amount of the minor phase calcite in the quartz veins by eye. Depending on the size of the calcite grains in the quartz veins, the calcite content could have contributed to a decrease or increase in viscosity in the veins and therefore to a higher ductility (e.g. Brodie and Rutter, 2000, Mancktelow and Pennacchioni, 2010). We investigated differences in water content in the veins via FTIR spectroscopy since different water contents could have been a sign of differential hydrolytic weakening (e.g. Griggs, 1967). The FTIR measurements were done by Klaus Röller and Rita Seifert at RuhrUniversity Bochum (Germany). A summary of the FTIR measurements was written by Bernhard Stöckhert (also Ruhr-University) and adapted and extended by me to incorporate it into the manuscript. We measured titanium isotopes in some of the sampled quartz veins via LA ICP-MS. We applied Titanium-in-Quartz geothermometry to determine if local differences in recrystallisation temperature could have led to the observed variable ductilities. To further constrain the deformational temperatures, quartz-calcite oxygen isotope thermometry was undertaken on mm-thick fibrous quartzcalcite veins that have syn-deformationally infilled the brittle faults in the schist. The measurements for the quartz-calcite oxygen isotopes were done by Ruth Wightman in the course of her $\mathrm{PhD}$ studies and are again cited in a relevant context here (Appendix 4.A).

Chapter 5 summarises the findings and conclusions of all three preceding chapters and proposes further research ideas for the brittle-ductile shear array. 


\title{
Chapter 2
}

\section{A Graphical-Algebraic Method for Analysing Shear Zone Displacements from Observations on Arbitrarily Oriented Outcrop Surfaces}

\author{
Susanne Grigull \\ Timothy A. Little \\ School of Geography, Environment and Earth Sciences \\ Victoria University of Wellington \\ PO Box 600 \\ Wellington 6140 \\ New Zealand
}

\begin{abstract}
We present a practical graphical-algebraic method that enables one to achieve the true displacement and shape of deformed geological markers in fault or shear zones as observed on arbitrarily oriented outcrop surfaces. We use as our natural example deformed quartz veins that have been sheared across brittle-ductile faults in the Southern Alps of New Zealand. The technique is based on the assumption that simple shear has dominated the shear zone formation. For input data we require the strikes and dips of the outcrop surfaces, the offset markers, and the shear zones as well as the pitch of the simple shear vector in the plane of the shear zone. The paper develops a set of algebraic and graphical operations that allows one to convert photographs of faulted or sheared planar markers observed on an arbitrary outcrop surface into an equivalent view that is coincident with the movement $(\mathrm{m})$ plane of the fault or shear zone. This view displays the true displacement of the offset marker and delineates its deformed shape as seen in a section that is parallel to the slip vector.
\end{abstract}




\subsection{Introduction}

When investigating planar geological structures in the field that show an offset of older marker planes (e.g. fault zones, shear zones) we have to deal with the fact that in many cases the outcrop plane does not coincide with the movement plane (i.e. the plane perpendicular to the fault or shear zones, that coincides with the true slip direction). This is crucial, for example, if maps or photographs are used to constrain the rheology of rocks (e.g. Talbot, 1999; Pennacchioni, 2005; Fusseis et al., 2006). Ignoring the "distorted" nature of fault or shear zone offset geometries on arbitrary outcrop planes can yield to inaccurate measurements of slip or shear strain, and the deformed shape of offset markers.

This paper offers a "recipe" on how to translate geological offset data from an arbitrary outcrop plane onto the movement plane. ${ }^{1}$ The paper is based on geological investigations of rocks in a fault array that has been exhumed from mid-lower crustal depths $(\sim 20 \mathrm{~km})$ and is now exposed in glaciated outcrops in the central Southern Alps, New Zealand. Here, faults brittlely offset biotite-zone Alpine Schist, and where the tips of these faults encounter older quartz veins that are hosted by these schists, they terminate into local ductile shear zones in the quartz veins (Fig.2.1).

As a first step towards retrieving rheological information from the deformed shape of the marker veins, the exposures were photographed and measurements were made of the fault attitudes (strike, dip), the quartz marker vein attitudes (strike, dip), the pitch of the slip lineations in the fault planes, and the strikes and dips of the outcrop surfaces. Unfortunately, rarely do the glaciated outcrop surfaces coincide exactly with the actual movement plane. Digitising the photographs of the faults and the quartz veins offset across them enabled us to extract $x-y$ coordinates for the fault and vein margins in the outcrop plane. We then projected these $x-y$ data onto the movement plane to derive a depiction of the true offsets and shapes of the displaced planar markers.

\footnotetext{
${ }^{1}$ Interested researchers can contact the corresponding author for an electronic copy of a MATLAB7 script (including a short manual on using the script) that can read and process their data as described in the paper and outputs the data in a plot similar to Fig. 2.5 (c). The MATLAB script is included in Appendix A at the back of this thesis.
} 


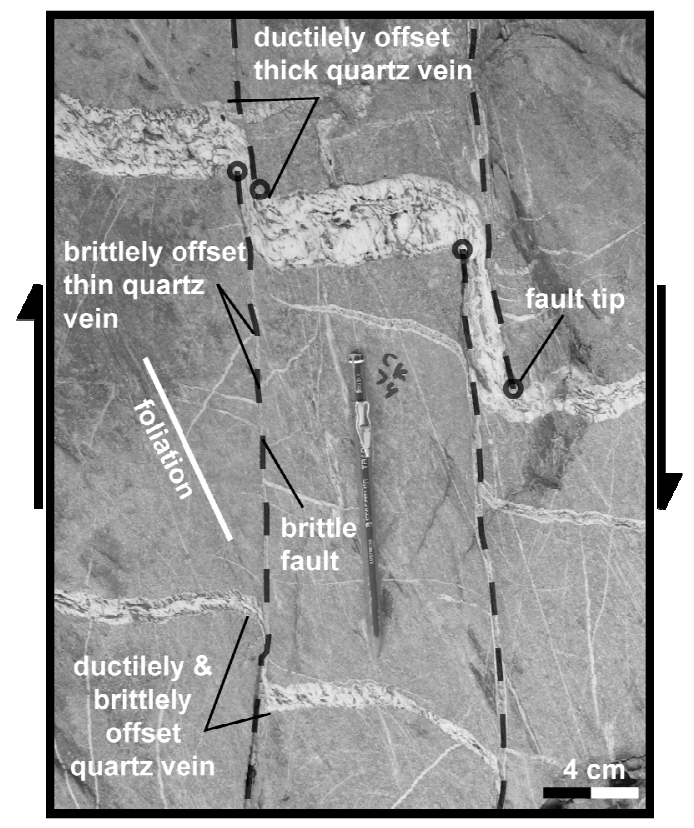

Figure 2.1: Outcrop photograph showing brittle faults (dashed lines) terminating into quartz veins and offsetting them ductilely to brittlely. Location: Crawford Knob, central Southern Alps, New Zealand.

\subsection{Assumptions}

Before projecting the data onto the movement plane, several assumptions must be made:

1) that it is possible to measure the fault plane orientation, the marker vein orientation, the trend and plunge of the slip lineation on the fault surface, and the outcrop orientation,

2) that the observed slip lineation is a faithful indicator of the finite slip direction, and that it is viewable nearby on another plane than the outcrop plane, or that it is otherwise known,

3) that the fault plane can be approximated as a flat, non-bending surface,

4) that the orientation and thickness of the original marker vein did not, prior to offset, change in the third dimension, i. e. that it was tabular in shape,

5) that the subsequent deformational curvature of this marker was dominantly a result of simple shear, leading to a cylindrical "drag fold" geometry (Ramsay and Huber 1987, p. 509),

6) that the photographs were taken normal to the outcrop surface, or that it is possible to undistort photographs that were taken at an oblique angle using e.g. the method of Cooper and Bamford (1987). 


\subsection{Preparing $x-y-z$ data from photographs (Step 1)}

For the denotation of vectors, variables and coefficients refer to the glossary in Appendix (2.A).

\subsubsection{Coordinate systems}

In this paper, the right-hand-rule applies for all geological orientation measurements, where the thumb represents the strike of a plane and the index finger points into the dip direction. All planar measurements are given in 'strike/dip' and all linear measurements in 'trend/plunge'.

All Cartesian coordinate systems used in this paper are right-handed. A geographical and an outcrop coordinate system have been defined that have a common spatial origin located on the fault trace in the outcrop plane at the midpoint of the two halves of an offset marker vein (star in Fig. 2.2). The geographical coordinate system has got the axes $x_{g}=$ North, $y_{g}=$ East, and $z_{g}=$ "down", where $\hat{\bar{x}}_{g}=\left(\begin{array}{l}1 \\ 0 \\ 0\end{array}\right), \hat{\bar{y}}_{g}=\left(\begin{array}{l}0 \\ 1 \\ 0\end{array}\right)$, and $\hat{\bar{z}}_{g}=\left(\begin{array}{l}0 \\ 0 \\ 1\end{array}\right)$ are the unit vectors that point along the respective axes. The outcrop coordinate system is spanned by the axes $x_{o c}, y_{o c}$, and $z_{o c}$, where the positive $x_{o c}$-axis is equivalent to the fault trace on the outcrop and pointing in the down-plunge direction of that trace. $y_{o c}$ lies in the outcrop face pointing $90^{\circ}$ clockwise from the fault trace with respect to the positive $z_{o c}$-axis. $z_{o c}$ is represented by the pole to the outcrop surface pointing "inwards" (Fig. 2.2). $\hat{\bar{x}}_{o c}=\left(\begin{array}{c}x_{g}^{x o c} \\ y_{g}^{x o c} \\ z_{g}^{x o c}\end{array}\right), \hat{\bar{y}}_{o c}=\left(\begin{array}{c}x_{g}^{y o c} \\ y_{g}^{y o c} \\ z_{g}^{y o c}\end{array}\right)$ and $\hat{\bar{z}}_{o c}=\left(\begin{array}{l}x_{g}^{z o c} \\ y_{g}^{z o c} \\ z_{g}^{z o c}\end{array}\right)$ are the unit vectors and their vector components in geographical coordinates that are parallel to the outcrop coordinate system axes.

In order to determine $\hat{\bar{x}}_{o c}$, we first need to find the orientation of the pole to the outcrop plane and the pole to the fault plane by calculating the direction cosines (App. 2.B.1) of those poles from the strike and dip angles of the respective planes. The pole to the outcrop plane yields $\hat{\bar{z}}_{o c}$. The pole to the fault plane yields the unit vector $\hat{\bar{f}}$ (Fig. 
2.3a). The normalised right-handed cross-product of $\hat{\overline{\vec{z}}}_{o c} \times \hat{\vec{f}}$ results in $\hat{\bar{x}}_{o c}$, the unit vector parallel to the fault trace on the outcrop surface. To derive consistency for the following transformations, we define $\hat{\bar{x}}_{o c}$ to always point downwards, i.e. if $\hat{\bar{z}}_{o c} \times \hat{\vec{f}}$ results in a negative value for $z_{g}^{x o c}$, we have to multiply the coordinates for $\hat{\bar{x}}_{o c}$ by $(-1)$. The normalised right-handed cross-product $\hat{\bar{z}}_{o c} \times \hat{\bar{x}}_{o c}$ will then result in the Cartesian vector coordinates for $\hat{\bar{y}}_{o c}$ (Fig. 2.2).

\subsubsection{Digitising}

For the projection of the marker veins onto the movement plane, they need to be digitised. In a graphics programme (e.g. Adobe Illustrator) the photograph is rotated in such a way that the positive $x_{o c}$-axis (i.e. down-plunge "end" of the fault trace) points towards the top. The positive $y_{o c}$-axis should now point to the right. The rotated photograph is then resized to a desired scale, imported into a digitising programme (e.g. Replica by Graphic Edge Ltd.) and digitised. For this, the origin is chosen such that it lies on the midpoint between the two offset parts of the markers. This origin corresponds to the spatial origin (star) in Fig. 2.2 and will remain the same throughout the following coordinate transformations. The digitising output are coordinates of points in the $x_{o c}-y_{o c}$-plane of the outcrop coordinate system, with $z_{o c}=0$. Note that most digitising software applications use left-handed coordinate systems, and close attention has to be paid not to confuse the $x$ - and $y$-coordinates.

\subsubsection{Geographical coordinates of points}

Now the position of the digitised points has to be recast in terms of the geographical coordinate system. As the outcrop and geographical coordinate systems both have the same origin, a change of orthonormal basis can be performed using Eqs. (2.1a) and (2.1b), below, in order to transform the outcrop coordinates of a point $P$ $\left(x_{o c}^{P}, y_{o c}^{P}, z_{o c}^{P}=0\right)$ into its geographical coordinates $P\left(x_{g}^{P}, y_{g}^{P}, z_{g}^{P}\right)$.

$$
P:=\vec{p}=\left(\begin{array}{c}
x_{g}^{P} \\
y_{g}^{P} \\
z_{g}^{P}
\end{array}\right)=\left[\begin{array}{lll}
\hat{\bar{x}}_{g} \cdot \hat{\bar{x}}_{o c} & \hat{\bar{x}}_{g} \cdot \hat{\bar{y}}_{o c} & \hat{\bar{x}}_{g} \cdot \hat{\bar{z}}_{o c} \\
\hat{\bar{y}}_{g} \cdot \hat{\bar{x}}_{o c} & \hat{\bar{y}}_{g} \cdot \hat{\bar{y}}_{o c} & \hat{\bar{y}}_{g} \cdot \hat{\bar{z}}_{o c} \\
\hat{\bar{z}}_{g} \cdot \hat{\bar{x}}_{o c} & \hat{\bar{z}}_{g} \cdot \hat{\bar{y}}_{o c} & \hat{\bar{z}}_{g} \cdot \hat{\bar{z}}_{o c}
\end{array}\right] \cdot\left(\begin{array}{c}
x_{o c}^{P} \\
y_{o c}^{P} \\
z_{o c}^{P}
\end{array}\right)
$$


where $P:=\vec{p}$ means that the coordinates of point $P$ are defined by its position vector $\vec{p}$ that is anchored at the common spatial origin $(0,0,0)$.

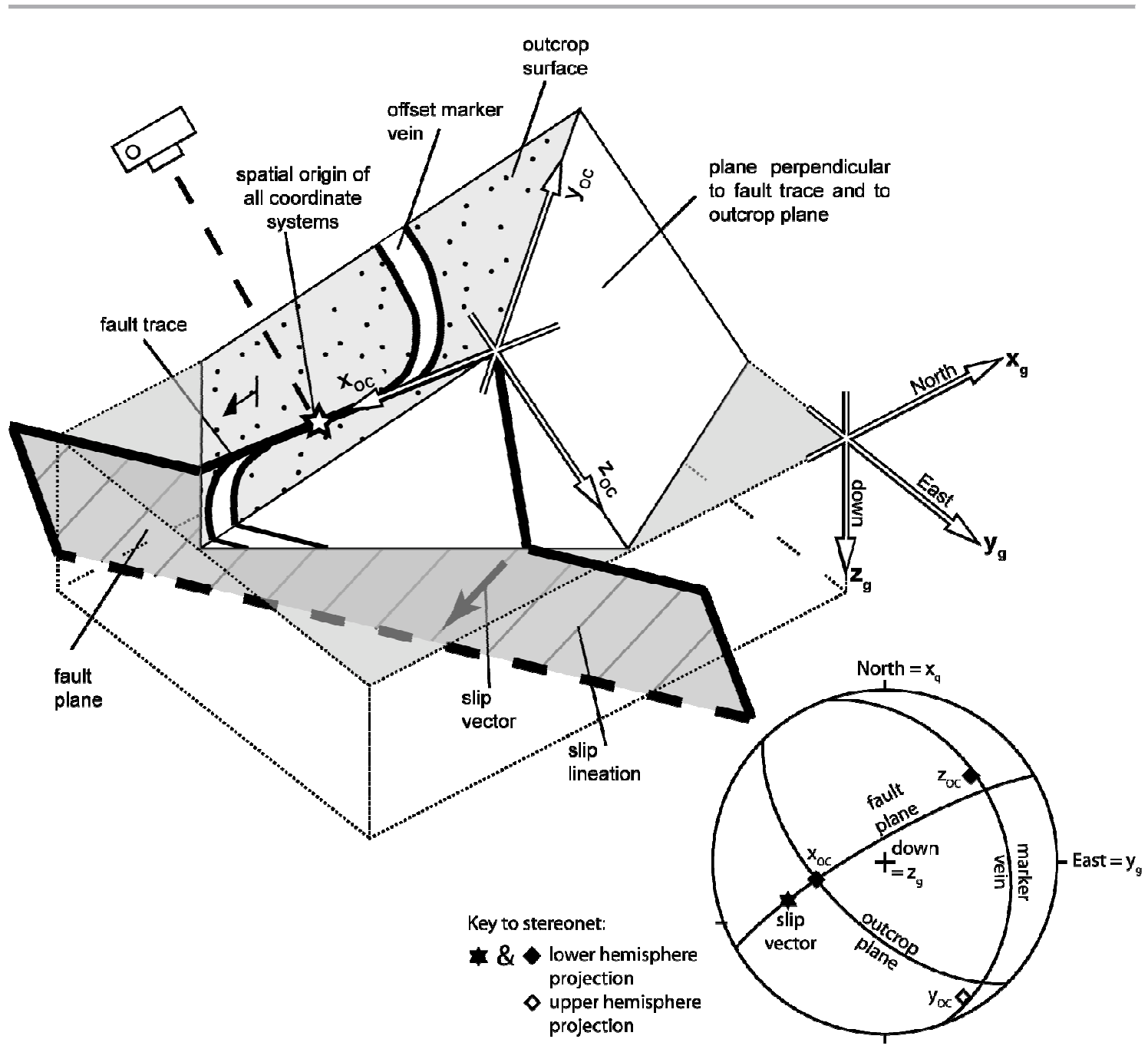

Figure 2.2: Block diagram illustrating the spatial relationship between the outcrop plane and the fault plane as well as the two coordinate systems defined in 3.1. ( $x_{O C}$ : $\mathrm{x}$-axis of the outcrop coordinate system, parallel and down-plunge to the fault trace and lying within the outcrop plane; $y_{O C}$ : at a right angle to $x_{O C}$ and lying within the outcrop surface; $\mathrm{z}_{\mathrm{OC}}$ : pole to the outcrop plane; $x_{g}, y_{g}, z_{g}$ : geographical coordinate axes). The spatial origin common to both coordinate systems is indicated by the white star. Due to clarity, the axes of the outcrop and geographical coordinate systems have been shifted away from the origin. In an ideally taken photograph, the photo axis (dashed line between camera and outcrop) is perpendicular to the outcrop surface (cf. assumption 6) in 2.). The corresponding planes, the slip vector and the three axes of the outcrop coordinate system are plotted in a lower hemisphere stereonet. Note that $y_{O C}$ is pointing upwards in the block diagram and would therefore plot on the upper hemisphere. The stereonet displays the negative end of the $y_{O C^{-}}$axis. 
Knowing that $\hat{\bar{x}}_{g}=\left(\begin{array}{l}1 \\ 0 \\ 0\end{array}\right), \hat{\bar{y}}_{g}=\left(\begin{array}{l}0 \\ 1 \\ 0\end{array}\right)$, and $\hat{\bar{z}}_{g}=\left(\begin{array}{l}0 \\ 0 \\ 1\end{array}\right)$, Eq. (2.1a) can be simplified to

$$
P:=\vec{p}=\left(\begin{array}{c}
x_{g}^{P} \\
y_{g}^{P} \\
z_{g}^{P}
\end{array}\right)=\left[\begin{array}{lll}
x_{g}^{x o c} & x_{g}^{y o c} & x_{g}^{z o c} \\
y_{g}^{x o c} & y_{g}^{y o c} & y_{g}^{z o c} \\
z_{g}^{x o c} & z_{g}^{y o c} & z_{g}^{z o c}
\end{array}\right] \cdot\left(\begin{array}{c}
x_{o c}^{P} \\
y_{o c}^{P} \\
z_{o c}^{P}
\end{array}\right)
$$

This operation results in the vector components of vector $\vec{p}$ determining the position of a digitised point $P$ in the geographical reference system.

\subsection{Projection into the movement plane (Step 2)}

\subsubsection{The movement plane (m-plane) in point-normal form}

The movement plane or "m-plane" (Fig. 2.3a) is perpendicular to the fault plane and parallel to the unit vector of the direction of movement (i. e. parallel to the slip lineation). The pole to the m-plane $\hat{\bar{m}}$ in geographical coordinates can therefore be calculated from the right-handed cross-product of the unit vector $\hat{\bar{S}}$ parallel to the slip direction and the unit vector $\hat{\bar{f}}$ parallel to the pole of the fault plane:

$$
\hat{\bar{m}}=\frac{\hat{\vec{s}} \times \hat{\vec{f}}}{|\hat{\vec{s}} \times \hat{\bar{f}}|}=\left(\begin{array}{l}
x_{m} \\
y_{m} \\
z_{m}
\end{array}\right)
$$

$\hat{\bar{m}}$ originates at the spatial origin of all coordinate systems.

In algebraic terms a plane in 3-space is uniquely defined by a point that lies within the plane and a vector normal to the plane, so that the point-normal form of the equation of the movement plane becomes

$$
\vec{r} \cdot \hat{\bar{m}}=0
$$

where $\vec{r}$ is a vector in the m-plane.

\subsubsection{The projection vector and projection line}

Similar to the axes of drag folds (Ramsay \& Huber, 1987, their Fig. 23.9) the projection vector $\hat{\vec{v}}$ corresponds to the intersection lineation of the fault surface and the marker vein (Fig. 2.3b). $\hat{\bar{v}}$ is independent of the direction of movement and only 
depends on the marker vein orientation and the orientation of the fault plane. In fact, $\hat{\vec{v}}$ is parallel to both the fault and the marker vein. Thus, the projection vector $\hat{\bar{v}}$ is given by the cross product of the pole to the fault surface $\hat{\bar{f}}$ and the pole to the marker vein $\hat{\bar{q}}$ :

$$
\hat{\bar{v}}=\frac{\hat{\bar{f}} \times \hat{\bar{q}}}{|\hat{\vec{f}} \times \hat{\bar{q}}|}=\left(\begin{array}{l}
x_{v} \\
y_{v} \\
z_{v}
\end{array}\right)
$$

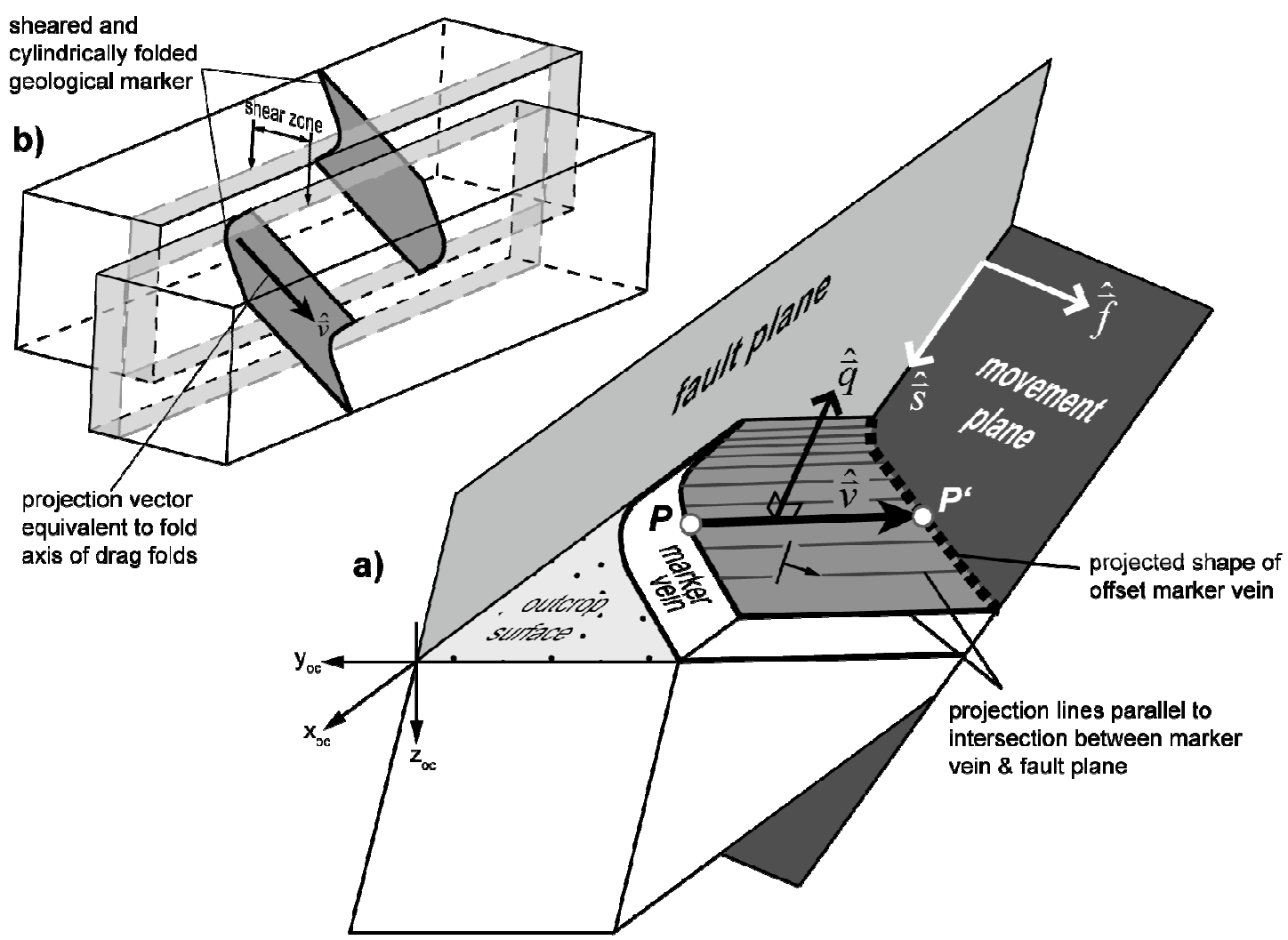

Figure 2.3: (a) Block diagram showing the downthrown half of a shear zone and the relationships between fault plane and movement plane as well as fault plane, marker vein and projection vector. $\hat{\vec{S}}$ (slip vector) and $\hat{\vec{f}}$ (pole to fault plane) span the movement plane. The cross product of $\hat{\bar{q}}$ (pole to marker vein) and $\hat{\bar{f}}$ results in the projection vector $\hat{\vec{v}}$. Point $P^{\prime}$ is the projection of point $P$ onto the movement plane along a projection line parallel to $\hat{\vec{v}}$. The stippled bold black line represents the projected shape of the marker vein on the m-plane. (b) Block diagram showing the concept for deriving the projection vector $\hat{\vec{v}}$. Assuming that the deformation of the geological marker (dark grey) was due to simple shear, $\hat{\vec{v}}$ is equivalent to the fold axis of the geological marker, and corresponds to the intersection of the geological marker and the shear plane. The area shaded in light grey indicates the extent of the shear zone and the dashed grey lines mark the shear zone boundaries. 
In Eq. (2.4) the direction of the cross product does not matter as the projection vector is only used as a direction vector for the 'projection line'.

The projection line (Fig. 2.3a) runs through the point $P\left(x_{g}^{P}, y_{g}^{P}, z_{g}^{P}\right)$ sitting on the outcrop surface and is parallel to the projection vector. The point $P^{\prime}\left(x_{g}^{P^{\prime}}, y_{g}^{P^{\prime}}, z_{g}^{P^{\prime}}\right)$ at which the projection line cuts through the m-plane is the projection of point $P$ onto the movement plane.

A line in 3-space is determined uniquely by specifying a point on the line and a nonzero vector parallel to the line so that the vector equation of the projection line becomes

$$
\vec{r}=\vec{p}+\lambda \hat{\vec{v}}
$$

where $\vec{p}=\left(\begin{array}{c}x_{g}^{P} \\ y_{g}^{P} \\ z_{g}^{P}\end{array}\right)$ is the position vector of point $P$ in the geographical coordinate system

derived from Eq. (2.1b), $\hat{\vec{v}}$ is the projection vector derived from Eq. (2.4), and $\lambda$ is a scalar parameter with $-\infty<\lambda<+\infty$ which reflects the fact that the line extends indefinitely.

\subsubsection{The projection process}

In order to find the point $P^{\prime}$, where the projection line cuts the m-plane, Eqs. (2.2) and (2.5) need to be inserted into Eq. (2.3) and the resulting equation be solved for $\lambda$ :

$$
\lambda=-\frac{x_{m} x_{g}^{P}+y_{m} y_{g}^{P}+z_{m} z_{g}^{P}}{x_{m} x_{v}+y_{m} y_{v}+z_{m} z_{v}}
$$

Placing $\lambda$ back into Eq. (2.5) and solving for all vector coordinates leads to the coordinates of $P^{\prime}$ :

$$
P^{\prime}:=\vec{r}=\left(\begin{array}{c}
x_{g}^{P} \\
y_{g}^{P} \\
z_{g}^{P}
\end{array}\right)-\frac{x_{m} x_{g}^{P}+y_{m} y_{g}^{P}+z_{m} z_{g}^{P}}{x_{m} x_{v}+y_{m} y_{v}+z_{m} z_{v}}\left(\begin{array}{c}
x_{v} \\
y_{v} \\
z_{v}
\end{array}\right)=\left(\begin{array}{c}
x_{g}^{P^{\prime}} \\
y_{g}^{P^{\prime}} \\
z_{g}^{P^{\prime}}
\end{array}\right)
$$




\subsection{Plan view of the m-plane (Step 3)}

In order to achieve a plan view of the projected marker points on the m-plane, the strike and dip of the m-plane (strike $e_{m-p l a n e}$, dip $p_{m-p l a n e}$, App. 2.B.2) needs to be found and a rotation in 3-space undertaken, to bring that plane and its points into horizontality and to a position where all fault traces on the m-plane are parallel to one another. This rotation is subdivided into two steps. The first step consists of two rotations (Eqs. (2.8a) and $(2.8 \mathrm{~b})$ ) that will be comprised into one rotation under Eq. (2.8c). The strike line of the m-plane is the rotation axis for these first two rotations. First, the points on the $\mathrm{m}$ plane are rotated about the vertical axis $\left(z_{g}\right)$ until the strike line of the m-plane is E-W, i.e. parallel to $y_{g}$. After this first rotation, the m-plane dips towards the negative $x_{g}$ direction. This rotation is called "rotl", and the new position vectors of the projected points are called $\vec{p}^{\prime}{ }_{\text {rot } 1}$ :

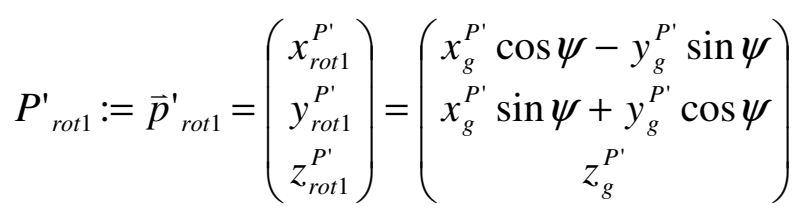

The rotation angle for this first step is $\psi=90^{\circ}-s_{\text {strike }}$-plane . For those strike angles between $0^{\circ}$ and $90^{\circ}, \psi$ will be positive and the rotation will be anticlockwise with respect to the positive $z_{g}$-axis. For all other orientations, $\psi$ will be negative and the rotation clockwise. Eq. (2.8a) rotates point $P^{\prime}$ (Eq. 7) about the $z_{g}$-axis and results in point $P_{r o t 1}^{\prime}$.

In the second step the coordinates of point $P_{r o t 1}^{\prime}$ derived from Eq. (2.8a) are rotated about the now strike-parallel, E-W $y_{g}$-axis (Eq. 8b). This rotation is called "rot2". As point $P_{r o t 1}^{\prime}$ is part of the dipping m-plane, the rotation angle for the rotation about the $y_{g}$-axis becomes $\varphi=-d i p_{m-p l a n e}$ and the rotation is clockwise with respect to the positive $y_{g}$-axis.

$$
P_{r o t 2}^{\prime}:=\vec{p}^{\prime}{ }_{r o t 2}=\left(\begin{array}{c}
x_{r o t 2}^{P^{\prime}} \\
y_{r o t 2}^{P^{\prime}} \\
z_{r o t 2}^{P^{\prime}}
\end{array}\right)=\left(\begin{array}{c}
x_{r o t 1}^{P^{\prime}} \cos \varphi+z_{r o t 1}^{P^{\prime}} \sin \varphi \\
y_{r o t 1}^{P^{\prime}} \\
-x_{r o t 1}^{P^{\prime}} \sin \varphi+z_{r o t 1}^{P^{\prime}} \cos \varphi
\end{array}\right)
$$


Eqs. (2.8a) and (2.8b) can be merged into Eq. (2.8c), where $P^{\prime}{ }_{\text {rot } 12}$ is the projection of point $P$ onto the movement plane and in plan view of the movement plane. The $z_{\text {rot } 12}^{P^{\prime}}$-coordinate of point $P_{\text {rot } 12}^{\prime}$ must be 0 after the rotation.

$$
P_{\text {rot } 12}^{\prime}:=\vec{p}_{\text {rot } 12}^{\prime}=\left(\begin{array}{c}
x_{\text {rot } 12}^{P^{\prime}} \\
y_{\text {rot } 12}^{P^{\prime}} \\
z_{\text {rot } 12}^{P^{\prime}}
\end{array}\right)=\left(\begin{array}{c}
\left(x_{g}^{P^{\prime}} \cos \psi-y_{g}^{P^{\prime}} \sin \psi\right) \cos \varphi+z_{g}^{P^{\prime}} \sin \varphi \\
x_{g}^{P^{\prime}} \sin \psi+y_{g}^{P^{\prime}} \cos \psi \\
-\left(x_{g}^{P^{\prime}} \cos \psi-y_{g}^{P^{\prime}} \sin \psi\right) \sin \varphi+z_{g}^{P^{\prime}} \cos \varphi
\end{array}\right)
$$

After having rotated the m-plane and its points into horizontality, the trace line of the fault on the m-plane need not necessarily be exactly N-S. The second step of this rotation in 3-space aims to make the plots of the shapes and offsets of multiple cases of displaced markers easily comparable, i.e. we need to rotate all projected points lying in the m-plane to a position where the fault traces of all cases are parallel to one another. The easiest solution to this problem is to conduct one further rotation ("rot3") of each point about the vertical $z_{g}$-axis, which will bring all the fault traces (on the m-plane) into N-S parallelism, with all of them containing the spatial origin. The trace $\hat{\bar{t}}$ of a fault on the m-plane is the intersection between the fault plane and the m-plane. $\hat{\vec{t}}$ is therefore the right-handed normalised cross-product of the pole to the m-plane $\hat{\vec{m}}$ and the pole to the fault $\hat{\bar{f}}$ :

$$
\hat{\bar{t}}=\frac{\hat{\bar{m}} \times \hat{\bar{f}}}{|\hat{\bar{m}} \times \hat{\bar{f}}|}=\left(\begin{array}{c}
x_{t} \\
y_{t} \\
z_{t}
\end{array}\right)
$$

We define $\hat{\vec{t}}$ to always point downwards, i.e. if $z_{t}$ is negative, we additionally need to multiply Eq. (2.9) by the factor (-1).

Applying the rotation in Eq. (2.8c) to $\hat{\bar{t}}$ yields horizontality of the fault trace in the m-plane. We call the resulting vector $\hat{\bar{t}}^{\prime}{ }_{\text {rot } 12}=\left(\begin{array}{c}x_{\text {rot12 }}^{t^{\prime}} \\ y_{\text {rot12 }}^{t^{\prime}} \\ z_{\text {rot } 12}^{t^{\prime}}\end{array}\right)$.

The rotation angle for this third rotation ("rot3") is the angle $\delta$ (Fig. 2.4) between the positive $x_{g}$-axis (North) and the trace of the fault on the horizontal m-plane $\hat{\bar{t}}^{\prime}{ }_{\text {rot } 12}$, that was derived by executing first Eq. (2.9) and then Eq. (2.8c). The angle $\delta$ is the result of the dot product between $\hat{\bar{x}}_{g}$ and $\hat{\bar{t}}^{\prime}{ }_{\text {rot } 12}$ : 


$$
\delta=\arccos \left(\hat{\bar{x}}_{g} \cdot \hat{\bar{t}}_{r o t 12}^{\prime}\right)
$$

However, we must take into account that Eq. (2.10) will only result in values for $\delta$ ranging from $0^{\circ}$ to $180^{\circ}$. Thus, if $y_{\text {rot } 12}^{t^{\prime}}$ is positive, $\delta$ must be negative and the rotation would be clockwise with respect to the positive $z_{g}$-axis. If $y_{\text {rot } 12}^{t^{\prime}}$ is negative, we must choose $\delta$ to be positive for an anticlockwise rotation about the $z_{g}$-axis. The final rotation "rot3", to be applied to all points is then given by the matrix:

$$
P_{r o t 3}^{\prime}:=\hat{\vec{p}}_{r o t 3}^{\prime}=\left(\begin{array}{c}
x_{r o t 3}^{P^{\prime}} \\
y_{r o t 3}^{P^{\prime}} \\
z_{r o t 3}^{P^{\prime}}
\end{array}\right)=\left(\begin{array}{c}
x_{r o t 12}^{P^{\prime}} \cos \delta-y_{r o t 12}^{P^{\prime}} \sin \delta \\
x_{r o t 12}^{P^{\prime}} \sin \delta+y_{r o t 12}^{P^{\prime}} \cos \delta \\
z_{r o t 12}^{P^{\prime}}
\end{array}\right)
$$

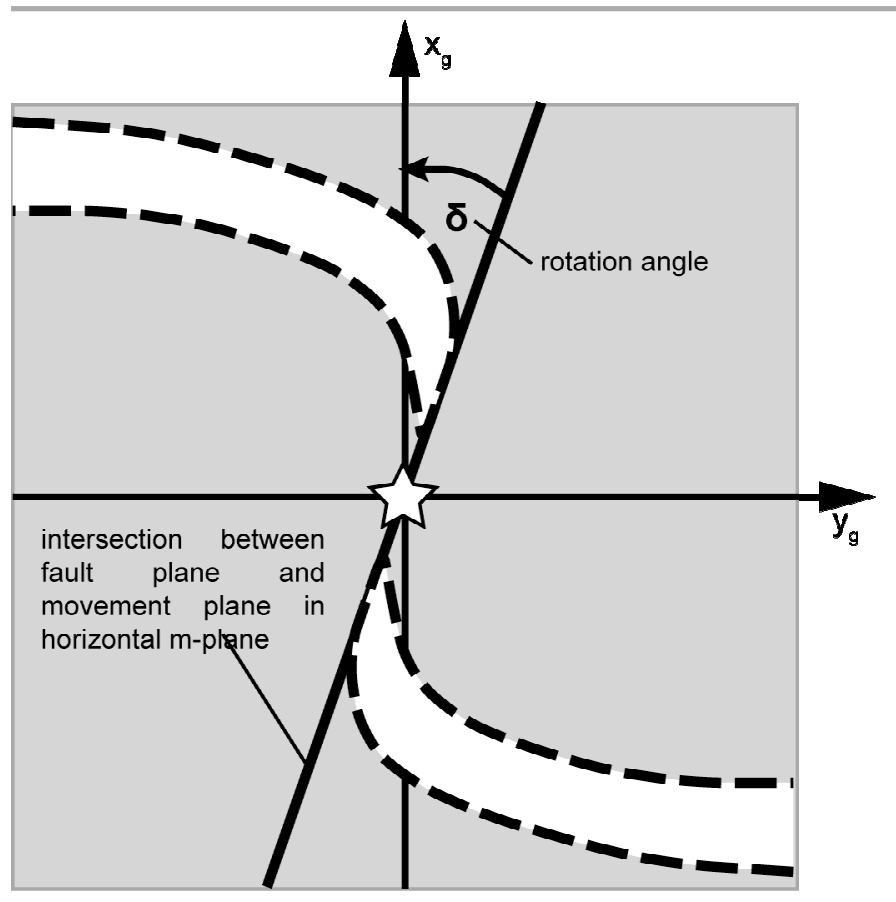

Figure 2.4: Schematic diagram of plan view of the movement plane (grey shaded) after the first two rotations "rotl" (Eq. (2.8a)) and "rot2" (Eq. (2.8b)). The rotation angle $\delta$ for the third rotation "rot3" (Eq. (2.11)) is the angle between the positive $x_{g}$-axis (North) and the trace of the fault plane in the horizontal movement plane.

\subsection{Examples}

In order to demonstrate the usefulness and significance of the projection of geological field data into the movement plane, we chose two examples (Fig. 2.5) from an exhumed brittle-ductile fault array in the central Southern Alps, New Zealand (e. g. Wightman et al., 2006). The first example is a case, where the orientation of the outcrop plane is not very different from the orientation of the m-plane (left diagrams in Fig. 
2.5), whereas in the second example the outcrop orientation differs strongly from the m-plane orientation (right diagrams in Fig. 2.5).

a)
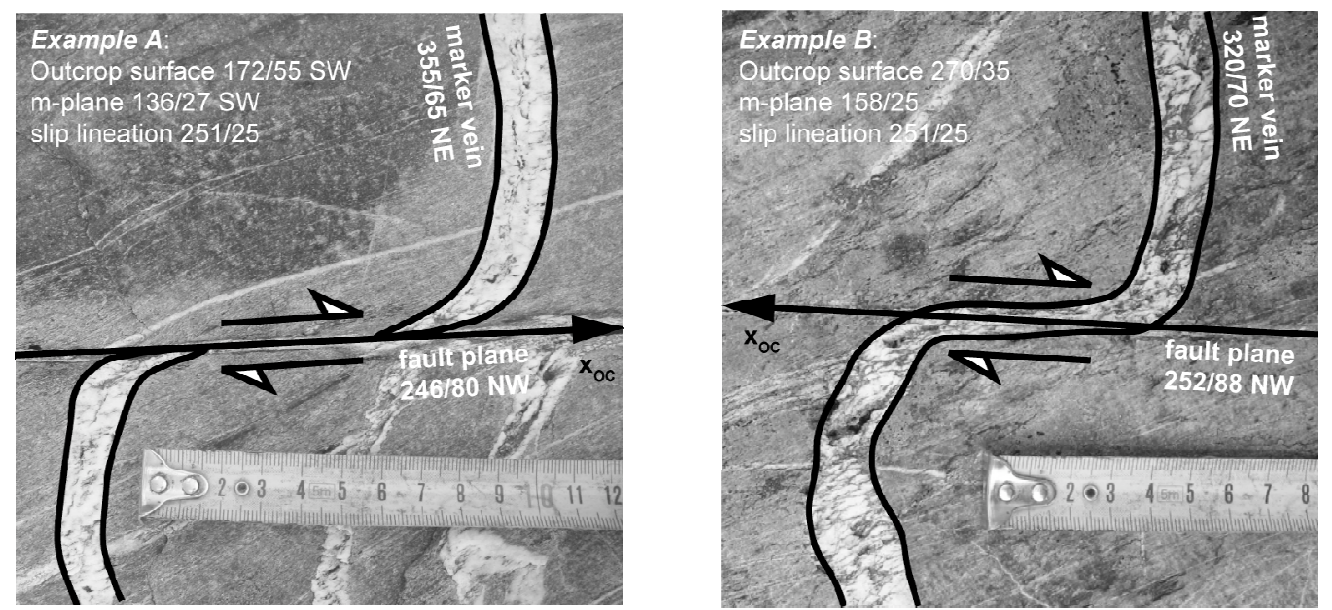

b)
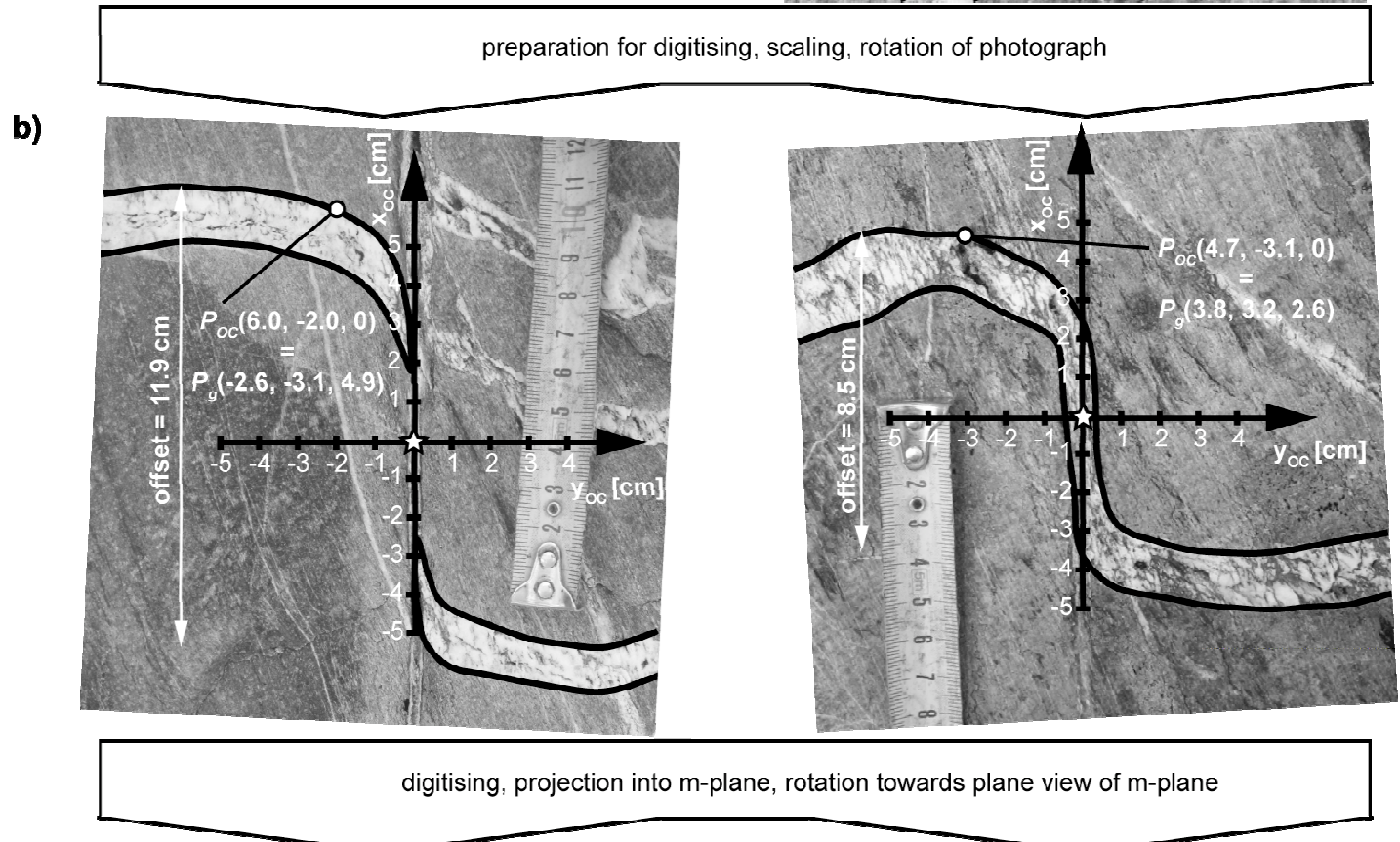

c)

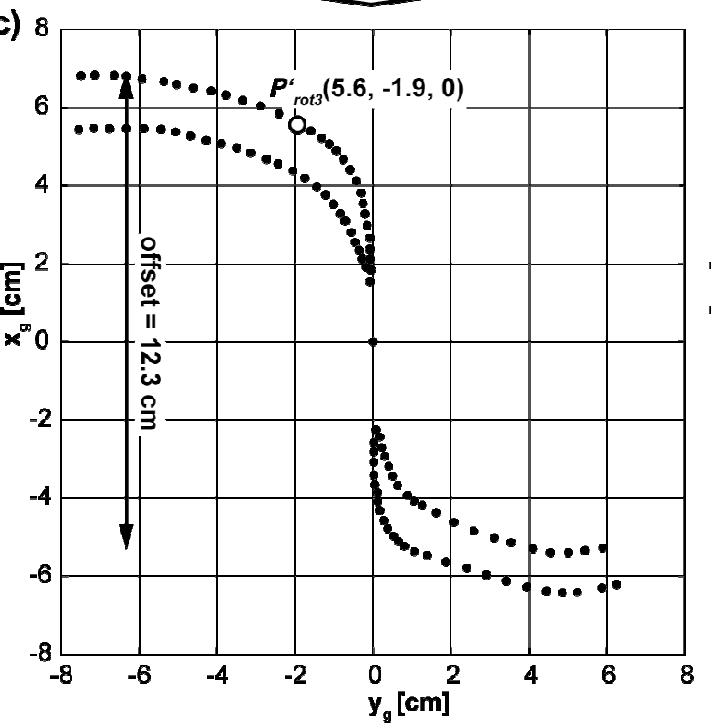

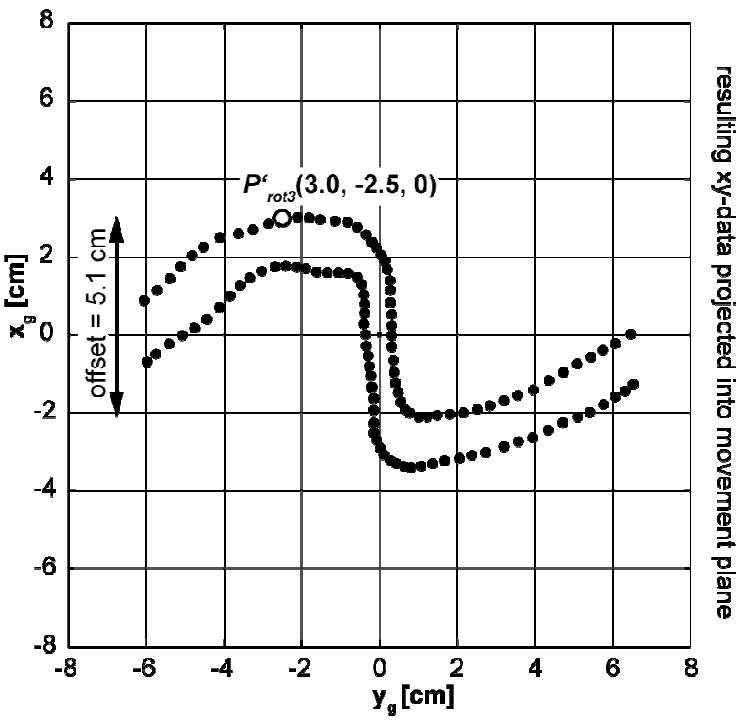


Figure 2.5 (previous page): Flow diagram of the two examples described in the main text. (a) original photographs with required orientation measurements of planes and slip lineation. (b) Photograph has been rotated such that the $x_{O C}$-axis points towards the top of the page. The spatial origin of all coordinate systems is marked with a white star. The white circle marks an exemplary digitised point on the boundary between marker vein and wall rock. The point is given in both the coordinates of the outcrop coordinate system and the geographical coordinate system. The white double arrows mark the offsets that were measured on the outcrop surface. (c) xy-data of the marker veins after the projection plotted within the m-plane and rotated after Eq. (2.11). The true offsets within the m-plane are marked by black double arrows. The points $P^{\prime}$ rot 3 are the projections of the points $P_{O C}$ chosen in (b).

\subsubsection{Example A}

The fault in example $A$ strikes at an angle of $246^{\circ}$ and dips with $80^{\circ}$ towards the $\mathrm{NW}$, the orientation of the marker vein is $355 / 65 \mathrm{NE}$ and the slip lineation trends $251^{\circ}$ and plunges $25^{\circ}$. The outcrop orientation (172/55 SW) differs by $36^{\circ}$ in strike angle and by $28^{\circ}$ in dip angle from that of the movement plane (136/27 SW). Plotting the transformed coordinates of example $A$ (Fig. 2.5c) and comparing them to the original coordinates derived from digitising the marker vein on the photograph (Fig. 2.5b) shows that there is hardly any difference in offset and shape between the original vein and its projection. The curvature of the projected vein is only slightly less, and with $12.3 \mathrm{~cm}$ the total offset of the projected vein is only $0.4 \mathrm{~cm}$ higher than the one measured in the outcrop plane $(11.9 \mathrm{~cm})$.

\subsubsection{Example $B$}

In Example $B$, the orientation of the fault is $252 / 88 \mathrm{NW}$, the marker vein strikes with an angle of $320^{\circ}$ and dips $70^{\circ}$ to the NE, and the trend and plunge of the slip lineation are the same as in example $A(251 / 25)$. The difference in strike between the outcrop plane $(270 / 35 \mathrm{~N})$ and the m-plane $(158 / 25 \mathrm{SW})$ is $112^{\circ}$ and the difference in dip angles is $10^{\circ}$. The plots in Fig. $2.5 \mathrm{c}$ show that the curvature of the projected vein is significantly higher than the one of the original vein. The total offset of the marker vein measured on the outcrop surface is $8.5 \mathrm{~cm}$, whereas the true offset measured in the movement plane is only $5.1 \mathrm{~cm}$, meaning that the true offset is $3.4 \mathrm{~cm}(40 \%)$ less than the apparent offset measured directly on the outcrop surface.

\subsection{Discussion and conclusions}

In this paper we presented a simple method for the translation of geological field data from an outcrop surface into the movement plane of a fault or shear zone. This 
enables us to calculate true displacements from separation data on outcrop faces and the "true" shape of curved and deformed geological markers. This method is also an algebraic-graphical way to solve for slip from arbitrary outcrop offsets. If using the method described in this paper, it is no longer necessary to search for optimally oriented outcrops as, by following the steps above, any outcrop data can be projected into the desired plane, if all variables that are necessary for the projection are known.

As indicated by the two given examples, the projection into the movement plane is especially important for outcrop orientations that deviate strongly from the orientation of the movement plane. However, this is a statement without mathematical proof, and one should consider using the described method for any case of outcrop orientation in order to achieve a high accuracy when investigating offsets and shapes of displaced geological markers. The results of these coordinate transformations clearly depend on the accuracy of the orientation measurements of planes and lineations and also on the verticality of the photo axis with respect to the outcrop surface. Also, if one of the assumptions in section 2.2 is incorrect (e.g. if the deformation was not only due to simple shear) this technique will fail. However, an error propagation analysis would go beyond the scope of this paper and will be left to keen mathematicians.

\section{Acknowledgements}

We wish to thank Susan M. Ellis (GNS Science) very much for constructive and helpful discussions as well as for proof reading this paper. We would also like to thank Declan DePaor and Kieran Mulchrone for thoughtful reviews and comments that significantly improved the original manuscript. 


\section{Appendix 2.A - Glossary}

\section{A.1 Denotation}

$\begin{array}{ll}\vec{a} & \text { vector } a \\ \hat{\bar{a}} & \text { unit vector in direction of } a \\ \left(\begin{array}{l}x_{a} \\ y_{a} \\ z_{a}\end{array}\right) & \text { vector components or coordinates of } a \\ \vec{a} \times \vec{b} & \text { right-handed cross product } \\ \vec{a} \cdot \vec{b} & \text { dot product } \\ |\vec{a}| & \text { length / norm of } a\end{array}$

\section{A.2 Subscripts and Superscripts}

$\begin{array}{ll}g & \text { geographical } \\ o c & \text { outcrop } \\ m & \text { movement plane } \\ v & \text { projection vector } \\ \text { rot } & \text { rotation }\end{array}$

\section{A.3 Key}

$x_{g}, y_{g}, z_{g} \quad$ axes spanning geographical coordinate system

$x_{o c}, y_{o c}, z_{o c} \quad$ axes spanning outcrop coordinate system

$\vec{f} \quad$ vector in direction of pole to fault plane

$\vec{s} \quad$ slip vector

$\vec{m} \quad$ vector in direction of pole to m-plane

$\vec{r} \quad$ position vector of point $P$

$\vec{q} \quad$ vector in direction of pole to marker vein

$\vec{v} \quad$ projection vector

$\lambda \quad$ scalar parameter

$\psi \quad$ rotation angle for first rotation about $z_{g}$-axis

$\varphi \quad$ rotation angle for rotation about $y_{g}$-axis

$\delta \quad$ rotation angle for second rotation about $z_{g}$-axis 


\section{Appendix 2.B - Conversions}

\section{B.1 - Conversion from geological attitudes to Cartesian coordinates}

Converting the geological attitudes of a plane or a line into Cartesian coordinates means determining direction cosines from strike and dip or trend and plunge measurements. Direction cosines are the cosines of the angles $\alpha, \beta$, and $\gamma$ that a vector makes with the positive $x, y$, and $z$-axes respectively. For planes, the direction cosines are calculated after Eq. (2.B.1-1) and result in a unit normal vector pointing in the direction of the pole to the plane:

$$
\hat{\bar{n}}_{p}=\left(\begin{array}{l}
n_{p x} \\
n_{p y} \\
n_{p z}
\end{array}\right)=\left(\begin{array}{c}
\cos \alpha \\
\cos \beta \\
\cos \gamma
\end{array}\right)=\left(\begin{array}{c}
\sin \omega \sin \theta \\
-\cos \omega \sin \theta \\
\cos \theta
\end{array}\right),
$$

where $\hat{\bar{n}}_{p}$ denotes the unit normal vector of the plane, $\omega$ is the strike angle of the plane and $\theta$ is the dip angle.

The direction cosines of lines are calculated as in Eq. (2.B.1-2).

$$
\hat{\bar{n}}_{l}=\left(\begin{array}{l}
n_{l x} \\
n_{l y} \\
n_{l z}
\end{array}\right)=\left(\begin{array}{l}
\cos \alpha \\
\cos \beta \\
\cos \gamma
\end{array}\right)=\left(\begin{array}{c}
\cos \eta \cos \varepsilon \\
\sin \eta \cos \varepsilon \\
\sin \varepsilon
\end{array}\right)
$$

where $\hat{\vec{n}}_{l}$ denotes the unit vector in trend direction of the line, $\eta$ is the trend of the line, and $\varepsilon$ is the plunge.

\section{B.2 - Conversion from Cartesian coordinates to geological attitudes}

In order to convert the Cartesian vector components $\left(\begin{array}{l}n_{x} \\ n_{y} \\ n_{z}\end{array}\right)$ of a unit vector $\hat{\vec{n}}$ (e.g. $\hat{\vec{n}}_{p}$ or $\hat{\vec{n}}_{l}$ ) into geological attitudes, several rules must be observed. The conversion to polar coordinates results in the trend and plunge of the line that contains $\hat{\bar{n}}$.

From trigonometrical and geometrical relationships, the preliminary trend $\mu$ of the line can generally be calculated as

$$
\mu=\arctan \left(\frac{n_{y}}{n_{x}}\right) \text {. }
$$

If $n_{x}=0$, then the trend is calculated as 


$$
\mu=\frac{n_{y}}{\left|n_{y}\right|} \cdot 90^{\circ},
$$

which means that the line would trend East-West. The first factor on the right hand side of Eq. (2.B.2-2) is normalised to $+/$ - One.

If $n_{x}<0$, then the calculation of the trend is

$$
\mu=\arctan \left(\frac{n_{y}}{n_{x}}\right)+180^{\circ},
$$

meaning that $90^{\circ}<\mu<270^{\circ}$. As in this case arctan results in negative (anti-clockwise) angles between the $y$-axis and the trend-line, $180^{\circ}$ have to be added to achieve a trend measured clockwise from North ( $x$-axis).

$$
\begin{aligned}
& \text { If } \arctan \left(\frac{n_{y}}{n_{x}}\right)<0, \text { then the equation to determine the trend becomes } \\
& \mu=\arctan \left(\frac{n_{y}}{n_{x}}\right)+360^{\circ} .
\end{aligned}
$$

In this case, the trend would be negative (anti-clockwise) from North ( $x$-axis), thus $360^{\circ}$ need to be added in order to achieve the correct trend measured clockwise from North.

The plunge $\rho$ of the line is determined by

$$
\rho=\arctan \left(\frac{n_{z}}{\sqrt{n_{x}^{2}+n_{y}^{2}}}\right) .
$$

The only rule that applies for finding the plunge is that if $\sqrt{n_{x}^{2}+n_{y}^{2}}=0$, then the plunge is to be calculated as

$$
\rho=\frac{n_{z}}{\left|n_{z}\right|} \cdot 90^{\circ} .
$$

This means that the line would be vertical.

Finally, in case the plunge is negative $(\rho<0)$, more rules apply for finding the correct trend $\mu_{0}$ and plunge $\rho_{0}$.

$$
\begin{aligned}
& \text { If } \rho<0 \text { and if }\left(\mu+180^{\circ}\right)>360^{\circ} \text {, then } \\
& \mu_{0}=\mu-180^{\circ} \text {. }
\end{aligned}
$$


If $\rho<0$ and if $\left(\mu+180^{\circ}\right)<360^{\circ}$, then

$$
\mu_{0}=\mu+180^{\circ} \text {. }
$$

In all other cases the true trend and plunge of the line are

$$
\mu_{0}=\mu \text { and } \rho_{0}=|\rho| \text {. }
$$

Assuming $\hat{\bar{n}}_{p}$ was the unit normal vector to a plane, and having derived the trend and plunge of the line that contains $\hat{\bar{n}}_{p}$, the strike angle $\xi$ and dip angle $\chi$ of the plane can be calculated observing the following rules:

If $90^{\circ}+\mu_{0}>360^{\circ}$, then the strike of the plane is given by

$\xi=\mu_{0}-270^{\circ}$.

In all other cases, the strike is

$\xi=\mu_{0}+90^{\circ}$

and the dip of the plane is

$\chi=90^{\circ}-\rho_{0}$. 


\title{
Chapter 3
}

Rheological constraints on quartz derived from scaling relationships and numerical models of sheared brittle-ductile quartz veins, central Southern Alps,

New Zealand

\author{
Susanne Grigull ${ }^{1}$ \\ Susan M. Ellis ${ }^{2}$ \\ Timothy A. Little \\ Matthew P. Hill ${ }^{1,3}$ \\ Susanne J. H. Buiter ${ }^{4}$
}

${ }^{1}$ School of Geography, Environment and Earth Sciences

Victoria University of Wellington

PO Box 600

Wellington 6140

New Zealand

${ }^{2}$ GNS Science

1 Fairway Drive

PO Box 30368

Avalon

Lower Hutt 5010

New Zealand

${ }^{3}$ Kenex Knowledge Systems Ltd.

16 Oroua Street

PO Box 41136

Eastbourne

Wellington

New Zealand

${ }^{4}$ Centre for Geodynamics

Geological Survey of Norway

Leiv Eirikssons vei 39

7491 Trondheim

Norway 


\subsection{Introduction}

Quartz is one of the most abundant minerals in the Earth's crust, and the rheology of quartz-dominated rocks is thought to be the main control on the depth of the brittleductile $^{1}$ transition and the nucleation depth of major earthquakes (e.g., Scholz, 1988). However, we know very little about the rheological behaviour and the brittle-ductile transisiton of quartz under geological conditions. Most of our knowledge of the ductile behaviour of quartz is based on laboratory experiments conducted under unnaturally hot and fast deformation conditions, i.e., temperatures of $>700^{\circ} \mathrm{C}$ and strain rates in the order of $10^{-7}$ to $10^{-4} \mathrm{sec}^{-1}$ (e.g., Hirth and Tullis, 1992; Rutter and Brodie, 2004; Paterson and Luan, 1990; Luan and Paterson, 1992; Gleason and Tullis, 1995). Flow laws for quartz that are derived in the laboratory are of the form

$$
\dot{\varepsilon}=A_{E} \cdot \sigma_{d}^{n} \cdot f_{H_{2} O}^{m} \cdot d^{-r} \cdot \exp (-Q / R T)
$$

where $\dot{\varepsilon}$ is the uniaxial strain rate in $\left[\mathrm{s}^{-1}\right], A_{E}$ is the experimentally derived preexponential factor with units $\left[\mathrm{MPa}^{-\mathrm{n}} \mathrm{s}^{-1}\right], \sigma_{d}$ is the differential stress in $[\mathrm{MPa}], n$ is the stress exponent, $f_{\mathrm{H}_{2} \mathrm{O}}$ is water fugacity in [MPa], $m$ is the water fugacity exponent, $d$ is grain size in $[\mu \mathrm{m}], r$ is the grain size exponent, $Q$ is activation enthalpy with units of $[\mathrm{J}$ $\mathrm{mol}^{-1}$ ], $R=8.314 \mathrm{~J} \mathrm{~mol}^{-1} \mathrm{~K}^{-1}$ is the universal gas constant, and $T$ is temperature in [K]. For a grain size exponent $r=0$ and a stress exponent $n \geq 2$, equation (1) describes typical grain size insensitive dislocation creep behaviour. For a grain-size exponent $r \geq 1$ and a stress exponent $n<2$, the flow law becomes grain size dependent and deformation will be accommodated by diffusional processes. The question is whether or not we can extrapolate those experimentally derived flow laws for quartz to natural geological conditions.

Several authors have used field observations to test the experimentally derived flow laws for quartz and quartz-dominated rocks against natural examples. For example, Kenis et al. (2004) and Kenis et al. (2005) have investigated the relationship between the shape of mullions and the power law stress exponent as well as the competence contrast between quartz and psammite, Treagus (1999) discussed the relationship

\footnotetext{
${ }^{1}$ In this paper we use the term 'ductile' in a similar way to Fusseis et al. (2006), i.e., as a synonym to 'solid-state viscous'. However, we kept in mind that 'ductility' is merely a description of distributed coherent deformation and does not describe a 'mechanistic concept'.
} 
between effective viscosity ratios and cleavage refraction in different rock layers, and Hudleston and Lan (1993, 1994, 1995) and Lan and Hudleston (1995a, 1995b, 1996) used fold shapes and scaling relationships between the amplitude, wavelength, and layer thickness in folds to deduce information about rock rheology in the form of viscosity ratios. Treagus and Treagus (2002) modelled viscosity ratios from strain variations in conglomerates with varying rock phase fractions. Treagus et al. (1996) and Treagus and Lan $(2000,2003,2004)$ derived information about rock rheology and competence contrasts from geological and numerical observations of the shape of boudins (i.e., the deformation of initially square objects to 'fish-mouth' vs. barrel-shaped boudins). Attempts at retrieving rheological information from ductile shear zones (especially about the stress exponent $n$ ) have been made by Talbot (1999); see also discussions of Talbot's method and corrections in Fletcher (2001), Sonder (2001), and Talbot (2001). Hirth et al. (2001) were able to obtain a quartzite flow law for rocks deformed in the Ruby Gap duplex, Australia (e.g., Dunlap et al., 1997), by comparing laboratory derived microstructures to the microstructures that were found in their naturally deformed rocks and by adjusting experimentally derived flow laws to their deformation conditions.

All the examples mentioned above use the contrast between quartz-dominated layers and the surrounding less quartzose matrix to derive rheological parameter values. They also assume that both quartz and matrix are deforming viscously. However, many field examples of deformed rocks display a mixture of brittle, semi-brittle, and viscous behaviour. The natural system is more complex to interpret, yet critical to our understanding of crustal rheology in the mid-crust. Several authors have investigated this type of behaviour; for example Mancktelow and Pennacchioni (2005) describe the role of precursory brittle faults on the development of ductile shear zones. Fusseis et al. (2006) described the interactions and networking of brittle to ductile shear zones in Cap de Creus, Spain. A numerical modelling study on brittle-viscous coupling of linear viscous layers surrounding a strain softening brittle material has been published by Schueller et al. (2005). Huismans et al. (2005) set up crustal-scale extension models in order to investigate the control of a layer with different linear viscosities on the choice of failure mode ("pure shear", "symmetric plug", and "asymmetric plug") in an overlying uniform purely plastic (i.e., brittle) layer. Their results show that the resulting failure mode depends on the viscous and frictional energy dissipation rates. Nagel and Buck (2006) derived similar results to those by Huismans et al. (2005) from numerical extension models that simulate the normal faulting behaviour of a brittle layer on top of 
a thin viscous layer. Nagel and Buck (2006) observed that the localisation of a fault in the brittle layer is not only dependent on the viscosity of the underlying thin layer but also on the thickness of that layer. They predict that the thinner that ductile layer the less localised that deformation will be in the adjacent brittle layer.

In this paper we attempt to extract information about quartz rheology from field observations and computer modelling of variably brittlely to ductilely sheared quartz veins in a neotectonic fault array in the central Southern Alps, New Zealand. We also try to extract comparative rheological information about the schistose psammitic and pelitic rocks that host those quartz veins (Alpine Schist). Previous geological studies (mainly Wightman, 2005; Wightman et al., 2006; Wightman and Little, 2007) in this brittle-ductile fault array have established constraints on the physical conditions of deformation of these veins (i.e., time, strain rate, stress, depth, lithostatic pressure, fluid pressure, and temperature). Because of this context and the well understood contemporary deformational setting of the fault array and the veins, this site can be considered to function as a rare natural laboratory into quartz rheology and the interplay between brittle and ductile deformation in mid-crustal rocks. Within the boundaries imposed by the set of geologically measured physical constraints, we use finite element modelling in order to replicate the observed geological structures in the sheared veins and to estimate flow law parameters that are applicable to the deformed veins and quartzofeldspathic schist host in the Southern Alps. Our field studies show that the variably faulted and ductilely sheared quartz veins follow a set of scaling relationships between various geometrical parameters associated with the brittle-ductile shear zones (e.g., shear zone width vs. total amount of slip). These scaling relationships provide us with important further constraints on the behaviour of the natural veins and their wall rocks, allowing us to explore and limit the relevant properties in our modelling space.

The main questions we address in this paper are: What rheological information can be gained from the interaction between brittle and ductile deformation in those quartzrich rocks? Can we use the deformed shape and geometrical scaling relationships of the quartz veins to constrain operative flow law parameters for those quartz veins? Are laboratory-derived flow laws applicable to those naturally deformed quartz veins? 


\subsection{Tectonic setting and outcrop scale studies}

\subsubsection{The Southern Alps of New Zealand and the Alpine Fault}

The Alpine Fault is the main and most obvious expression of the Pacific-Australian plate boundary on the South Island of New Zealand (Fig. 3.1a). At the surface, it strikes $\sim 055^{\circ}$ and dips $\sim 30-50^{\circ} \mathrm{SE}$ in the central part of the Southern Alps (e.g., Norris and Cooper, 1995; Kleffmann et al., 1998; Stern et al., 2007; Little et al., 2007; and references therein). During the past several m.y. the direction of relative plate motion between the Australian and the Pacific plate has been obliquely convergent at $37 \pm 2$ $\mathrm{mm} / \mathrm{yr}$ at $\mathrm{N} 71^{\circ} \mathrm{E}$ (averaged over $3 \mathrm{Ma}$; NUVEL-1A global plate motion model of DeMets et al., 1990, 1994). This is approximately $16^{\circ}$ clockwise from the strike of the Alpine Fault. The Alpine Fault accommodates about $70-75 \%$ of both the marginparallel and margin-transversal components of the plate motion between the Pacific and the Australian plates (Norris and Cooper, 2001). In the central Southern Alps, the dextral-reverse Alpine Fault has moved with an average late Quaternary strike-slip rate of 22-32 mm/yr, and dip slip rates of 8-12 mm/yr (Sutherland et al., 2006; Norris and Cooper, 2001, 2007).

Uplift rates along the central part of the Alpine Fault are a maximum between the Fox and Franz Josef glaciers ( $\sim 10 \mathrm{~mm} / \mathrm{yr}$, Wellman, 1979, Bull and Cooper, 1986; Tippett and Kamp, 1993; Beavan at al., 2007) (Fig. 3.1b). It has been conjectured that erosion rates are approximately equal to these uplift rates (Adams, 1980, 1981), leading to what is inferred to be a relatively steady-state topography in the Southern Alps. In the central Southern Alps, Mesozoic quartzofeldspathic rocks (termed "Alpine Schist") have been exhumed to the east of the Alpine Fault. The metamorphic grade of the rocks to the east of the fault decreases from amphibolite facies adjacent to the mylonites of the Alpine Fault to prehnite-pumpellyite facies at the Main Divide 15-20 km east of the Alpine Fault (Grapes \& Watanabe, 1992). Approximate mineral isograds are plotted in Fig. 3.1b (after Cox and Barrell, 2007).

Through seismic experiments, Stern et al. (2001, 2007; and references therein) were able to trace the Alpine Fault down to $35 \mathrm{~km}$ depth. At that depth, Stern et al. (2007) imaged sub-horizontal reflectors, interpreted as a detachment along which 
crustal rocks from greater than $25 \mathrm{~km}$ depth are delaminated and transported onto the Alpine Fault (Fig. 3.1c)

Stern at al. (2001, 2007) also describe an approximately $30 \mathrm{~km}$ thick low-velocity zone above the fault surface extending to $35 \mathrm{~km}$ depth. They interpreted this low velocity zone as being interconnected metamorphic fluids that were derived during shearing and dewatering of the rocks above the detachment. These interpretations are further supported by a magnetotelluric study in that area (Wannamaker et al., 2002), which showed a high conductivity region coinciding approximately with the lowvelocity zone (resistivity contours in Fig. 3.1c).

\subsubsection{Study area: An array of brittle-ductile faults}

The study area is located in the central Southern Alps, New Zealand (Fig. 3.1a and 1b). Within this area, a 1-2 km wide array of closely spaced, near-vertical, brittle-ductile faults is found in the uplifted and exhumed hanging wall of the Alpine Fault, 5-7 km structurally above it (Fig. 3.1b and 3.1c). The field data for this paper was derived from two locations in this fault array: Chancellor Ridge and Crawford Knob (Fig. 3.1b). Here, the brittle-ductile faults are exposed in 3D in recently glaciated outcrops.

The Alpine Schist in our study area consists mainly of biotite-grade quartzofeldspathic meta-greywacke (psammites with intercalated pelite layers). The dominant foliation in the schist strikes $030^{\circ}-060^{\circ}$ and typically dips steeply to the SE (Fig. 3.2e).

Planar, closely spaced, near-vertical faults cut and offset the dominant schist foliation at an acute angle and truncate other pre-existing structures such as older quartz veins (Fig. 3.2a-d). These faults strike sub-parallel to the Alpine Fault. At Crawford Knob, they strike $\sim 23^{\circ}$ clockwise of the dominant foliation, and at Chancellor Ridge $\sim 12^{\circ}$ anticlockwise of that fabric. The faults are nearly planar and extend laterally and vertically for up to $10 \mathrm{~s}$ of metres. Throughout the fault array, the faults consistently show both dextral and NW-up senses of slip. Where the faults intersect older quartz veins embedded within the brittlely deformed schist host, the quartz veins are typically ductilely sheared rather than brittlely displaced. Some of these deformed quartz veins have been smoothly and coherently smeared out to ductile shear strains of up to 15 across shear zones (in the quartz veins) that are $\sim 3 \mathrm{~cm}$ wide (Fig. 3.2c, 3.2d). Other quartz marker veins show both brittle and ductile slip components. 

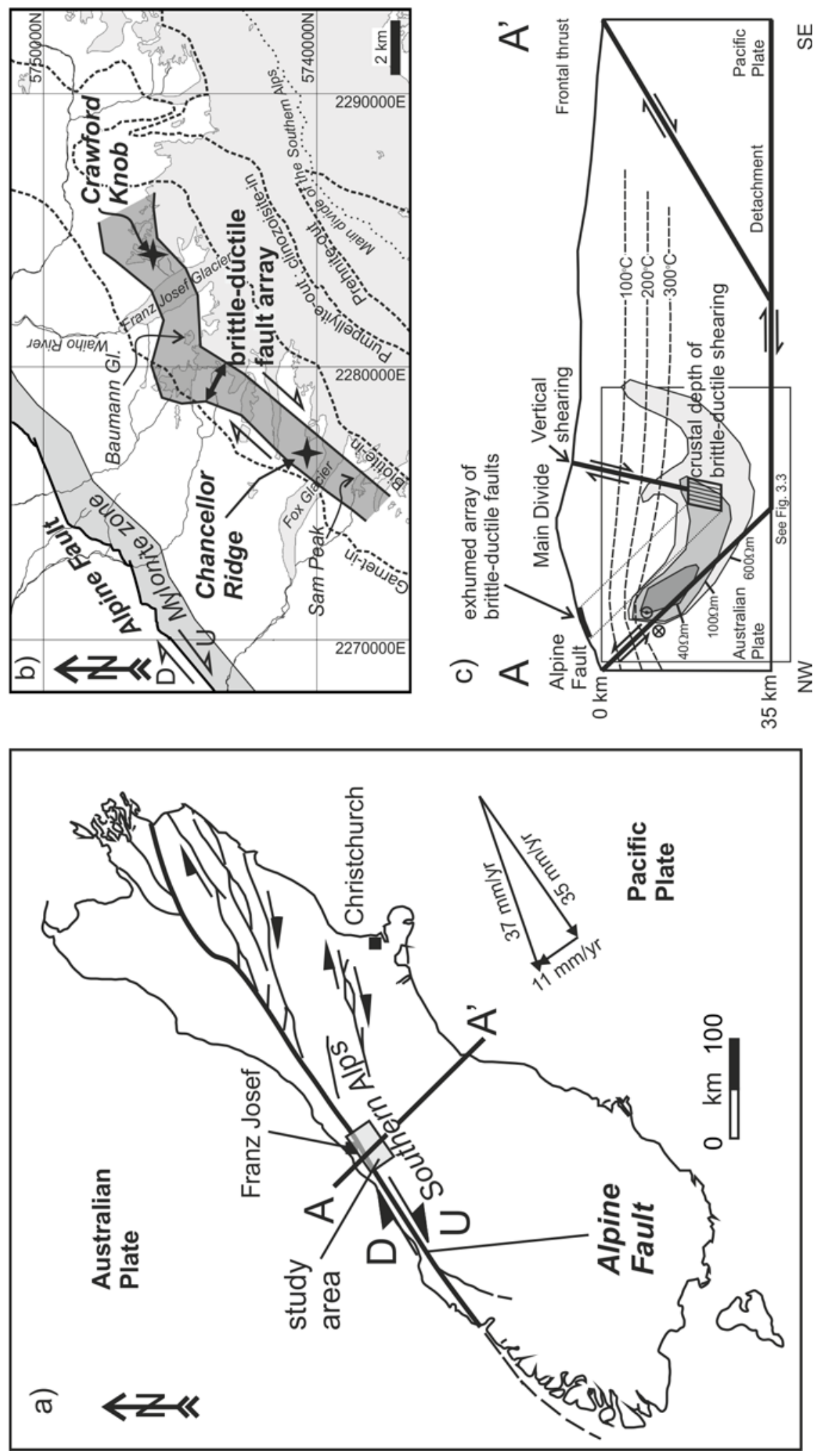

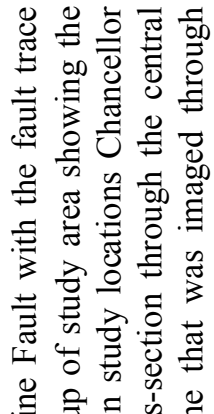

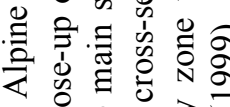

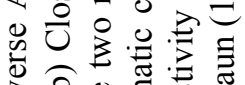

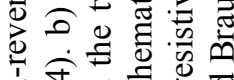

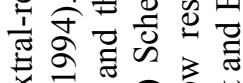

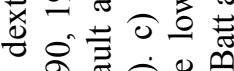

‡

on

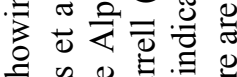

की

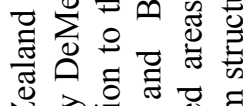

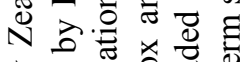

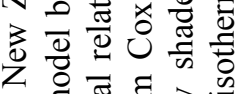

乙

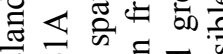

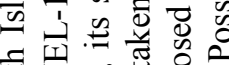

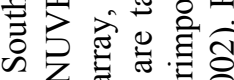

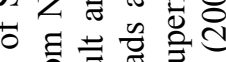

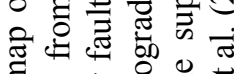

马

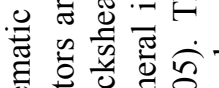

造 造

ฮ. 율류

bi 음

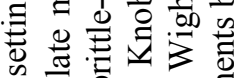

0 定

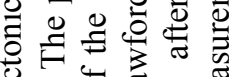

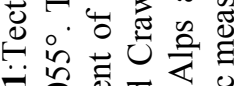

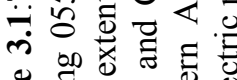

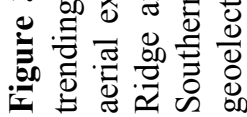



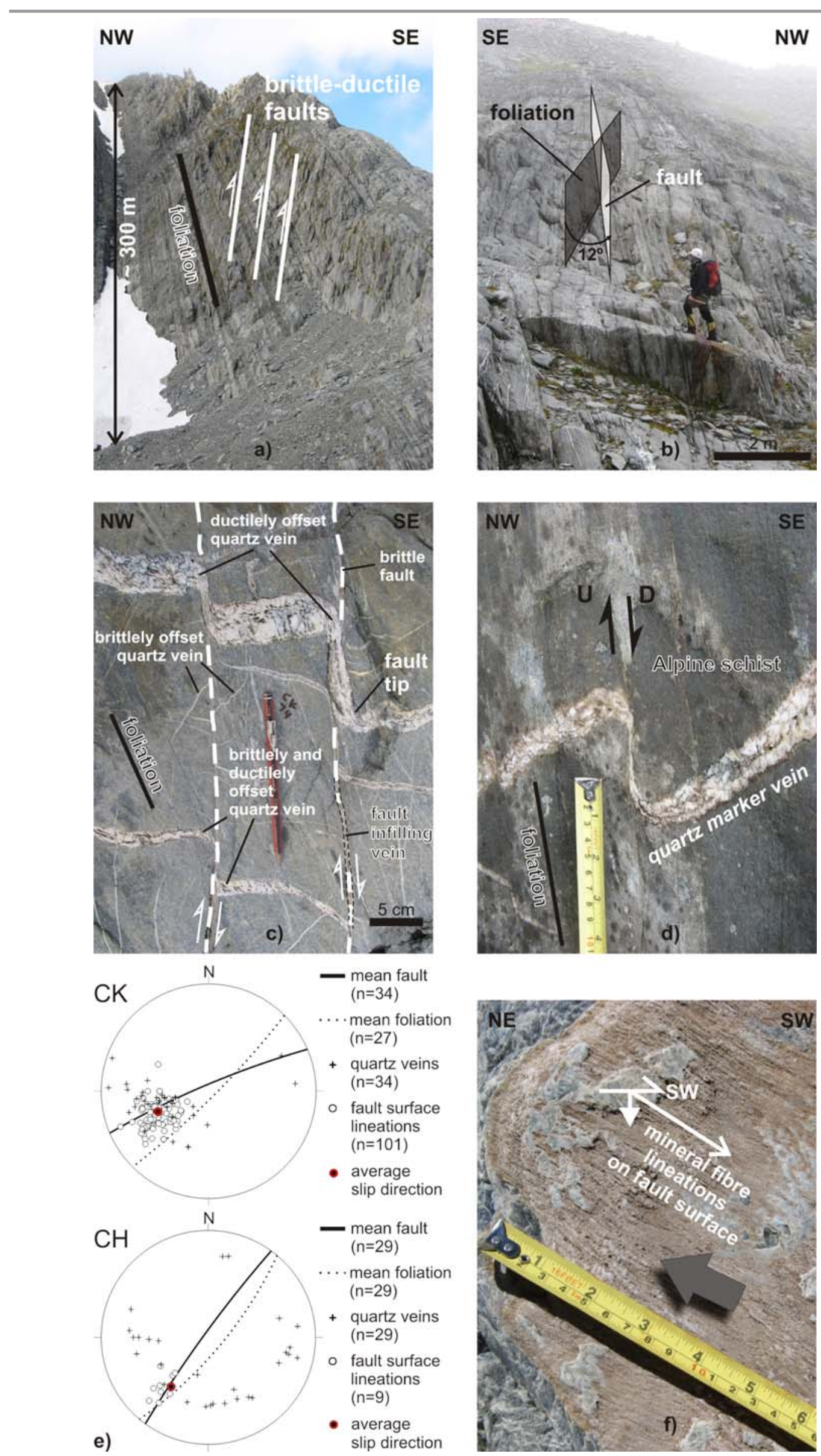
Figure 3.2 (previous page): Rocks and structures in the brittle-ductile fault array. Note the consistent dextral, NW-up sense of movement of the backshears in all photographs. a) c. $300 \mathrm{~m}$ high cliff at Crawford Knob, facing NE, showing the nearly vertical brittle-ductile faults with respect to the dominant foliation. b) Glaciated outcrops near Chancellor Ridge. Photograph taken facing SW. The superposed planes indicate the systematically dihedral angle of $\sim 12^{\circ}$ between the main foliation and the planar brittle-ductile faults which are spaced at $\sim 40 \pm 53 \mathrm{~cm}$ intervals. c) Outcrop photograph, Crawford Knob. Here, backshears brittlely offset the host quartzofeldspathic Alpine Schist as well as some of the thinnest $(<1 \mathrm{~cm})$ quartz veins embedded in that schist. Where the tips of the faults truncate thicker quartz veins, they deform them brittlely-to-ductilely or entirely ductilely. The dashed line marks a fault infilling vein. d) Single quartz vein from Chancellor Ridge being displaced fully ductilely where a brittle fault in the host schist intersects the vein. Note how the fault bends slightly around the outside margin of the deformed quartz vein and the extreme vein attenuation in the shear zone centre, which is typical for the ductilely shearing veins. e) Mean attitudes of brittle faults, mean foliation, poles to deformed quartz veins, fault surface lineations, and average slip direction plotted on stereonet, lower hemisphere. $\mathrm{CK}=$ Crawford Knob, $\mathrm{CH}=$ Chancellor Ridge. f) Photograph of $\mathrm{qtz}+\mathrm{cal}+\mathrm{chl}$ vein infilling brittle faults. Incrementally grown fibre lineations indicate the direction of slip. The grey arrow points in the direction in which the (now eroded) hanging wall moved.

Some of the faults are infilled with fibrous veins of quartz + calcite \pm chlorite. In these, a distinct alignment of mineral fibres records the slip direction on the faults (Fig. 3.2f). The fault-infilling veins are $\sim 2 \mathrm{~mm}$ wide on average. The width of the infilling veins equates to the dilative fault width. On the basis of these delicate structures of fibrous, incrementally grown fault-infilling veins (Fig. 3.2f), shearing is interpreted to have been accommodated by an aseismic stable sliding process that included some dissolution-precipitation creep along the sliding surface (e.g., Gratier and Gamond, 1990; Ohlmacher and Aydin, 1997; Wightman, 2005).

The aqueous metamorphic fluids from which the fault-infilling veins were precipitated are inferred to have been released from ductilely deforming rocks that lay beneath the brittle-ductile fault array (Wightman, 2005; Wightman and Little, 2007). Progressive growth of such mineral fibres would only have been possible if the shearing was slow and not abrupt as during an earthquake (e.g., Gratier and Gamond, 1990). Also, the remarkable lack of brittle deformation of many of the strongly and smoothly sheared older quartz veins implies that strain rates were low enough to prevent their brittle fracture. Further, the complete absence of fault gouge, pseudotachylites, or other cataclastic or seismically-induced fault rocks along the sharply expressed fault planes strongly supports the assumption that the deformation of the schist and the quartz veins was due to an aseismic stable sliding process (Little et al. 2002a).

As a result of rapid uplift in the hanging wall of the Alpine Fault and high erosion rates, the biotite zone rocks hosting the shears have been exhumed from $>20 \mathrm{~km}$ depth 
during the past $\sim 3$ Myrs (Little et al. 2002a). Little et al. (2002a), Wightman et al. (2006), and Wightman and Little (2007) have suggested a model for the formation and evolution of the brittle-ductile fault array (Fig. 3.3). They propose that rocks in the hanging wall of the Alpine Fault were first displaced along a sub-horizontal detachment before being tilted eastward and sheared in an oblique, escalator-like fashion upon reaching the base of the Alpine Fault ramp (Fig. 3.3). When the rocks negotiated the step at the foot of this fault ramp, they were transiently subject to high shear stresses and strain rates leading to a temporary embrittlement into the lower crust. This caused the array of faults to form in lower crustal rocks that had previously been experiencing only ductile deformation. Alternatively, this transient embrittlement might be related to movement of overlying brittle faults in the upper crust, associated with straining of the upper crust as it negotiated the Alpine Fault ramp.

Crystallographic preferred orientation (CPO) measurements on ductilely sheared quartz marker veins by Wightman (2005), Wightman et al. (2006), and Hill (2005) has revealed that despite finite ductile shear strains of 5-10, the CPO in these deformed veins are everywhere very weak to random. Wightman et al. (2006) suggest that a combination of sufficiently reduced grain-sizes through dynamic recrystallisation and rapidly waning stresses towards the end of the shearing process could have allowed for a late increment of diffusion creep-accommodated grain boundary sliding which may have weakened or randomised a pre-existing CPO in the veins (cf. Appendix 3.A).

Today, the grain-boundaries in the deformed quartz veins are consistently polygonal (mostly straight grain boundaries and $120^{\circ}$ triple junctions; Fig. 3.4), and the mean grain diameter is $126 \pm 16 \mu \mathrm{m}$ in the sheared part of the vein and $171 \pm 14 \mu \mathrm{m}$ in the unsheared part (2D-grain sizes from Hill, 2005). This microstructure reflects a period of static recrystallisation of the veins subsequent to their ductile shearing. After the rocks passed the foot of the Alpine Fault, that was subject to elevated stresses and strain rates, the rocks were transported upwards along the fault ramp and away from this "corner region" without undergoing any further shearing (Fig. 3.3, "inactive faults"). Static recrystallisation during their transport to the surface may then have led to grain growth and the observed foam-like microstructures (Wightman, 2005; Wightman et al., 2006). 


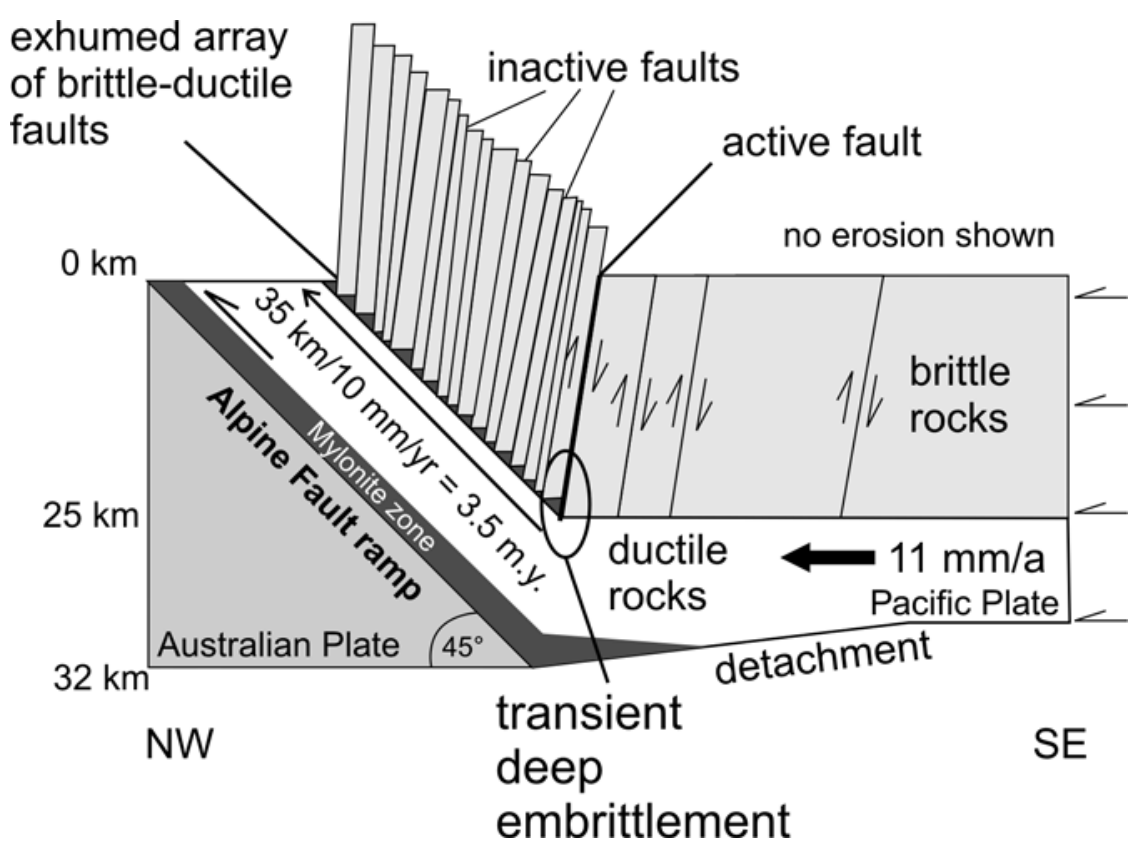

Figure 3.3: Escalator model after Little et al. (2002a), Little (2004). Pacific Plate rocks are delaminated along a detachment and undergo transiently high shear stresses and embrittlement when they pass the foot of the Alpine Fault ramp. After passing this critical point, hanging wall deformation stops and the rocks get transported to the surface (inactive faults).
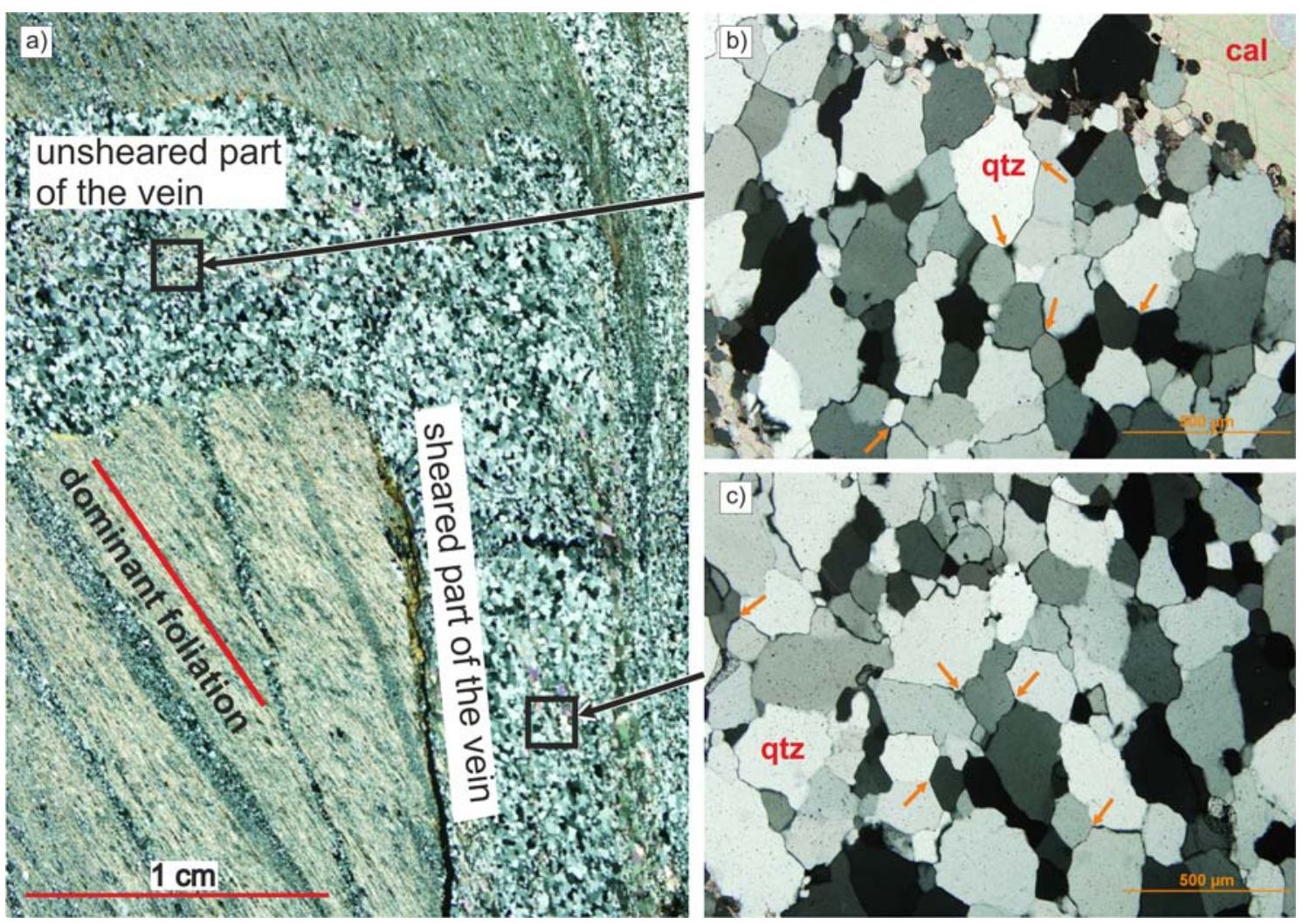
Figure 3.4 (previous page): Microphotographs of a ductilely sheared quartz vein from Crawford Knob under crossed polarisers. a) Stitched microphotograph of deformed vein. Note the smooth, fracture-free bend in the quartz vein where the shear zone transects it. The dominant foliation is clearly expressed by biotite alignment in the wall rock schist. b) statically recrystallised, foam-like microstructure in unsheared part of the vein, external to the ductile shear zone. c) statically recrystallised, foam-like microstructure in sheared part of the vein, internal to the ductile shear zone. Note how similar the polygonised grain shapes and the microstructure are in both the sheared and the unsheared part of the quartz vein. Orange arrows point to $120^{\circ}$ triple junctions, showing the polygonised grain shapes

\subsection{Summary of geological and physical constraints on vein deformation}

3.3.1 Time available for ductile deformation and subsequent static recrystallisation of the quartz veins

Wightman (2005) calculated a maximum time interval of 1.5 Myrs between deformation of the quartz veins at the ramp step and their subsequent cooling through $300^{\circ} \mathrm{C}$ (Fig. 3.1c). This calculation is based on an Alpine Fault dip of $45^{\circ}$ (e.g., Norris and Cooper, 1995), a late Quaternary dip-slip rate in the central part of the Alps of 10 $\mathrm{mm} / \mathrm{yr}$ (Norris and Cooper, 2001), and a $300^{\circ} \mathrm{C}$ isotherm that is placed at $\sim 10 \mathrm{~km}$ depth (Shi et al., 1996; Batt and Braun, 1999). We assume that at temperatures less than $300^{\circ}$ C quartz will cease to deform by crystal plastic creep (e.g., Hirth and Tullis, 1994; Stöckhert et al., 1999). This time estimate also includes the time for static recrystallisation, to allow for vein recovery and grain growth. Wightman (2005) used experimental grain growth rates in quartz and calculated the time-interval that was necessary for grain growth from $1 \mu \mathrm{m}$ (original estimated dynamically recrystallised grain size after shearing) to $100 \mu \mathrm{m}$ (approximate grain size after static recrystallisation) to be $\sim 1$ Myrs. Subtracting this time-interval from the total available time of 1.5 Myrs, the maximum time for vein deformation is only 0.5 Myrs.

\subsubsection{Temperature}

Several constraints can be placed on the temperature during shear activity and deformation of the quartz veins. An upper limit for deformation temperature of $600 \pm$ $50^{\circ} \mathrm{C}$ is given by late Cenozoic metamorphism temperatures in the amphibolite facies rocks closer to the Alpine Fault that structurally underlie the faulted rocks in our study area (Vry et al., 2004). The rocks that host the brittle-ductile faults are greenschist facies rocks in the biotite-zone, that do not show any signs of retrogressive metamorphism that may have been associated with late Cenozoic shearing or fluid infiltration. These 
observations are consistent with deformation temperatures of $350-500^{\circ} \mathrm{C}$. Also, some of the fault-infilling quartz-calcite veins contain coexisting biotite and muscovite, which implies precipitation temperatures of these veins between $300-400^{\circ}$ C (e.g., Spear, 1993, p. 345). Grigull et al. (this study, section 4.6.7.1.2) measured Ti-concentrations in the deformed and undeformed parts of the shearing veins. Using Titanium-in-quartz geothermometry (TitaniQ, Wark and Watson, 2006), they were able to measure minimum static recrystallisation temperatures of $425 \pm 38^{\circ} \mathrm{C}$ for deformed veins from Chancellor Ridge and $400 \pm 21^{\circ} \mathrm{C}$ for veins from Crawford Knob. For the undeformed parts of the same veins they measured minimum recrystallisation temperatures of $c$. $530^{\circ} \mathrm{C}$, presumably a relict of the original vein emplacement process prior to shearing. After demonstrating isotopic equilibrium conditions, Wightman (2005) performed quartz-calcite oxygen isotope studies on four of the fault-infilling veins to estimate a temperature of $480 \pm 50^{\circ} \mathrm{C}$ for the time of vein deformation. From the TitaniQ and oxygen-isotope geothermometry, we predict a temperature range of $400-530^{\circ} \mathrm{C}$ at the time of vein deformation. For the geodynamic models presented in this paper we will use a mean temperature of $450^{\circ} \mathrm{C}$ for the deformation of the quartz veins.

\subsubsection{Deformation depth and stress state}

We calculated a minimum depth of vein deformation of $\sim 21 \mathrm{~km}$ as follows. Late Cenozoic ${ }^{40} \mathrm{Ar} /{ }^{39} \mathrm{Ar}$ muscovite cooling (plateau) ages in the host rocks at Crawford Knob of 3.4-4.5 Ma (Wightman, 2005) record the time of cooling of the rocks through $\sim 400 \pm 50^{\circ} \mathrm{C}$. These ages correspond to temperatures of cooling that are within the lower range of the deformation temperature of the quartz veins. The late Quaternary dip-slip rate on the Alpine Fault (10 $2 \mathrm{~mm} / \mathrm{yr}$, Norris and Cooper, 2001) and the dip of the Alpine Fault $\left(45^{\circ}\right)$ can then be used to calculate the minimum depth of exhumation of those rocks of $\sim 28 \pm 7 \mathrm{~km}$. This analysis suggests a minimum depth for vein deformation of $\sim 21 \mathrm{~km}$.

Petrologically based estimates for the exhumation depth of rocks currently exposed in the mylonite zone at the Alpine Fault are 25-35 km (e.g., Norris and Cooper, 2003; Vry et al, 2004; Toy, 2007). Seismic reflection data suggests a detachment depth of 35 $\mathrm{km}$ for the Alpine Fault (Stern et al., 2007). Since the faulted rocks that are exhumed at Crawford Knob lie 5-7 km structurally above the mylonites of the Alpine Fault, these data imply an original depth of $20-25 \mathrm{~km}$ for the faulted array. The minimum depth 
estimate of $\sim 21 \mathrm{~km}$ leads us to infer an overburden pressure of $P_{\text {lith }} \geq 560 \mathrm{MPa}$ (assuming a rock density $\rho=2700 \mathrm{~kg} / \mathrm{m}^{3}$ and $P_{\text {lith }}=\rho g z$ ).

Entrapment fluid pressure of primary aqueous fluid inclusions in the fault-infilling veins was estimated by Wightman (2005) to have been $P_{f} \geq 310 \pm 90 \mathrm{MPa}$, which is based on fluid inclusion isochors combined with the temperature range of $400-530^{\circ} \mathrm{C}$ that was derived from quartz and calcite ${ }^{18} \mathrm{O} /{ }^{16} \mathrm{O}$ thermometry in the syndeformational shear-infilling veins and TitaniQ geothermometry in the deformed and undeformed parts of the sheared veins. This $P_{f}$ is inferred to have been the fluid pressure during growth of the fluid-entrapping infilling veins after development of the fractures and during their passive infilling as a result of fluid flow along these fractures. This suggests a ratio of fluid pressure to lithostatic pressure at the time of vein growth and fluid inclusion entrapment of $\lambda=P_{f} / P_{\text {lith }} \approx 0.55 \pm 0.16$, which is above the theoretical hydrostatic ratio of $\lambda \approx 0.37-0.4$.

Simple Mohr-Coulomb fault mechanical analyses (Wightman and Little, 2007; Grigull et al., this study, section 4.6.7.2) indicate that during brittle failure of the Alpine Schist in the lower crust, fluid pressures were probably near-lithostatic, resulting in a fluid pressure ratio $\lambda=P_{f} / P_{\text {lith }} \approx 0.98$, an observation that is consistent with several types of geophysical data that have been interpreted to represent enhanced (nearlithostatic) fluid pressures in the hanging wall of the Alpine Fault (Stern et al. 2001, 2007).

Wightman (2005) interpreted microstructures (relict quartz grains with elongate shape and crystallographic preferred orientations at high angles to the faults) in the dilative shear-infilling veins as indicators of original vein emplacement through crackseal processes into hybrid extensional-shear fractures in the quartzofeldspathic rocks, although the relative timing of dilation and shear on the fractures is unclear. Assuming a depth of $21 \mathrm{~km}$, and using a combined Mohr-Coulomb-Griffith analysis of brittle fracture for intact rock, Wightman (2005) derived a minimum estimate for the differential stress at the time of brittle failure of the host schist of $\sigma_{d}=\left(\sigma_{1}-\sigma_{3}\right)=100$ $\mathrm{MPa}$. To cause brittle failure at this depth, such a differential stress would have required pore fluid pressures that were at least near lithostatic $\left(P_{f}=500-530 \mathrm{MPa}\right)$ at the time of brittle failure (Wightman, 2005; Wightman and Little, 2007). Considering that fluid pressures were $\sim 310 \pm 90 \mathrm{MPa}$ (i.e., $\lambda=0.39-0.71$ ) at the time of the fluid inclusion entrapment in the infilling veins, one infers that the fluid pressure in the vein must have 
fallen post-failure. At this $P_{f}$, the expected differential stress for conditions of brittle failure would have been $\sim 340 \pm 90 \mathrm{MPa}$.

Considering the near-vertical attitude of the brittle faults, which strike subparallel to the plate margin in this transpressive plate boundary setting, Wightman (2005) inferred that the intermediate principal stress was nearly vertical and hence equal to the overburden lithostatic pressure, i.e., $\sigma_{2}=P_{\text {lith }}=560 \mathrm{MPa}$. For an ideally oriented fault, forming in intact rock, the maximum principal compressive stress $\sigma_{l}$ will lie in the movement plane of the fault, i.e., the plane that is spanned by the slip vector and the pole to the fault plane. If the coefficient of friction in that intact rock was 0.6, the maximum principal stress would act at an angle of $30^{\circ}$ to the fault plane. Consequentially, since the faults are near-vertical and oblique-slip (the slip striae plunge $30-40^{\circ} \mathrm{SW}$ ) occurs along them, both the maximum and minimum principal stresses cannot have been horizontal relative to the Earth's surface (Wightman and Little, 2007, their Fig. 3.5d). In accord with this observation, two-dimensional sandbox modelling by Koons (1990) and three-dimensional numerical modelling by Koons et al. (1998) predicted this rotation of the principal stress directions from the outboard region of the Southern Alps orogen to the inboard region. The principal stress directions depend on the friction angle of the deforming material, on the topographic slope, on the dip of the detachment, and importantly on the obliquity of the convergent motion (Dahlen, 1984; Koons, 1990, Koons et al., 1998).

\subsubsection{Fault slip rates}

Grigull and Little (2008) developed a graphical-algebraic method that applies several mathematical operations (rotations, translations) to enable one to project outcrop traces of cylindrically curved veins into the fault movement plane, which is the plane that contains the slip vector and the pole to the fault planes. Once the vein contours have been projected into the movement plane, one can measure the 'true' vein shape and amount of slip in those veins. We traced 29 vein-fault sets from Chancellor Ridge and 43 sets from Crawford Knob directly from the outcrop surface onto transparencies and applied the projection method of Grigull and Little (2008) to those sets. The method requires knowledge of the direction of slip on the fault planes. Based on a set of $n=101$ slip lineations measured on exhumed fault planes at Crawford Knob and $n=9$ at Chancellor Ridge, we infer that the average slip vectors are pitching $36 \pm 11^{\circ} \mathrm{SW}$ and 
$30 \pm 11^{\circ} \mathrm{SW}$ respectively. Those numbers are in good agreement with the results of Wightman (2005) who calculated a mean slip vector pitch of $36^{\circ} \pm 5^{\circ} \mathrm{SW}$ for the entire fault array based on an analysis of both fault surface lineations and a detailed analysis of the cutoff-orientations and outcrop separations of the quartz marker veins.

In order to constrain maximum and minimum possible slip rates for the shears to have caused the observed vein deformation, we followed the method of Wightman and Little (2007). As one end-member, one can apply the kinematic "escalator" model that assumes sequential activation of individual shears through repeated and systematic slip on the faults (Fig. 3.5). We used an average of the remarkably constant spacing $(S=37$ $\pm 54 \mathrm{~cm}$ ) between the shears at both field locations (Table 1), as well as the known plate boundary-normal convergence rate $v_{\text {normal }}=11 \mathrm{~mm} / \mathrm{yr}$, (NUVEL-1A model of DeMets et al., 1990, 1994) to calculate the average duration on an individual shear during its (in this model) temporary period of activity:

$$
d t=\frac{S}{v_{\text {normal }}}
$$

where $d t$ is the time that is necessary for one active shear to move across the distance $S$ (spacing) at the velocity $v_{\text {normal }}$ and subsequently become inactive. Based on this extreme assumption that only one shear was active at a time (sequential activation), we calculated an average 'lifespan' for the shears of $d t \approx 34 \pm 49$ years. Dividing the average total slip $y_{t o t}=72 \pm 58 \mathrm{~mm}$ (Table 1) by $d t$ results in a maximum estimate for the slip rate of $\dot{y}_{\text {max }}=y_{\text {tot }} / d t \approx 2 \pm 3.3 \mathrm{~mm} / \mathrm{yr}$.

At the other extreme, a minimum estimate for the slip rate can be made by assuming that not only one shear was active at a time but that all shears were active simultaneously across the $2 \mathrm{~km}$ width of the entire shear array $W_{\text {array }}$ (Fig. 3.5). This model assumes that $S$ is equal to the width of the entire shear array $\left(S=W_{\text {array }}\right)$. Using Eq. (2) with $S=2 \mathrm{~km}$ and the same plate boundary-normal velocity of $11 \mathrm{~mm} / \mathrm{yr}$ results in $d t \approx 182 \mathrm{kyrs}$ and thus in a minimum slip rate of $\dot{y}_{\min }=y_{t o t} / d t \approx 4 \times 10^{-4} \mathrm{~mm} / \mathrm{yr}$.

An alternative way to estimate fault slip rate simply divides the mean slip per fault $(\sim 72 \mathrm{~mm})$ by the above mentioned maximum limit on the duration of ductile vein deformation (0.5 m.y., section 3.1). This analysis yields a minimum slip rate of 1.4 x $10^{-}$ ${ }^{4} \mathrm{~mm} / \mathrm{yr}$. This is a minimum slip rate because it assumes constant and continued activity on the fault throughout its residence in the brittle regime. 


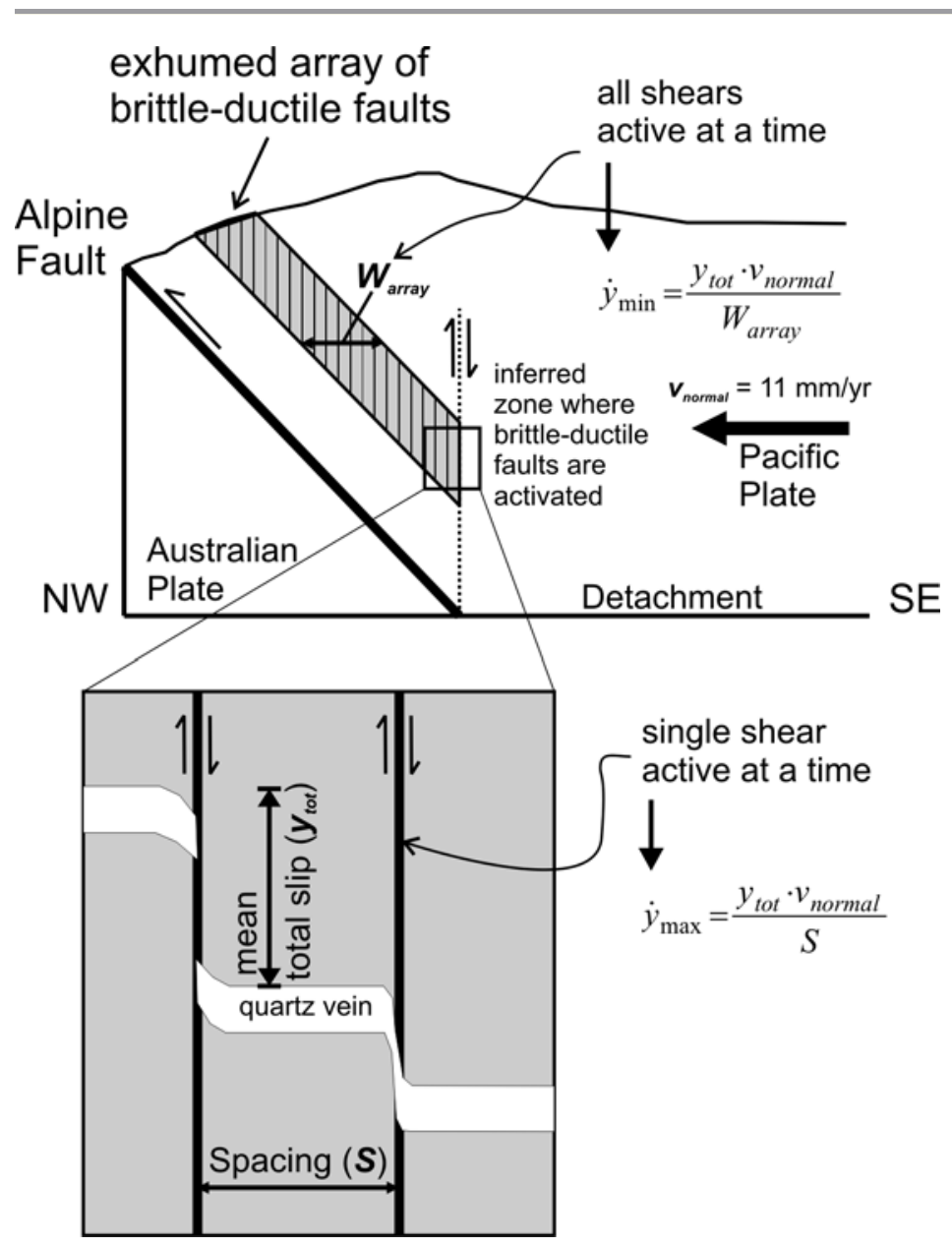

Figure 3.5: Sketch, illustrating the variables needed to calculate minimum and maximum slip rates $\dot{y}_{\min }$ and $\dot{y}_{\max }$ for the brittle-ductile faults (see main text). $v_{\text {normal }}$ is plate-normal convergence rate based on NUVEL-1A model by DeMets et al. (1990, 1994), $S$ is the spacing between two adjacent shears, $W_{\text {array }}$ is the width of the entire fault array (corresponds to $S=2 \mathrm{~km}$ ).

Table 3.1 Field based maximum slip rate estimates, based on escalator model of sequential shear activation (one shear active at a time) and using the method by Wightman and Little (2007)

\begin{tabular}{lccccc}
\hline location & $\begin{array}{c}\text { number } \\
\text { of shears } \\
\text { measured }\end{array}$ & $\begin{array}{c}\text { mean fault } \\
\text { spacing } \\
\boldsymbol{S}\end{array}$ & $\begin{array}{c}\text { mean slip } \\
\text { per fault } \\
\boldsymbol{y}_{\text {tot }}\end{array}$ & $\begin{array}{c}\text { predicted time } \\
\text { of shear activity } \\
\boldsymbol{d t}\end{array}$ & $\begin{array}{c}\text { max. slip rate } \\
\dot{y}_{\max }=y_{\text {tot }} / d t\end{array}$ \\
\hline $\begin{array}{l}\text { Chancellor } \\
\text { Ridge }\end{array}$ & 29 & $230 \pm 260 \mathrm{~mm}$ & $83 \pm 42 \mathrm{~mm}$ & $21 \pm 24 \mathrm{yrs}$ & $4.0 \pm 5.0 \mathrm{~mm} / \mathrm{yr}$ \\
\hline $\begin{array}{l}\text { Crawford } \\
\text { Knob }\end{array}$ & 43 & $510 \pm 480 \mathrm{~mm}$ & $62 \pm 39 \mathrm{~mm}$ & $46 \pm 44 \mathrm{yrs}$ & $1.3 \pm 1.5 \mathrm{~mm} / \mathrm{yr}$ \\
\hline & Average & $370 \pm 544 \mathrm{~mm}$ & $72 \pm 58 \mathrm{~mm}$ & $34 \pm 49 \mathrm{yrs}$ & $\mathbf{2 . 0} \pm \mathbf{3 . 3} \mathbf{~ m m} / \mathbf{y r}$ \\
& & & & &
\end{tabular}

In most of the numerical models detailed later in this paper, we used a slip rate of $y_{\text {tot }} / d t=0.5 \mathrm{~mm} / \mathrm{yr}$. This modelling slip rate falls between the maximum and minimum bounds outlined above. It is 4 times less than the average calculated value of the maximum slip rate (escalator model) and $\sim 2500$ times more than the range of minimum slip rates derived from the model that assumes $S=W_{\text {array }}$ and from the model based on 
the estimate of maximum time available for deformation $\left(1.4-4 \times 10^{-4} \mathrm{~mm} / \mathrm{yr}\right)$. We will show that the actual chosen slip rate does not matter for most of our numerical models since we are mostly dealing with viscosity and stress ratios rather than absolute values (section 3.5).

\subsection{Field data - Fault-shear zone scaling relationships}

In the field, we examined several geometric scaling relationships relating to the sheared quartz veins. These were compiled by a detailed analysis of outcrop exposures of nineteen wholly ductilely sheared and ten part-brittlely, part-ductilely sheared quartz veins at Chancellor Ridge; as well as from thirty fully ductilely sheared and thirteen part-brittlely, part-ductilely sheared quartz veins from Crawford Knob. Fig. 3.6a illustrates the various measurements that were recorded on detailed maps of the outcrop traces of the sheared veins and faults after projection of the vein and fault traces into the movement plane using the method of Grigull and Little (2008). For each exposure, we measured the following geometrical parameters: total slip $\left(y_{t o t}\right)$, brittle component of slip (b), ductile component of slip $\left(d=d_{1}+d_{2}\right)$, original vein thickness $\left(t h_{\text {orig }}\right)$, minimum (strongly deformed) vein thickness $\left(t h_{\min }\right)$, and the fault-normal width of the ductilely sheared part of the vein $(d s w)$. We then used these diagnostic scaling relationships as a filter to distinguish between successful and unsuccessful modelling runs (section 3.5).

\section{1) Ductilely sheared width (dsw) vs. original vein thickness (thorig)}

Fig. 3.6b shows that there is a positive correlation between the undeformed vein thickness $t h_{\text {orig }}$ and the width of ductile shearing in the deflected or deformed part of a quartz vein $(d s w)$. In other words, the thicker the original vein, the wider the ductile shear zone that later developed in that quartz vein. Although these two parameters at first glance may seem to scale linearly, a linear relationship is not statistically well demonstrated by the data. The values for the ductilely sheared width range between 1 $\mathrm{cm}$ and $4 \mathrm{~cm}$ with an average of $c .2 \mathrm{~cm}$.

\section{2) Ratio of ductile / total slip $\left(D=d / y_{\text {tot }}\right)$ vs. original vein thickness ( th $\left._{\text {orig }}\right)$}

One way to describe the "ductility" $(D)$ of a quartz vein is to specify the ratio between ductile component of slip to total slip $\left(D=d / y_{t o t}\right)$. For example, if $D=1.0$ the vein has 
been deformed in a fully ductile manner, and if $D=0.0$ the vein was displaced in a fully brittle way. The plot ductile / total slip $(D)$ versus original vein thickness $t h_{\text {orig }}$ shows that most veins with an original thickness greater than $\sim 2 \mathrm{~cm}$ are usually $100 \%$ ductilely deformed $(D=1.0)$, whereas veins with thicknesses of less than $\sim 2 \mathrm{~cm}$ may show a component of brittle offset as well (Fig. 3.6c); that is, $D<1.0$. By contrast, no clearly recognisable relationship between $D$ and $t h_{\text {orig }}$ occurs for $t h_{\text {orig }}<2 \mathrm{~cm}$. An apparently robust observation is that for all but one of the $(<2 \mathrm{~cm}$ thick) deformed quartz veins which have experienced some amount of brittle slip, the ratio of ductile / total slip is D $\leq 0.5$.

\section{3) Ratio of "ductility" $\left(D=d / y_{\text {tot }}\right)$ vs. total slip $y_{\text {tot }}$}

The plot of $D$ versus total slip $y_{\text {tot }}$ shows that only veins that have been displaced at least $\sim 3 \mathrm{~cm}$ have any brittle slip component $(D \leq 1)$, whereas those displaced by $<3 \mathrm{~cm}$ are typically only ductilely deformed $(D=1)$. For slips greater than $3 \mathrm{~cm}$, there is no obvious scaling relationship between the ductility of a deformed quartz vein $(D)$ and the finite slip (Fig. 3.6d).

\section{4) Ductilely sheared width (dsw) vs. ductile component of slip (d)}

Fig. 3.6e shows that there is also a positive correlation between the ductile component of slip $(d)$ in a vein and the ductile width of its shear zone $(d s w)$ : the larger the ductile offset of a vein $(d)$, the greater the width of ductile shearing in that vein $(d s w)$. We note that for $d<3 \mathrm{~cm}$ (especially) this relationship is non-linear. Non-linear retrogression of the data indicates that the scaling relationship between $d s w$ and $d$ seems to follow a power law with $d s w=10^{(0.16 \pm 0.04)} \cdot d^{(0.26 \pm 0.12)}$.

\section{5) Vein attenuation factor $\left(t h_{\text {att }}=t h_{\text {min }} / t h_{\text {orig }}\right)$ vs. ductile component of slip (d)}

We define the vein attenuation factor $t h_{\text {att }}=t h_{\text {min }} / t h_{\text {orig }}$ to be the ratio of the minimum thickness of the most deformed part of a sheared vein $\left(t h_{m i n}\right)$ to the inferred original thickness of that vein $\left(t h_{\text {orig }}\right)$ as preserved in the external part of a vein away from the fault-shear zone. There is an inverse correlation between the vein attenuation factor $t_{\text {att }}$ and the ductile component of slip $(d)$ : the higher the value of $d$, the lower (more attenuated) the value of $t h_{\text {att }}$. We note that at a ductile displacement of just $2 \mathrm{~cm}$, most of the wholly ductilely deformed quartz veins have already been thinned to at least $40 \%$ 
of their original thickness. At offsets greater than $2 \mathrm{~cm} t h_{\text {att }}$ decreases with a relatively shallow gradient. This leads us to infer that these two scaling parameters are related by a power law with a negative power law exponent. Non-linear regression suggests a power law of the form $t h_{\text {att }}=10^{(-0.34 \pm 0.08)} \cdot d^{(-0.53 \pm 0.12)}$ (Fig. 3.6f).
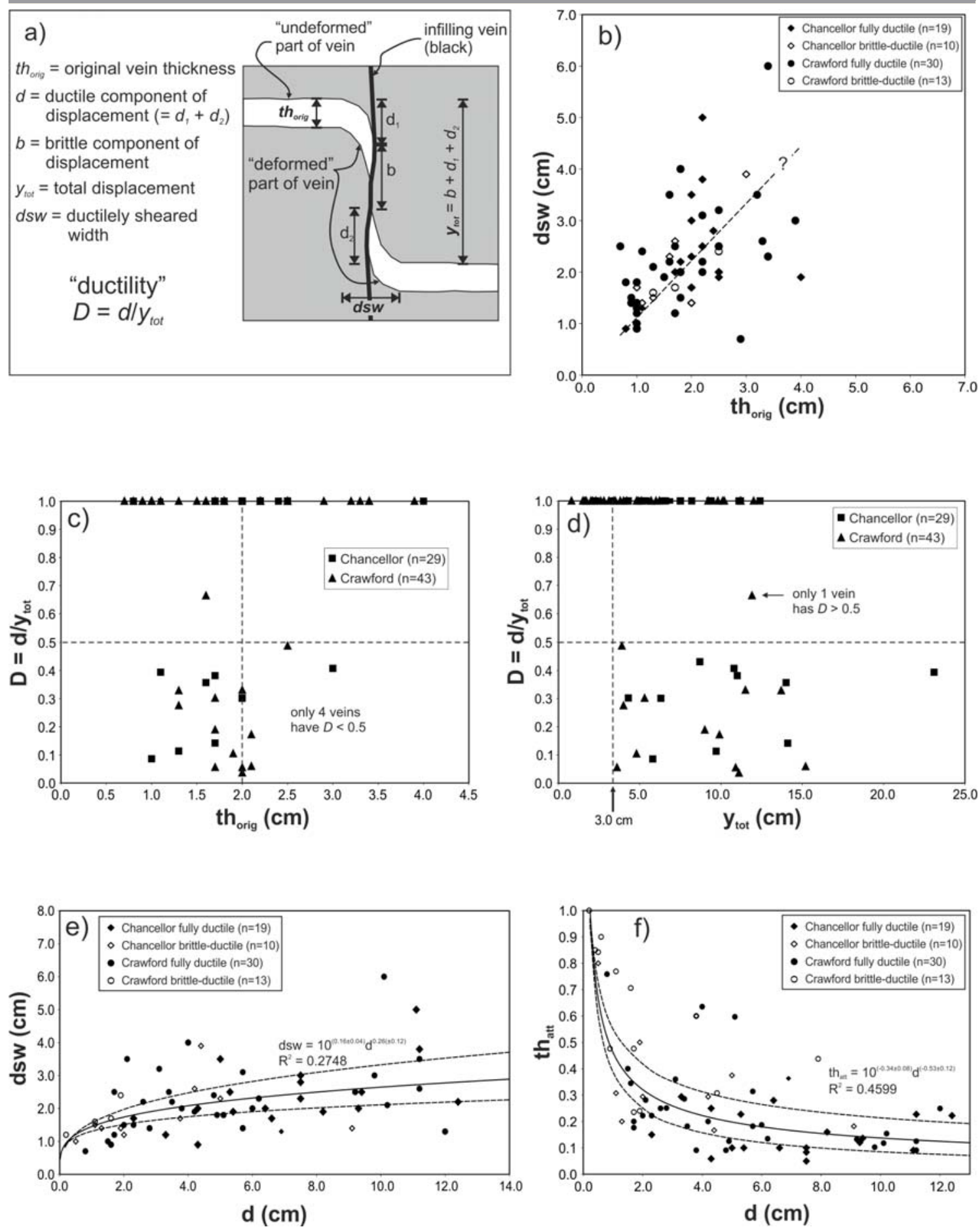
Figure 3.6 (previous page): Field data-derived plots of scaling relationships measured in the quartz veins. All data have been separated by location and 'ductility'. Measurement uncertainty is $\pm 0.2 \mathrm{~cm}$. Where plausible, we put trendlines through the field data. a) Schematic overview of measurements that were taken from the vein-fault sets after having been projected into the movement plane of the brittle faults; $t h_{\text {orig }}$ : original vein thickness, $t h_{\min }$ : thinned vein thickness, $d_{l} \& d_{2}$ : ductile components of slip, $d=$ $d_{1}+d_{2}$ : total ductile slip, $b$ : brittle component of slip, $y_{t o t}$ : total slip, $d s w$ : ductilely sheared width. b) Ductilely sheared width $(d s w)$ vs. original vein thickness $\left(t h_{\text {orig }}\right)$. c) Ratio ductile/total slip $(D)$ vs. original vein thickness $\left(t h_{\text {orig }}\right)$. d) Ratio ductile/total slip $(D)$ vs. total slip $\left(y_{t o t}\right)$. e) Ductilely sheared width $(d s w)$ vs. ductile component of slip $(d)$. f) Vein attenuation factor $\left(t h_{a t t}\right)$ vs. ductile component of slip $(d)$. The dashed lines in e) and f) correspond to the errors calculated for the trendlines.

\subsection{Numerical experiments}

The analysis of the geological field data in section 3.4 indicates that there are some interesting and systematic scaling relationships between several geometrical parameters related to the quartz veins and their brittle to ductile offset across the shears. These are inferred to reflect some aspects of the rheology during deformation. In order to refine our understanding of the rheological properties of these natural quartz veins during their shearing, we have modelled several vein deformation scenarios in an attempt to replicate the observed patterns.

\subsubsection{Experimental framework - Rheological end-members}

The field observations indicate that narrow brittle faults offset the quartzofeldspathic host schist, but that these faults commonly did not transect quartz veins embedded within the schist along strike. Instead, the quartz veins were mostly subject to ductile shearing. However, as detailed in section 3.4, the quartz veins did not necessarily undergo only ductile deformation but may also have experienced a component of brittle slip. Moreover, we observed some ductile deformation of the quartzofelpspathic wall rock schist in the deeper structural levels of the fault array. This might be attributed to higher deformation temperatures existing in the deeper parts of the otherwise brittle fault array leading to an overall lower flow strength of the rocks (Wightman, 2005). In the rest of the array, macroscopic ductile deformation of the host schist is localised to step-over zones between two non-coplanar faults, where strain is distributed across a larger volume of rocks (Fig. 3.7). We infer that the strain rates across those step-over zones must have been low enough to enable ductile flow in the schist host instead of the much more prevalent brittle faulting. The ductile deformation of the schist in those stepovers is usually expressed as a rotation of the dominant foliation that is consistent with 
dextral shearing along the two adjacent faults (Fig. 3.7). We hence need to account for at least two rheological end-members (and combinations thereof) in our numerical models. We include "frictional" (i.e., brittle) and "viscous" (i.e., ductile) material behaviour for both the quartz vein material and the quartzofeldspathic host rocks. Fig. 3.8 gives an overview of possible combinations of frictional and viscous material behaviours in the schist and the quartz. Cases A-F (black outlines in Fig. 3.8) are all required by our field observations of the naturally deformed quartz veins, with cases AE being the most common.

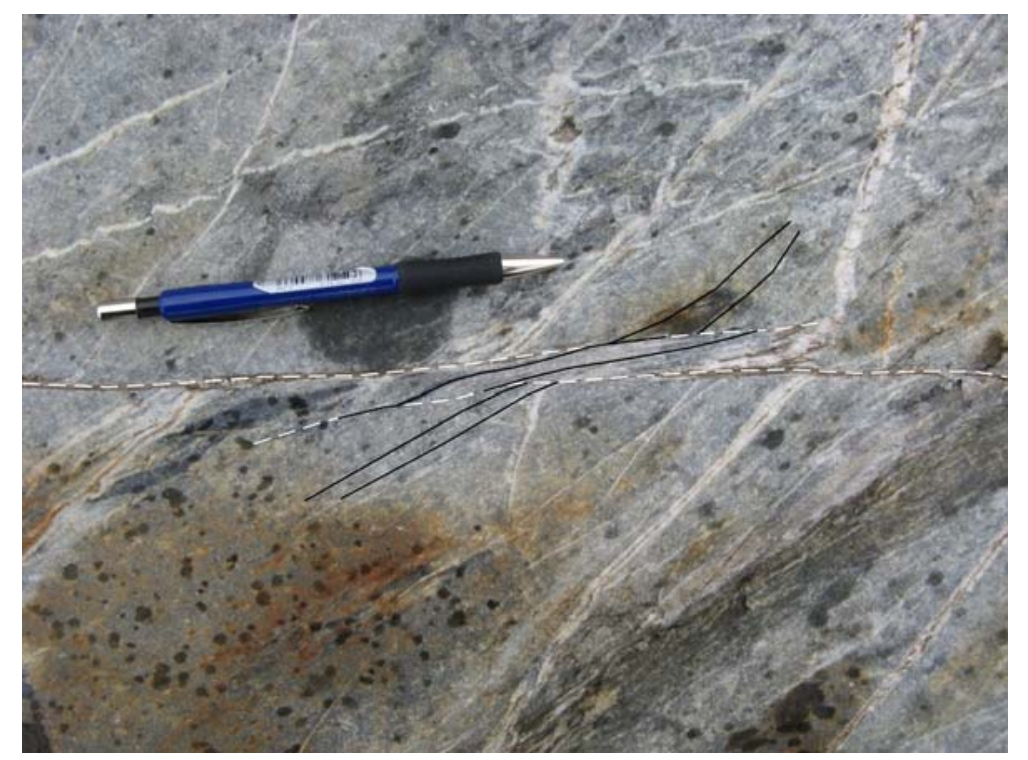

Figure 3.7: Example of the ductile deformation of quartzofelpspathic schist localised to the step-over zones between two non-coplanar faults. The two fault terminations (white stippled lines) are overlapping and the rotation of the foliation (black lines) is consistent with dextral shearing along those faults. The overlapping zone is $c .2 \mathrm{~cm}$ wide and $c .14 \mathrm{~cm}$ long.

The most likely combinations embrace fully frictional or frictional-viscous behaviour of the host schist; and fully viscous, frictional-viscous, or fully frictional behaviour of the quartz veins embedded in that schist. Even at locations in the field where the quartzofeldspathic schist exhibits ductile deformation, we always observe a precursory brittle fracture in that host schist; the schist always has a frictional component of deformation, and only deforms ductilely after precursory embrittlement so that we can exclude the rheological end-member combinations depicted in cases G-I (grey outlines in Fig. 3.8) as these would produce only viscous structures in the schist. For this reason, we did not attempt to model cases G-I. 


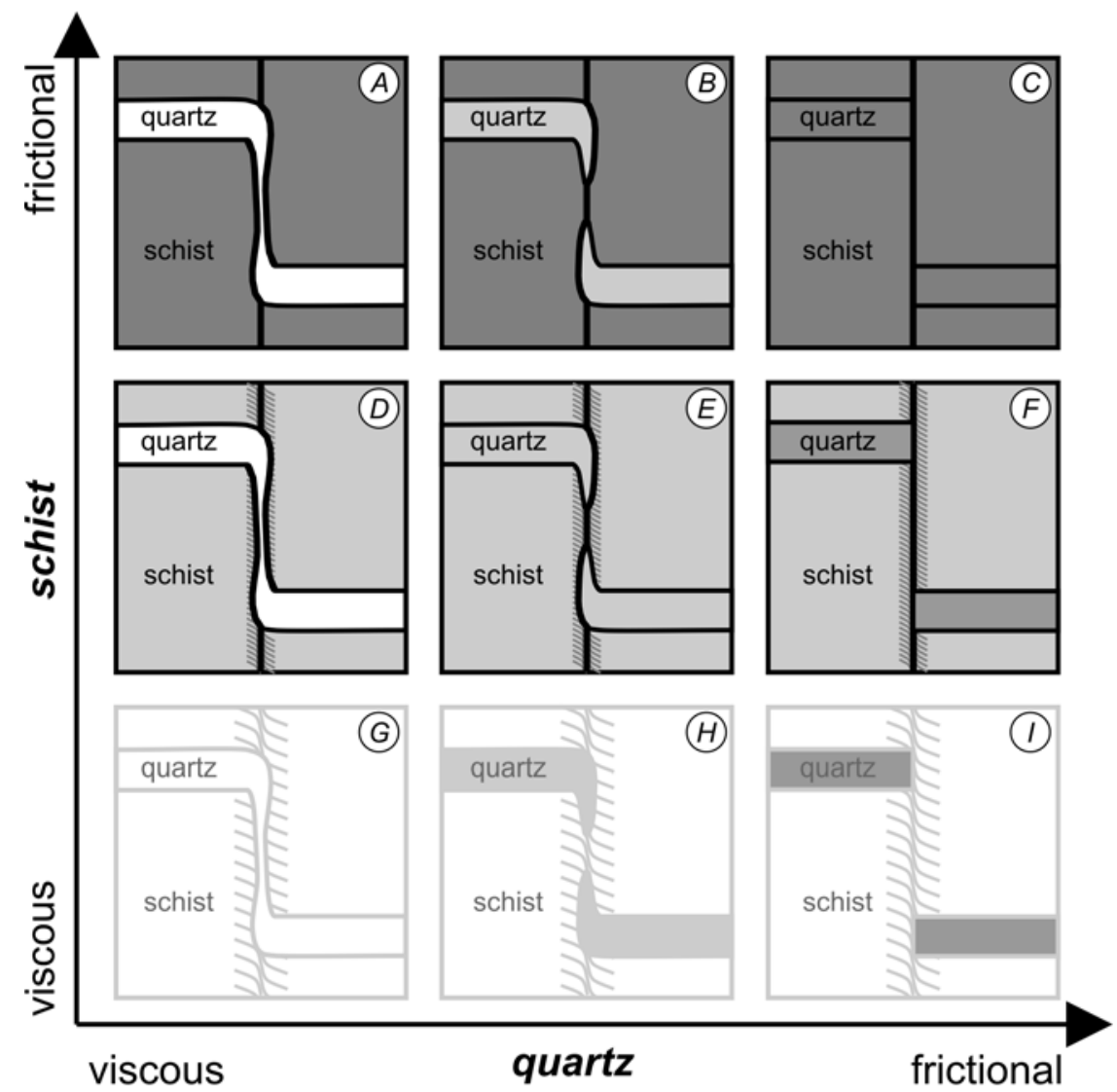

\section{Material behaviour:}

fully viscous

frictional-viscous

fully frictional fully ductile shear zone in schist (not realised)

brittle-ductile shear zone in schist

fully brittle fault in schist (most common)

Figure 3.8: Overview of possible combinations of the two end-members frictional (dark grey) and viscous (white) deformation in the quartz and the schist. Frictional-viscous deformation is marked in light grey. Cases A-E are the most common cases in our area. Cases G-I (no brittle component in schist) were not observed in the field.

\subsubsection{Description of numerical technique}

We have constructed a two-dimensional visco-plastic Lagrangian-Eulerian finite element code (referred to as "our code" or "the code" in the following) that has been specifically adapted for this study to investigate the effect of rheology, geometry, and deformation history on vein shape and flow mechanism. We have benchmarked our code against the commercial Lagrangian finite element code "Abaqus" 
(Abaqus/Standard version 6.7; Simulia, Providence, RI) and attain similar results, for small deformation (Appendix B). Our code uses a tracer-in-cell approach, in order to advect quantities such as strain, temperature, and material properties through a stationary grid which is used for the finite element computation. This approach allows large finite strains to accumulate without affecting the quality of the computational mesh (cf. Abaqus/Standard). Non-linear viscous rheology is represented assuming the Stokes equation for creeping flow (e.g., Fullsack, 1995; Moresi et al., 2003). Pressure is solved via a penalty approach, and plasticity is implemented according to a Von Mises flow rule by iterating on effective plastic viscosity until yield stress is attained (e.g., Fullsack, 1995).

\subsubsection{Model setup}

We set up four model series in order to examine different aspects of the rheology in the brittle-ductile shear array, especially the interplay between ductile and brittle deformation ahead of the fault tip in the deformed quartz veins. All models include a quartz vein and a fault propagating from the upper and lower boundaries towards the quartz vein. In model series 1 , we investigate the influence of the contrast between viscous strength of the quartz and frictional strength of the schist on the propagation behaviour and final geometry of the brittle fault. Model series 2 addresses the question of whether there are some predictable conditions (initial vein thickness and frictionalviscous strength contrast in the quartz) under which the quartz vein would cease to deform ductilely and instead begin to deform brittlely. In the third model series we analyse the influence of the stress exponent $n$ for quartz (e.g., Eq. (3.1)) on the shape of the deformed veins and their shear zones in an attempt to fit the modelling data to the observed field observations and afore mentioned scaling relationships. These first three model series employ fully frictional deformation behaviour in the schist, corresponding to cases A-C in Fig. 3.8. In model series 4, we examine if and how the scaling relationships, shear localisation, and the frictional-viscous transition in the quartz are influenced by a schist that can deform (to some degree) viscously as well as frictionally (cases D-F in Fig. 3.8).

\subsubsection{Initial geometry and boundary conditions}

The initial model dimensions are $0.1 \mathrm{~m}$ x $0.1 \mathrm{~m}$ (Fig. 3.9). The structured mesh resolution is $100 \times 100$ elements so that element side dimensions are $1 \mathrm{~mm}$. Each 
element originally contains four tracers amounting to a total of 40,000 tracers in the entire model. An initially horizontal quartz vein is embedded in the middle of the model. The quartz vein can be included into the model with different original thicknesses $\left(t_{\text {orig }}\right)$.

We apply constant velocity boundary conditions ( $d y / d t$, Fig. 3.9) around the model domain in order to simulate slip on a mode II crack in the schist external to the embedded quartz vein and the propagation path of that fault towards the vein. The velocity boundary conditions (incl. slip rate) have already been described and justified in section 3.4. The width of the external fault zone at the top and bottom of the model are set to $2 \mathrm{~mm}$ ( $f z w$, Fig. 3.9). This equates to the observed average fault width measured in the field $(\sim 1.9 \mathrm{~mm}$; this width is the average dilative thickness of the infilling veins).

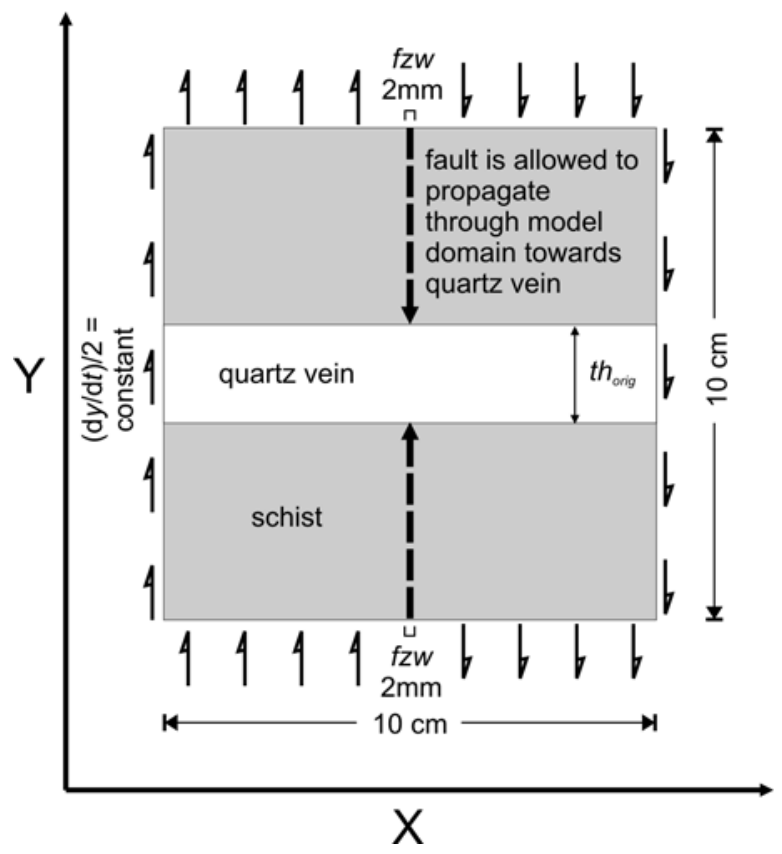

Figure 3.9: Initial model setup for numerical modelling. $(\mathrm{d} y / \mathrm{d} t) / 2$ is half of the externally imposed total slip rate $(\mathrm{d} y / \mathrm{d} t)$ on the fault. $f z w$ is the prescribed fault zone width $(2 \mathrm{~mm}$, which equals the mean dilative width of the fault infilling quartz-calcite veins). Note that there is no pre-exististing fault but that we model the propagation of a brittle fault through the schist into the quartz vein.

We chose to model a fault propagating into the modelled domain rather than setting the fault as an initial condition and imposing its geometry because field observations show that the brittle faults interact with the quartz veins and are usually deflected around them (Fig. 3.10). Since the veins accumulate a large finite ductile shear strain at sub-dynamic strain-rates (as already discussed in section 3.3), and since there is no evidence for seismically induced fault rocks, we assume that the faults did not form first as dynamic cracks, but underwent a slow propagation. The incrementally grown fibrous 
quartz-calcite-chlorite veins that infill some of the brittle faults (section 3.2) are also consistent with such slow fault propagation.

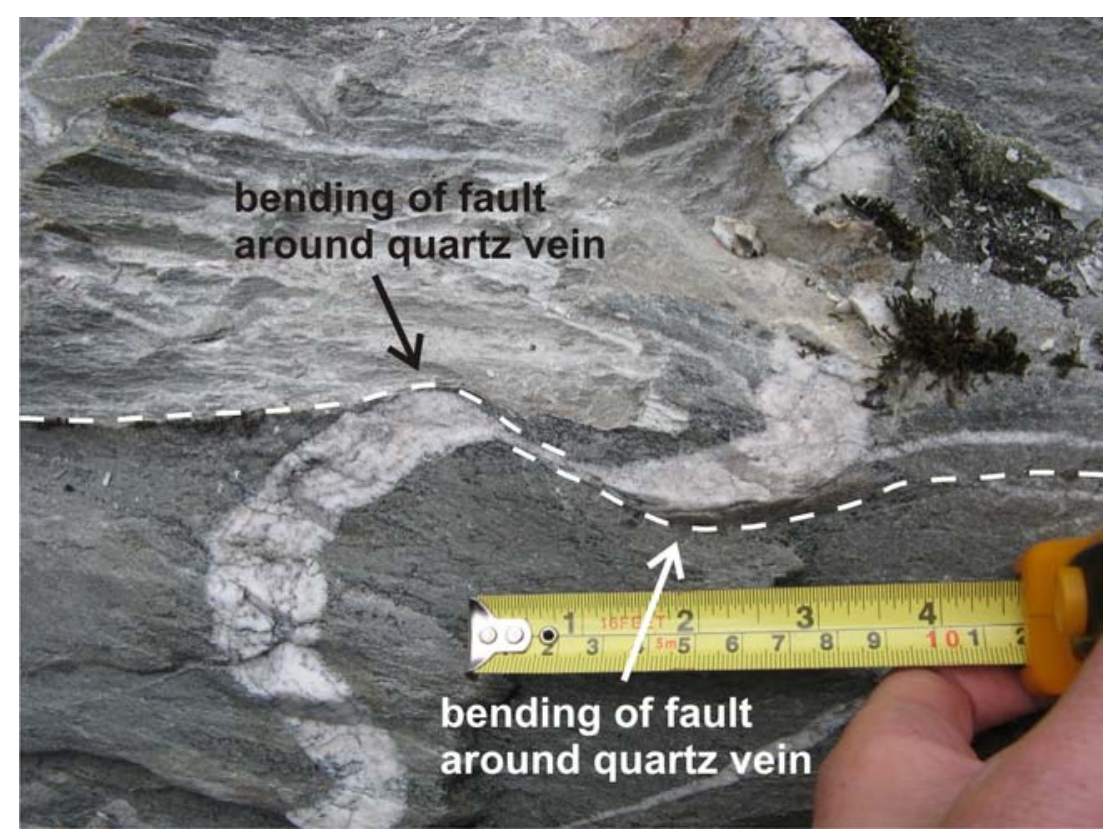

Figure 3.10: Photograph of fully ductilely displaced quartz vein embedded in brittlely deforming schist. This photograph shows the brittle fault deflecting and bending around the ductilely shearing quartz vein.

\subsubsection{Choice of material parameters used in model series 1 to 4}

a) Plasticity, frictional yield strength

In order to simulate frictional material behaviour, we included a Tresca yield criterion in both materials. Plastic strain softening is active in the schist in order to achieve strain localisation in the fault zone (Fig. 3.9). As justified in section 3.3, we chose an initial frictional yield stress for the intact schist of $\tau_{f}^{s}=50 \mathrm{MPa}$ (corresponding to a differential stress of $\sigma_{d}^{s}=100 \mathrm{MPa}$ ). The schist is softened to $\tau_{f}^{s}=15 \mathrm{MPa}$ after accumulation of $\sim 10 \%$ plastic strain resulting in a narrow fault zone (App. 3.B). This is in agreement with long, discrete, well formed cracks that are seen in the field, some of which have offsets of only a few millimetres.

In model series 2 and 3 we also incorporated frictional yield stresses in the quartz. The quartz frictional yield strength was also set at $\tau_{f}^{q}=50 \mathrm{MPa}$, but we assumed that the quartz did not undergo frictional strain-softening. That is because usually the cracks 
blunt into the quartz veins, and deformation is spread out by viscous flow and not frictional yielding (e.g., Fig. 3.2d).

b) Viscosity, flow law

Assuming that the main active deformation mechanism was grain size-independent dislocation creep in the quartz vein (App. 3.A; see also Wightman et al., 2006), we can exclude the grain-size term in Eq. (3.1) and simplify it to:

$$
\dot{\varepsilon}_{s}=A_{M} \cdot \tau_{v}^{n}
$$

where $\dot{\varepsilon}_{s}$ is the shear strain rate as defined in App. 3.B, and $\tau_{v}$ is the (flow) stress in shear. Factor $A_{M}$ is a material constant that includes the experimentally derived preexponential factor $A_{E}$, water fugacity $f_{\mathrm{H}_{2} \mathrm{O}}$, the exponential term $\exp (-Q / R T)$, and a geometry factor $G$ necessary for the conversion from triaxial experiments to plane strain (see App. 3.A):

$$
A_{M}=G \cdot f_{H_{2} O} \cdot \exp (-Q / R T) \cdot A_{E}
$$

The geologically constrained quartzite flow law of Hirth et al. (2001) was used as an initial input for the viscous creep behaviour of the quartz vein, with Hirth et al.'s original parameters: $A_{E}=10^{-11.2} \mathrm{MPa}^{-\mathrm{n}} \mathrm{sec}^{-1}, Q=135 \mathrm{~kJ} / \mathrm{mol}$, and a stress exponent of $n$ $=4.0$. In all the experiments we chose a temperature of $450^{\circ} \mathrm{C}$ in accordance with the temperature estimates of vein deformation that were described in section 3.2. Since there is good evidence for fluids and high fluid pressures near the Alpine Fault in the Southern Alps (e.g., Wannamaker, 2002; Stern et al., 2001, 2007), eqs. (1) and (4) contain a water fugacity term. For a lithostatic pressure of $560 \mathrm{MPa}$ at $\sim 21 \mathrm{~km}$ depth and a temperature of $450^{\circ} \mathrm{C}$, we estimated a water fugacity of $f_{\mathrm{H}_{2} \mathrm{O}}=200 \mathrm{MPa}$ under fully water-saturated conditions (using published fugacity coefficients, cf. App. 3.F). With the above specified flow law parameters applied to Hirth et al.'s flow law we calculated an initial material constant of $A_{M}=10^{-17.76} \mathrm{MPa}^{-\mathrm{n}} \mathrm{sec}^{-1}$ in eq. (4). Using $A_{M}=$ $10^{-17.76} \mathrm{MPa}^{-\mathrm{n}} \mathrm{sec}^{-1}$ in eq. (3.3) and, for example a shear strain rate of $3.95 \times 10^{-9} \mathrm{sec}^{-1}$ (corresponding to a total differential velocity of $d y / d t=0.5 \mathrm{~mm} / \mathrm{yr}$ ) over a fault zone width of $2 \mathrm{~mm}$, we calculate a flow stress in the quartz vein of $\tau_{v}^{q}=219 \mathrm{MPa}$ using the Hirth et al. (2001) flow law parameters with a water fugacity of $200 \mathrm{MPa}$. This calculated flow stress is only a theoretical value, since it is based on the assumption that 
the $2 \mathrm{~mm}$ wide shear zone is maintained throughout the quartz vein once the "brittle" fault encounters the model vein. In reality, deformation spreads out in the quartz, and strain rates and flow stresses decrease there. In order to derive varying strength ratios in the numerical models, we changed $A_{M}$-values in the quartz vein in model series 1 and 2 as well as in the schist in model series 4 .

c) Contrast between viscous strength of quartz and frictional strength of schist

We define the quartz-to-schist viscous-to-frictional or "ductile-to-brittle" strength contrast between the two materials, quartz (mostly ductile) and schist (mostly brittle), to be equivalent to the ratio

$$
R^{q s}=\tau_{v}^{q} / \tau_{f}^{s}
$$

where $\tau_{v}^{q}$ is the viscous (ductile) flow strength of the quartz, and $\tau_{f}^{s}$ is the frictional (brittle) yield strength of the unsoftened schist. For example, using $\tau_{v}^{q}=219 \mathrm{MPa}$ (as calculated in section 3.5.3.2.2) and $\tau_{f}^{s}=50 \mathrm{MPa}$ (sections 3.5.3 and 3.5.3.2.1) with eq. (3.5) would give a strength contrast of $R^{q s}=4.38$. In order to derive varying theoretical strength ratios in the numerical models, we changed $A_{M}$-values in the quartz vein in model series 1 and 2 as well as in the schist in model series 4 .

\subsubsection{Results - model series 1: Influence of the viscous-to-frictional (quartz-to-schist)} strength contrast $R^{q s}$ and of the flow law stress exponent (n) on the propagation behaviour of the brittle fault

In this section, we investigate the influence of the viscous-to-fritional (quartz-toschist) strength ratio $R^{q s}=\tau_{v}^{q} / \tau_{f}^{s}$ (Eq. 3.5) between a fully viscous (wholly ductile), non-frictional quartz vein and purely frictional (wholly brittle) schist (Fig. 3.8, case A) on the propagation behaviour of the fault through the schist and into the quartz vein. All of the following models include a $2 \mathrm{~cm}$ thick horizontal quartz vein at right angles to the fault and are deformed by a constant differential velocity along the boundaries of 0.5 $\mathrm{mm} / \mathrm{yr}$.

In order to qualitatively test in which way the propagation and/or bifurcation of the brittle fault might be affected by the brittle-ductile strength contrast $\left(R^{q s}\right)$ and also by the stress exponent for flow of the quartz vein $\left(n_{q}\right)$, we set up models with different 
$R^{q s}$-values $(0.01,1.2,5.0,13.2)$. For these (theoretical) ratios $\tau_{v}^{q}$ was calculated via Eq. (3.3) for different $A_{M}$-values, a nominal initial strain rate of $3.95 \times 10^{-9} \mathrm{~s}^{-1}$ at the faultquartz vein intersection, and two different stress exponents $\left(n_{q}=1\right.$ and $\left.n_{q}=4\right)$. For simplicity, we prescribed that the quartz must be fully viscous at all times, and that the frictional yield stress in the quartz is never reached, by setting the frictional yield stress for the quartz to $10 \mathrm{GPa}$ (i.e., $\tau_{v}^{q}<<\tau_{f}^{q}$ ). The frictional yield strength in the unsoftened schist was set to $50 \mathrm{MPa}$ and was reduced to $15 \mathrm{MPa}$ in the strain-softened areas, as described in section 3.5.3.2.1. In order to ensure purely frictional behaviour in the schist, the schist rheology was chosen such that the flow strength in the schist was always significantly higher than its frictional strength (i.e., $\tau_{v}^{s}>>\tau_{f}^{s}$ ). Table 3.2 summarises the material parameters that were used in the models.

Table 3.2 Material parameters used in section 3.5.4. $R^{q s}$ is ductile-to-brittle strength contrast between viscous quartz and frictional schist, eq. (3.5). Numbers in table are corresponding values of $\log _{10}\left(A_{M}\right)$. Lmodels assume a linear viscous rheology with a flow law stress exponent $n_{q}=1.0$ and P-models power law creep in the quartz vein with $n_{q}=4.0$.

\begin{tabular}{ccccc}
\hline viscous-frictional (quartz-schist) strength ratio $R^{q s}$ & $\mathbf{0 . 0 1}$ & $\mathbf{1 . 2}$ & $\mathbf{5 . 0}$ & $\mathbf{1 3 . 2}$ \\
\hline $\log _{\mathbf{1 0}}\left(\boldsymbol{A}_{M}\right)\left[\mathrm{MPa}^{-\mathbf{n}} \mathbf{s}^{-1}\right]$ for L-models $\left(\boldsymbol{n}_{\boldsymbol{q}}=\mathbf{1 . 0}\right)$ & -8.1 & -10.2 & -10.8 & -11.0 \\
\hline $\log _{\mathbf{1 0}}\left(\boldsymbol{A}_{M}\right)\left[\mathrm{MPa}^{-\mathbf{n}} \mathbf{s}^{-1}\right]$ for P-models $\left(\boldsymbol{n}_{\boldsymbol{q}}=\mathbf{4 . 0}\right)$ & -7.2 & -15.5 & -18.0 & -19.7 \\
\hline
\end{tabular}

Results

Fig. 3.11 shows contour plots of strain rates after 5, 25, and 100 years of deformation. Models with a linear viscosity in the quartz vein $\left(n_{q}=1\right)$ are denoted with "L" whereas models with a power law quartz rheology $\left(n_{q}=4\right)$ are denoted with "P". The viscous-to-brittle (quartz-to-schist) strength contrast $R^{q s}$ is labelled above the model-plots.

Early stages of deformation (5 years of deformation, $2.5 \mathrm{~mm}$ total displacement)

The most evident observation from these models is that there are large differences in fault localisation between the linear and the power law model types especially at the early stages of deformation (Fig. 3.11, $0.25 \mathrm{~cm}$ displacement after $5 \mathrm{yrs}$ ).

In all the models with a linear quartz vein rheology (L-models), the shear does not localise but bifurcates at a distance of roughly $\sim t h_{\text {orig }}$ (where $t h_{\text {orig }}$ is vein thickness) from the quartz veins for all calculated strength contrasts. The two branches of the split- 
up faults are connected through subhorizontal cross-shears, creating "Eiffel tower"patterns in the strain rate contours.

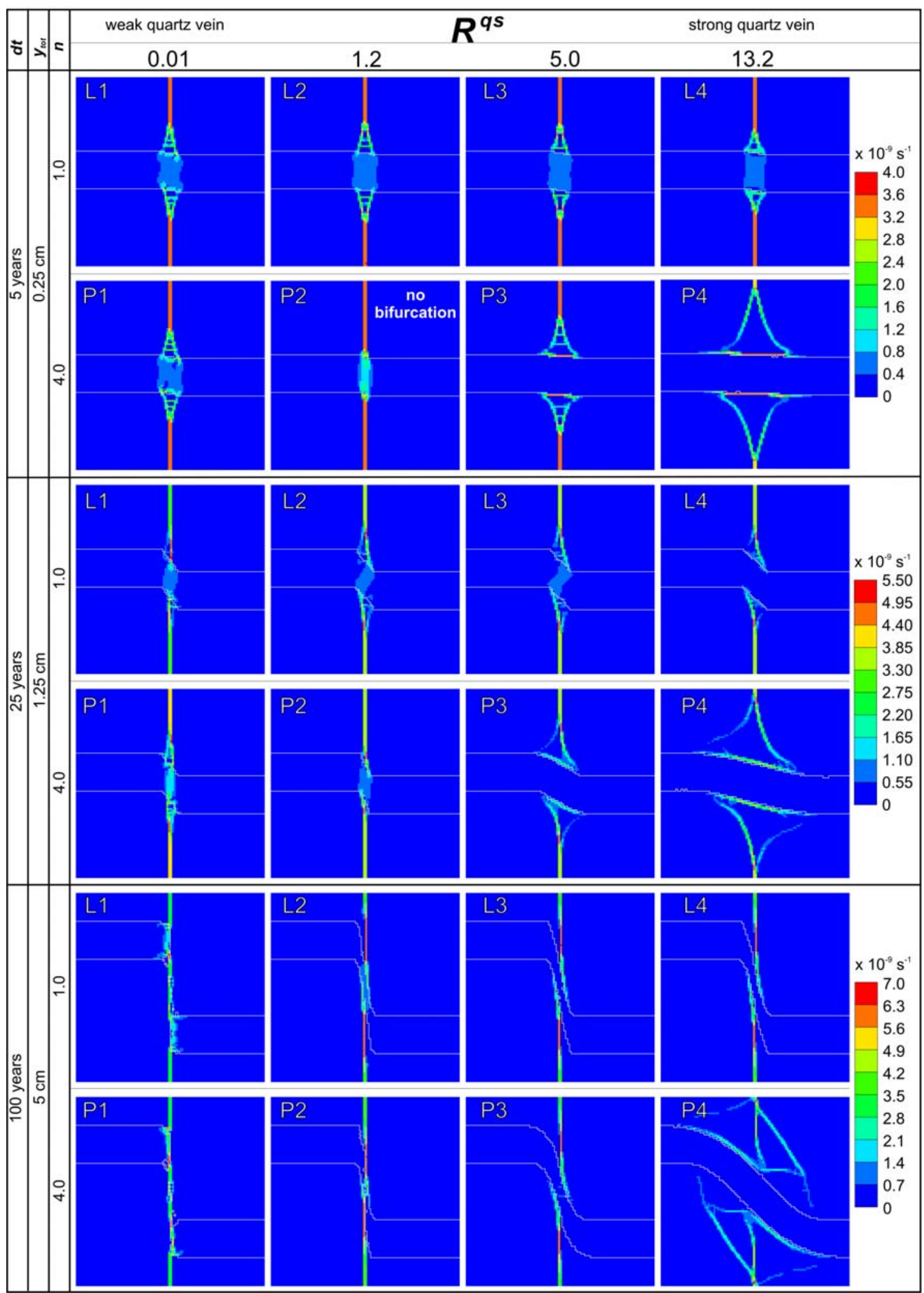


Figure 3.11 (previous page): Results of model series 1 - the influence of a viscous layer (quartz vein) on the propagation behaviour of an external brittle fault. Model plots are strain rate contours at 0.25 , 1.25 , and $5 \mathrm{~cm}$ total vein displacement. $R^{q s}$ is the viscous-to-frictional strength ratio between the ductilely deformed quartz and the brittlely yielding schist. Effective viscosity is increasing towards the right. Lmodels use linear viscosity, P-models use power law quartz rheology. Note the 'Eiffel-tower'-patterns (e.g., L1, P1) in the models with the weak quartz layers and the tent-like patterns in the models with a strong quartz (e.g., P4). P2 is the only model that has a fully and well localised fault from the beginning of deformation ("no bifurcation"). Note also, that the fault in none of the L-models ever localises in the initial stages of deformation.

The models with the power law quartz rheology (P-models) show fault bifurcation for $R^{q s}$-values of $0.01,5.0$, and 13.2. However, model P2 with a viscous-to-frictional strength contrast (quartz/schist) of 1.2 shows a well localised shear even at the early stages of deformation (Fig. 3.11; 'no bifurcation').

The Eiffel tower-patterns in L-models 1 to 3 and in model P1 developed because in those models, the quartz vein is so weak $\left(\tau_{v}^{q}<<\tau_{f}^{s}\right)$, that the vein-schist interface acts like a free boundary in the quartz allowing strain accommodation in the high-stress halo near the fracture tip through the rotation of small schist blocks between the fault branches. The rotational movement of those "blocks" is impeded by the stiffness of the schist, leading to the formation of strain-softened subhorizontal cross-shears. This phenomenon is discussed in more detail in section 3.6.1.

In models P3 and P4, slip occurs at the quartz vein-schist interface in the schist material. In model P3, the fault bifurcates and rotational cross-shears form in the schist. In P3, the viscous yield in the quartz vein is much higher $\left(\tau_{v}^{q}=250 \mathrm{MPa}\right)$ than the frictional strength of the schist in the unsoftened $\left(\tau_{f}^{s} 50 \mathrm{MPa}\right)$ or the softened state $(15$ $\mathrm{MPa}$ ). This means that almost the entire deformation needs to be accommodated by the schist. The stiff quartz vein impedes the rotation of the schist blocks, leading to the cross-shears in the strain-softening schist. In contrast, model P4 $\left(R^{q s}=13.2\right)$ shows a tent-like pattern without the formation of cross-shears. Here, the quartz vein is so strong $\left(\tau_{v}^{q} \gg>\tau_{f}^{s}\right)$ that it acts almost like a rigid block, forcing the deformation to spread out in the quartz and enhancing bifurcation in the schist. The tent-like appearance of the fault in P4 is due to the top and bottom boundary conditions that force the model to initiate faulting at the imposed $2 \mathrm{~mm}$ wide zone (Fig. 3.9, model setup). If the top and bottom boundaries of model P4 were instead free and the location of fault initiation was not predefined, one would expect two separate (subparallel) shears to form at those boundaries. 
Later deformation stages $(25+$ years, displacement $>1.25 \mathrm{~cm})$

At higher displacements, all the models with a linear quartz rheology (L-models) and all the power law models (P-models) except P4 start to abandon one branch of the initially bifurcating faults. This is partly due to the external asymmetric velocity boundary conditions, but it is mostly an effect of progressive vein attenuation, since the shears prefer to take the "path of least resistance" in order to minimise the energy dissipation in the system (see section 3.6.1). In models L1 and P1, the path of least resistance is through the quartz vein, since it has a low effective viscosity; i.e., a lower strength than the schist. This results in the shear bending into the quartz vein (Fig. 3.11, L1 and P1 at $5 \mathrm{~cm}$ displacement). Conversely, in models L2, L3, L4, and P2, P3, where effective quartz viscosities are higher, the path of least resistance is along the quartz schist boundary, and the shear takes the shortest way through the quartz vein, resulting in the shear bending around the quartz vein. In the field, we mostly observe the latter: a shear bending around the quartz vein (e.g., Figs. 3.2c, 3.2d, 3.10).

The fault in model P4 also abandons its left branch, but because of the high strength of the quartz, an additional new branch has formed in between the two older ones at 100 years of deformation.

From the results of modelling series 1, we infer that the frictional-viscous strength ratio between the schist and the quartz veins strongly controls the localisation and propagation of the brittle fault. In the field, we usually observe a well localised fault intersecting a quartz vein without bifurcating at the intersection with the vein. We therefore assume that $R_{c c}^{q s}$ was probably close to 1.0 during the shearing of the veins.

\subsubsection{Results - model series 2: brittle-ductile transition in the quartz veins}

From the field data that is described in section 3.4, we found that veins that are initially thicker than $2 \mathrm{~cm}$ usually deform in an entirely ductile fashion, whereas veins with original thicknesses $<2 \mathrm{~cm}$ typically show a brittle slip component as well, with most of the brittle-ductile veins having $D<0.5$ (Fig. 3.6c). We also described the relationship between the total amount of slip and the ratio ductile / total slip, where we found that only at total offsets $>3 \mathrm{~cm}$ do sheared quartz veins show a measurable brittle slip component (Fig. 3.6d).

In this section we investigate under which deformation conditions ( $A_{M}$-values, initial vein thickness, and total displacement) a quartz vein embedded in the brittlely 
deforming schist would deform with mixed ductile and brittle components across that shear. The following models represent cases A to C in Fig. 3.8. Since there are several independent parameters involved that can possibly influence the brittle-ductile transition in the quartz veins, we need to ensure that we address those parameters separately while keeping the other parameters constant.

\subsubsection{Vein thickness $h_{\text {orig }}$ and $A_{M^{-} \text {values }}$}

We first set up models that include a horizontal quartz vein each with a thickness range of $0.5 \mathrm{~cm}$ to $3.0 \mathrm{~cm}$ with $0.5 \mathrm{~cm}$ steps in between. The velocity boundary conditions are $0.5 \mathrm{~mm} / \mathrm{yr}$. We set the frictional yield strength in the quartz veins for these models to $\tau_{f}^{q}=50 \mathrm{MPa}$, identical to that of the intact schist, and we used the same entirely frictional schist rheology as in section 3.5.4 $\left(\tau_{f}^{s}<<\tau_{v}^{s}\right)$.

Table 3.3: Model parameters for testing the brittle-ductile transition in the quartz veins

\begin{tabular}{lll}
\hline$A_{M}\left(\mathrm{MPa}^{-\mathrm{n}} \mathrm{s}^{-1}\right)$ & $\tau_{v}^{q}$ (calculated flow stress) & $R^{q}=\tau_{v}^{q} / \tau_{f}^{q}$ \\
\hline $6.35 \times 10^{-16}$ & $50 \mathrm{Mpa}$ & 1.0 \\
\hline $3.06 \times 10^{-16}$ & $60 \mathrm{Mpa}$ & 1.2 \\
\hline $1.65 \times 10^{-16}$ & $70 \mathrm{Mpa}$ & 1.4 \\
\hline
\end{tabular}

Under these boundary conditions, frictional yielding of an intact quartz vein will depend on the ratio of the nominal flow stress to the frictional yield stress in that vein $\left(R^{q}=\tau_{v}^{q} / \tau_{f}^{q}\right)$ and on its thickness. We set up models with different $R^{q}$-values by changing the $A_{M}$-value for the quartz flow law. For all of the following models, a stress exponent of $n=4.0$ was used. The values for $A_{M}$ resulting in $R^{q}$-values of 1.0, 1.2, and 1.4 are summarised in table 3.3 .

In Fig. 3.12 we plot the ratio $D$ against the original vein thicknesses $t h_{\text {orig }}$ at a total displacement of $5.0 \mathrm{~cm}$ (i.e., after 100 years of deformation). For all three $R^{q}$-values, there is a positive but non-linear correlation between $t h_{\text {orig }}$ and the ratio $D$ with the ductile component of slip increasing with increasing initial vein thickness (Fig. 3.12). For $R^{q}=1.0$ and $R^{q}=1.2$ only the $2.5 \mathrm{~cm}$ and the $3.0 \mathrm{~cm}$ thick veins have deformed entirely ductilely, whereas the veins with thicknesses $\leq 2.0 \mathrm{~cm}$ all yield frictionally as well. For $A_{M}=1.65 \times 10^{-16} \mathrm{MPa}^{-\mathrm{n}} \sec ^{-1}\left(R^{q}=1.4\right)$ all but the $3.0 \mathrm{~cm}$ thick veins are 
ductilely and brittlely deformed. The reason for the 'bump' (orange dashed line in Fig. 3.12 ) in the curve for $R^{q}=1.4$ is due to the veins thinner than $2.5 \mathrm{~cm}$ yielding frictionally first, then ductilely (see section 3.5.5.2 below).

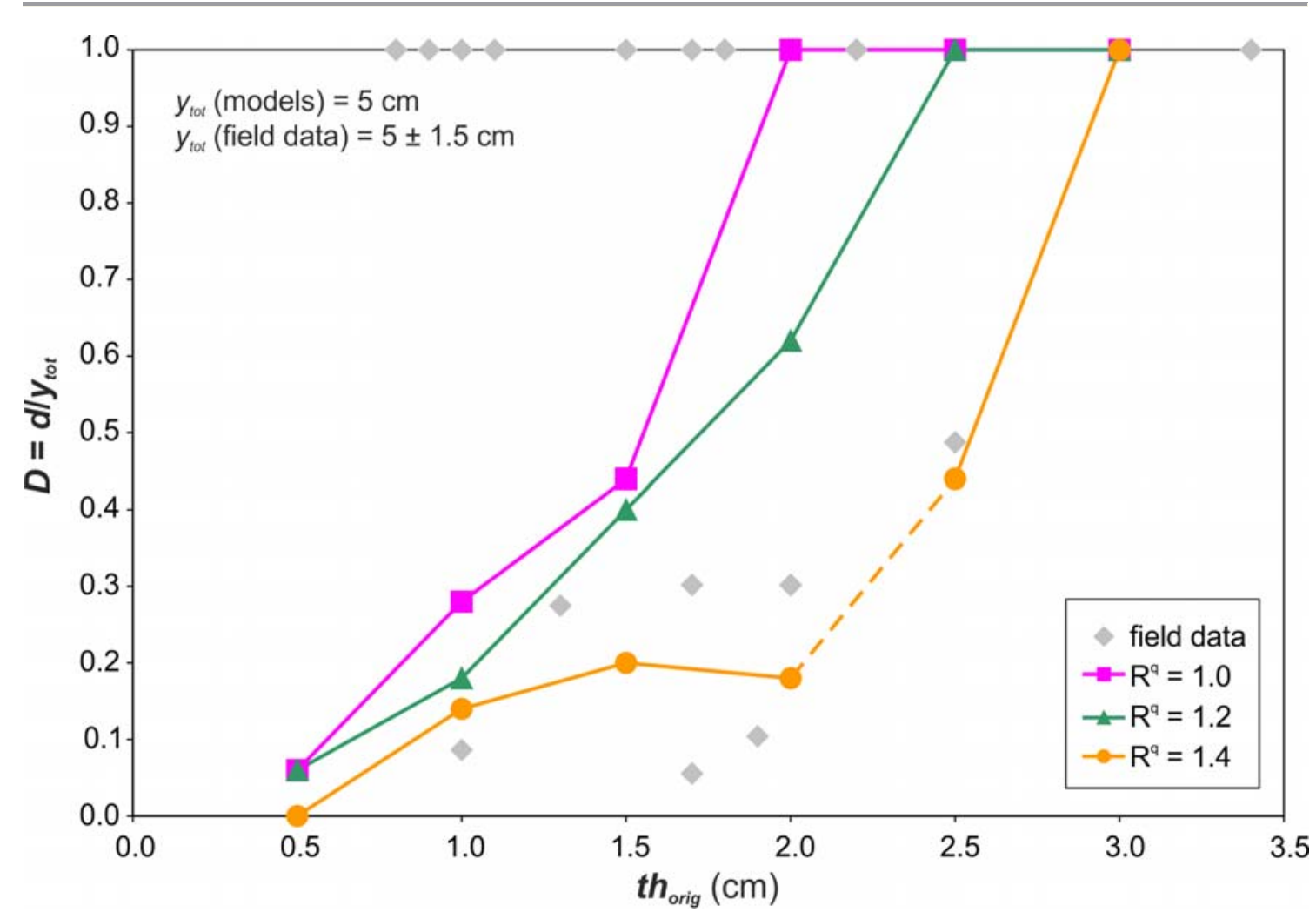

Figure 3.12: Results of model series 2 - plot of "ductility" $D$ against original vein thickness $t h_{\text {orig }}$ at a total displacement of $y_{\text {tot }}=5 \mathrm{~cm}$. Only field data with $y_{\text {tot }}$ between 3.5 and $6.5 \mathrm{~cm}$ are shown. $D=1.0$ is fully ductile, $D=0.0$ is fully brittle. The data suggests that $D$ increases with original vein thickness. The kink in the line for $R^{q}=1.4$ expresses the modelled relationship that all veins that were originally thinner than $2 \mathrm{~cm}$ are predicted to fail frictionally first. Those veins acquire a final $D$-value of less than 0.2 .

In summary, the numerical models show that the ductility or $D$-value of a sheared quartz vein does not only scale with the original undeformed vein thickness, but also depends strongly on the ratio between viscous and frictional yield strength for quartz in the quartz veins $\left(R^{q}\right)$. The brittle-ductile transition in the quartz veins seems to be very sensitive to $R^{q}$. Even small changes $( \pm 10 \mathrm{MPa})$ in the calculated flow strength can apparently control whether a quartz vein yields brittlely or ductilely and how high the resulting brittle component of slip is. When compared to the field data, the models with $R^{q}=1.2$ and $R^{q}=1.4$ fit the best. 


\subsubsection{Total vein displacement $y_{\text {tot }}$}

In order to find out what influence the total displacement has on the ratio ductile / total slip $D$, we had to slightly modify our model geometry to $0.2 \mathrm{~m}$ high and $0.1 \mathrm{~m}$ wide. We had to increase the height of the models to be able to achieve higher displacements (up to $10 \mathrm{~cm}$ ). This did not affect the outcome of the models, when compared to the ones deformed to only $5 \mathrm{~cm}$ displacement.

Fig. 3.13a-c are plots of the ratio of $D$ versus total displacement $y_{\text {tot }}$ for the different vein thicknesses and the three $A_{M}$-values that were used in the models. For $A_{M}=6.35 \mathrm{x}$ $10^{-16} \mathrm{MPa}^{-\mathrm{n}} \sec ^{-1}\left(R^{q}=1.0\right)$ the $0.5,1.0,1.5$, and $2.0 \mathrm{~cm}$ thick veins show a non-linear inverse relationship between the ratio $D$ and the total displacement $y_{\text {tot }}$, i.e., the higher the displacement, the lower $D$ (Fig. 3.13a). The model with the thinnest quartz vein $\left(t h_{\text {orig }}=0.5 \mathrm{~cm}\right)$ produces the curve with the steepest gradient .

Fig. $3.13 \mathrm{~b}$ shows the plot of $D$ versus total displacement for $R^{q}=1.2$ for different vein thicknesses. From this graph it is evident that there are two ways for a quartz vein to accommodate both brittle and ductile deformation behaviour: i) the two veins with $t h_{\text {orig }}=0.5$ and $1.0 \mathrm{~cm}$ both fail frictionally first and then continue to deform ductilely with increasing slip, since strain rates wane away from the vein centres and deformation spreads out through viscous flow; ii) the quartz veins that were initially thicker than 1.0 $\mathrm{cm}$ deform viscously at first and then yield frictionally at a total displacement greater than $2.5 \mathrm{~cm}$. This is due to ductile vein thinning so that the two stress tips at the fault tips are able to meet and join.

For $R^{q}=1.4$, all veins but the $3 \mathrm{~cm}$ thick vein yield frictionally first and then start to show viscous deformation behaviour as well (Fig. 3.13c). The $0.5 \mathrm{~cm}$ thick vein stays fully brittle. Interestingly, the models show that if the quartz veins fail frictionally before reaching their flow yield stress, $D$-values of all those veins lie under 0.5 at $y_{\text {tot }}=$ $5 \mathrm{~cm}$. Those veins show a peak in $D$ before this ratio starts to decrease again.

Figure 3.13 (next page): Results of model series 2 - plot of ductility $D$ against total displacement for different $R^{q}$ values. Each colored line represents a different original vein thickness $t h_{\text {orig. These graphs }}$ show that there is a relationship between total displacement $\left(y_{t o t}\right)$ and vein ductility $(D)$ : the higher $y_{t o t}$, the lower $D$. It is also evident from these graphs that two different failure sequences can occur: i) ductile yield first, then brittle as for all veins in (a), ii) brittle first, then ductile as for example in (c). See text for detail. 


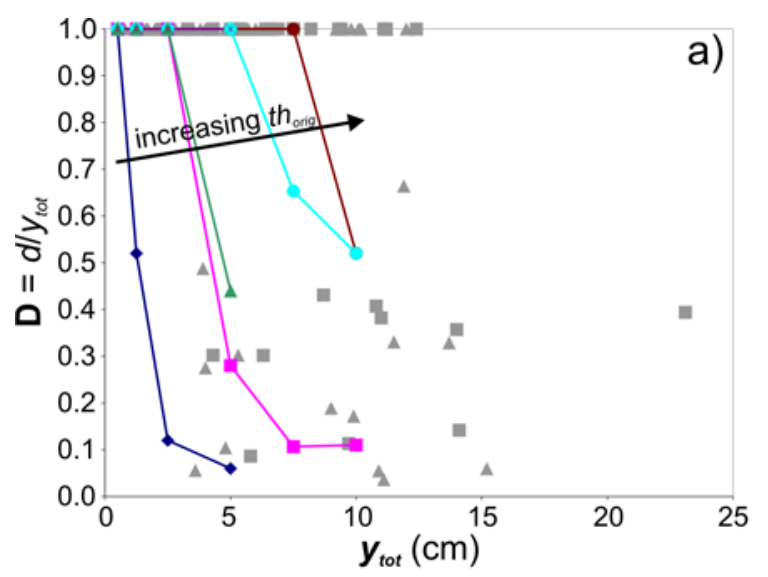

$$
\begin{array}{ll}
R^{q}=1.0 & \text { quartz veins } \\
A_{M}=6.35 \times 10^{-16} & \text { relatively weak, } \\
& \text { less viscous }
\end{array}
$$
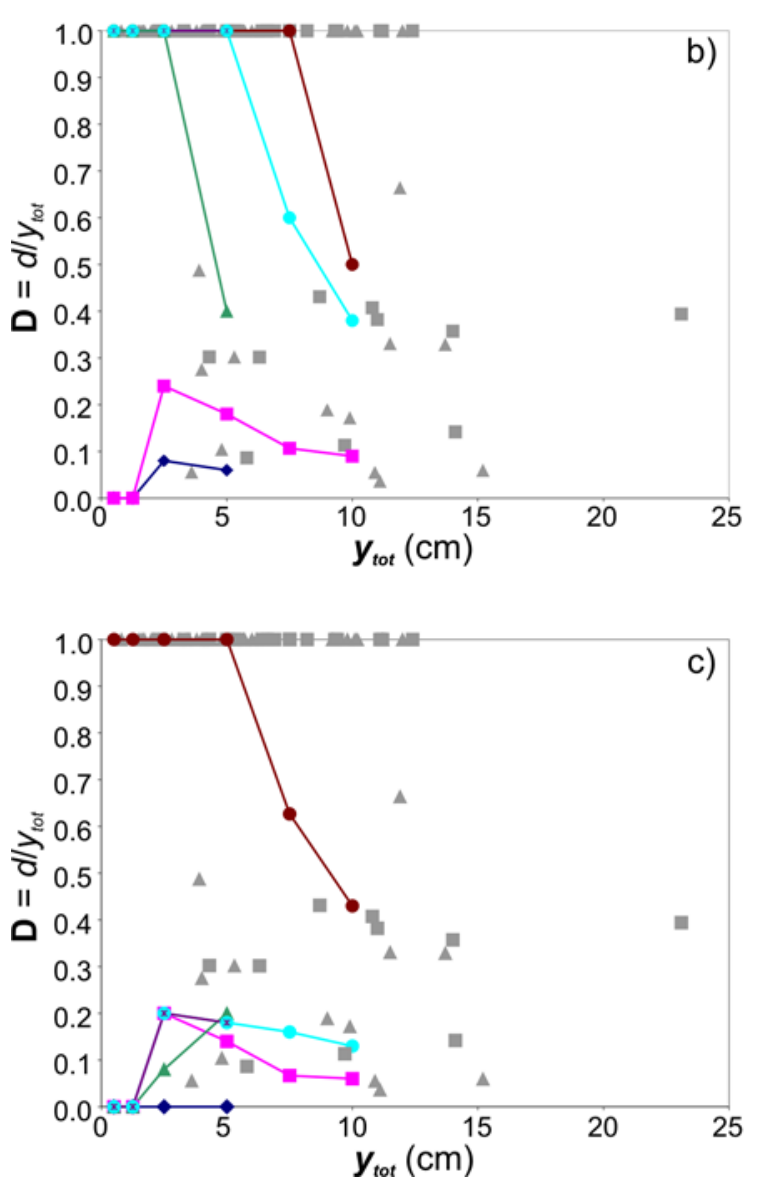

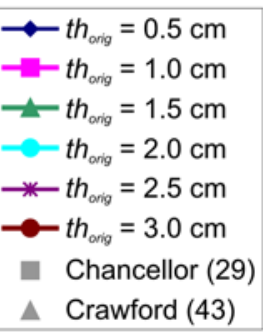

A Crawford (43)

$$
A_{M}=3.06 \times 10^{-16}
$$

$$
\begin{aligned}
& \longrightarrow t_{\text {orig }}=0.5 \mathrm{~cm} \\
& -t_{\text {orig }}=1.0 \mathrm{~cm} \\
& -t_{\text {orig }}=1.5 \mathrm{~cm} \\
& -t_{\text {orig }}=2.0 \mathrm{~cm} \\
& -t_{\text {orig }}=2.5 \mathrm{~cm} \\
& -t_{\text {orig }}=3.0 \mathrm{~cm} \\
& \text { Chancellor (29) } \\
& \Delta \text { Crawford (43) }
\end{aligned}
$$

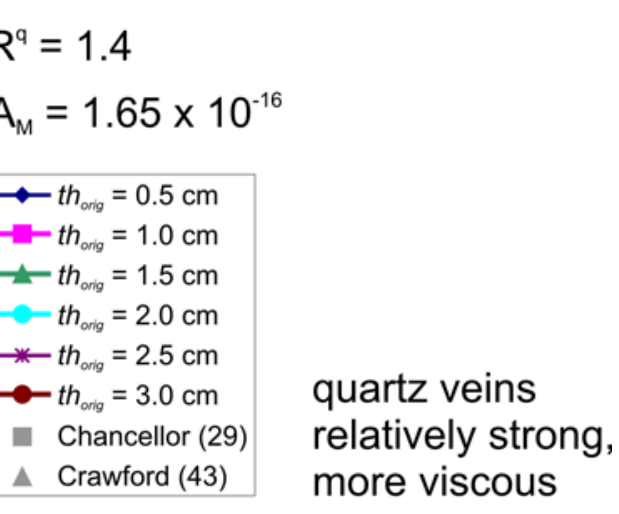

3.5.6 Results - model series 3: influence of stress exponent $n_{q}$ on deformed quartz vein shape

In model series 3 we investigate the sensitivity of the final shape of the sheared quartz veins to the stress exponent $n_{q}$ in Eq. (3.3) in the quartz veins. Again, we set up $0.1 \times 0.1 \mathrm{~m}$ models with a $2 \mathrm{~cm}$ thick horizontal quartz vein and a boundary velocity of $0.5 \mathrm{~mm} / \mathrm{yr}$. The frictional yield stress was $50 \mathrm{MPa}$ in the quartz vein. We used stress exponents of $n_{q}=1.0,2.0,3.0$, and 4.0. In order to maintain the viscous-frictional 
strength ratio $R^{q}=\tau_{v}^{q} / \tau_{f}^{q}=1.2$ in the quartz (cf. section 3.5.5), i.e., to maintain the same overall viscous strength in the quartz vein of $60 \mathrm{MPa}$, we adjusted $A_{M}$-values for different stress exponents nq according to Eq. (3.3) (Fig. 3.14; see also Kenis et al., 2004).

The schist was chosen to be fully frictional again so that this model series corresponds to cases A-C in Fig. 3.8.

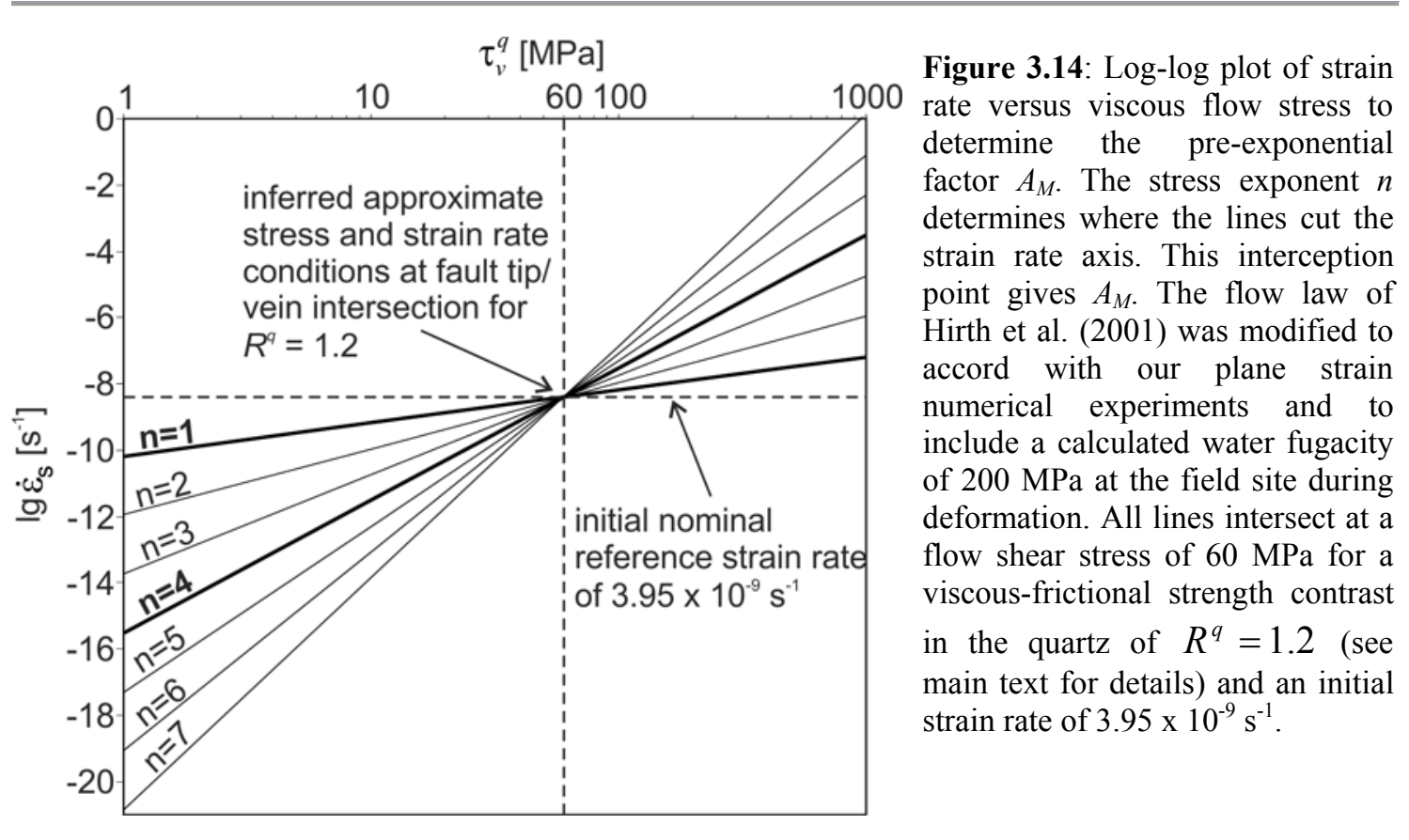

Figure 3.15 shows the results of the model runs at $2.5 \mathrm{~cm}$ and at $5.0 \mathrm{~cm}$ total displacement. Perhaps surprisingly, the stress exponent has little influence on the deformed shape of the quartz vein. For $n_{q}=1.0$ and 2.0, the subtle differences in the shapes of the quartz veins in Fig. 3.15 arise from incipient broadening or bifurcation of the brittle fault in the schist (section 3.5.4).

The reason for this insensitivity to $n_{q}$ is that, under the chosen conditions, with relatively uniform quartz strength (effective viscosity), the rheological behaviour and the shape of the deformed veins seems to be predominantly controlled by the higher viscous strength of the enclosing wall rock material (the schist), rather than by the stress exponent of the vein material (cf. section 3.5.7). 


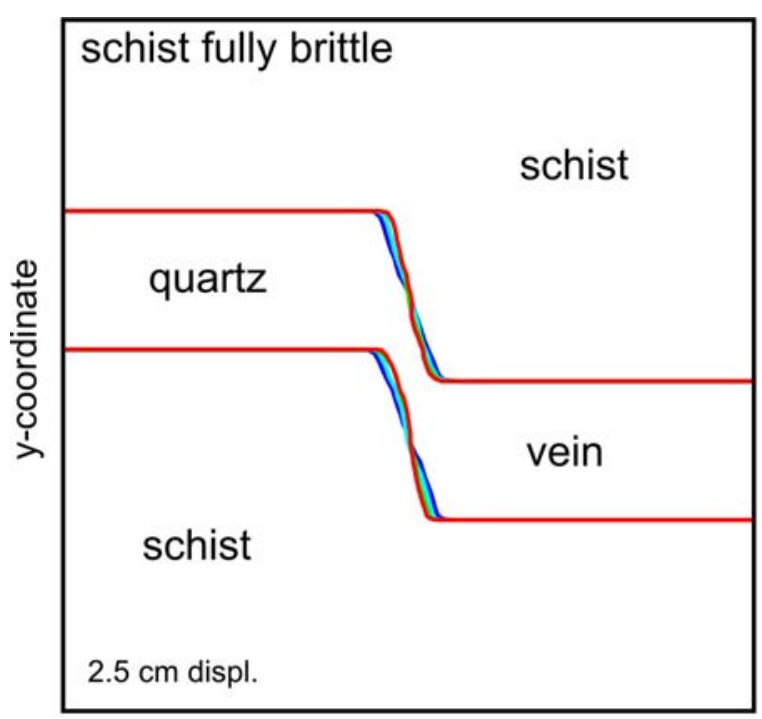

x-coordinate

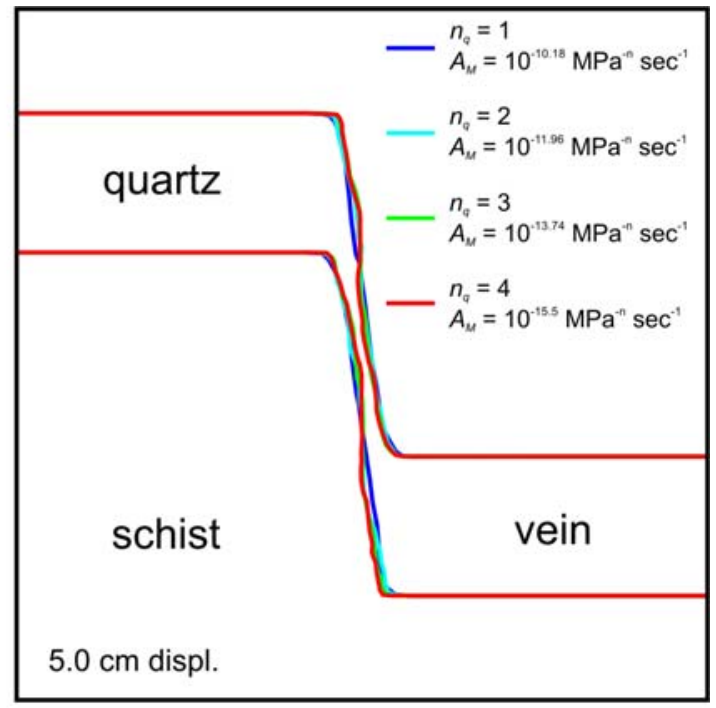

x-coordinate

Figure 3.15: Modelling results of series 3 - influence of stress exponent on shape of vein. We plotted the shape of deformed quartz veins for different stress exponents at total displacements of 2.5 and 5.0 $\mathrm{cm}$. Note the remarkably similar shape of all four veins.

3.5.7 Results - model series 4: influence of the quartz-to-schist viscous-viscous strength ratio $V^{q s}=\tau_{v}^{q} / \tau_{v}^{s}$ on the deformed vein shape

Until now we have treated the discretely faulted schist as a fully frictional material. However, locally the schist has been deformed viscously as well (e.g., in step-over zones between two adjacent faults, or at deeper structural levels towards the bottom of the shear array), so that in this section, we investigate the influence of a schist that is no longer required to fail fully frictional but can also deform viscously.

We learned from section 3.5.4 that the ratio of viscous quartz strength to frictional schist strength $\left(R^{q s}=\tau_{v}^{q} / \tau_{f}^{s}\right)$ needs to be close to 1 or slightly higher than 1 (e.g., 1.2) in order for the fault to stay localised where it transects a quartz vein, not to bifurcate, and to cause it to deflect around the outer margin of the sheared quartz vein, rather than to cut across it.

In this series of experiments, we maintained a $2 \mathrm{~cm}$ thick horizontal quartz vein with a power law rheology for all models of this section $\left(n_{q}=4.0, A_{M}^{q}=3.06 \times 10^{-16}\right.$ $\left.\mathrm{MPa}^{-\mathrm{n}} \mathrm{sec}^{-1}\right)$. In addition, the wall rock schist was assigned a power law rheology with 
$n_{s}=4.0$. For the schist, different values of $A_{M}^{s}$ were used in a series of experiments, resulting in different viscous-to-frictional strength ratios in the schist $\left(R^{s}\right)$ as is summarised in Table 3.4.

Table 3.4 Model parameters for model series 4

\begin{tabular}{ccc}
\hline$A_{M}^{s}\left(\mathrm{MPa}^{-\mathrm{n}} \mathrm{s}^{-1}\right)$ & $V^{q s}$ & $R^{s}$ \\
\hline $1.25 \times 10^{-16}$ & 0.8 & 1.5 \\
\hline $3.94 \times 10^{-17}$ & 0.6 & 2.0 \\
\hline $1.91 \times 10^{-17}$ & 0.5 & 2.4 \\
\hline $7.80 \times 10^{-18}$ & 0.4 & 3.0 \\
\hline $2.48 \times 10^{-18}$ & 0.3 & 4.0 \\
\hline
\end{tabular}

Fig. 3.16a plots the ductilely sheared width $(d s w)$ from the quartz veins against their ductile displacement $(d)$ across the shear. From this plot we conclude that the ductilely sheared width in the quartz veins is quite sensitive to the quartz-to-schist effective viscosity ratio $V^{q s}$. The stiffer the schist, i.e., the lower the ratio $V^{q s}$, the smaller is the $d s w$ in the enclosed quartz vein. This relationship follows a power law for all values of $V^{q s}$. There is a decrease in the gradient of the curves for decreasing values of $V^{q s}$.

We compared our modelling results for the $2 \mathrm{~cm}$ thick vein models with the subset of our field data embracing veins that have a thickness between 1.5 and $2.5 \mathrm{~cm}$. When the modelling predictions are compared to the field data, the two model-based curves that best envelope the corresponding field data are those for $V^{q s}$-ratios of 0.4 and 0.6 , that is, where the effective viscosity of the schist is 2.5 to 1.6 times greater than that of the quartz veins.

For this run of experiments, we also plotted the degree of vein thinning $t h_{\text {att }}$ versus the ductile slip $(d)$. However, this parameter seems less useful, as all $V^{q s}$ values seem to fit the field data approximately (Fig. 3.16b). 

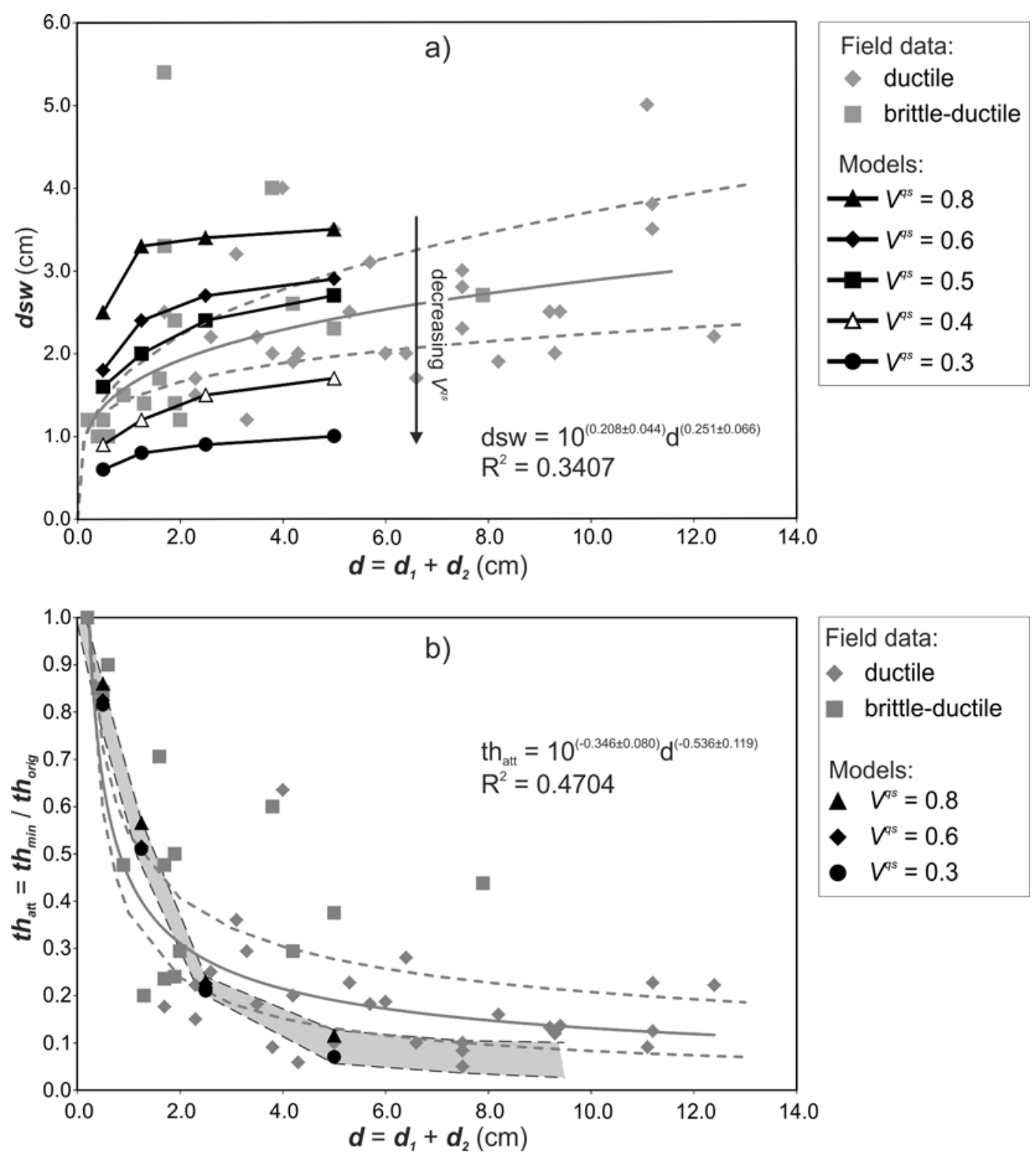

Figure 3.16: Results of model series 4 - viscosity ratio of schist and quartz. a) Plots of ductilely sheared width $(d s w)$ versus ductile component of slip $\left(d=d_{l}+d_{2}\right)$ for model vein with $t h_{\text {orig }}=2 \mathrm{~cm}$. The field data (grey) is plotted for veins with original thicknesses between 1.5 and $2.5 \mathrm{~cm}$. All curves for the models follow a power law relationship between $d$ and $d s w$. The field data is best bracketed by the curves for $0.4 \leq V^{q s} \leq 0.6$. b) Plot of vein attenuation $\left(t h_{\text {att }}\right)$ versus ductile component of slip $(d)$. It is not possible to clearly discriminate between the results for vein attenuation under different $V_{c c}$. The range of thatt values from the computer models is indicated by the grey shaded area. Measurement uncertainties are $\pm 0.2 \mathrm{~cm}$. The dashed lines correspond to the errors calculated for the trendlines

Recall that from the field data presented in section 3.4, we inferred that there is a positive scaling relationship between the original vein thickness $t h_{\text {orig }}$ and the ductile shear zone width $(d s w)$. Above, we argued that the best estimate of $V^{q s}$ is 0.5 , i.e., the 
effective viscosity of the schist is 2 times greater than that of the quartz. As a final set of experiments, we modelled the shear deformation of the quartz veins across a range of original vein thicknesses of $1.0,2.0$, and $3.0 \mathrm{~cm}$ with that $V^{q s}$-ratio. For these models we set the frictional yield stress in the quartz veins to $10 \mathrm{GPa}$ again, so that they do not yield frictionally (our way of focussing on the wholly ductilely deformed veins, which are common for veins with $t h_{\text {orig }}>2 \mathrm{~cm}$ ).

Fig. 3.17 shows the comparison of the modelling results at 2.5 and $5 \mathrm{~cm}$ total displacement. The field data was divided into two groups of ductile slip: a) $1.5-3.5 \mathrm{~cm}$ and b) 4.0-6.0 $\mathrm{cm}$ in order to make the modelling results comparable to the field data. The modelling results fit well within the field data and both suggest that there is a linear relationship between $t h_{\text {orig }}$ and $d s w$.

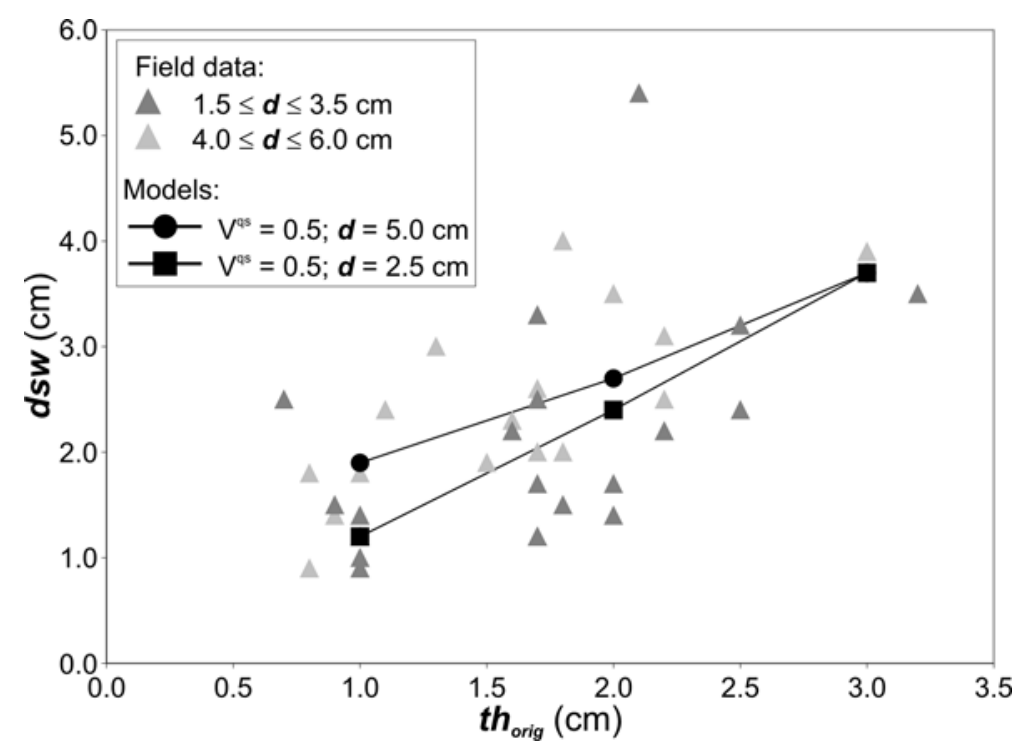

Figure 3.17: Modelling results of series $4-$ plot of $d s w$ versus $t h_{\text {orig. }}$ Results for $V^{q s}=0.5$; i.e., schist $=$ $2 \times$ quartz. There is a linear relationship between the resulting ductile shear zone width $(d s w)$ and the original vein thickness $\left(t h_{\text {orig }}\right)$. This relationship has a different slope depending on the total amount of ductile displacement $(d)$. Measurement uncertainties are $\pm 0.2 \mathrm{~cm}$.

\subsection{Discussion}

3.6.1 Shear bifurcation, energy dissipation, and frictional-viscous coupling between schist and quartz

Since the majority of the surveyed fault-vein sets shows that the faults are either nearly straight or bend around the outside margins of the sheared quartz veins, we can 
infer from model series 1 that the viscous-to-frictional strength ratio between viscous quartz and frictional schist (respectively) must have been close to $1\left(R^{q s}=1.2\right)$ or slightly higher $\left(R^{q s}=5.0\right)$; that is, very nearly balanced. Additionally, in the field we only observed a single fault close to each sheared vein. We were only able to simulate a single fully localised fault propagating towards the quartz vein without bifurcating for a viscous-frictional ratio of $R^{q s}=1.2$.

The difference in fault bifurcation and propagation behaviour between the models with a linear quartz viscosity (L-models) versus those with a power law quartz rheology (P-models) can be understood by considering the effects of energy dissipation minimisation. Both frictional and viscous energy dissipation rates increase with increasing strain rate, most markedly for non-linear viscous materials. To reduce the dissipation rate, deformation may become more spread out or diffuse in the quartz, a relationship that can encourage bifurcation of shears in the schist. For example, for the same imposed boundary slip rates and flow stress in the linear vs. power-law model (e.g., a flow stress of $60 \mathrm{MPa}$, Fig. 3.14), it can be shown that to obtain the same rate of viscous energy dissipation, a lower viscous strain-rate is needed for the linear flow-law case. A reduction in strain-rate can most easily be attained by widening the ductile shear width. The statements above follow from the observation that viscous energy dissipation rate (per unit volume) in a power law material is proportional to the strain rate and depends on the stress exponent:

$$
\dot{w}_{v} \propto \dot{\varepsilon}_{s}^{1+1 / n}
$$

(e.g., Malvern, 1969, p. 300), where $\dot{w}_{v}$ is the viscous energy dissipation rate, $\dot{\varepsilon}_{s}$ is shear strain rate, and $n$ is the stress exponent. Fig. 3.18 depicts the physical meaning of Eq. (3.6) schematically: the higher the value of $n$, the closer to linearity the relationship between dissipation rate and strain rate (Fig. 3.18), which means that where $n>1$ an increase in strain-rate causes a lesser increase in energy dissipation rate compared to the equivalent case with lower stress exponent $(n=1)$. 


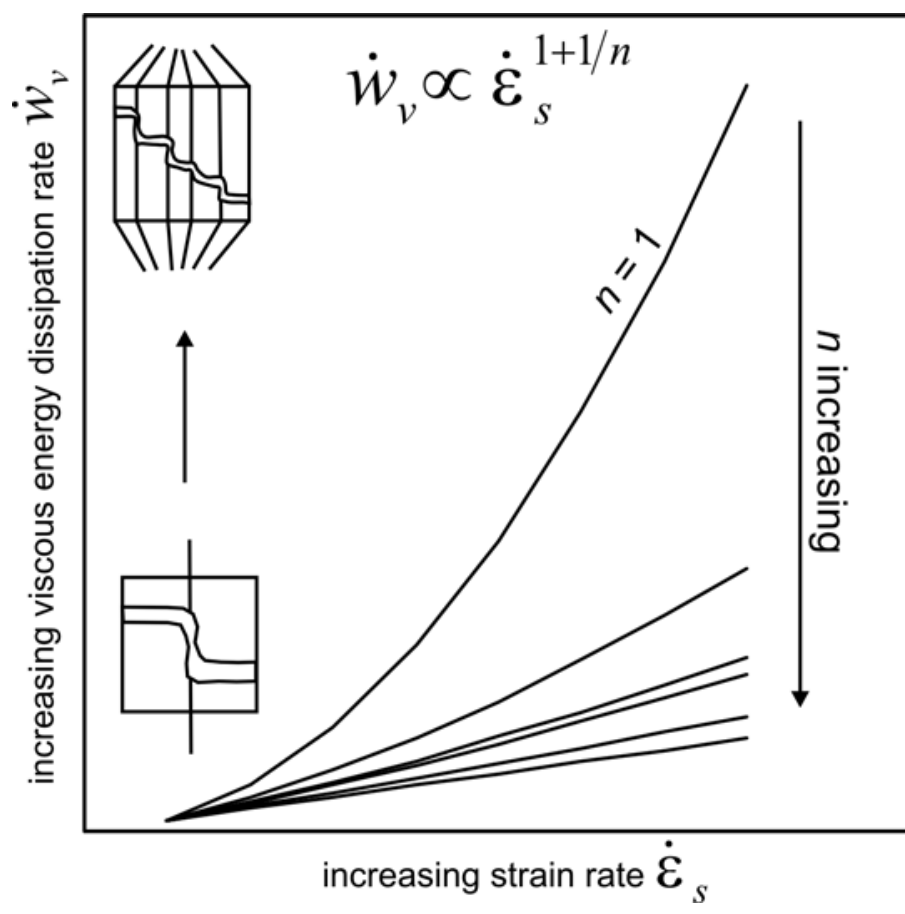

Figure 3.18: Schematic plot of eq. (3.6), viscous energy dissipation rate $\dot{w}_{v}$ versus shear strain rate $\dot{\varepsilon}_{s}$. Viscous energy dissipation is slower for higher stress exponents $n$. More brittle faults form for higher dissipation rates. The biggest difference in energy dissipation rate is between $n=1$ and all stress exponents that are higher than 1 . This explains the discrepancies between the L- and the P-models in section 3.5.4.

Considering an isolated shear with a constant yield strength in the schist, the total frictional energy dissipation rate (per unit volume) is linearly proportional to the strain rate $\dot{\varepsilon}_{s}$ and depends on the shear stress $\tau$ :

$$
\dot{w}_{f} \propto \tau \cdot \dot{\varepsilon}_{s}
$$

where $\dot{w}_{f}$ is the frictional energy dissipation rate. The bifurcation of one shear results in two shears that each move at only half of the total strain rate. In other words, the frictional dissipation rate also depends on the number of shears $\left(N_{\text {shears }}\right)$ that form ( $\left.\dot{w}_{f} \propto \tau \cdot \frac{\varepsilon_{s}}{N_{\text {shears }}}\right)$. This is a way to reduce the energy dissipation in the schist. Integrated over the whole volume, however, the frictional energy dissipation rate for the same system split into two or many shears is the same, so that there is no inherent tendency of a frictional material to localise (e.g., Huismans et al., 2005). It is only with the imposition of strain softening that localisation of frictional shearing onto one through-going shear becomes favoured. Since the schist is inferred to be a strainsoftening frictional material, the lowest energy configuration for the schist after softening has occurred and at high strain rates will be along narrow and strongly localised shears or faults (e.g., Huismans et al., 2005). Therefore, a competition exists 
between the "lowest energy dissipation configuration" for ductile vs. brittle materials; that is, localisation in the frictional schist and diffuse deformation in the viscously shearing quartz.

For the frictional-viscously coupled quartz vein-fault sets in the Southern Alps, the frictional and viscous energy dissipation rates must have been nearly equal, since the faults that offset the quartz veins are very well localised (and they do not bifurcate in the vicinity of the quartz veins). This energy balance is also reflected in the modelling results: as we found that it was possible to achieve fault localisation from the earliest stages of deformation when the viscous-frictional (quartz-schist) strength contrast $R^{q s}$ was close to 1 . These results are supported by the numerical model series of Schueller et al. $(2005,2009)$ who found that it is possible to achieve plastic strain localisation in a brittle material bracketed by two ductile layers for low to medium viscosities of the ductile material. An $R^{q s}$-ratio of around 1 in our models would correspond to a viscosity of $\sim 100$ in the models of Schueller et al. (2005); the upper end of their "viscosity-dependent mode".

\subsubsection{Brittle-ductile transition in quartz veins}

When compared to the field data in Fig. 3.6c and 3.6d, the numerical models with the frictional-viscous ratio $R^{q}=1.2$ for quartz best simulate the scaling relationships observed in the field. Fig. 3.6c and 3.6d showed that the $D$-ratios of the majority of the veins with a brittle slip component lie below 0.5. The models in section 3.5.5 may provide one reason for this behaviour. We showed that there are two paths to producing vein displacements that have both brittle and ductile slip components: a) distributed ductile vein deformation first, followed by extreme vein attenuation, followed by brittle failure of the quartz vein or b) localised brittle failure first, followed by ductile shearing of the quartz vein in the areas of reduced strain rates that are away from the central shear zone (where strain rates are high). The question remains whether the brittle faults formed first or whether the distributed ductile shearing was first. If we assume that both failure sequences could have been present in the quartz veins, we can argue that $R^{q}=$ 1.2 is the best estimate for these quartz veins.

We could explain that $D<0.5$ for most of the brittle-ductile quartz veins by assuming that frictional slip continued to accumulate after brittle failure of the quartz veins. Soon after brittle failure of a quartz vein, ductile slip $(d)$ stops whereas the total 
slip $\left(y_{t o t}\right)$ continues to increase by frictional slip. Since $D=d / y_{t o t}$, this results in the ductility $D$ asymptotically approaching zero with increasing $y_{\text {tot }}$. If this hypothesis proves true, $y_{\text {tot }}$ was high enough compared to $d$ to result in $D<0.5$ for most brittleductile quartz veins in the study area.

\subsubsection{Stress exponent in the quartz veins}

At first we were surprised to find in our model series 3 that the choice of stress exponent in the quartz flow law did not have an influence on the resulting shape of the sheared quartz veins (section 3.5.6). Following the work of Talbot et al. (1999) and Kenis et al. (2004), we expected the shape of the quartz veins (in particular the ductile shear zone width) to carry information about the stress exponent and therefore also about the deformation mechanism. For example, if the modelling results suggested that $n_{q}=1$ for our field observations, then we would infer that the veins were probably deformed by diffusion creep or solution-precipitation creep. By contrast, if $n_{q} \gg 1$, we would conclude that the main deformation mechanism prior to static localisation was dislocation creep (cf. section 3.1). Our modelling suggests that even if there were a change in deformation mechanism, the macroscopically observed shape of a quartz vein would not reflect this transition because as shown in Fig. 3.15, the stress exponent (e.g., $n_{q}=1$ or $\left.n_{q}=4\right)$ in the quartz does not significantly influence the shape of the sheared vein as long as the surrounding schist is stronger than the quartz. Talbot (1999) describes the influence of the stress exponent on the width of a shear zone: the higher the stress exponent $n$, the narrower the shear zone. However, Talbot (1999) investigates shear zones in homogeneous, fully viscous materials, whereas our models include two materials (quartz and schist) with two different rheologies (viscous vs. frictional). Our data reveal that as soon as there is some frictional behaviour involved in the shearing of a transverse marker, the relationship between $n$ and shear zone width $(d s w)$ and deformed marker shape is no longer simple.

\subsubsection{Viscosity contrast between schist and quartz}

That the quartz veins in our study area are typically deformed in a ductile way, whereas the schist is brittlely displaced across narrow shear cracks leads to an inference that the schist was viscously stronger than the unfaulted quartz veins embedded within it. The stiffer schist reacted to the brittle yield criterion whereas the softer, flowing 
quartz veins did not. In section 3.5.7 we were able to constrain the viscosity ratio between schist and quartz to $0.4<V^{q s}<0.6$. This means that the schist had approximately twice the ductile strength of the quartz veins during shearing. This strength contrast is surprisingly small, but is in agreement with other rheological studies, that derived viscosity contrasts of 1-10 between quartz and psammite materials (e.g., Treagus, 1999; Treagus and Treagus, 2002, and references therein; Kenis et al., 2004). We have shown that, even at a small viscosity contrast between schist and quartz vein, the rheology of the stronger material (schist) controls the resulting shape of the weaker material (quartz).

\subsubsection{Estimation of quartz flow parameters constrained by modelling}

The determination of the viscous-to-frictional strength contrasts of ductile quartz and brittle schist and of viscosity ratios of those two rock materials enables us (under certain assumptions) to calculate a minimum and maximum pre-exponential factor $A_{E}$ for the quartz veins across the full range (maximum and minimum) of possible mean slip rates for the shear array (cf. section 3.4). Based on a Mohr-Coulomb failure criterion, we could assume a minimum frictional yield strength in the quartz veins and the schist of $\tau_{f}^{q}=\tau_{f}^{s}=50 \mathrm{MPa}$. Using the previously determined viscous-to-frictional strength ratios that best fit our field data $\left(R^{q s}=\frac{\tau_{v}^{q}}{\tau_{f}^{s}}=1.2\right.$, and $\left.R^{q}=\frac{\tau_{v}^{q}}{\tau_{f}^{q}}=1.2\right)$, we calculate from our models and field data a best-fit viscous quartz flow strength of $\tau_{v}^{q}=$ $60 \mathrm{MPa}$. The minimum slip rate estimate for the brittle-ductile shears was $1.4 \times 10^{-4}$ $\mathrm{mm} / \mathrm{yr}$ and the maximum estimate was $2 \mathrm{~mm} / \mathrm{yr}$ resulting in natural (= model) shear strain rates of $2.7 \times 10^{-12} \mathrm{~s}^{-1}$ and $3.18 \times 10^{-8} \mathrm{~s}^{-1}$ in the shears respectively. Assuming a stress exponent $n_{q}=4$ and inserting those values into Eq. (3.3) gives $A_{M}=2.08 \times 10^{-19}$ $\mathrm{MPa}^{-\mathrm{n}} \mathrm{s}^{-1}$ for the slowest (all shears active) and $A_{M}=2.45 \times 10^{-15} \mathrm{MPa}^{-\mathrm{n}} \mathrm{s}^{-1}$ for the fastest strain rate (one shear active). In a triaxial deformation experiment, the calculated natural minimum and maximum shear strain rates would correspond to $3.12 \times 10^{-12} \mathrm{~s}^{-1}$ and $3.67 \times 10^{-8} \mathrm{~s}^{-1}$. Excluding water fugacity, these strain rates would result in $A_{E} \approx 10^{-12}$ $\mathrm{MPa}^{-\mathrm{n}} \mathrm{s}^{-1}$ and $A_{E} \approx 10^{-8} \mathrm{MPa}^{-\mathrm{n}} \mathrm{s}^{-1}$.

In combination with numerical modelling, we were able to derive a flow law for quartz from a) the interaction between brittle faults and quartz veins that have been 
ductilely-to-brittlely offset across those faults and from b) geometrical scaling relationships in those sheared quartz veins:

$$
\dot{\varepsilon}=10^{-10 \pm 2} \cdot f_{\mathrm{H}_{2} \mathrm{O}} \cdot \sigma_{d}^{4.0} \cdot \exp \left(\frac{135 \mathrm{~kJ} \cdot \mathrm{mol}^{-1}}{R T}\right)
$$

where $\dot{\varepsilon}$ is the uniaxial strain rate, $f_{\mathrm{H}_{2} \mathrm{O}}$ is water fugacity, $\sigma_{d}$ is differential stress, $n$ is the stress exponent, $R$ is the universal gas constant, and $T$ is temperature. In Fig. 3.19 , we plotted this flow law using a geological strain rate of $\dot{\varepsilon}=1.0 \times 10^{-14} \mathrm{~s}^{-1}$ (at this strain rate, Fig. 3.19 can be compared to Fig. 1.1 in section 1.2).

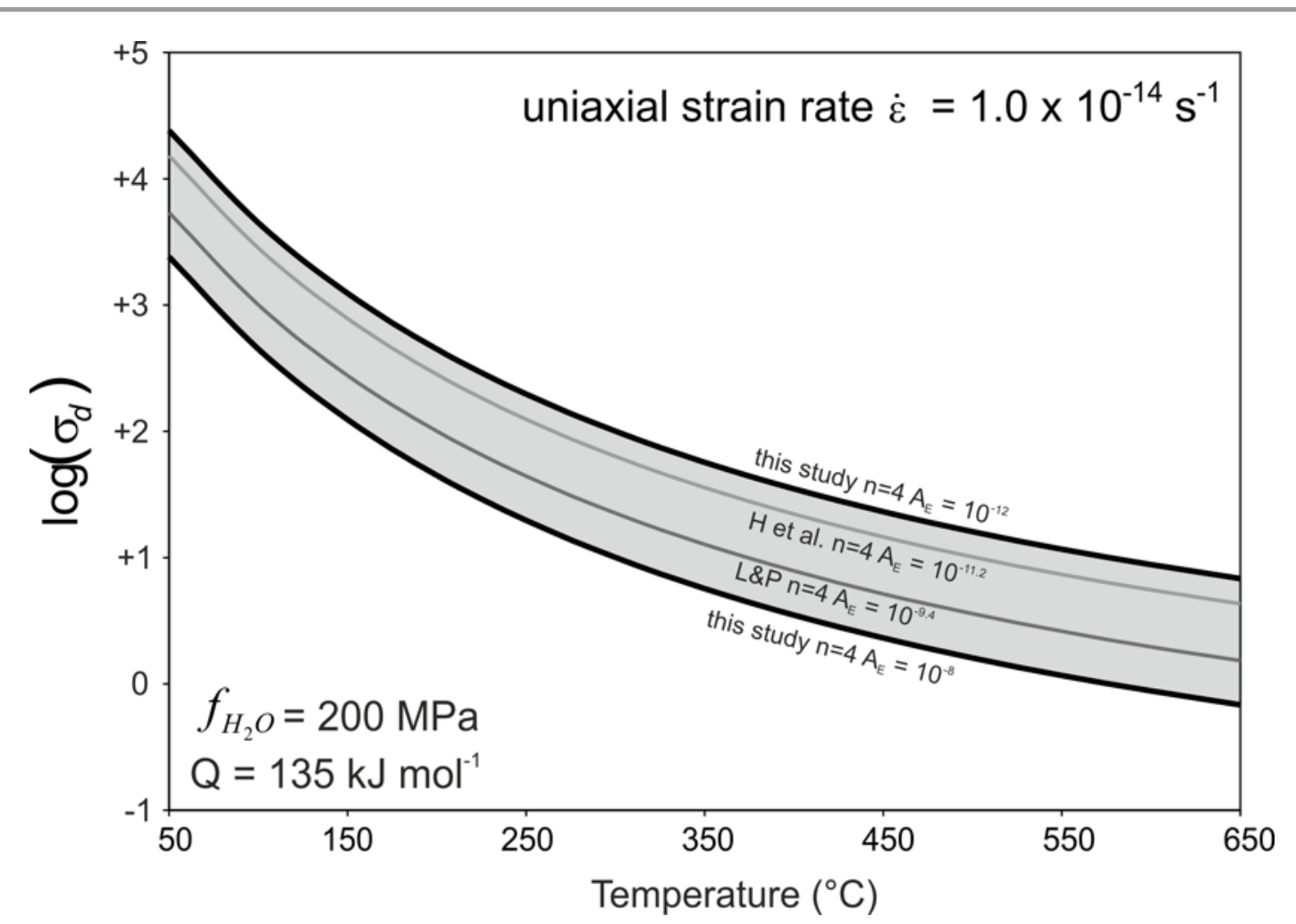

Figure 3.19: Plot of differential stress versus temperature using eq. (3.1) with the flow law parameters that were derived for the quartz veins in this study. Plotted for a natural strain rate of $1.0 \times 10^{-14} \mathrm{~s}^{-1}$ (compare to Fig. 1.1 in section 1.2). Flow laws of Hirth et al. (2001) and Luan and Paterson (1992) are shown for comparison. Both published flow laws fall within the grey shaded area that indicates the range of differential stresses that are possible with our flow law parameters at that fixed strain rate. $A_{E}=$ preexponential factor; $n=$ stress exponent for quartz.

For comparison, we also plotted the laboratory-derived flow law of Luan and Paterson (1992) and the partly geologically derived flow law of Hirth et al. (2001). These flow laws are frequently used to describe the viscous behaviour of the Earth's crust. The flow law that resulted from this study and the ones by Luan and Paterson (1992) and Hirth et al. (2001) all have a stress exponent of $n=4.0$. Luan and Paterson's 
as well as Hirth et al.'s flow laws predict $Q=135 \mathrm{~kJ} \mathrm{~mol}^{-1}$, which we adapted for our models so we can directly compare them. Fig. 3.19 shows that our results bracket the flow laws by Luan and Paterson (1992) and Hirth et al. (2001). We therefore conclude that (under certain assumptions) experimentally derived flow laws can be used to describe the rheology of quartz, at least in the neotectonically deformed quartz veins from the Southern Alps, New Zealand.

\subsection{Conclusions}

The newly exhumed fault-vein arrays in the central Southern Alps, New Zealand provide a valuable natural laboratory for the investigation of quartz rheology and the interaction between viscous and brittle deformation. By comparing numerical models to field-based scaling relationships that were measured in ductilely to brittlely sheared quartz veins, we have derived two important ratios relating to the effective rheology of natural quartz veins: we concluded that due to the principles of energy dissipation minimisation the viscous-to-frictional strength ratio between ductile quartz veins and brittle host schist $R^{q s}=\tau_{v}^{q} / \tau_{f}^{s}$ must lie between 1.0 and 5.0, in order to form a single localised fault, and in order for that fault to bend around the margin of the deforming quartz vein rather than cutting across the vein. We further conclude that the viscous-tofrictional strength ratio inside the quartz veins $\left(R^{q}=\tau_{v}^{q} / \tau_{f}^{q}\right)$ needs to be between 1.2 and 1.4 in order for the models to simulate that veins with original thicknesses greater than $2 \mathrm{~cm}$ commonly remained partly to fully unbroken or ductile up to a displacement of $\sim 7.5 \mathrm{~cm}$, whereas veins of less than $2 \mathrm{~cm}$ thickness commonly are fractured and include a significant brittle component of slip as well.

We conclude that we cannot use the macroscopic deformed shape of the sheared quartz veins by itself to deduce operative flow law parameters such as the stress exponent for the quartz veins. In our numerical models, we were only able to attain planar fault localisation at its intersection with a quartz vein (as observed in the field) when that quartz vein had a power law stress exponent of $n_{q}=4$. We assume therefore that $n_{q}$ was probably closer to 4 than to 1 . This means that the quartz veins in our study area probably deformed by dislocation creep rather than diffusional or dissolution processes. We further conclude that the viscous quartz material controls the propagation and bifurcation behaviour of the fault in a purely frictional schist. 
We can, however use the scaling relationship between ductile shear zone width in the quartz vein and ductile displacement of the quartz vein to deduce a viscosity ratio between the quartz veins and the surrounding host schist. We have demonstrated that in an environment where the schist may deform viscously as well as frictionally, the viscosity contrast $V^{q s}$ between quartz and schist seems to be the major control on the final shape of the sheared quartz veins. Our models predict that the schist host rock to the shears was effectively ca. 2 times more viscous than the quartz veins embedded in that schist $\left(0.4 \leq V^{q s} \leq 0.6\right)$.

Using the viscous-to-frictional and viscous-to-viscous ratios between schist and quartz, and assuming a minimum frictional yield strength for both materials, the schist and the quartz, as well as a stress exponent of 4 for the quartz, we are able to calculate a range of pre-exponential factors that seem to fit our field data well. If water fugacity is included in the flow law, this set of flow law parameters envelopes published experimentally derived flow laws. We therefore conclude, that laboratory derived flow laws are applicable to the naturally deformed quartz veins in the Southern Alps of New Zealand. Although we confirm that experimentally derived flow laws for quartz are applicable to the quartz veins in our study area, they may not be valid for quartz in the highly strained rocks of the Alpine Fault mylonite zone, where the deformational history and the preservation of an early high temperature fabric in these mylonites influenced the later flow behaviour and development of the final CPO (e.g., Toy et al., 2008). 


\section{Glossary}

$\dot{\varepsilon}, \dot{\varepsilon}_{s} \quad$ uniaxial strain rate, shear strain rate

$\sigma_{d}, \tau \quad$ differential stress, shear stress

$\tau_{v}^{q}, \tau_{v}^{s} \quad$ viscous flow stress in quartz, schist

$\tau_{f}^{q}, \tau_{f}^{s} \quad$ frictional yield stress in quartz, schist

$n$

stress exponent

$A_{E} \quad$ experimentally derived pre-exponential factor

$A_{M} \quad$ pre-exponential factor used in models

$R^{q s} \quad$ ratio $\tau_{v}^{q} / \tau_{f}^{s}$, viscous-to-frictional strength contrast between quartz and schist

$R^{q}, R^{s} \quad$ ratios $\tau_{v}^{q} / \tau_{f}^{q}, \tau_{v}^{s} / \tau_{f}^{s}$, viscous-to-frictional strength contrast in quartz, schist

$V^{q s} \quad$ ratio $\tau_{v}^{q} / \tau_{v}^{s}$, viscous-to-viscous strength contrast between quartz and schist

$y_{\text {tot }} \quad$ total displacement or slip

$b \quad$ brittle component of displacement or slip

$d \quad$ ductile component of displacement or slip $\left(d_{1}+d_{2}\right)$

D ratio $d / y_{\text {tot }}$

$\mathrm{d} y / \mathrm{d} t \quad$ differential velocity or total slip rate

$\dot{y}_{\min }, \dot{y}_{\max }$ minimum, and maximum field-based slip rate estimates

$d s w \quad$ ductilely sheared width

th orig original vein thickness

$t h_{\text {min }} \quad$ minimum vein thickness

$t h_{\text {att }} \quad$ attenuation ratio $t h_{\text {min }} / t h_{\text {orig }}$ 


\section{Appendix 3.A - The choice of initial flow law for the quartz veins}

Wightman at al. (2006) and Hill (2005) have investigated crystallographic preferred orientations (CPOs) in the deformed quartz veins at the studied sites of Crawford Knob and Chancellor Ridge. They have described the CPOs as being very weak to random. This is surprising considering the observed high shear strains of 5-15. The model for quartz vein deformation by Wightman et al. (2006) suggests a late increment of diffusion creep-accommodated grain boundary sliding which may have weakened or randomised a pre-existing CPO in the veins. Diffusion creep is a grain size sensitive flow mechanism and usually requires low differential stresses and a small grain size. To our knowledge, diffusion creep has only been detected and described in ultrafine grained $(<4.5 \mu \mathrm{m})$ quartz by the deformation experiments of Brodie and Rutter (2000) and Rutter and Brodie (2004a). The model of Wightman et al. (2006) essentially describes three stages in the deformation of the veins: a) grain-size reduction through dynamic recrystallisation (i.e., dislocation creep) during shearing of the rocks, b) a stress-drop once the shearing stopped, i.e., once the rocks have passed the foot of the Alpine Fault ramp, c) grain growth through static recrystallisation (annealing) while the rocks are being shifted upwards along the ramp. Small grain sizes after phase a) and the waning differential stress in b) may have induced a change in deformation mechanism from dislocation creep to diffusion creep-accommodated grain boundary sliding and hence randomisation of the CPO.

In order to preselect an initial flow law for input into the numerical models (main text) we have investigated several published grain size sensitive (GSS) and grain size insensitive (GSI) flow laws as well as grain size - stress relationships (paleopiezometers) for quartz against the background of the geological setting of the Southern Alps (inset in Fig. 3.A-1a). For these models we assumed an Alpine Fault dip of $45^{\circ}$, a convergence rate of $11 \mathrm{~mm} / \mathrm{yr}$, and a temperature gradient of $\sim 21^{\circ} \mathrm{C} / \mathrm{km}$ (resulting in a temperature of $450^{\circ} \mathrm{C}$ at $21 \mathrm{~km}$ depth; Fig. 3.A-1a). The linear temperature gradient simplifies the true thermal structure beneath the Southern Alps in that the gradient is thought to steepen to up to $95^{\circ} / \mathrm{km}$ in the Franz Josef area closer to the Alpine Fault and closer towards the Earth's surface (e.g., Shi et al., 1996). In agreement with the entrapment fluid pressure that was measured in primary fluid inclusions in the shear-infilling veins ( $\sim 310 \mathrm{MPa}$, cf. main text and Wightman, 2005), the ratio fluid pressure / lithostatic pressure was set to $\lambda=0.6$ (Fig. 3.A-1a). It was also 
assumed that the escalator model of Little (2002a) could be used to simulate the evolution of the brittle-ductile fault array, and that only one shear was active at a time and that shearing continued until this shear reached the surface (depth $=0 \mathrm{~km}$ ).

In order to justify the choice of a dislocation creep flow law as input into the numerical models (main text), we demonstrate how different the amounts of shear strain are, that are accumulated over a time period of 0.5 Myrs through 1) a grain size independent dislocation creep flow law, and 2) a grain size dependent diffusion creep flow law. We used the dislocation creep flow law of Hirth et al. (2001), the diffusion creep flow law of Brodie and Rutter (2000) and the paleopiezometer of Stipp and Tullis (2003) in order to investigate the contribution of GSI and GSS flow to the accumulated shear strain. Table 3.A-1 summarises the parameters that were used to calculate strain rates and accumulated strains.

Since both flow laws include a water fugacity term, and since water fugacity is temperature and pressure dependent, we used a "water fugacity calculator" that is available on a webpage by the University of Minnesota (http://www.geo.umn.edu/people/researchers/withe012/fugacity.htm) and is based on the equation by Pitzer \& Sterner (1994), in order to calculate the water fugacities for these temperature and pressure values.

Table 3.A-1 Flow law parameters that were used to calculate accumulated strain by GSS and GSI processes. Note that $A_{M}$ includes the geometrical factor that converts triaxial data to plane strain simple shear. $A_{M}$ does however not include water fugacity since fugacity changes with depth.

\begin{tabular}{|c|c|c|c|c|c|}
\hline & Equation & $\begin{array}{c}\mathbf{A}_{M} \\
\left(\mathrm{MPa}^{-\mathrm{n}} \mathrm{s}^{-1}\right) \\
\end{array}$ & $\mathbf{n}$ & $\mathbf{r}$ & $\begin{array}{c}\mathrm{Q} \\
(\mathrm{kJ} / \mathrm{mol}) \\
\end{array}$ \\
\hline $\begin{array}{l}\text { GSI flow law } \\
\text { (Hirth et al., 2001) }\end{array}$ & $\dot{\gamma}=A_{M} \tau^{n} \exp$ & $4.92 \times 10^{-11}$ & 4.0 & --- & 135 \\
\hline \multirow[t]{2}{*}{$\begin{array}{l}\text { GSS flow law } \\
\text { (Brodie and Rutter, } \\
\text { 2000) } \\
\end{array}$} & $\dot{\gamma}=A_{M} \tau^{n} \exp$ & 0.945 & 1.0 & 2.0 & 220 \\
\hline & Equation & $\begin{array}{c}A \\
\left(\mathrm{MPa} \mu \mathrm{m}-{ }^{1 / \mathrm{m}}\right)\end{array}$ & $\mathbf{k}$ & & \\
\hline $\begin{array}{l}\text { Paleopiezometer } \\
\text { (Stipp and Tullis, } \\
\text { 2003) }\end{array}$ & $d_{g}=\left(\frac{\sigma_{d}}{A}\right)^{-1 / k}$ & 3630.78 & 1.26 & & \\
\hline
\end{tabular}


a) $\quad \mathrm{T}\left({ }^{\circ} \mathrm{C}\right), \mathbf{f}_{\mathrm{H} 2 \mathrm{O}}(\mathrm{MPa}), \mathrm{P}_{\text {litht }}(\mathrm{MPa}), \mathrm{P}_{\text {eft }}(\mathrm{MPa})$

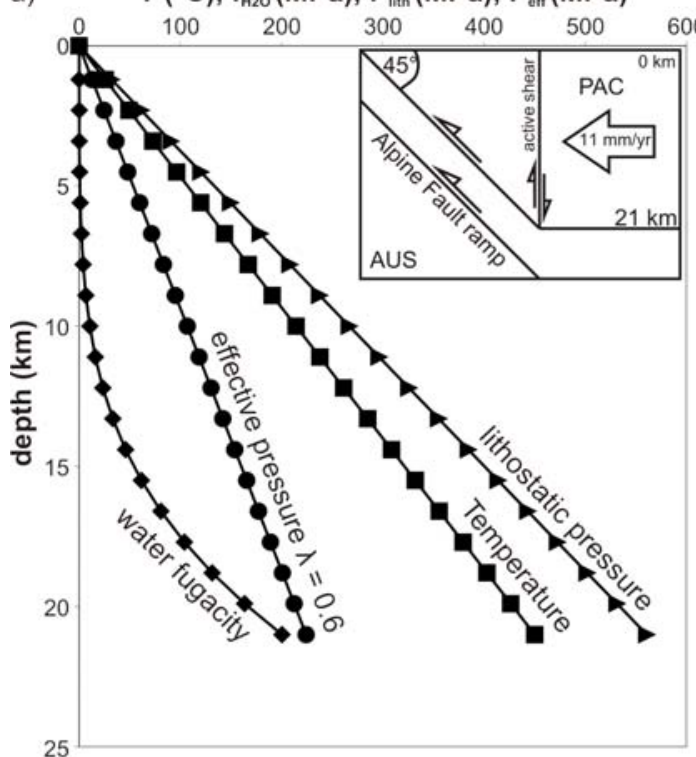

Figure 3.A-1: a) Simplified PT-conditions that could have prevailed during the activity of a shear. We also plotted water fugacity according to the changes in pressure and temperature following the equation of Pitzer and Sterner (1994). Inset: kinematic setting in the Southern Alps that was used to calculate pressures, temperatures and strain rates. b) plot of shear strain that was accumulated by grain size insensitive power law creep during 0.5 Myrs of shearing under changing water fugacity, temperature, and effective pressure conditions. c) plot of shear strain that was accumulated under the same conditions as (b) but by grain size sensitive creep (linear creep law) also in 0.5 Myrs. Note that in (c), 50000 times less shear strain than in (b) is accumulated. b)

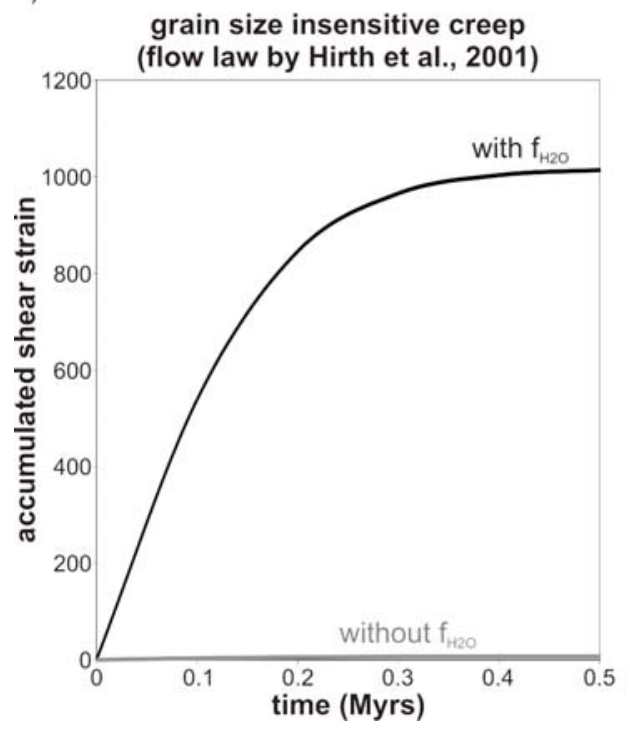

c)

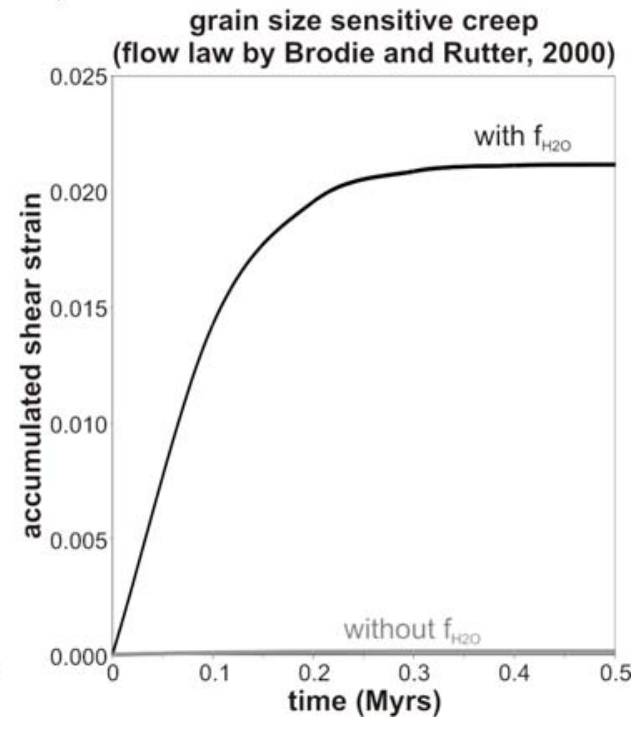

The graphs in Figs. 3.A-1b and 3.A-1c show clearly that the GSI accumulated shear strain is approximately 50000 times higher than the shear strain that was accumulated by GSS creep. The maximum shear strain that is achieved by grain size sensitive creep is $\sim 0.02$ using the paleopiezometer by Stipp and Tullis (2003) to calculate the corresponding grain sizes. The fraction of shear strain that is contributed to the total accumulated shear strain by GSS creep is therefore negligible. To match our field data, we would have required a shear strain of at least 2 .

We therefore conclude that even if diffusion creep-accommodated grain boundary sliding had been active at some stage in the deformation of the veins, it barely 
contributed to the high strains in the veins, and would therefore not affect the deformed vein shapes observed in the field. We further conclude that GSI dislocation creep seems to be the dominant deformation mechanism during shearing of the veins, and that this deformation mechanism is responsible for the high shear strains and deformed vein shapes. We therefore used the GSI power law by Hirth et al. (2001) as an initial flow law input in the numerical models in this study.

\section{Appendix 3.B - Strain softening used in models}

In general, the faults that displace the quartz veins and Alpine Schist host rocks are narrow ( $\sim 2 \mathrm{~mm}$ wide) and planar, and are inferred to have propagated as cracks through the brittle schist to the quartz veins (section 3.5.3.1). In order to achieve crack propagation and fault localisation in the schist in the models, the brittle material (schist) needs to be strain softened. We ran four preliminary models (S1, S2, S3, S4) to find a plausible strain softening case resulting in a model that is able to simulate our field observations: a well-formed, narrow, straight fault (even at mm-scale offset) that has propagated as a crack to the quartz vein. In these models we varied a) the total amount of strain softening and $b$ ) the strain softening gradient (Fig. 3.B-1). The results of these models show that the fault localisation in the schist depends primarily on the slope of the stress-plastic strain curve (models S1, S2, S4 in Fig. 3.B-1) rather than the total absolute value of the softened yield strength (models S2, S3 in Fig. 3.B-1). The steeper the strain softening gradient is, the more localised and the further propagated is the shear. If the gradient is very steep as in S1, however, the shear is not well localised at the intersection with the quartz vein. For a shallow gradient (S4), the fault has not reached the quartz vein yet after $1 \mathrm{~mm}$ of displacement, and deformation is more diffuse than in the other cases. The results for cases S2 and S3 are very similar since both have the same softening gradient. The absolute value of the softened yield strength does not matter. For all the models in the main modelling series (1 to 4) presented in this paper, we chose softening case S2 (bold line in Fig. 3.B-1), so that the brittle fault is fully established after a maximum of $1 \mathrm{~mm}$ total displacement corresponding to a plastic strain of $\sim 0.1$. 


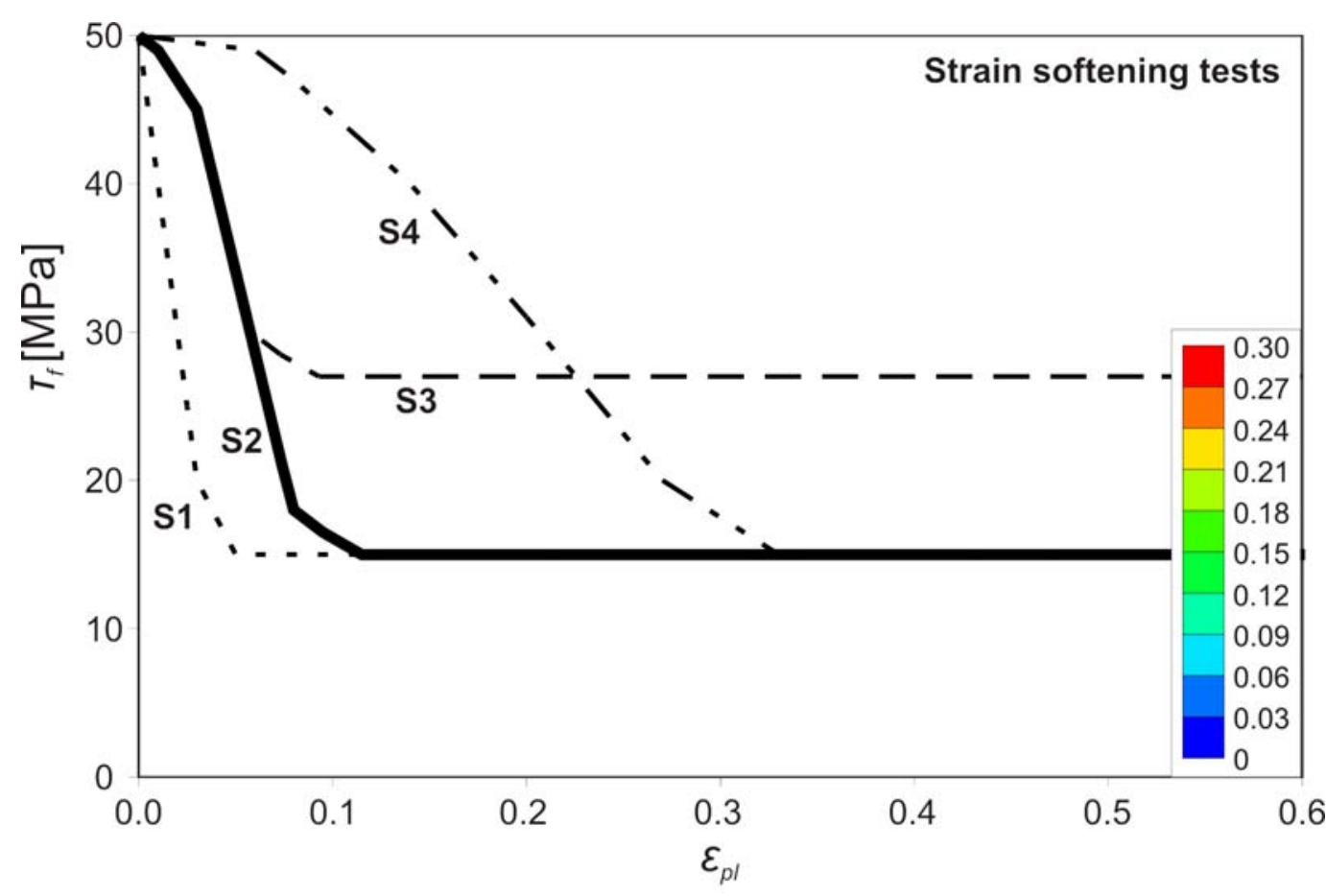

Results:

softening case used in models
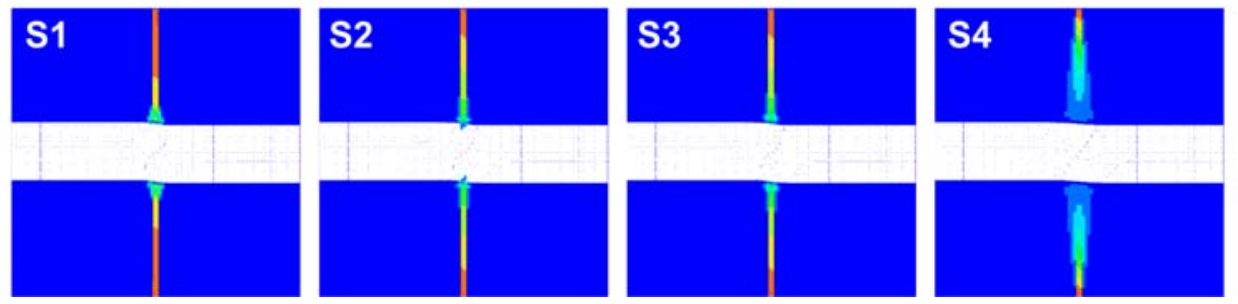

Figure 3.B-1: Strain softening tests. The graph represents frictional yield stress plotted against plastic strain in a series of experiments. We chose to use the strain softening case that is represented by the bold black line in the models (S2), since it best represents our field observations. Results are contour plots of plastic strain after 2 years of shearing (corresponding to $1.0 \mathrm{~mm}$ displacement). Note how the models with the steeper softening gradients have already fully established fault zones whilst the fault in the model with the shallower gradient has not propagated as a crack to the quartz vein yet. 


\section{Appendix 3.C - Conversion of triaxial laboratory experiments to plane strain numerical experiments}

When flow laws that were derived from laboratory experiments are used to assign rheologies in plane strain numerical models, it is essential to ensure that the laboratoryderived stress-strain rate relationships are correctly expressed in terms of these modelled plane strain conditions. In general, experimental deformation apparatus work under a triaxial (or more correctly, biaxial) stress state (e.g., Griggs-type apparatus) in that they exert principle stresses $\sigma_{1}>\sigma_{2}=\sigma_{3}$ on the sample, where $\sigma_{1}$ is in the direction of compression (piston direction). The mean pressure $p$ in this system is equal to the mean of the three principle stresses:

$p=\left(\frac{\sigma_{1}+\sigma_{2}+\sigma_{3}}{3}\right)$

The triaxial stress state can be described equivalently in terms of the three principle deviatoric stresses $\sigma_{1}^{\prime}>\sigma_{2}^{\prime}=\sigma_{3}^{\prime}$, where we used the dash to differentiate deviatoric from principal stresses. Here,

$$
S^{\prime}=\left[\begin{array}{ccc}
\sigma_{1}-p & 0 & 0 \\
0 & \sigma_{2}-p & 0 \\
0 & 0 & \sigma_{3}-p
\end{array}\right]=\left[\begin{array}{ccc}
\sigma_{1}^{\prime} & 0 & 0 \\
0 & \sigma_{2}^{\prime} & 0 \\
0 & 0 & \sigma_{3}^{\prime}
\end{array}\right]
$$

is the deviatoric stress tensor.

Laboratory deformation experiments are often reported in terms of an equation relating strain-rate $\dot{\varepsilon}$ to differential stress $\sigma_{d}=\left(\sigma_{1}-\sigma_{3}\right)$ :

$\dot{\varepsilon}=A_{E} \exp (-Q / R T)\left(\sigma_{1}-\sigma_{3}\right)^{n}$

where $A_{E}$ is the experimentally derived pre-exponential constant for a triaxial experiment, and $\sigma_{3}$ is equal to the confining pressure of the apparatus. It is understood that $\dot{\varepsilon}$ refers to the uniaxial strain-rate in the 1-direction (E11-direction) so that, for clarification, we should add the index "1" to the strain rate and rewrite Eq. (3.C.3) to $\dot{\varepsilon}_{1}=A_{E} \exp (-Q / R T)\left(\sigma_{1}-\sigma_{3}\right)^{n}$ 
Since a flow law is a material property, it cannot be affected by the choice of experiment type or the choice of coordinate system (e.g., Paterson, 1981). Hence, we need to generalise the flow law by expressing it in terms of the effective strain rate and effective stress:

$\dot{\varepsilon}_{E}=A_{M} \exp (-Q / R T) \sigma_{E}^{n}$

where $\dot{\varepsilon}_{E}$ and $\sigma_{E}$ are the effective strain rate and effective stress respectively, and $A_{M}$ is the pre-exponential constant that we will use in the plane strain numerical models.

Following Ranalli (1987), the effective stress is computed as

$\sigma_{E}=\sqrt{\frac{1}{2}\left(\sigma_{11}^{\prime 2}+\sigma_{22}^{\prime 2}+\sigma_{33}^{\prime 2}\right)+\sigma_{12}^{\prime 2}+\sigma_{32}^{\prime 2}+\sigma_{13}^{\prime 2}}=\sqrt{\frac{1}{2}\left(\sigma_{i j}^{\prime} \sigma_{i j}^{\prime}\right)}$

or in terms of the three principle deviatoric stress components

$\sigma_{E}=\sqrt{\frac{1}{2}\left(\sigma_{1}^{\prime 2}+\sigma_{2}^{\prime 2}+\sigma_{3}^{\prime 2}\right)}$

and the effective strain rate as

$\dot{\varepsilon}_{E}=\sqrt{\frac{1}{2}\left(\dot{\varepsilon}_{11}^{\prime 2}+\dot{\varepsilon}_{22}^{\prime 2}+\dot{\varepsilon}_{33}^{\prime 2}\right)+\dot{\varepsilon}_{12}^{\prime 2}+\dot{\varepsilon}_{32}^{\prime 2}+\dot{\varepsilon}_{13}^{\prime 2}}=\sqrt{\frac{1}{2}\left(\dot{\varepsilon}_{i j} \dot{\varepsilon}_{i j}\right)}$

or equivalently as

$\dot{\varepsilon}_{E}=\sqrt{\frac{1}{2}\left(\dot{\varepsilon}_{1}^{\prime 2}+\dot{\varepsilon}_{2}^{\prime 2}+\dot{\varepsilon}_{3}^{\prime 2}\right)}$

In order to compute the deviatoric stress components in terms of the principal stress $\sigma_{1}$ and the confining pressure $p_{c}$, we first consider a case where confining pressure $p_{c}=0$ (i.e., a true uniaxial experiment). Then:

$\sigma_{2}=\sigma_{3}=0$ and from Eq. (3.C.1): $p=\frac{1}{3} \sigma_{1}$.

Inserting into Eq. (3.C.2) results in

$\sigma_{1}^{\prime}=\frac{2}{3} \sigma_{1}$ and $\sigma_{2}^{\prime}=\sigma_{3}^{\prime}=-\frac{1}{3} \sigma_{1}$

In an experiment with confining pressure (triaxial experiment), $\sigma_{2}$ and $\sigma_{3}$ are no longer zero, but are equal to the confining pressure $p_{c}$, and $\sigma_{1}$ is equal to the applied $\operatorname{load} \sigma_{1}^{a p p}$ : 
$\sigma_{2}=\sigma_{3}=p_{c} ; \sigma_{1}=\sigma_{1}^{a p p}$ and the pressure becomes $p=\frac{\sigma_{1}+2 p_{c}}{3}$.

Inserting into Eq. (3.C.2) results in the following deviatoric stress components, written in terms of the principal stress $\sigma_{1}$ and confining pressure $p_{c}$ :

$$
\begin{aligned}
& \sigma_{1}^{\prime}=\frac{2}{3}\left(\sigma_{1}-p_{c}\right) \\
& \sigma_{2}^{\prime}=\sigma_{3}^{\prime}=-\frac{1}{3}\left(\sigma_{1}-p_{c}\right) .
\end{aligned}
$$

Since the confining pressure $p_{c}$ is equal to the principal stress in the 3-direction, we can express the deviatoric stresses in terms of the differential stress $\sigma_{d}$ :

$\sigma_{1}^{\prime}=\frac{2}{3}\left(\sigma_{1}-\sigma_{3}\right)=\frac{2}{3} \sigma_{d}$ and $\sigma_{2}^{\prime}=\sigma_{3}^{\prime}=-\frac{1}{3}\left(\sigma_{1}-\sigma_{3}\right)=-\frac{1}{3} \sigma_{d}$.

Substitution into Eq. (3.C.6b) relates the effective stress to the differential stress as follows:

$\sigma_{E}=\frac{1}{\sqrt{3}} \sigma_{d}$ or $\sigma_{d}=\sqrt{3} \sigma_{E}$

We assume that the sample is incompressible, so that we can express the components of the deviatoric strain rate in terms of the rate of shortening in the 1direction $\dot{\varepsilon}_{1}$ in the following way:

$\dot{\varepsilon}_{1}^{\prime}=\dot{\varepsilon}_{1}$

and $\dot{\varepsilon}_{2}^{\prime}=\dot{\varepsilon}_{3}^{\prime}=-\frac{1}{2} \dot{\varepsilon}_{1}$

Inserting the deviatoric strain rates into Eq. (3.C.7b) relates the effective strain rate to the uniaxial strain rate as follows:

$\dot{\varepsilon}_{E}=\frac{\sqrt{3}}{2} \dot{\varepsilon}_{1}$ or $\quad \dot{\varepsilon}_{1}=\frac{2}{\sqrt{3}} \dot{\varepsilon}_{E}$

Using the relationships of Eqs. (A.8) and (A.9) and substituting in Eq. (A.4) gives:

$$
\begin{aligned}
& \frac{2}{\sqrt{3}} \dot{\varepsilon}_{E}=A_{E} \exp (-Q / R T)\left(\sqrt{3} \sigma_{E}\right)^{n} \\
& \text { or } \dot{\varepsilon}_{E}=\frac{3^{(n+1) / 2}}{2} A_{E} \exp (-Q / R T) \sigma_{E}^{n}
\end{aligned}
$$


Setting Eqs. (3.C.5) and (3.C.10) equal leads to the following relationship between the experimentally derived pre-exponential factor $A_{E}$ and the pre-exponential factor we wish to use in the plane strain models $A_{M}$ :

$A_{M}=\frac{3^{(n+1) / 2}}{2} A_{E}$

\section{Appendix 3.D - Strain rate conventions in our code}

Our code reports shear strain (and shear strain-rate) as:

$$
\dot{\varepsilon}_{s}=\frac{1}{2}\left(\dot{\varepsilon}_{i j}+\dot{\varepsilon}_{j i}\right)
$$

For example, consider the shear strain rate near the upper boundary of a model where a differential velocity $V$, is applied across a total length $d l$. Our code will report the shear strain rate as:

$$
\dot{\varepsilon}_{s}=\frac{1}{2}\left(\dot{\varepsilon}_{i j}+\dot{\varepsilon}_{j i}\right)=\frac{V}{2 d l}
$$

\section{Appendix 3.E - Frictional yield parameters in our code}

The code used in this paper assumes a Coulomb yield criterion of the form:

$$
\tau_{\max }=p \sin \phi+c \cos \phi
$$

which is derived from the yield on a particular surface, by assuming slip occurs on optimally-oriented planes, and where $\tau_{\max }=\frac{1}{2} \sigma_{d}, p$ is pressure, $c$ is cohesion and $\phi$ is the slope of the failure envelope, i.e., the angle of friction (e.g., Ranalli, 1987, pp. 95).

If we set $\phi=0$ then Eq. (3.E.1) reduces to the "maximum shear stress criterion" (also known as Tresca criterion):

$\tau_{\max }=c$

Therefore, for the experiments performed here, where $\phi$ is set to zero and the frictional strength is prescribed as a cohesion, the cohesion should be entered as the maximum shear stress in our code. 


\section{Appendix 3.F - Creep flow parameters in our code}

Our code uses a creep flow law that relates flow stress and strain rate by a factor known as effective viscosity $\eta_{\text {eff }}$ (e.g., Ranalli, 1987):

$\sigma_{i j}^{\prime}=2 \eta_{e f f} \dot{\varepsilon}_{i j}$

Eq. (3.F.1) expressed as a power law and solved for stress results in

$\sigma_{i j}^{\prime}=2 B \exp \left(\frac{Q}{n R T}\right) \dot{\varepsilon}_{i j}^{1 / n}$

where $B$ is the pre-exponential factor that we input into our code. Here, too we need to find a relationship between $B$ and the pre-exponential factor $A_{M}$ derived in App. 3.C.

Eq. (3.F.2a) can also be written as

$\sigma_{i j}^{\prime}=2 B \exp \left(\frac{Q}{n R T}\right)\left(E_{I I}\right)^{\frac{1}{n}-1} \dot{\varepsilon}_{i j}^{1 / n}$

where $E_{I I}$ is the second invariant of the strain rate tensor.

This leaves the effective viscosity to be

$\eta_{\text {eff }}=B \exp \left(\frac{Q}{n R T}\right)\left(E_{I I}\right)^{\frac{1}{n}-1}$

Since our models are plane strain simple shear models, $\sigma_{12}^{\prime}$ and $\dot{\varepsilon}_{12}$ are the only nonzero component of the deviatoric stress tensor and the strain rate tensor respectively, and we can define

$\sigma_{E}=\sigma_{i j}^{\prime}=\sigma_{12}^{\prime}$

and

$\dot{\varepsilon}_{E}=\dot{\varepsilon}_{i j}=\dot{\varepsilon}_{12}$

and can hence rewrite Eq. (F.2a) in terms of effective strain rate and effective stress:

$\sigma_{E}=2 B \exp \left(\frac{Q}{n R T}\right) \dot{\varepsilon}_{E}^{1 / n}$

Recalling Eq. (3.C.5) and solving for the effective stress gives

$\sigma_{E}=A_{M}^{-1 / n} \exp \left(\frac{Q}{n R T}\right) \dot{\varepsilon}_{E}^{1 / n}$

so that we can relate $B$ and $A_{M}$ as follows:

$B=\frac{1}{2} A_{M}^{-1 / n}$ 


\title{
Chapter 4
}

Controls on shear zone formation in brittlely to ductilely deformed rocks from the central Southern Alps of New Zealand

\author{
Susanne Grigull ${ }^{1}$ \\ Timothy A. Little ${ }^{1}$ \\ Ruth H. Wightman ${ }^{1,3}$ \\ Susan M. Ellis ${ }^{2}$ \\ Matthew P. Hill ${ }^{1,5}$ \\ Rita Seifert ${ }^{4}$
}

${ }^{1}$ School of Geography, Environment and Earth Sciences

Victoria University of Wellington

PO Box 600

Wellington 6140, New Zealand

${ }^{2}$ GNS Science

1 Fairway Drive

PO Box 30368

Avalon

Lower Hutt 5010, New Zealand

${ }^{3}$ Midland Valley Exploration Ltd.

144 West George Street

Glasgow G2 2HG, United Kingdom

${ }^{4}$ Fakultät für Geowissenschaften

Ruhr University

Universitätsstrasse 150

44801 Bochum, Germany

${ }^{5}$ Kenex Knowledge Systems Ltd.

16 Oroua Street

PO Box 41136

Eastbourne

Wellington, New Zealand 


\subsection{Introduction}

Exhumed shear zones provide an excellent opportunity to study the interplay between brittle and ductile rock deformation. In homogeneous rocks, it is impossible to form a localised ductile shear zone without the introduction of a rheological inhomogeneity into the rocks. Such a change in rock strength may be related to a change in deformation conditions, e.g., strain rate, stress state, temperature (e.g., Hobbs et al., 1990; Burlini and Bruhn, 2005). Effective rock viscosities may also be changed by grain size reduction, followed by a switch to grain-size sensitive deformation mechanisms (Handy, 1989; Montési and Zuber, 2002; Jin et al., 1998; see also discussions in De Bresser et al., 2001, and in Montesi and Zuber, 2002), or by reaction-induced changes in mineral composition, or by hydrolytic weakening (chemical softening). Many studies conclude that it is not possible to localise ductile deformation in a homogeneous rock without precursory brittle deformation of that rock (e.g., Simpson, 1986; Tourigny and Tremblay, 1997; Pennacchioni, 2005; Mancktelow and Pennacchioni, 2005; Pennacchioni and Mancktelow, 2007; Fusseis et al., 2006; Fusseis and Handy, 2008). Brittle precursory fracturing may occur on all scales. i.e., from microfracturing to crustal scale faults. The precursory embrittlement may or may not be followed by the ingress of fluids into the fractured rocks, which may subsequently lead to fluidalteration of the affected rocks and create a rheological inhomogeneity that can later be exploited as a ductile shear zone (Fig. 4.1). Using numerical modelling, Ellis and Stöckhert (2004) showed that a seismogenic brittle fault in the upper crust can also induce periodic shear zone localisation in a viscous lower crust. In numerical computer models of ductile shear zones in homogeneous material, strain localisation is usually initiated by introducing a thermal or a viscous "perturbation" into the model (e.g., by attributing a slightly different temperature or viscosity to a small part of the model (e.g., Kaus \& Podlachikov, 2006; Mancktelow, 2006). Kaus \& Podlachikov (2006) conclude that the degree of localisation and the maintenance of a shear zone depend on the size of that initial perturbation among other factors. Another common way to achieve strain localisation in numerical models is simply to prescribe a plastic strain softening behaviour for the modelled rocks (e.g., Schueller et al., 2005; Grigull et al., this study, section 3.5.3.2; for a summary of localisation methods see Montesi and Zuber, 2002). Although such methods can lead to the formation of a localised shear zone in the 
homogeneous material, neither of them bears information about the actual weakening processes affecting naturally deformed rocks.

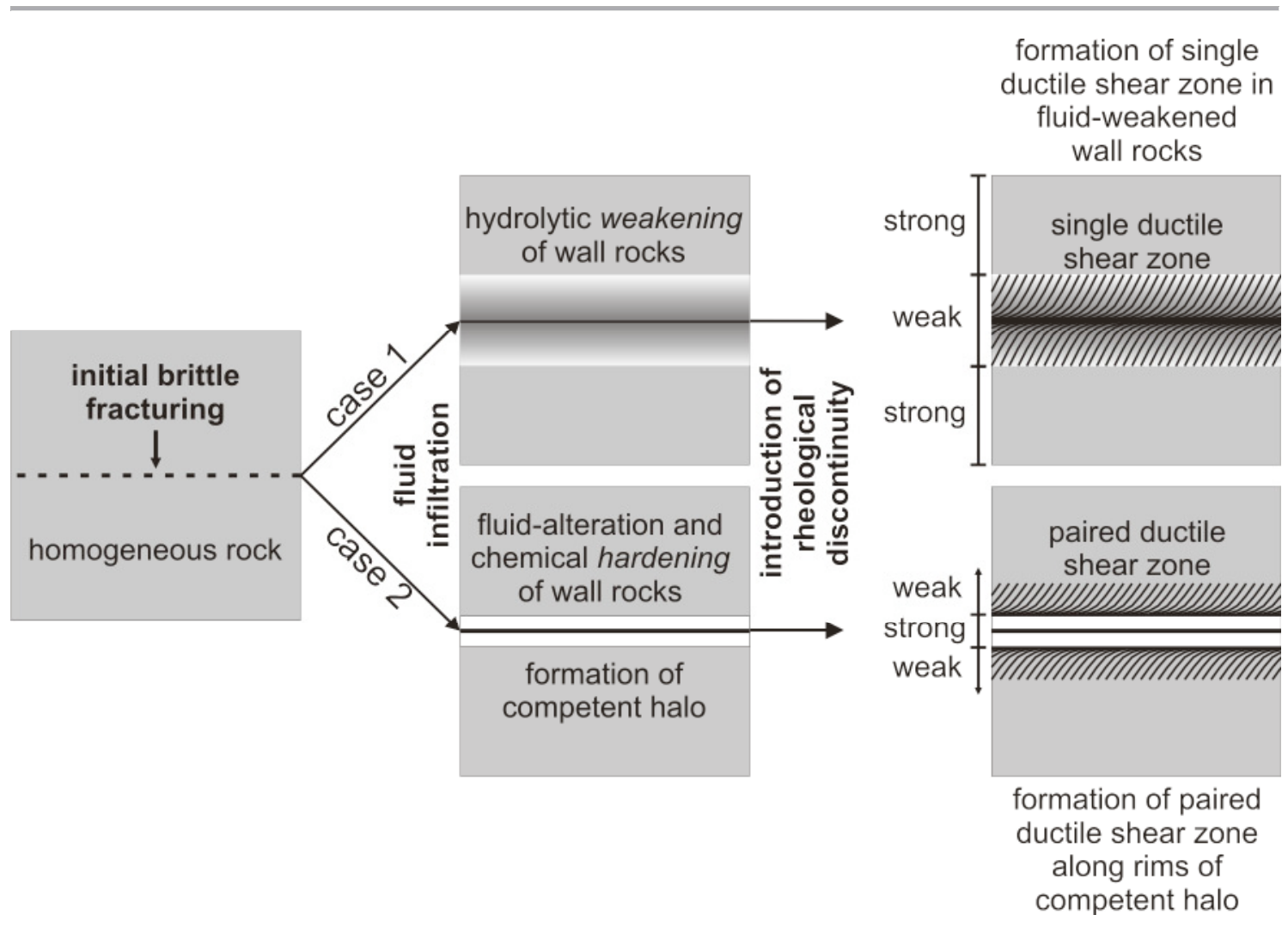

Fig. 4.1: Flow diagram illustrating two ways (out of many) to form localised ductile shear zones in homogeneous, isotropic rock. Precursory brittle fracturing is followed by fluid infiltration and either hydrolytic weakening (case 1) or chemical hardening (case 2) of the wall rocks. The resulting type of ductile shear zone depends on whether the wall rocks were chemically hardened or weakened by the introduced fluids. In both cases, the introduced rheological contrasts determine where the shear zones form.

In this paper, we present a case study of naturally formed mid- to lower-crustal faults and shear zones deforming quartzofeldspathic, foliated schist and quartz veins in the central Southern Alps, New Zealand. Here, an array of shears accommodating variably brittle to ductile displacement of the quartz veins has been exhumed from $\geq 20$ km depth during the past 3-4 m.y. (Little at al., 2002a, b; Wightman, 2005; Wightman et al, 2006; Wightman and Little, 2007).

In order to retrieve information about the localisation process at this site which has led, in particular, to the ductile shearing of some of the quartz veins, this study addresses the evolution of shear zones in these layered rocks. We focus on the variable brittle to ductile behaviour expressed by compositionally similar quartz veins. Some quartz veins have been displaced across fully ductile shear zones whereas others have 
instead been brittlely displaced. Whereas the quartz veins may be either brittlely or ductilely displaced, their quartzofeldspathic schist country rock is everywhere displaced across a narrow, fault-like, brittle crack (Fig. 4.2).

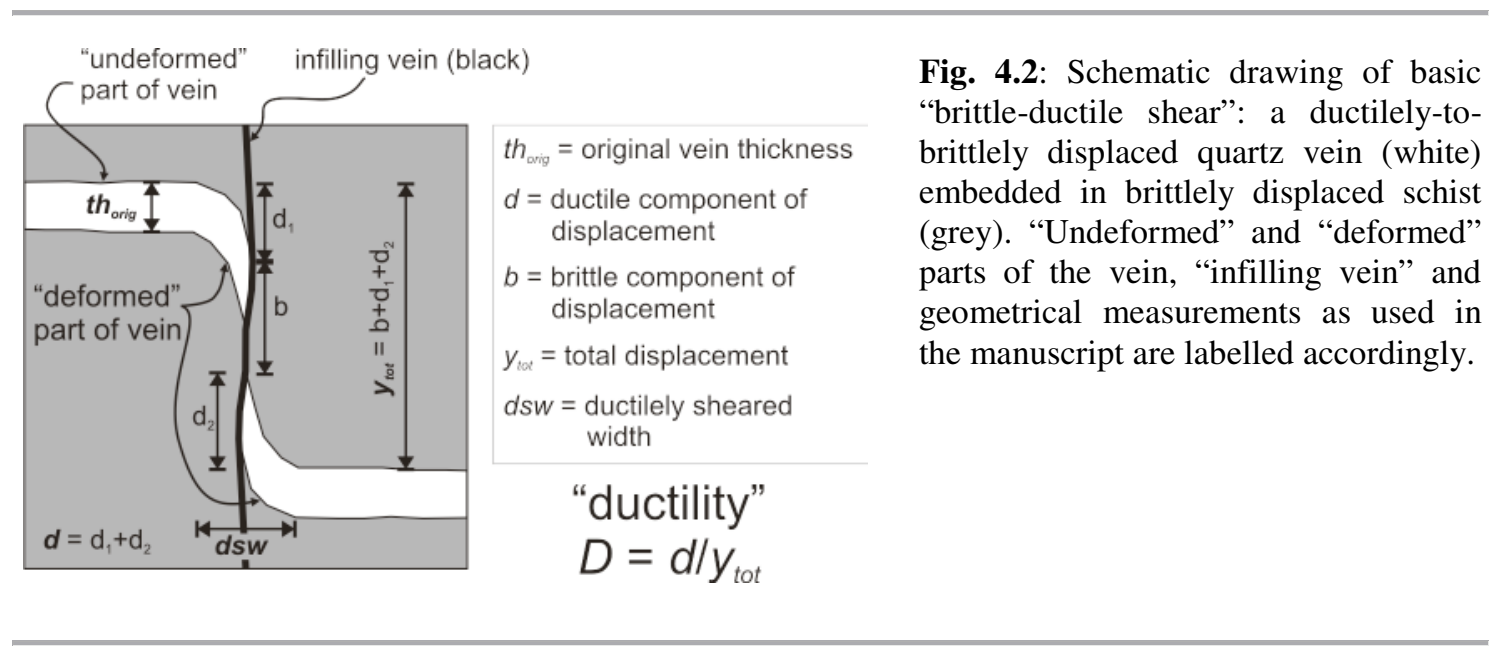

In this paper, we will investigate potential causes for either a potential softening or hardening behaviour of the quartz veins, and in particular evidence for precursory brittle deformation prior to shear zone formation. A key geometrical scaling parameter used in this paper is the "ductility" $D$ of a quartz vein offset. The ductility is defined as the ratio between the ductile component of slip $d$ and the total slip $y_{t o t}$, i.e., $D=d / y_{\text {tot }}$ of a displaced quartz vein marker across a given brittle-ductile shear zone (Fig. 4.2). When $D$ is plotted against the original vein thickness $t h_{\text {orig }}$ of the displaced veins or against the total vein displacement $y_{t o t}$, the diversity of observed scaling ratios between these parameters suggests that the rheological properties of the individual quartz veins must have varied significantly between one vein and the next. A goal of this paper is to understand what has led to this variability in $D$ between individual quartz veins and to extract any information on inherited pre-deformational rheological conditions that might be provided by these differential $D$-values. In summary, we try to answer the following fundamental questions. How did the ductile shear zones initiate in the quartz veins? Was a hardening or weakening process operative to localise the ductile shear zones? Was precursory brittle deformation of the rocks with associated fluid ingress a necessary pre-condition for the formation of the highly localised ductile shear zones in the quartz veins? What controlled the variable style of rock deformation in the quartz veins (i.e., brittle vs. ductile)? 
In order to answer these questions, we will present detailed meter-scale outcrop maps of the brittle-ductile shears, and plots of several geometrical scaling relationships to analyse vein to vein variability in $D$. We then evaluate three possible factors that may have caused differential softening or hardening between one quartz vein and the next, and which resulted in the observed variations in the ratio $D$. These factors are: calcitefraction, molecular water content and local slip rates. We also evaluate whether any of these factors may have facilitated shear zone localisation in the quartz veins. In addition, we evaluate whether local (meter-scale) changes in deformation conditions (e.g., temperature or stress state) could have led to the variable $D$-values measured in the sheared quartz veins.

\subsection{Geological and tectonic setting}

The shear array is situated in the central Southern Alps, New Zealand (Figs. 4.3a, 4.3b). Here, glaciated outcrops provide the opportunity to study the development of the shears and to document the interplay between the brittle and ductile deformation that variably affects the host rocks of these shears. The shear array formed during the late Cenozoic in the hanging-wall of the Alpine Fault (e.g., Little et al. 2002a, b). The Alpine Fault is the main structural expression of the Pacific-Australian plate boundary (Fig. 4.3a), accommodating $\sim 75 \%$ of the convergence between those two major plates (Norris and Cooper, 2001). In the central Southern Alps, the Alpine Fault strikes approximately $055^{\circ}$ and dips moderately $\left(\sim 45^{\circ}\right)$ to the SE (e.g., Norris and Cooper, 1995; Kleffman et al., 1998; Stern at al., 2007; Little et al., 2007). Convergence during the past several m.y. has been oblique at $37 \mathrm{~mm} / \mathrm{yr}$ at $\mathrm{N} 71^{\circ} \mathrm{E}$ (NUVEL-1A global plate motion model of DeMets et al., 1990, 1994). In the central Southern Alps, the dextralreverse Alpine Fault has moved with an average late Quaternary strike-slip rate of $27 \pm$ $5 \mathrm{~mm} / \mathrm{yr}$, and a reverse dip-slip rate of 8-12 mm/yr (Sutherland, 2006; Norris and Cooper, 2001, 2007). Uplift rates are reported to be a maximum of $c . \sim 10 \mathrm{~mm} / \mathrm{yr}$ in the area between the Franz Josef and Fox glaciers (Wellman, 1979; Bull and Cooper, 1986; Tippet and Kamp, 1993; Beavan et al., 2007). The high uplift rates have led to the exhumation of Mesozoic quartzofeldspathic rocks (metagreywacke) along and to the east of the Alpine Fault ramp. This east-tilted crustal section of metamorphic rocks is termed Alpine Schist. The Alpine Schist ranges from amphibolite facies metamorphic 
grade adjacent to the Alpine Fault and its adjacent $\sim 1 \mathrm{~km}$-wide mylonite zone to prehnite-pumpelleyite facies in the supracrustal greywacke sequences near the Main Divide of the Southern Alps 15-20 km to the east of the Alpine Fault (Fig. 4.3b; Grapes \& Watanabe, 1992; Cox and Barrell, 2007). Recent earthquake refraction travel-time studies across South Island have led to a crustal thickness estimate of $48 \pm 4 \mathrm{~km}$ beneath the Southern Alps in the southern part of South Island (Bourguignon et al., 2007). This depth of the crustal root is $18 \mathrm{~km}$ beneath the average $30 \mathrm{~km}$ at the coast and corresponds to approximately twice the thickness that would be expected for the recent topographic elevation of the Southern Alps (Stern et al., 2002; Bourguignon et al., 2007).

Stern et al. $(2001,2007)$ have traced the Alpine Fault down to $35 \mathrm{~km}$ depth via seismic experiments. At that depth, Stern et al. (2001, 2007) imaged sub-horizontal reflectors that they interpreted as a detachment along which crustal rocks are being delaminated and transported westward onto the Alpine Fault ramp (Fig. 4.4). These authors also imaged a zone of low P-wave velocity above the fault surface that extended from $\sim 8 \mathrm{~km}$ down to $35 \mathrm{~km}$ depth. This low-velocity zone parallels a low-resistivity anomaly and is interpreted as interconnected fluids that were expelled and have travelled upward during shearing and dewatering of the rocks above the detachment (Stern et al., 2001, 2007; Wannamaker et al., 2002). A recent study of devolatilisation in an Alpine Schist sample by Vry et al. (2009) also argues for the presence of fluids down-dip of the Alpine Fault near the region of this upward ramp step. They propose that, during exhumation, metagreywacke rocks are dehydrated largely as a result of decompression following the peak conditions of temperature $\left(\sim 600^{\circ} \mathrm{C}\right.$; Vry et al., 2004). Vry et al. (2009) propose that this fluid expulsion accompanied the sudden upramping and deformation of the Pacific plate from the flat detachment onto the locally steeper dipping plane of the Alpine Fault, as has been proposed by Little (2004), Little et al. (2005) and Wightman and Little (2007).

Based on seismicity cut-off depths, Leitner et al. (2001) inferred that the brittleductile transition zone (BDTZ) in the central Southern Alps is at 8-10 km depth. This depth corresponds approximately to the top of the low seismic velocity zone that was imaged by Stern et al. (2001). This is only slightly shallower than other typical depths of 12-15 km in such transpressive or convergent orogens in e.g., the western United States or the eastern European Alps (e.g., Sibson, 1983; Stöckhert et al., 1999). Such 
shallowness of the Southern Alps BDTZ has been attributed to an elevated thermal gradient in that central part of the orogen due to high uplift rates in that area (e.g., Shi et al., 1996; Leitner et al., 2001).
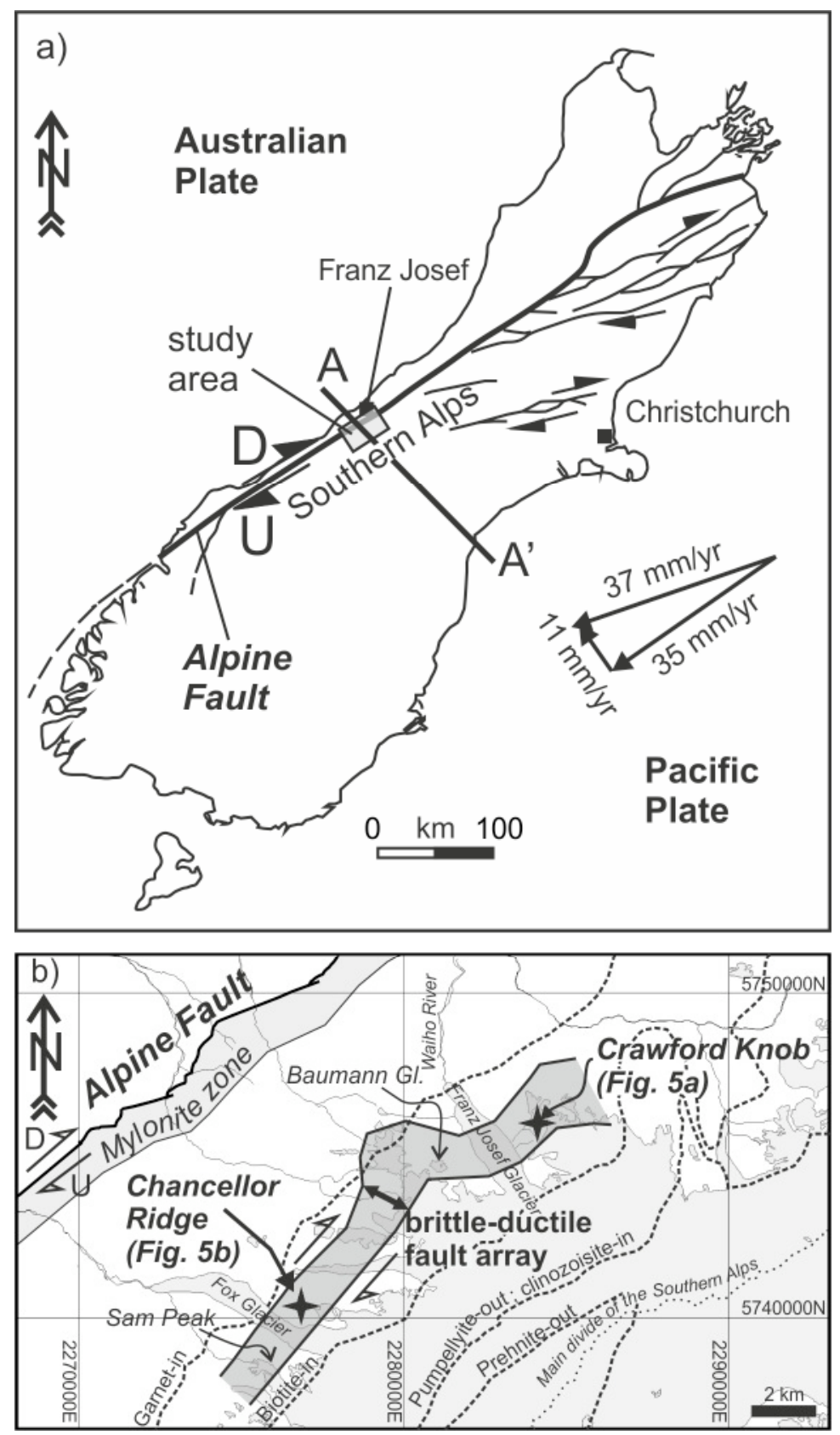

Fig. 4.3: Tectonic setting. a) Schematic map of South Island, New Zealand. The dextral-reverse Alpine Fault is the major expression of the Pacific-Australian plate boundary. The plate motion vectors are from the NUVEL-1A model by DeMets et al. $(1990,1994) . \mathrm{D}=$ Down, $\mathrm{U}=\mathrm{Up}$. b) Close-up of the study area showing the known aerial extent of the brittle-ductile shear or fault array, its spatial relation to the Alpine Fault and the two main study and sampling localities Crawford Knob (location of map in Fig. 4.5a) and Chancellor Ridge (location of map in Fig. 4.5b). Mineral isograds are taken from Cox and Barrell, 2007. 


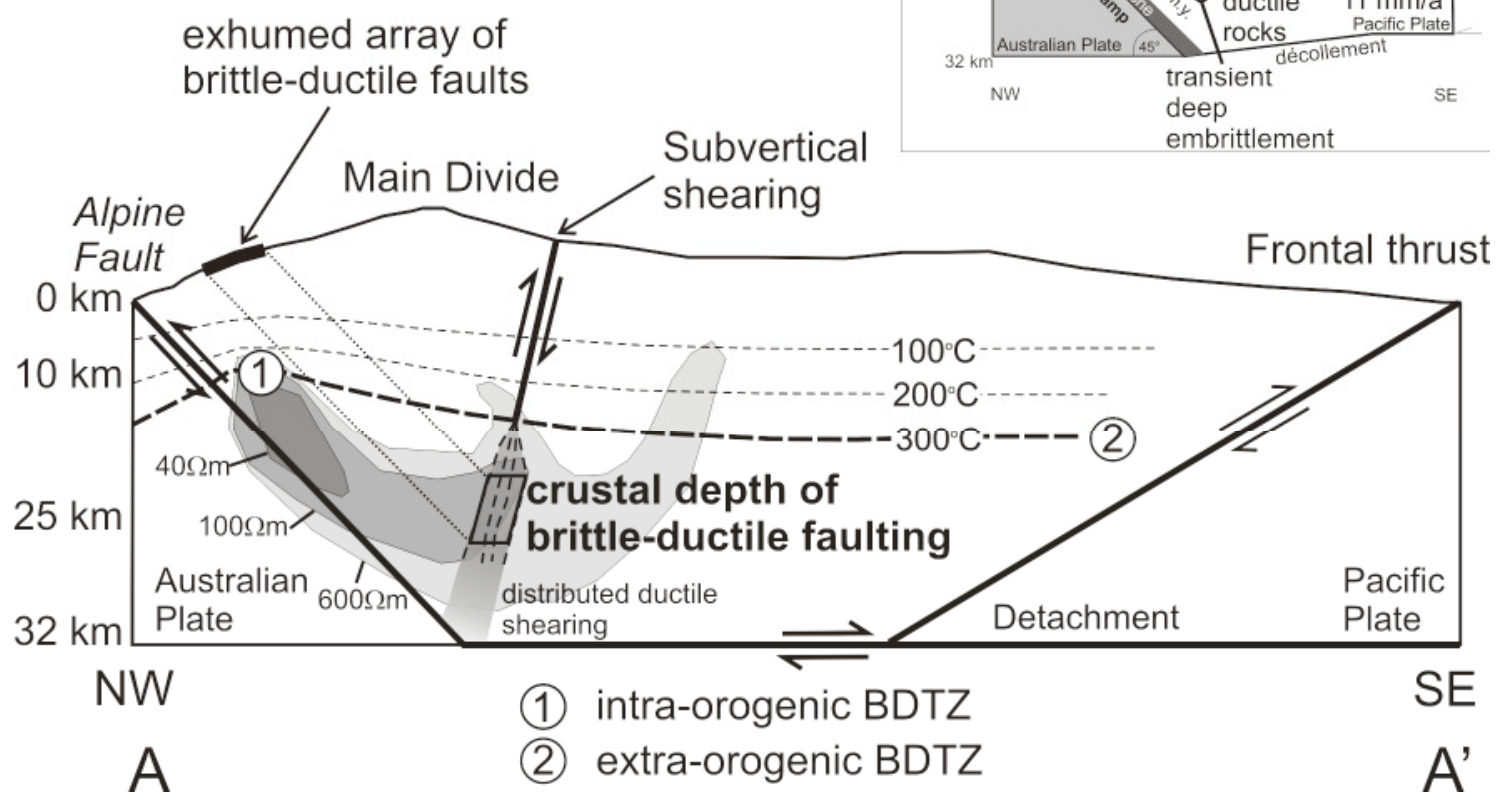

Fig. 4.4: Schematic cross-section through the central Southern Alps after Wightman and Little (2007). The grey shaded areas indicate the low resistivity zone that was imaged through geoelectric measurements by Wannamaker et al. (2002). Dashed lines are one possible isotherm structure after Batt and Braun (1999). The position of the $300^{\circ} \mathrm{C}$-isotherm is here taken to coincide with the bottom of the seismogenic zone. Note how rapid erosional exhumation has caused the isotherm to bend upwards near the Alpine Fault (1) and that this isotherm becomes progressively deeper to the SE of the Southern Alps (2).

Inset: Escalator model after Little (2004). Pacific Plate rocks are delaminated along a detachment and transported westwards towards the Alpine Fault ramp. While passing the foot of that fault ramp, the rocks are subjected to transiently high shear stresses and strain rates, leading to distributed ductile shearing in the lower crust and to embrittlement and the formation of discrete backshears in rocks that lie $\sim 7 \mathrm{~km}$ above the Alpine Fault. After passing this critical point, deformation stops and the rocks are passively transported to the surface in an escalator-like fashion.

As a result of the reverse component of slip on the Alpine Fault and high erosion rates, the Alpine schist and its cargo of ramp-related, late Cenozoic brittle-ductile shears have been exhumed to the surface from $\geq 20 \mathrm{~km}$ depth during the past 3-4 Myrs (Little et al. 2002a). The above mentioned shear array occurs in mid- to lower-crustal rocks (biotite-zone). There, the observed brittle deformation is inferred to have occurred at temperatures hotter and deeper than the seismogenically defined BDTZ (i.e., below 8-15 $\mathrm{km}$ depth). This deep embrittlement within otherwise ductilely deforming rocks of the 
lower crust is inferred to have been a transient process that resulted from an acceleration in strain rates and increase in differential stresses that affected the Pacific plate rocks, at near-lithostatic fluid pressures as they were upturned across the foot of the Alpine Fault ramp (e.g., Little et al., 2002a, 2002b, 2005; Wightman et al., 2006). Little (2004), Little et al. (2002a, 2002b), Wightman et al. (2006), and Wightman and Little (2007) have suggested a model for the formation and evolution of the brittle-ductile fault array. The model (Fig. 4.4, inset) proposes that rocks in the hanging wall of the Alpine Fault were first displaced along the sub-horizontal detachment before being tilted eastward and back-sheared in an oblique, escalator-like fashion upon reaching the base of the Alpine Fault ramp. When the rocks negotiated the step at the foot of this fault ramp, they were subject to high shear stresses and strain rates leading to a transient embrittlement into the lower crust (Fig. 4.4, inset). This neotectonic brittle-ductile regime forms the natural laboratory for this paper.

\subsection{Study area and field description of brittle-ductile shears}

The field data and samples for this paper were collected at two locations in the brittleductile shear zone array: Chancellor Ridge and Crawford Knob (Figs. 4.3b, 4.5a, 4.5b). There, biotite zone Alpine Schist consists mainly of quartzofeldspathic metagreywacke (metapsammite) that is interlayered with subordinate pelitic layers up to $2 \mathrm{~m}$ thick (Figs. 4.6a-c). The dominant foliation in the schist strikes between $030^{\circ}$ and $060^{\circ}$ and typically dips steeply to the SE (see stereograms in Figs. 4.5a, 4.5b and 4.9c, 4.10c). The mean foliation orientation at Crawford Knob is $133 / 88^{1}(\mathrm{n}=27)$, whereas at Chancellor Ridge it is $128 / 79(\mathrm{n}=29)$. Both compositional layers in the schist and abundant quartz veins which occur embedded in that schist are dextrally and vertically separated across a systematically and closely spaced array of parallel, planar, near-vertical faults (Figs. 4.5a, 4.5b, 4.6a-c, and 4.9a, 4.10a). The average orientation of these faults at Crawford Knob is 336/88 ( $n=34)$ and 307/89 ( $n=29)$ near Chancellor Ridge. At both locations, the faults strike approximately parallel to the Alpine Fault. The movement of the hanging wall along those faults was consistently both dextral and NW-up. This is revealed by 1) the consistent SW-rake of fault surface vein striae (e.g., Fig. 4.6d) and 2) a detailed fault

\footnotetext{
${ }^{1}$ If not stated otherwise, we will give the orientation measurements of planar geological features such as faults, foliations and quartz marker veins in 'dip direction / dip angle'. Linear features (e.g., fibre lineations) are given in 'trend / plunge'.
} 
kinematic analysis of the offsets of variably oriented planar markers by Wightman (2005) and Wightman and Little (2007). These studies indicate that the mean pitch of the slip vector was $36 \pm 5^{\circ} \mathrm{SW}$ in the near-vertical average fault plane.

At Chancellor Ridge, the faults cut the dominant foliation in the schist at a mean angle of $\sim 12^{\circ}$ anticlockwise of that fabric (Figs. 4.5b, 4.6b), whereas at Crawford Knob, they cut the foliation clockwise at a mean angle of $\sim 23^{\circ}$ (Figs. 4.5a, 4.6c). The deformed quartz veins that are embedded in the schist typically strike N-S and dip moderately to the east (Figs. 4.9a, 4.9d and 4.10a, d).

The style of deformation of the rocks displaced across these faults varies for different types of markers and rock types. The shears are sharp, discrete (mm-wide) faults and wholly brittle where they crosscut quartzofeldspathic schist. By contrast, quartz veins embedded in this quartzofeldspathic schist are typically partly to wholly ductilely displaced by the same shears (Fig. 4.6c). Some of the more ductile of the deformed quartz veins have been smoothly and coherently smeared out to achieve bulk ductile shear strains of 10-15 across shear zones transecting the veins that are $\sim 2-3 \mathrm{~cm}$ wide (Fig. 4.6c). The only places where ductile deformation of the host quartzofeldspathic schist occurs is in the local area of overlap between two adjacent strands that are arranged en échelon. There, we infer that the wider deformation volume caused lower strain rates, a change that reduced the effective viscosity of the quartzofeldspathic schist between the two fault strands. Everywhere else the shears are sharp and fault-like where they cut the quartzofeldspathic schist. The contrast in deformation behaviour between the schist host rocks (brittle) and the quartz veins (variably ductile) suggests a difference in their effective viscosity and probably points to a difference in operative deformation mechanism (e.g., viscous creep in the quartz veins vs. frictional sliding in the host rocks).

Most of the walls of the brittle faults in the schist host to the quartz veins are painted with slickenfibre veins of quartz + calcite + chlorite (Fig. 4.6d). The consistently aligned mineral fibres define a SW-pitching slip lineation on the faults (Fig. 4.6d). These laterally continuous fault-infilling veins are 1-2 mm wide on average, suggesting a mean fault dilation of this magnitude. On the basis of the similarity of oxygen isotope analyses in the fault-infilling veins and its surrounding schist, the aqueous fluids from which the fault-infilling veins were precipitated are inferred to have 
been released as metamorphic fluids expelled from actively metamorphosing and ductilely deforming rocks at a depth below the exposed levels of the brittle-ductile fault array (Wightman, 2005; Wightman and Little, 2007).

a) Crawford Knob - sample locations

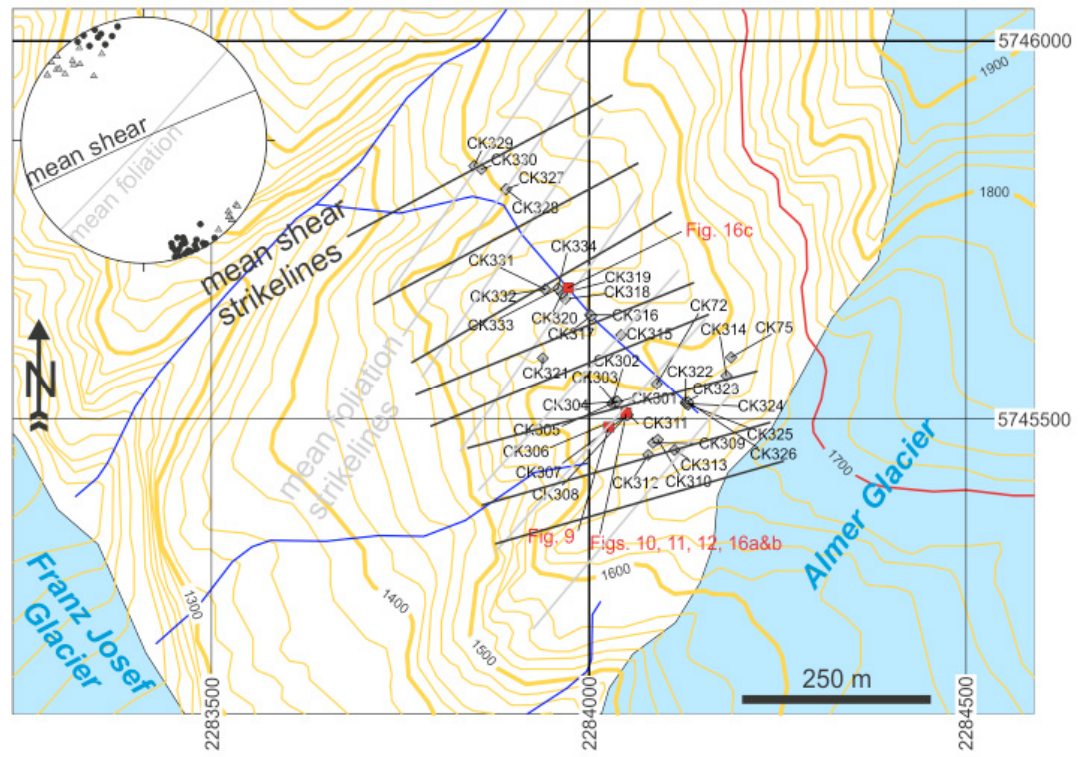

b) Chancellor Ridge - sample locations

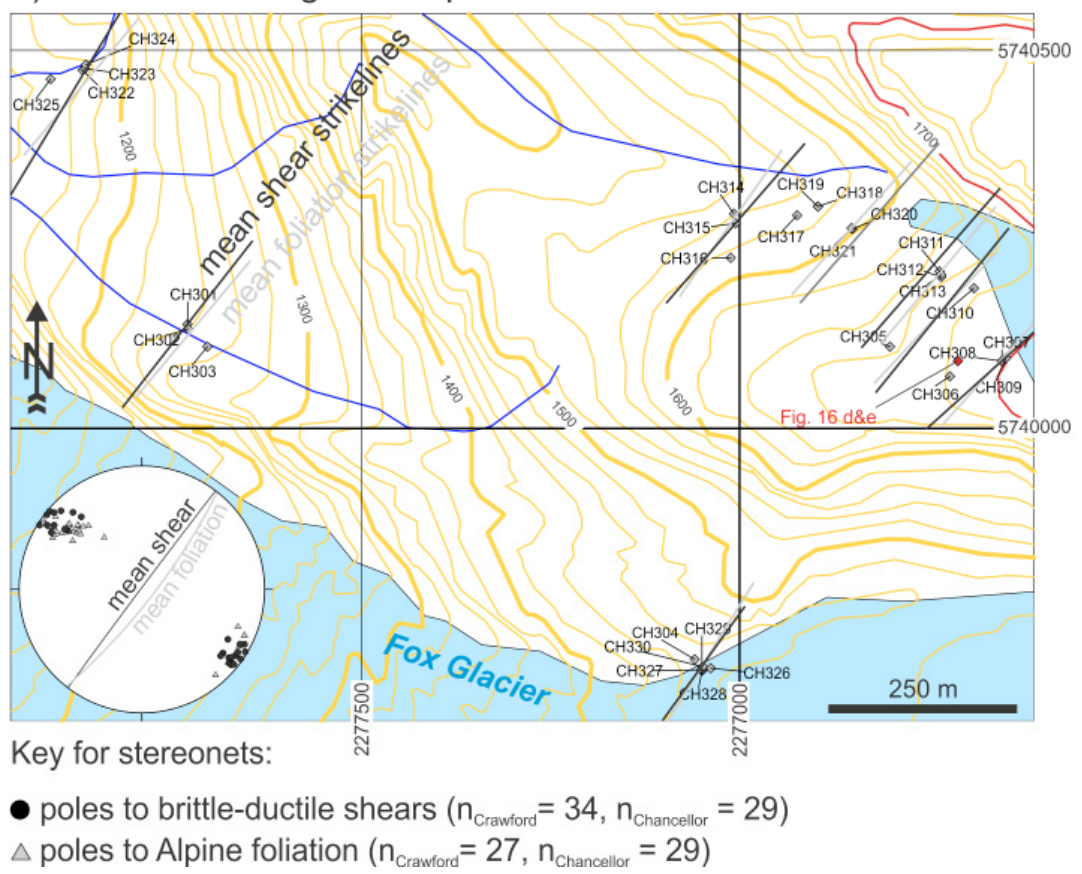

Fig. 4.5: Maps showing the locations of Figs. 4.9, 4.10, 4.11, 4.12, 4.16 (in red) and sample locations for laboratory analyses (calcite content, TitaniQ geothermometry, FTIR spectroscopy) at a) Crawford Knob and b) Chancellor Ridge. Grid-coordinates are in New Zealand Map Grid. Strikelines of the mean shear orientations are drawn in dark grey. Formlines showing the strike for the mean foliation are in lighter grey. For location of maps see Fig. 4.3b. Stereograms are lower hemisphere projections of the measured brittle-ductile shears and Alpine foliation attitudes. $\mathrm{n}_{\text {Crawford }}$ and $\mathrm{n}_{\text {Chancellor }}$ is number of attitudes measured at Crawford Knob and Chancellor Ridge respectively. 

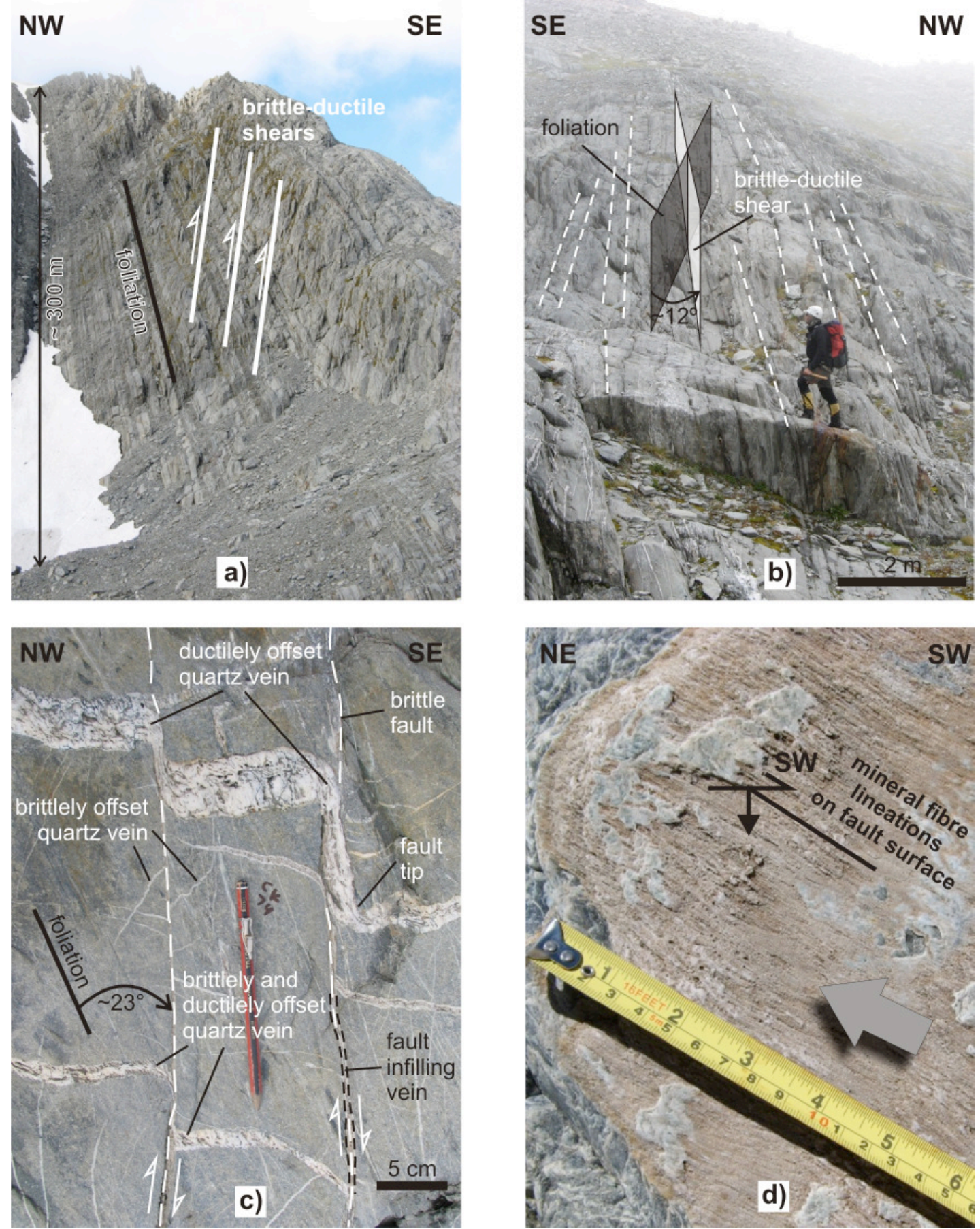

Fig. 4.6: Field photographs of the brittle-ductile shears. a) ca. $300 \mathrm{~m}$ high cliff at Crawford Knob, showing near-vertical brittle-ductile shears and steeply SE-dipping main Alpine foliation; facing NE parallel to the strike of the shears; the "stripey" appearance of the schist is due to alternated layering of metapelites (dark) and metapsammites (light). b) Glaciated outcrops near Chancellor Ridge. Photograph taken facing SW. Note the regular $(\sim 30-50 \mathrm{~cm})$ spacing of the brittle-ductile shears; c) Outcrop photograph, Crawford Knob. Here, the shears brittlely offset the host Alpine schist as well as some of the thinner quartz veins. Where the fault tips encounter thicker quartz veins, they tip out into those quartz veins and displace them entirely ductilely; d) Plan view of a fault surface at Crawford Knob. The fault plane dips steeply to the NW. A qtz + cal + chl vein has infilled the brittle fault. Incrementally grown fibre lineations in that vein indicate the direction of slip (NE-SW, top to the SE). The grey arrow points in the direction in which the (now eroded) hanging wall moved. 


\subsection{Microstructures and CPOs of the deforming quartz veins and the fault-infilling quartz-carbonate veins}

Today, the grain-boundaries in the ductilely sheared and deformed quartz veins are polygonal with straight grain boundaries and abundant $\sim 120^{\circ}$ triple junctions (Fig. 4.7). The mean 2D grain diameter in these quartz veins is $126 \pm 16 \mu \mathrm{m}$ in the internal sheared part of the vein and $171 \pm 14 \mu \mathrm{m}$ in the external unsheared part (grain sizes from Hill, 2005 measured in two orthogonal directions using the intercept method as described in Christie and Ord, 1980; Stipp et al., 2002). In the sheared veins, this strongly recovered, polygonal microstructure indicates a period of static recrystallisation subsequent to their ductile shearing. We infer that when the rocks passed the "corner region" at the foot of the Alpine Fault, they were temporarily subject to elevated stresses and rapid strain rates, but that subsequently they were unloaded while being passively advected upwards towards the surface in the hanging wall of the Alpine Fault ramp (Little et al. 2002b; Wightman et al., 2006). During this advective phase, they remained at high temperatures, but were not subject to further significant differential stress or shearing ("inactive faults" in inset of Fig. 4.4). Static recrystallisation and grain growth during their transport to the surface led to the observed foam-like microstructures (Figs. 4.7b, 4.7c; also Wightman et al., 2006).

Crystallographic preferred orientation (CPO) measurements on ductilely sheared quartz marker veins by Wightman (2005), Hill (2005), and Wightman et al. (2006) indicate that despite the demonstrably high finite ductile shear strains of 5-10 locally accommodated inside the sheared quartz veins, the CPO in these strongly and ductilely deformed veins is today either very weak or random. Wightman et al. (2006) suggest that dynamic recrystallisation led to very fine grain sizes during initial shearing. Waning stresses towards the end of the shearing deformation might have allowed activation of diffusion creep-accommodated grain boundary sliding for a final increment of ductile shearing prior to the later static recrystallisation phase. This grain-size sensitive process of grain boundary sliding may have weakened or randomised any pre-existing CPOs in the sheared veins that had been imposed by the initial dislocation creep. CPOs in the undeformed part of the older quartz veins are also relatively weak, but not as weak as in the sheared part of the same veins (Wightman, 2005; Hill, 2005; Wightman et al., 2006). Quartz c-axes in the undeformed vein parts are arranged in an expectable pattern 
about the Alpine Foliation for ductile shortening related to basal-<a $>$ slip during greenschist-facies deformation (Wightman, 2005; Hill, 2005; Wightman et al., 2006).

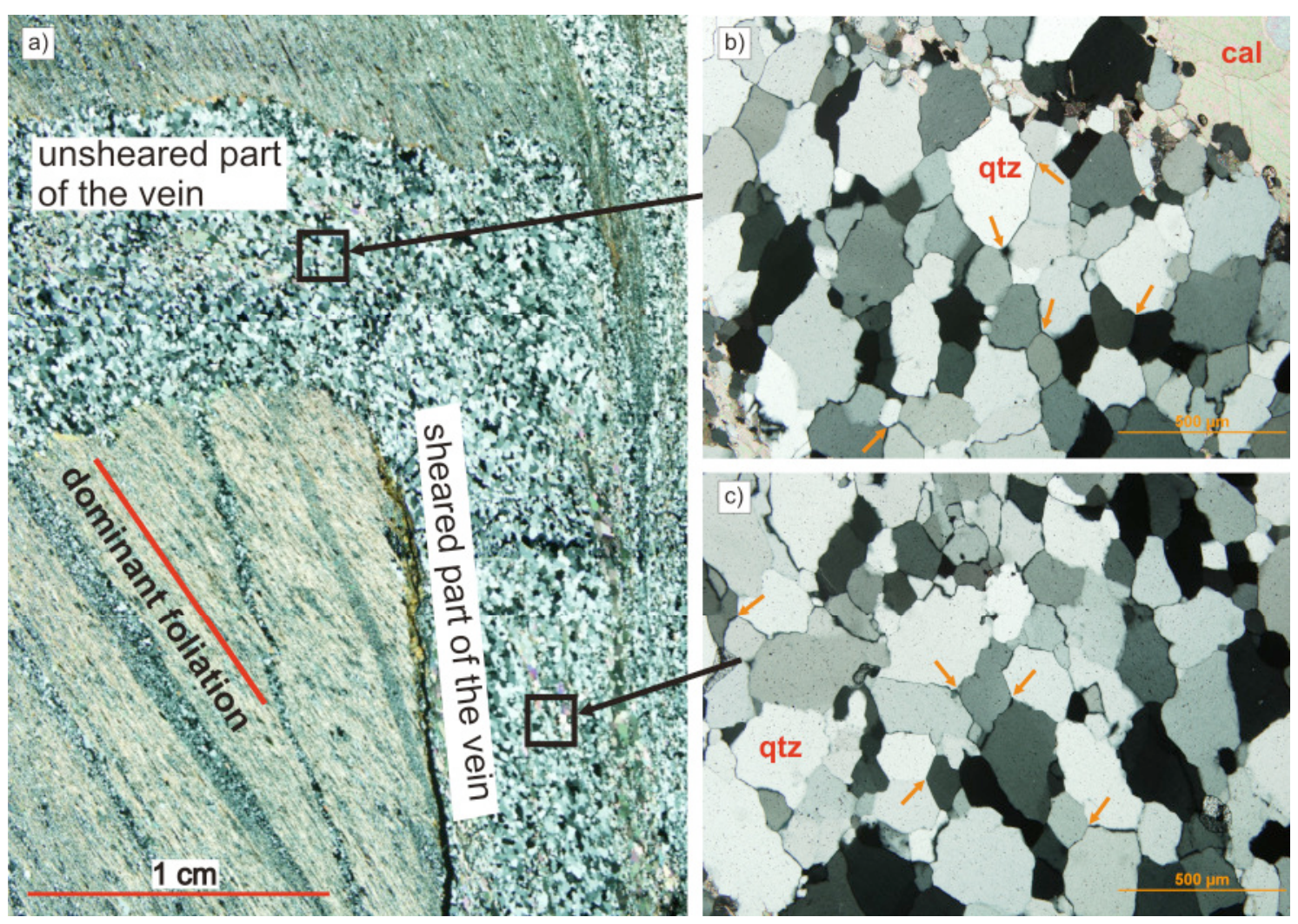

Fig. 4.7: Microphotographs of ductilely deformed quartz vein CK72 under cross-polarised light. For sample location see Fig. 4.5a. a) Stitched microphotograph of CK72. Note the smooth, fracture-free bend in the quartz vein where the shear zone transects it. The dominant foliation in the host schist wall rock to this vein is clearly expressed by a preferred dimensional alignment of biotite. b) Statically recrystallised, foam-like microstructure in unsheared part of CK72, external to the ductile shear zone. c) Statically recrystallised, foam-like microstructure in sheared part of CK72, internal to the ductile shear zone. Note how similar the polygonised grain shapes and the microstructure are in both the sheared and the unsheared part of the quartz vein. Orange arrows point to $\sim 120^{\circ}$ triple junctions between the approximately polygonal-shaped grains.

The younger, fault-infilling quartz-carbonate veins also show a statically recrystallised microtexture with a mean grain size of $141 \pm 20 \mu \mathrm{m}(2 \mathrm{D}$-grain sizes from Hill, 2005; Fig. 4.8a). Under the microscope, some of these fibrous infilling veins preserved elongate, remnant depositional quartz grains that are interpreted by Wightman (2005) as indicative of vein-growth during hybrid-extensional shear failure. Sub-parallel planar arrays of fluid inclusions in those large remnant quartz grains indicate that the veins grew incrementally through a crack-seal mechanism and that this brittle deformation was followed by partial healing of the fractured quartz (Fig. 4.8c; Wightman, 2005). Growth of such delicate and presumably progressively grown 
mineral fibres suggests that the causative displacements were slow and not abrupt as during an earthquake (e.g., Gratier and Gamond, 1990). The complete lack of any brittle wear products such as fault gouge, cataclasites or pseudotachylites implies that slip was sufficiently slow to prevent brittle comminution of the wall rocks. Also, the lack of macroscopically visible fracturing of many of the quartz veins displaced across the faults implies slow strain rates. On the basis of the delicate microstructure of the fibrous fault-infilling veins (Fig. 4.6d), shearing of the quartzofeldspathic host schist is interpreted to have been accommodated by an aseismic stable sliding process that included some dissolution-precipitation creep along the sliding surface (e.g., Gratier and Gamond, 1990; Ohlmacher and Aydin, 1997; Little et al., 2002a; Wightman, 2005).

The remnant quartz fibers in the fault-infilling quartz-carbonate veins are now largely recrystallised and show shape- and <c>-axis crystallographic preferred orientations at a high angle to the shear zone walls (Figs. $4.8 \mathrm{~b}, 4.8 \mathrm{c}$ ). The presence of undulous extinction, $<c>$-axis crystallographic preferred orientations and subgrain formation in the remnant grains indicates that the shear-infilling quartz-carbonate veins were subject to some dislocation creep after their precipitation (Fig. 4.8c).
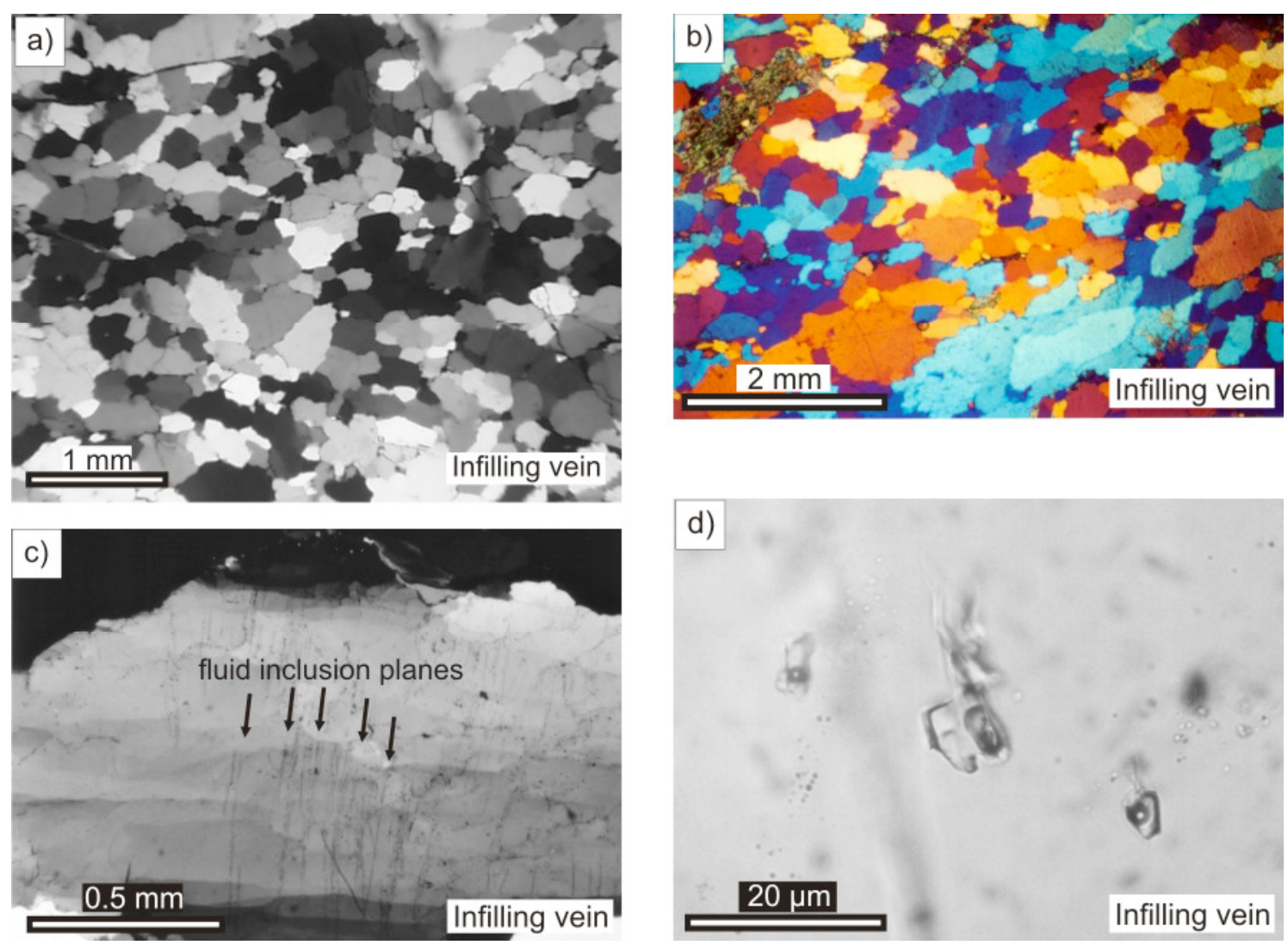
Fig. 4.8 (previous page): Microphotographs of fault-infilling quartz-calcite vein taken under crosspolarised light. Photographs from Wightman (2005). a) Microstructure of shear-infilling quartz-calcite vein. Note the polygonal foam-like grain-shape structure similar to that of the deformed quartz veins (Fig. 4.7c). b) Microstructure of shear-infilling quartz-carbonate vein showing local preservation of quartz porphyroclasts interpreted to be remnants of original fibrous vein structure in a dilational shear vein (hybrid extensional-shear) that has since been largely recrystallised. Gypsum plate inserted. c) Inferred remnant quartz fibre grain (now porphyroclastic) in shear-infilling vein that is transected by secondary fluid inclusion trails. Subgrains have formed in the relict grain also indicating some dynamic recrystallisation of the infilling vein after deposition. d) Primary fluid inclusions that occur trapped in a coarse, remnant quartz fibre in a fault-infilling vein. Fluid inclusions are two-phase, liquid-vapour $\mathrm{H}_{2} \mathrm{O}$.

\subsection{Field data documenting brittle-ductile deformation of quartz veins}

\subsubsection{Detailed maps showing brittle-ductile shear geometry}

Figs. 4.9a and 4.10a show detailed maps of the brittle-ductile shears from two glaciated surfaces at Crawford Knob. We mapped the rock surface using a 1 x $1 \mathrm{~m}$ grid that was divided into 10 x $10 \mathrm{~cm}$ sections. Mapping precision was $<1 \mathrm{~cm}$. Only outcrop separations (offsets) are revealed on these maps, because the outcrop planes did not exactly coincide with the average movement plane of the brittle-ductile shears (Grigull and Little, 2008). Using the average attitudes of the glaciated outcrop surfaces, the brittle-ductile faults and its slip lineations, and the average orientation of the quartz marker veins (Table 4.1), we were able to determine that offsets (strike separations) on the outcrop surfaces overestimate the true slip by $\sim 8 \%$ on average at the locality of Fig. 4.9a; and by $\sim 18 \%$ on average at the locality of Fig. 4.10a. In detail these differences vary slightly between the consistently oriented individual shears and individual quartz veins. The main point is that there is not much difference between the outcrop separation and true displacement at the localities of the maps in Figs. 4.9a, 4.10a. The $D$-value is a ratio of ductile slip to total slip across a marker vein and is relatively insensitive to errors that arise from the overestimated absolute displacement values.

The maps in Figs. 4.9a and 4.10a show how regularly spaced the shears are and how they cut and offset the dominant schist foliation (represented by grey pelite layers) at an angle of $\sim 23^{\circ}$. The maps also show the variable interaction between the faults and the older quartz veins that they crosscut. Mapping of individual shears along strike indicates that they persist both laterally and vertically over distances of 1 to $10 \mathrm{~s}$ of metres (Figs. 4.9a, 4.10a, 4.11, 4.12; e.g., shears labelled CK-A, CK-B and CK-D in the upper part of Fig. 4.10a). 


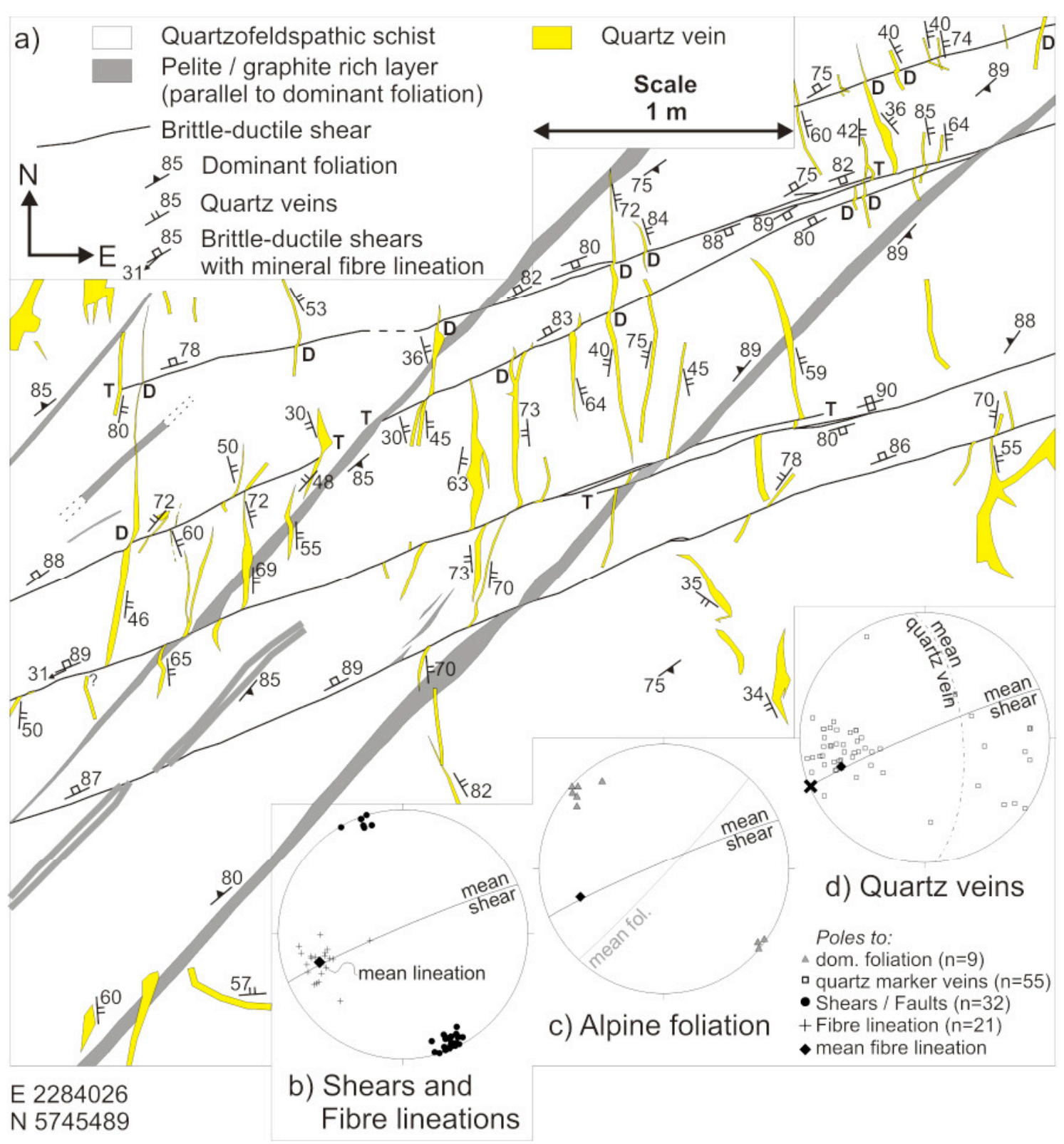

Fig. 4.9: a) Detailed outcrop map of brittle-ductile shears at Crawford Knob. For location of map see Fig. 4.5a. Maps were prepared using a $1 \times 1 \mathrm{~m}$ grid divided into $10 \times 10 \mathrm{~cm}$ sections. Mapping accuracy is $<1 \mathrm{~cm}$. "D" marks quartz veins that have been fully ductilely displaced; all other veins are displaced brittlely to various degrees. " $T$ " indicates fault terminations. b) Lower hemisphere equal area stereogram of brittle-ductile shear orientations in the mapped area, and their associated quartz-calcite fibre lineations. The lineations were measured in the vicinity and within the mapped area. The mean lineation is indicative of the slip direction on the shears (Wightman, 2005). It is represented by a diamond and plotted in c) and d) as well. c) Stereogram of dominant Alpine foliation in the mapped area. Mean orientation of foliation is indicated by grey line. Mean shear orientation is indicated by solid black line. d) Stereogram of quartz vein attitudes in the mapped area. Mean quartz vein orientation is indicated by stippled line. Mean shear orientation is indicated by solid line. Black diamond is mean mineral fibre lineation. The mean outcrop trace of the shears (intersection between mean outcrop surface and mean shear) is indicated by the " $\mathrm{X}$ ", and is only $29^{\circ}$ from the true slip direction. 


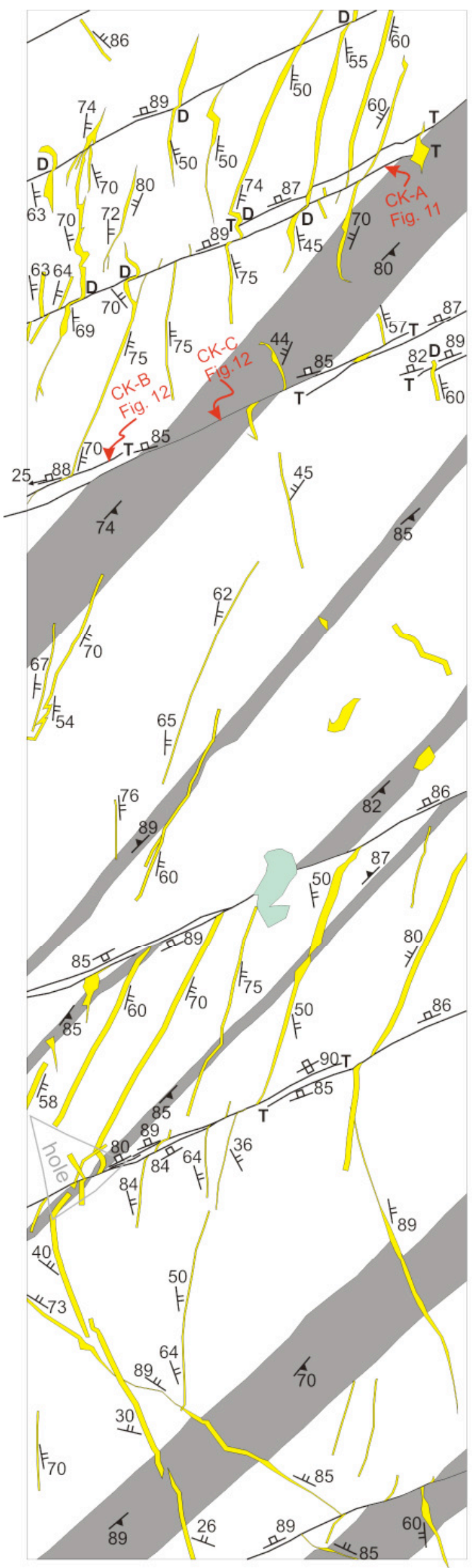

b) Shears and fibre lineations

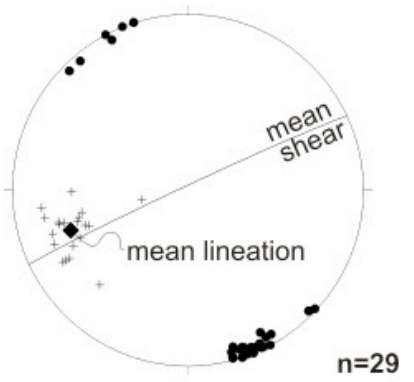

c) Alpine foliation

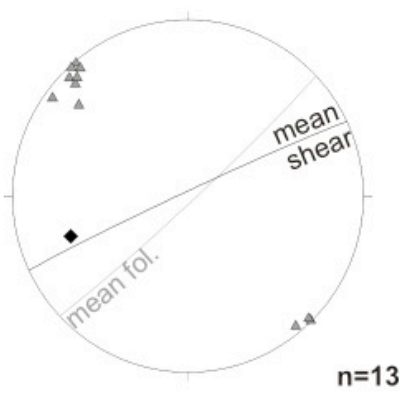

d) Quartz veins

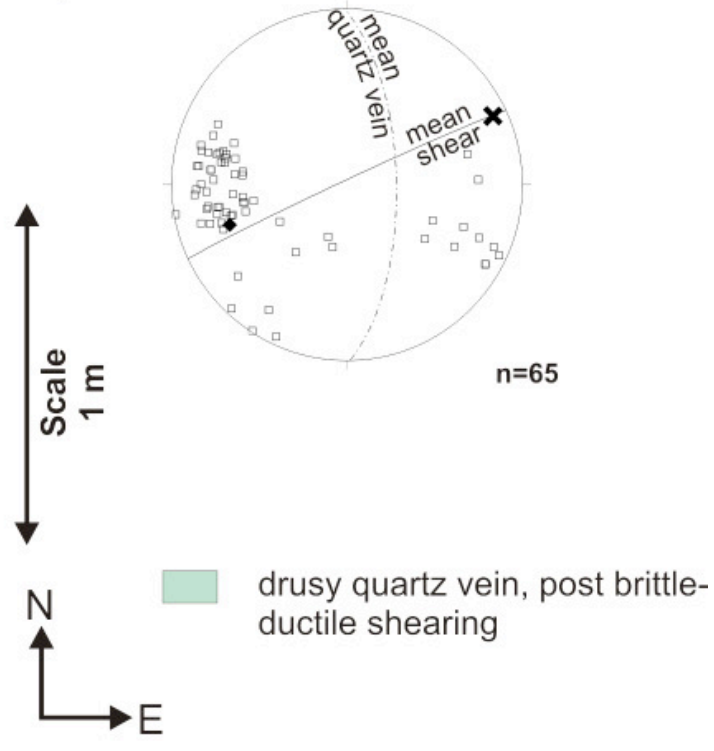

Fig. 4.10: a) Outcrop map of brittle-ductile shears at Crawford Knob. For location of map see Fig. 4.5a. Maps were prepared using a 1 x $1 \mathrm{~m}$ grid divided into $10 \times 10 \mathrm{~cm}$ sections. Mapping accuracy is $<1 \mathrm{~cm}$.

b) Lower hemisphere equal area stereogram of brittleductile shear orientation in the mapped area and mean orientation of mineral fibre lineation. c) Stereogram of dominant Alpine foliation in the mapped area. d) Stereogram of quartz vein attitudes in the mapped area. The mean outcrop trace is indicated by the ' $X$ ' and is $141^{\circ}$ from the true slip direction.

Symbols and unit patterns are the same as those used in Fig. 4.9. 
The brittle-ductile faults in the mapped areas strike SW-NE and dip steeply to the NW (see Table 4.1 and stereograms in Figs. 4.9b, 4.10b). The mineral fibre lineations on the fault planes have an average trend of $251^{\circ}$ and an average plunge of $30^{\circ}(n=21$; Table 4.1 and Figs. $4.9 \mathrm{~b}, 4.10 \mathrm{~b}$ ). We obtained this average striation attitude by taking lineation measurements within a radius of $\sim 300 \mathrm{~m}$ around the mapped fault traces. The dominant foliation strikes $\sim 045^{\circ}$ and is nearly vertical (Figs. $4.9 \mathrm{c}, 4.10 \mathrm{c}$, Table 4.1 ). Most of the sheared quartz veins at Crawford Knob dip moderately $\left(60-70^{\circ}\right)$ to the East. Only $\sim 19$ $\%$ of the veins dip to the opposite direction at relatively moderate angles of $\sim 30-70^{\circ}$ (see dip symbols in the detailed maps in Fig. 4.9a and 4.10a). In Fig. 4.9, the mean quartz vein marker has an attitude of 085/65 (Fig. 4.9d). In Fig. 4.10d it has an average attitude of $089 / 67$. Table 4.1 summarises the average orientation measurements of the relevant geological structures that were measured in and around the mapped areas.

Table 4.1 Mean attitudes (in dip direction and dip angle) of structural features at Crawford Knob (see also stereoplots in Figs. 4.7 and 4.8)

\begin{tabular}{ccc}
\hline & Fig. 4.9 & Fig. 4.10 \\
\hline Shear plane & $337 / 86(\mathrm{n}=31)$ & $335 / 88(\mathrm{n}=29)$ \\
Mineral fibre lineation & \multicolumn{2}{c}{$251 / 30(\mathrm{n}=21)$} \\
Dominant foliation & $133 / 87(\mathrm{n}=9)$ & $137 / 87(\mathrm{n}=13)$ \\
Quartz vein & $085 / 65(\mathrm{n}=53)$ & $089 / 67(\mathrm{n}=65)$ \\
Outcrop plane & $327 / 21(\mathrm{n}=30)$ & $352 / 29(\mathrm{n}=52)$ \\
Intersection outcrop/shear & $247 / 01$ & $065 / 09$ \\
\hline
\end{tabular}

At first glance, the faults may appear to be planar, straight, through-going structures; however, in detail fault-fault interactions and fault refraction across different lithological layers (e.g., quartz veins vs. pelite layers) causes them to be locally curved. Many faults deflect in a characteristic manner to follow the outer margins of the otherwise ductilely deformed quartz veins that they transect. Others terminate into the interior of quartz veins, across which the fault-slip is converted into a wholly ductile slip in those veins (in Figs. 4.9a and 4.10a these veins are marked with " $D$ " to indicate that $D=1.0$ ). The width of overlaps between two adjacent shears is typically on the order of $\sim 10 \mathrm{~cm}$, whereas the distance of their overlap is typically $20-100 \mathrm{~cm}$ (e.g., regions between overlapping fault terminations marked with " $T$ " in Figs. 4.9a and 4.10a). 
The displaced quartz veins and the pelite markers that are cross-cut by the shears can be used to measure the total separation $\left(y^{*}\right)$ across the shears as a function of strikeparallel distance $(x)$ along these shears (Figs. 4.11 and 4.12). Shears CK-A (Fig. 4.11) and CK-B (Fig. 4.12) both start within the map of Fig. 4.10a and extend to the SW, outside the mapped area. We traced the remaining lengths of those two shears from photographs that were stitched together. The mapping precision from photographs is $<2$ $\mathrm{cm}$. This is due to lens distortion of the photographs, which could not entirely be removed during photo stitching. Shear CK-C (Fig. 4.12) lies inside the mapped area and overlaps with CK-B.

The shape of the displacement-length curves for these three brittle-ductile faults is slightly asymmetric. CK-A (Fig. 4.11) extends over $396 \mathrm{~cm}$ and we measured a maximum separation of $8.2 \mathrm{~cm}$ along that shear. CK-A shows a crude apparent displacement plateau rather than a distinct maximum displacement. The plateau in the displacement profile may be due to the measurement plane not cutting through the centre of the fault and/or the fault surface not being exactly elliptical in shape (e.g., Cowie and Scholz, 1992). Shear CK-C (Fig. 4.12) is $192 \mathrm{~cm}$ long and has a maximum separation of $25.3 \mathrm{~cm}$; shear CK-B (Fig. 4.12) is $458 \mathrm{~cm}$ long and the maximum measured apparent offset is $38.2 \mathrm{~cm}$. Shears CK-B and CK-C overlap across a length of $58.5 \mathrm{~cm}$ (Fig. 4.12). The overlapping zone between CK-B and CK-C is $\sim 6 \mathrm{~cm}$ wide. The thick pelite layer close to the overlap is partly ductilely deformed in front of the NE termination of CK-B.

The Separation/length-gradient $(\Delta y * / \Delta x)$ near the shear terminations of those three shears (CK-A, CK-B, CK-C) are 0.48 on average. Locally the ratio is as low as 0.05 (SW-termination of CK-A, Fig. 4.11) or as high as 1.05 (NE-termination of CK-C, Fig. 4.12). These values are reminiscent of those measured by Christiansen and Pollard (1997) in ductile shear zones that had formed in granites in the Sierra Nevada, California. They reported 0.4-0.48 as separation/length-gradients for those shear zones. In a similar way, Pennachioni (2005) measured displacement gradients in the range of 0.1-0.3 (with a maximum of 0.8) in amphibolite facies ductile shear zones formed in tonalites in the Adamello massif, northern Italy. 


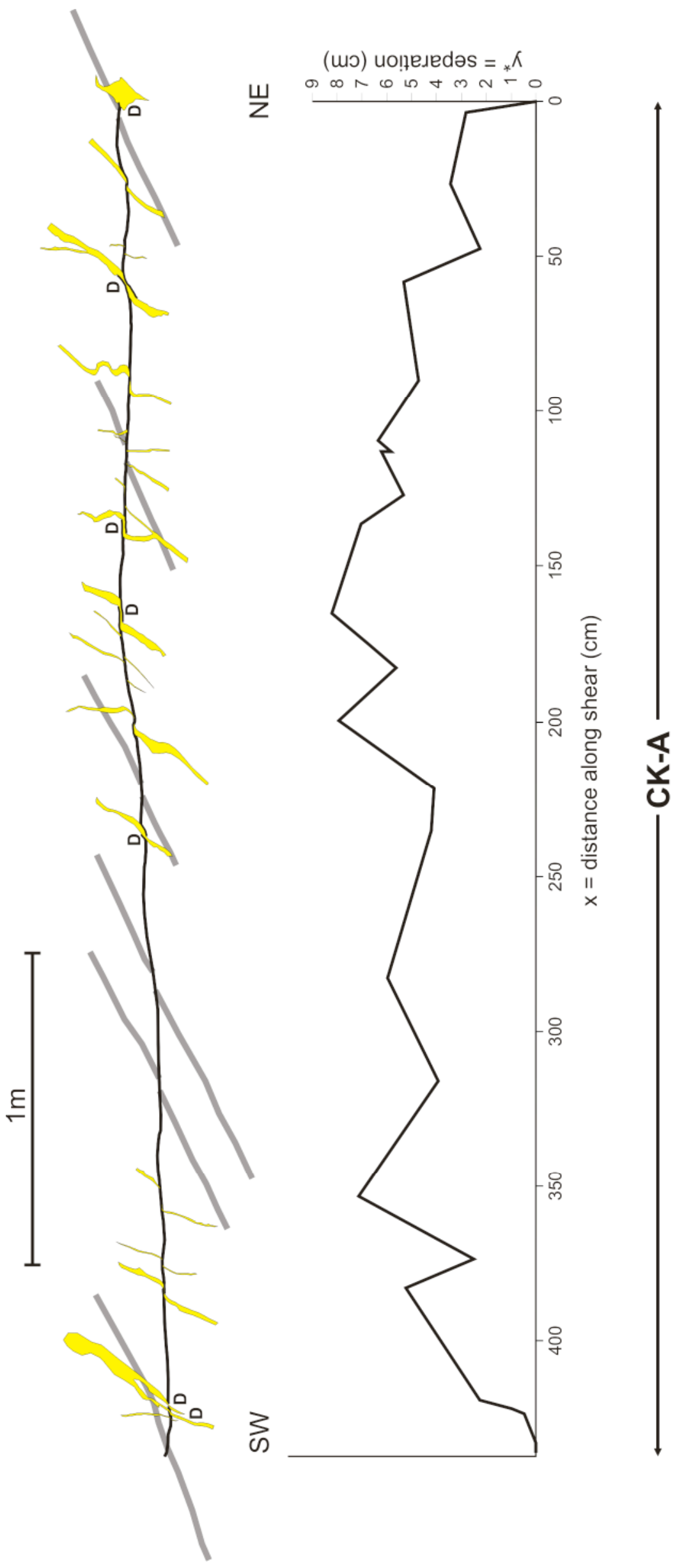

我

覀

包

을

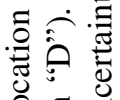

은

更

递

क ส

志芯

$\tau \frac{\pi}{n}$

흏

형

톨 웅 웅

㟧党

寻急

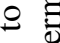

定它

赵

동

年

卷

o o

bo

$\frac{0}{\pi} \frac{2}{3}$

量:

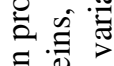

흑

념 를

己े

䔫

$\varangle \frac{5}{5}$

记宓导

离

棺氙总

을 을

萗

월

可

๑ั

$\ddot{\exists}$ z

比兽 


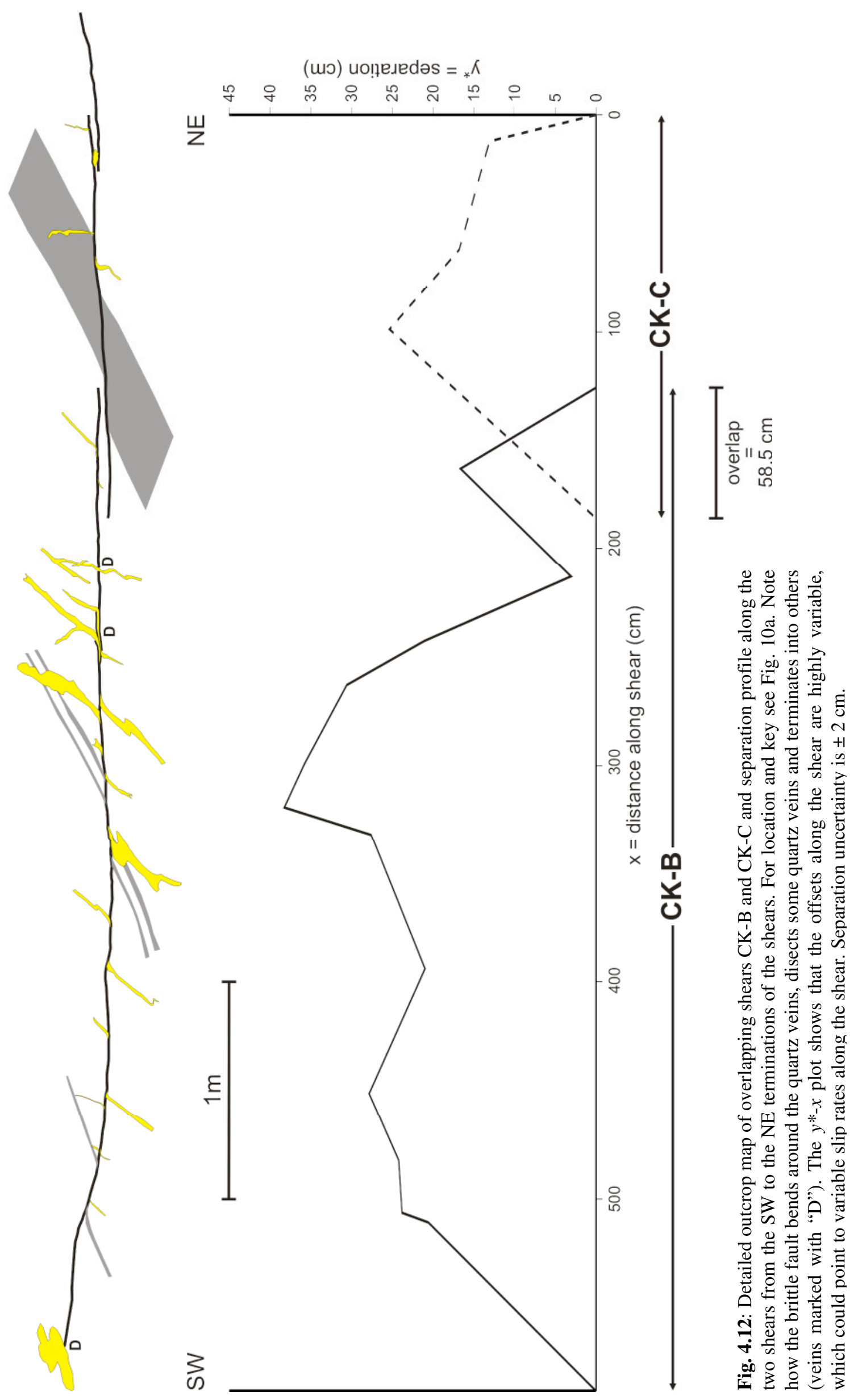


4.5.2 Geometrical scaling relationship between ductile displacement (d) of the quartz veins and ductile shear zone width (dsw) - Does it indicate shear zone hardening or softening?

We have measured the ductilely sheared width (equivalent to the shear zone width, $d s w$, Fig. 4.2) and the total ductile displacement $(d)$ of 72 quartz veins at Crawford Knob and Chancellor Ridge. In Fig. 4.13, we have plotted "true" $d$ and "true" $d s w$, i.e., these measurements have been corrected for the deviation of the outcrop plane from the actual movement plane. This correction was done following a projection method that has been developed and described by Grigull and Little (2008). Given the attitudes of the outcrop surface, marker vein, fault surface, and the slip vector, the method enables us to measure the true shape and offset of a deformed quartz vein as observed on an arbitrary outcrop plane by means of a projection of the map data onto the actual movement plane of the faults. Note that especially within the first $2-3 \mathrm{~cm}$ of displacement the ductile shear zone width $(d s w)$ increases in a non-linear fashion with increasing ductile slip $(d)$. The positive slope of this curve seems to indicate that the shear zones that have formed in these veins appear to have progressively widened into previously undeformed rocks as a function of slip (or time). This suggests that the shears were behaving as type I or type III shear zones in the sense of Means (1984, 1995) and Hull (1988); i.e., these shear zones probably hardened with progressive displacement, at least during the initial stages of shearing.

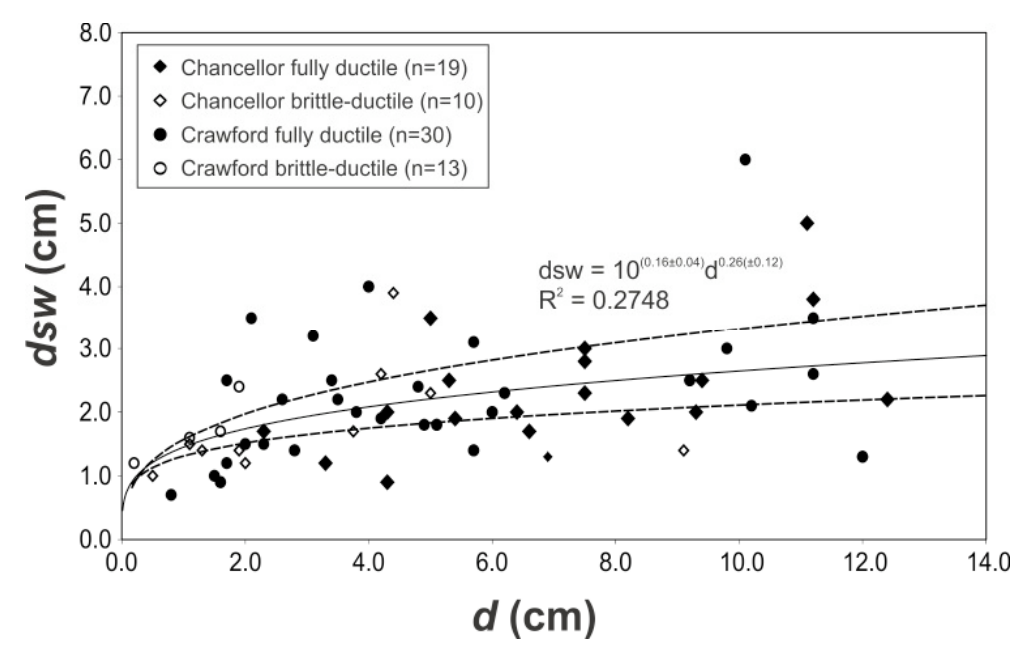

Fig. 4.13: Actual ductile shear-width $(d s w)$ of a deformed quartz vein plotted against the ductile component of slip $(d)$. Regression indicates a crude non-linear increase of $d s w$ (shear zone width) with increased $d$. The positive slope of the fitted curve suggests that the shearing quartz veins hardened with increasing ductile displacement (e.g., Means, 1984, 1995). Dashed lines correspond to trendline errors. 


\subsection{Variations in $D$-values - Do they hold information on rheological (pre)conditions of the quartz veins prior to shear zone localisation?}

\subsubsection{Preface - Which factors can cause different D-values?}

We have shown in Figs. 4.9a, 4.10a, 4.11 and 4.12 that not all quartz veins have slipped fully ductilely. Some have slipped completely brittlely, and others have both ductile and brittle slip components, probably indicating that the veins had different effective viscosities. In order to understand what has led to the variable $D$-values, we seek the factors that may have caused a change or a difference in the effective viscosity from one quartz vein to another. In the following, we will investigate whether differences in vein thickness $\left(t_{\text {orig }}\right)$ and total vein displacement $\left(y_{t o t}\right)$ or in pre-deformation conditions or rheology of the veins were responsible for the scattering of the scaling relationships or whether local differences in slip rate could explain this variable degree of embrittlement. Resolving this is a first step towards understanding the dominant shear zone localisation processes in the quartz veins. We will determine whether there are differences in calcite content, precursory embrittlement, water content and deformation temperature and try to correlate them with more ductile or more brittle deformation in the quartz veins. Fig. 4.14 summarises the dependency of $D$ on the factors that will be investigated in the following sections. Going into the study, we might expect that $D$ values decrease as a function of increasing total displacement, fault slip rate, pore fluid pressure, and differential stress, whereas $D$-values should be high for increasing original vein thickness, calcite content, water content, and deformation temperature (Fig. 4.14). It is difficult to estimate in what way these factors may influence one another. We will therefore investigate each factor separately, assuming that the other factors did not change during deformation. In each of the following sections, we first explain why $D$ may scale with the factors listed in Fig. 4.14.

Experimentally and geologically derived flow laws predict that the viscous yield strength of the quartz veins depends chiefly on creep strain rate, deformation temperature and water fugacity (Eq. 4.1; e.g., Paterson and Luan, 1990, Post and Tullis, 1998; Hirth et al., 2001). Impurities such as different mineral phases can also change the strength of the veins (e.g., Brodie and Rutter, 2000; Holyoke and Tullis, 2006; Mancktelow and Pennacchioni, 2010). Grigull et al. (this study, Chapter 3) have used a combination of field observations and numerical modelling to constrain aspects of the operative flow law for the quartz veins. Grigull et al. (this study, Chapter 3) found that 
the bulk shearing of the quartz veins was probably accommodated by a grain-size insensitive, dislocation creep process, following a power law of the form:

$$
\dot{\varepsilon}=A \cdot f_{\mathrm{H}_{2} \mathrm{O}} \cdot \sigma_{d}^{n} \cdot \exp (-Q / R T)
$$

where $\dot{\varepsilon}$ is the (uniaxial) strain rate in $\left[\mathrm{sec}^{-1}\right], A$ is the pre-exponential factor in $\left[\mathrm{MPa}^{-\mathrm{n}} \sec ^{-1}\right], f_{\mathrm{H}_{2} \mathrm{O}}$ is water fugacity in [MPa], $\sigma_{d}$ is the differential stress in [MPa], $n$ is the stress exponent, $Q$ is activation energy in $\left[\mathrm{J} \mathrm{mol}^{-1}\right], R$ is the universal gas constant [8.314 $\left.\mathrm{J} \mathrm{mol}^{-1} \mathrm{~K}^{-1}\right]$, and $T$ is temperature in [K]. Grigull et al. (this study) found that the numerical models that best reproduced the shape characteristics and scaling relationships of the naturally deformed quartz veins invoked $A=10^{-10 \pm 2} \mathrm{MPa}^{-\mathrm{n}} \mathrm{sec}^{-1}$ and $n=3-4$. They assumed $Q=135000 \mathrm{~J} \mathrm{~mol}^{-1}$ by reference to the geologically derived and frequently used quartzite flow law by Hirth et al. (2001). In their numerical computer models, Grigull et al. (this study) assumed that each quartz vein was homogeneous.

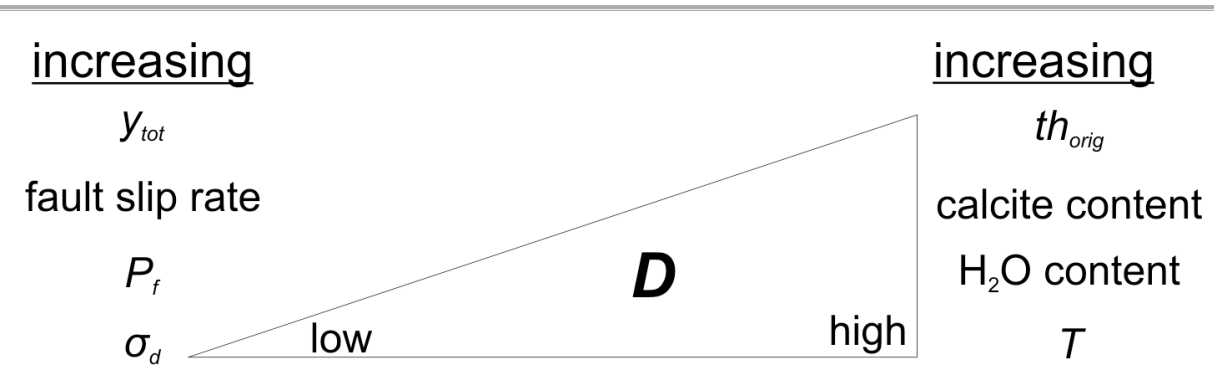

Fig. 4.14: Inferred dependency of ductility $D$ on increase in factors that could possibly influence $D$. $y_{t o t}$ is total displacement, $P_{f}$ is pore fluid pressure, $\sigma_{d}$ is differential stress, $t h_{\text {orig }}$ is original vein thickness, $T$ is deformation temperature. $D$-values are assumed to be low for increasing $y_{\text {tot }}$, fault slip rate, $P_{f}, \sigma_{d}$ and high for increasing $t h_{\text {orig }}$, calcite content, $\mathrm{H}_{2} \mathrm{O}$ content, and $T$.

\subsubsection{Variability of $D$ with original vein thickness $\left(t_{\text {orig }}\right)$ and total slip $\left(y_{\text {tot }}\right)$}

The displacement of the quartz veins is not always accommodated by purely ductile flow; however, most of the quartz veins that also slipped brittlely exhibit a ductile-to-total slip ratio of $D \leq 0.5$ (Figs. 4.15a and 4.15b). Moreover, to first order, the original thickness of a quartz vein seems to have determined whether its deformation was later largely brittle or ductile. Veins with an original (or undeformed) thickness $t h_{\text {orig }}>2.0 \mathrm{~cm}$ mostly deformed $100 \%$ ductilely, whereas thinner veins typically slipped with a mixed ductile to brittle style of offset (Fig. 4.15a). To some extent, the total vein displacement $y_{t o t}$ also seems to control the ductility ratio of the 
displaced quartz veins (Fig. 4.15b). This plot shows that measurable brittle slip of the quartz veins only occurs after a total slip of $\sim 3 \mathrm{~cm}$. After $\sim 3 \mathrm{~cm}$ of purely ductile slip of all quartz veins, some of the veins reacted brittlely to ongoing shearing resulting in $D<$ 1.0. Other veins continued to deform in a $100 \%$ ductile fashion $(D=1.0)$. Since $D$ is the ratio of ductile slip component $(d)$ to total slip $\left(y_{t o t}\right)$, one would expect $D$ to decrease as a function of increasing total slip if, after brittle failure of a quartz vein, $d$ remained relatively fixed whereas $y_{t o t}$ continued to increase. The variability of the data plotted in Figs. $4.15 \mathrm{a}$ and $4.15 \mathrm{~b}$ did not allow us to establish a scaling law that exactly describes the dependency of $D$ on $t h_{\text {orig }}$ or on $y_{t o t}$. In the following, we will investigate possible reasons for this scattering of $D$-values along-strike of individual faults.

a)

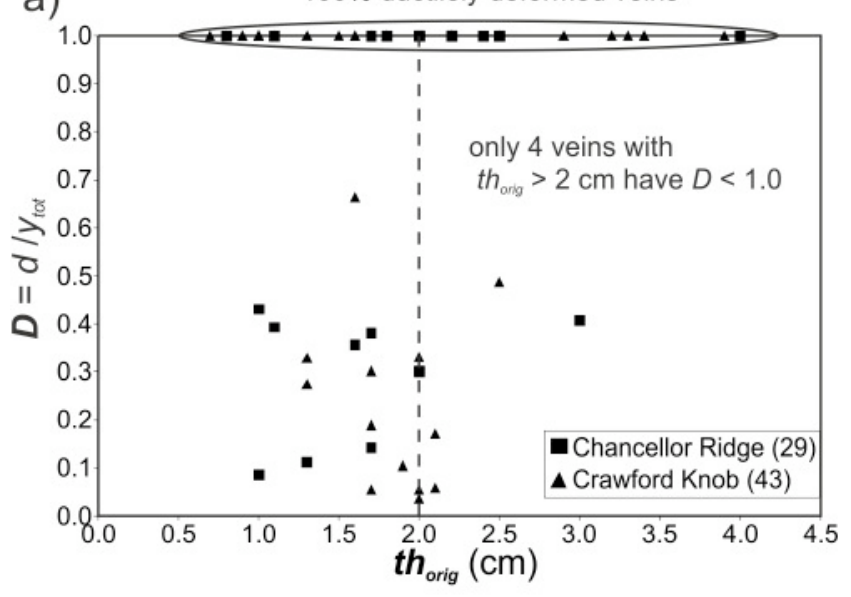

b) $100 \%$ ductilely deformed veins

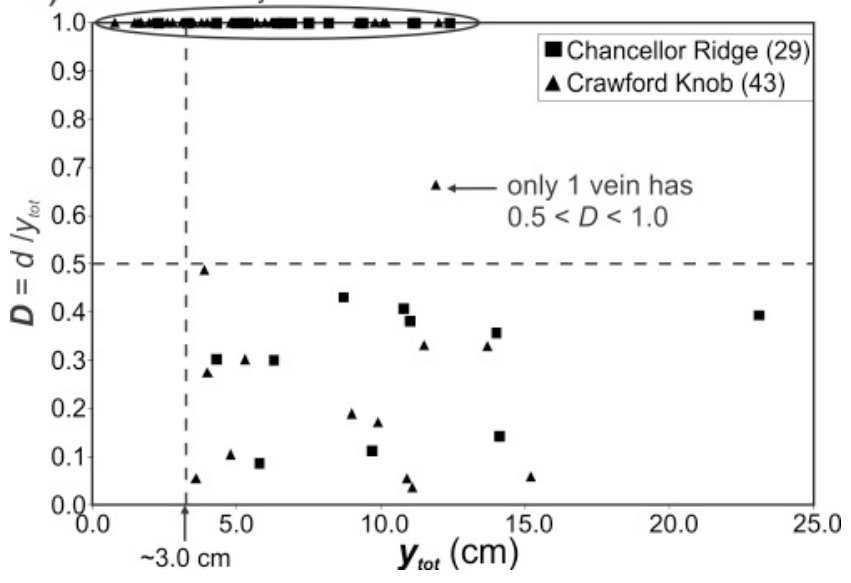

Fig. 4.15: a) Plot of ductility ratio $D$ against the original thickness $t h_{\text {orig }}$ of a vein, illustrating that quartz veins $>2 \mathrm{~cm}$ usually deform entirely ductilely $(D=$ 1.0) and quartz veins $\leq 2 \mathrm{~cm}$ can deform brittlely or ductilely or both $(D \leq 1.0)$. b) Plot of ratio $D$ against the total displacement $y_{\text {tot }}$ of the quartz veins, showing that generally $D \leq 0.4$ for veins that have failed in part brittlely. $t h_{\text {orig }}$ and $y_{\text {tot }}$ are inferred to control the $D$-ratio in the quartz veins. The scattering in those plots does not reveal a simple relationship between $t h_{\text {orig }}$ and $D$ or between $y_{\text {tot }}$ and $D$. This suggests that local variability in the viscous strength or rheology of the quartz veins controlled the diversity of observed brittle to ductile offset. The data plotted here was corrected for the deviation of the measurement plane from the movement plane using the method by Grigull and Little (2008). 

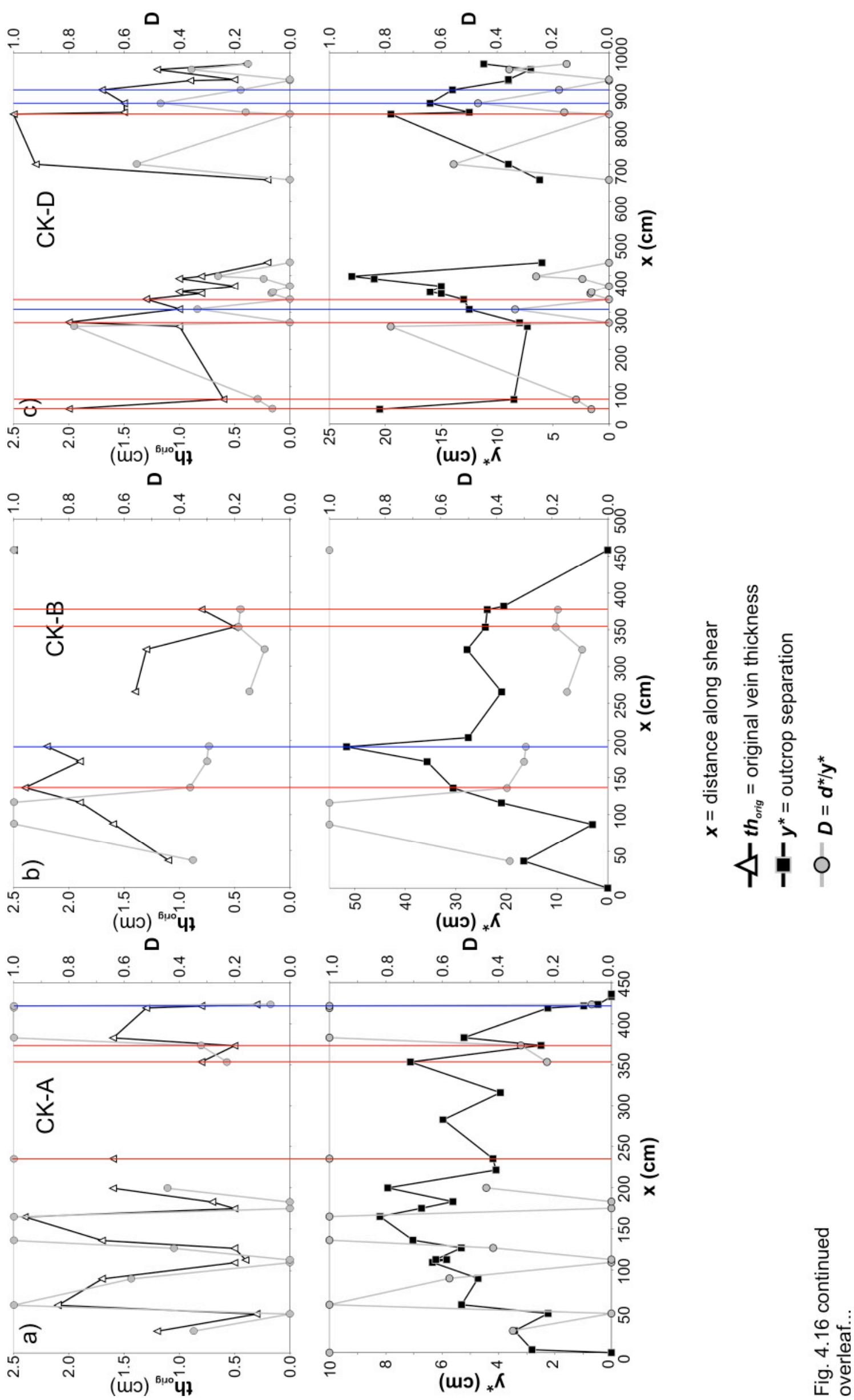

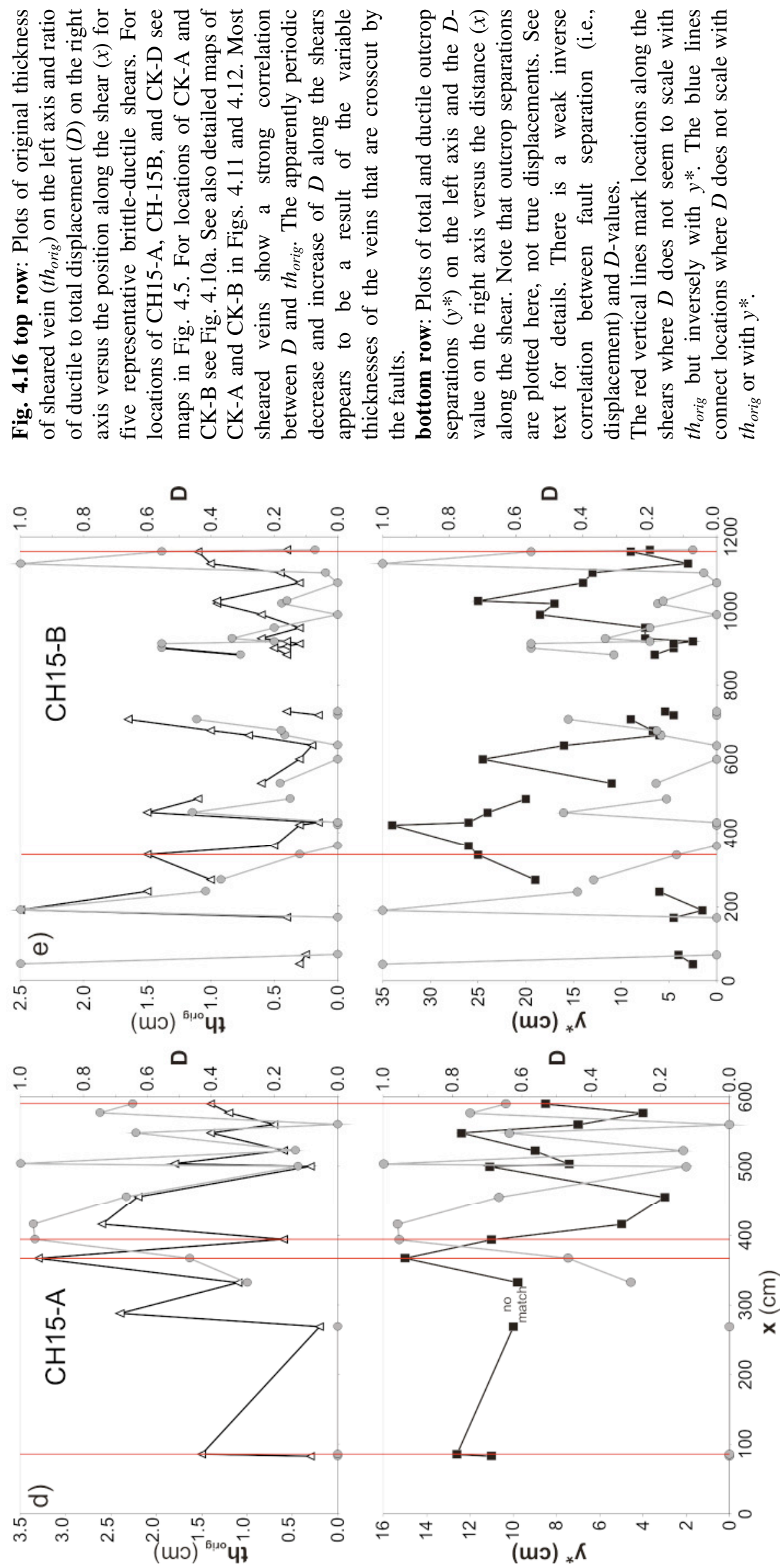
The data for the plots in Figs. 4.15a and 4.15b were collected from sheared quartz veins at various locations in the brittle-ductile shear array; i.e., these quartz veins were not displaced across the same individual faults. In the following, we investigate whether the scattering of $D$-values observed in Figs. $4.15 \mathrm{a}$ and $4.15 \mathrm{~b}$ occurs along-strike of individual faults. In Fig. 4.16, we show plots of $D$ vs. the position $x$ of each sheared quartz vein along-strike of the faults for the following examples: CK-A, CK-B, CK-D, CH15-A, CH15-B. D is plotted on the right axes. Additionally, on the left axes, we plotted original vein thickness $\left(t h_{\text {orig }}\right)$ and total outcrop separation $\left(y^{*}\right)$ of the sheared quartz veins in the top and bottom rows of Fig. 4.16 respectively. We were able to follow shears CK-A and CK-B along their entire length. The other three profiles are sections of representative brittle-ductile faults in the working area (for their locations refer to the maps in Fig. 4.5). The origins $(\mathrm{x}=0 \mathrm{~cm})$ of $\mathrm{CK}-\mathrm{A}$ and $\mathrm{CK}-\mathrm{B}$ correspond to the SW-terminations of these faults. The terminations of the other three faults were cut off by much younger joints perpendicular to their strike direction. For these faults we chose the origins of the fault profiles such that we could map sufficiently long, coherent fault sections towards the NE on an outcrop plane with an orientation similar to that of the movement plane of the shears. The outcrop separation $y^{*}$ along the faults in Fig. 4.16a-e is close to the true value of the total displacement $y_{t o t}$.

One of the main inferences to be made from the plots in Fig. 4.16a-e is that $D$ varies rapidly over small distances along the individual faults. To a first order and as expected from Fig. 4.15a, this variability mimics the variability of quartz vein thicknesses along the shears (top row of Fig. 4.16a-e). The vertical red lines in Fig. 4.16a-e mark locations along the faults, where $D$ does not seem to scale with $t h_{\text {orig. }}$. From Fig. 4.15b, we expect an inverse relationship between $D$ and $y^{*}$. The red lines extend into the bottom row of plots in Fig. 4.16a-e, where they intersect with the $y^{*}-x$ graphs. This is to show that in most cases at a location $x$ along a shear, where the $D$ ratio of a quartz vein does not scale with $t h_{\text {orig }}$, it does scale inversely with $y^{*}$. We can therefore assume that generally $D \propto \frac{t h_{\text {orig }}}{y^{*}}$. This relationship is probably oversimplified since there may be a co-dependence of $y_{\text {tot }}$ and $t h_{\text {orig }}$ in that a smaller amount of slip should be required in order to brittlely fracture a thin vein than a thick vein. The bottom row of plots in Fig. 4.16a-e also show that the total displacement does not only vary from fault tip to fault centre, but that $y^{*}$ also varies significantly over short distances along the shears. The difference in the displacements of neighbouring veins that are 
only a few centimetres apart can be $>20 \mathrm{~cm}$ from one vein to the next (e.g., shears CKB and CK-D in Figs. 4.16b and 4.16c respectively).

\subsubsection{Indicators of spatially variable fault slip rates}

We marked locations along the shears with blue vertical lines in Fig. 4.16 where $D$ does not scale with $t h_{\text {orig }}$ or with $1 / y^{*}$. Figs. $4.17 \mathrm{a}$ and $4.17 \mathrm{~b}$ illustrate two contrasting examples of different degrees of ductile and brittle deformation that relate to the blue lines in Fig. 4.16. Vein CK308 is displaced $100 \%$ ductilely $(D=1.0)$; whereas vein CK326 is displaced only $10 \%$ ductilely $(D=0.1)$. If original vein thickness and total displacement were the only factors controlling the ductility of offset, we would expect a higher $D$-value for CK326 than for CK308 because 1) CK326 is slightly thicker than CK308, and 2) CK326 is displaced $\sim 7 \mathrm{~cm}$ less than CK308. However, what we observed in the field is exactly opposite to these two predictions; that is, CK308 is completely ductilely deformed whereas the slip in CK326 was almost entirely brittle.

a)

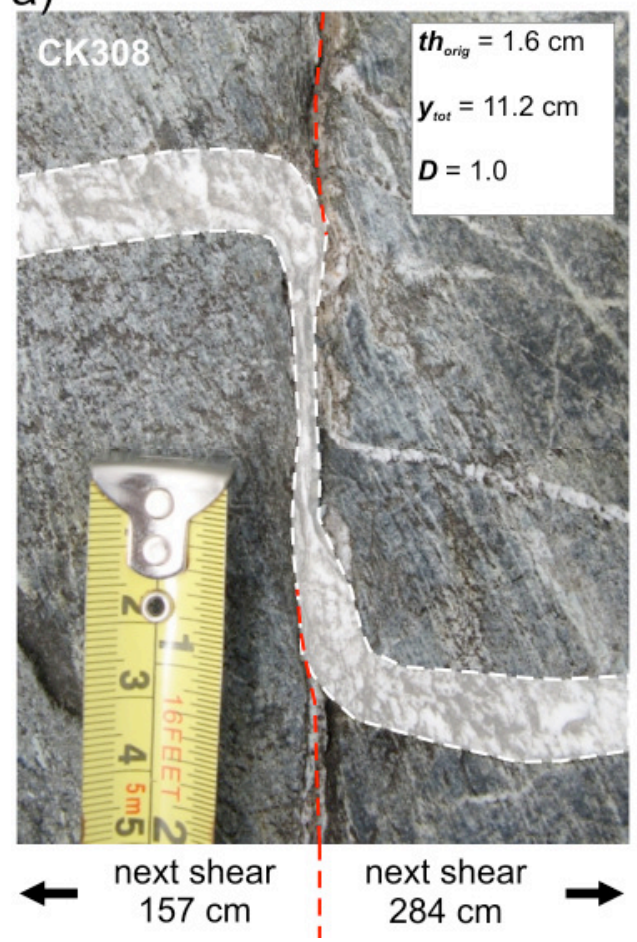

b)

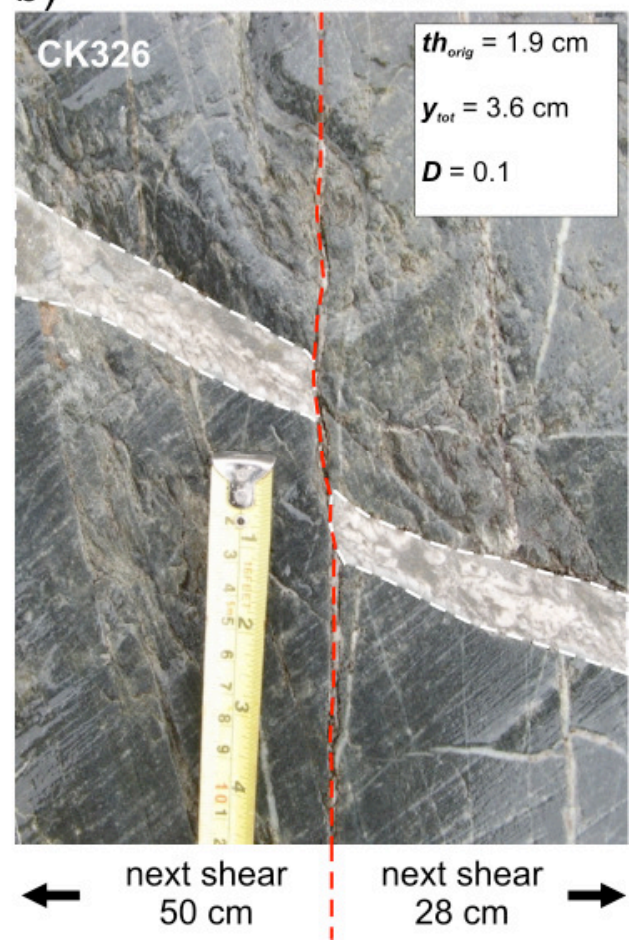

Fig. 4.17: Photographs of a) CK308 (fully ductile) and b) CK326 (90\% brittle), both from Crawford Knob. Despite having similar thicknesses, the $D$-ratios of those two veins are conspicuously different. Because of the higher displacement in CK308, one might expect this vein to conspicuously having failed more brittlely than CK326, but the opposite is the case. The displacement data in the white boxes have been corrected for outcrop deviation from the movement plane following the method of Grigull and Little (2008). 
Theoretically, if slip rates were constant along a given fault (here we do not consider the fault tip regions), and if the rheology of the quartz veins displaced by that fault were the same, one would expect adjacent quartz veins of similar thicknesses to exhibit very similar offsets and to have a similar ductile-to-total slip ratio $(D)$. The 'jaggedness' of the $y^{*}$-curves in Fig. 4.16, however, would seem to imply that the slip rate along a fault may not have been constant everywhere along that fault. Spatially variable slip rates along the faults could cause differences in the flow strain rate and therefore the flow stress of the viscously deforming quartz veins (Eq. 4.1). This could have led to differential ductility between one vein and another. With decreasing creep strain rate, the flow stress would also decrease, making brittle failure less likely. If there were no vein-to-vein differences in calcite content, precursory embrittlement, molecular water content, or temperature during deformation, and if water fugacity remained the same during deformation, variable slip rates along the faults may have been the chief factor leading to variable strain rates and therefore $D$-values. This condition might lead to brittle failure of quartz veins intersected by the more rapidly slipping fault sections at the same time that such yielding did not occur on other continuously ductilely deforming veins. In summary, fault slip rates and consequently shear strain rates seem to have varied rapidly along the brittle-ductile shear zones. Slip rate variation could have contributed to the differential ductilities in the sheared quartz veins. Some possible causes of the varying slip rates are discussed in section 4.7.3.

\subsubsection{Indicators of variable shear strain rates in regions of fault overlaps}

The effect of spatially variable strain rates on the $D$-ratio of a sheared vein is most obvious in the overlapping zones between some adjacent faults in the quartzofeldspathic host schist. Near the fault terminations ("T" in Fig. 4.9a, and 4.10a) deformation in the overlap zones caused the foliation to rotate dextrally into near-parallelism with the bounding shear zone walls. Fig. $4.18 \mathrm{a}$ and $18 \mathrm{~b}$ shows examples of overlapping zones and foliation rotation. The rotation of the foliation is indicative of ductile creep in the otherwise brittlely faulted quartzofeldspathic schist that is spatially localised to the volume of rock between the overlapping fault strands. This volume is much greater per unit fault length than the rest of the faults and implies that the reduced shear strain rates across these wide overlap zones were low enough to suppress brittle failure there. At a smaller scale, the quartz veins also become more ductile in the area of fault-overlaps. In Fig. $4.18 \mathrm{c}$, a single quartz vein has split up into two branches of approximately the same 
thickness; the upper branch has been sheared between two adjacent faults and has deformed entirely ductilely $(D=1.0)$ indicating low strain rates in the wide area between the overlapping fault strands, whereas the lower branch has been sheared along one single fault which led to mostly brittle deformation $(D \approx 0)$ of this branch, indicating that in this narrow zone, strain rates were high enough to achieve brittle yielding in the quartz vein (Fig. 4.18c). Fault-fault interaction in three dimensions may create areas of higher and lower shear strain rates and could also lead to variable ductility ratios in the sheared quartz veins.
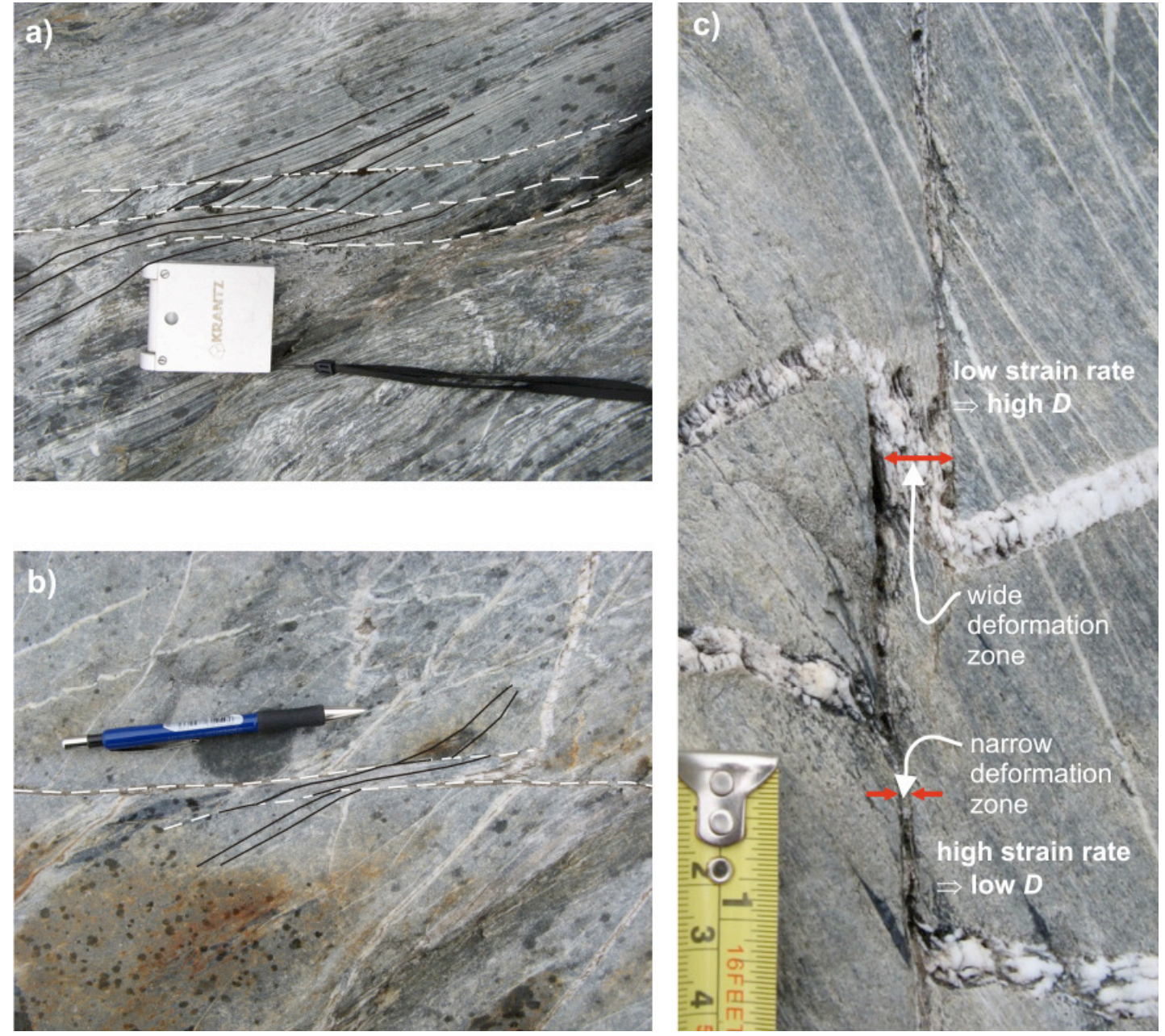

Fig. 4.18: Examples of the ductilely deformed zones of fault strand overlaps or step-overs and the effect of spatially variable strain rates on vein ductility $(D)$. a) Several overlapping strands (white dashed lines) with conspicuously, dextrally rotated foliation (black lines) in between them. b) Two fault terminations overlapping and rotation foliation consistent with dextral shearing along those faults. c) Two veins that are displaced across the same shear. The top vein is displaced in an entirely ductile way whereas the bottom vein is mostly brittlely offset. The schist foliation has been rotated into the overlap zone, consistent with a dextral shear sense. This photograph also shows that propagation of the shears was locally impeded by the uppermost quartz vein into which the fractures blunted and terminated. 


\subsubsection{Effect of varying calcite fraction in the quartz veins on $D$}

The occurrence of minerals other than quartz in the sheared veins could have influenced their rheologic behaviour, because the overall strength of a rock is governed by the composite strength of the polymineralic aggregate (e.g., Dell'Angelo and Tullis, 1996; Saha, 1997; Dresen et al., 1998; Bruhn et al., 1999; Stünitz and Tullis, 2001; Ji and Xia, 2002). Different mineral phases may also lead to variable degrees of strain partitioning within the veins (e.g., Holyoke and Tullis, 2006). Using optical microscopy, we investigated mineral composition in the veins to determine whether it could have been a cause of variable flow strengths for different veins, and thus led to the different offset styles (i.e., brittle vs. ductile).

Two chief minerals other than quartz are found in the deformed veins. Chlorite is sometimes present in small amounts $(<<5 \%)$ typically as a $<1 \mathrm{~mm}$ wide selvage along the vein margins. We infer that such small amounts are insufficient to alter the overall vein rheology. The major other mineral fraction in the veins from the Southern Alps is calcite. The calcite grains that occur in the undeformed part of the veins have a grain size of $93 \pm 6 \mu \mathrm{m}$ on average, and $116 \pm 5 \mu \mathrm{m}$ in the sheared part of the veins (2D grain sizes by Hill, 2005). At these grain sizes, calcite is usually inferred to be "weak" compared to quartz since diffusion-accommodated grain-size sensitive flow processes with $n=1-2$ can dominate the deformation behaviour of calcite (e.g., Brodie and Rutter, 2000; Renner and Evans, 2002; Rybacki et al., 2003; Mancktelow and Pennacchioni, 2010), whereas quartz is usually deformed through grain-size independent dislocation creep (i.e., $n=3-4$ in Eq. 4.1, leading to high viscous yield stress). If calcite played a key role in the overall rheological behaviour of the veins in the Southern Alps, then we should expect a positive relationship between calcite fraction of a sheared vein and the $D$-ratio of its offset. One might expect a lower viscous yield strength with increasing calcite fraction in a vein. Calcite, if present at all, is usually concentrated in thin, discontinuous layers that are aligned subparallel to the walls of the veins or in small clusters, and are never dispersed evenly throughout the vein (Fig. 4.19a). The calcite grains themselves have been dynamically recrystallised and show abundant deformation twinning with predominant slip on [r] and [f] planes (De Bresser and Spiers, 1990; Burkhard, 1993; Hill, 2005). Hill (2005) also describes a strong CPO in the calcite grains in the deformed part of some quartz veins. This reflects deformation of the calcite in the sheared veins by intracrystalline plasticity. 


\section{a)}

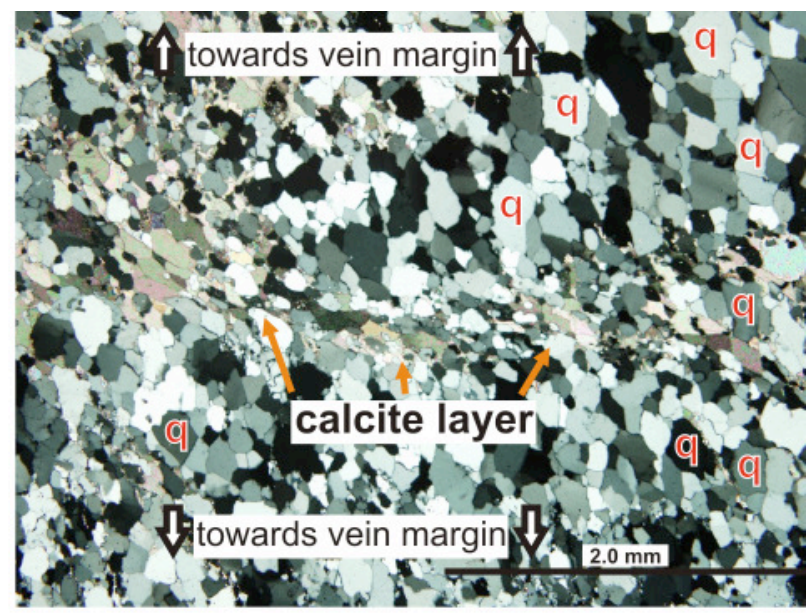

b) quartz fraction

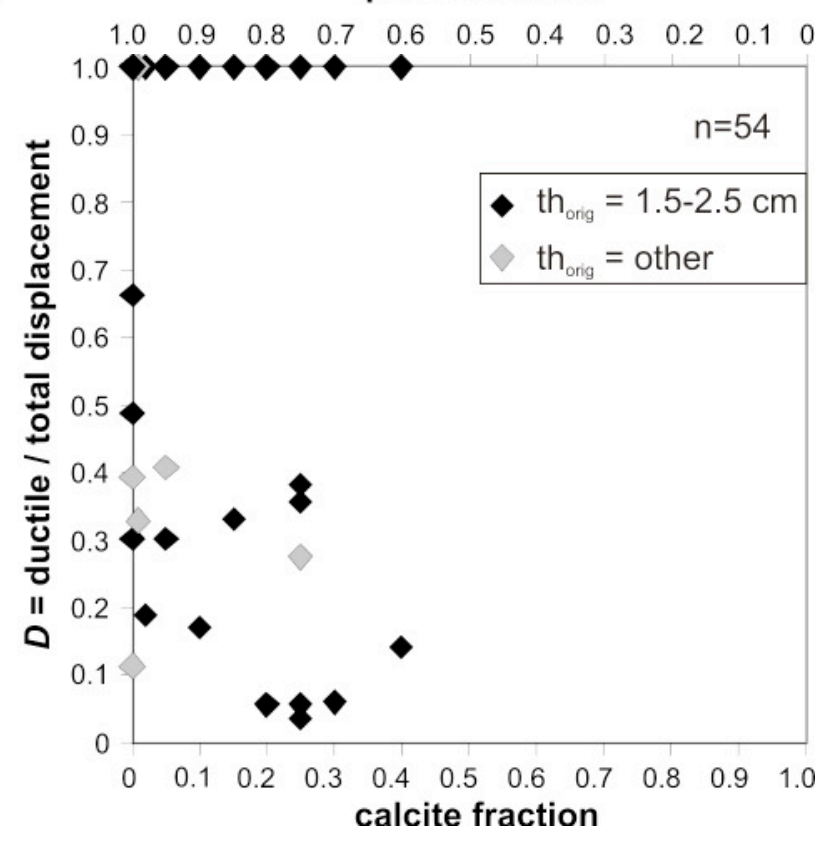

Fig. 4.19: a) Microphotograph of calcite in the undeformed part of a quartz vein (sample CK75). For sample location see Fig. 4.5a. Calcite occurs in layers or clusters in the quartz veins but not disseminated throughout the vein. "q" is quartz. b) Scatter plot of D-ratio versus calcite-fraction. Black diamonds: veins with original thicknesses $\left(t h_{\text {orig }}\right.$ ) of $1.5-2.5 \mathrm{~cm}$. Grey diamonds: veins outside that thickness range. No clear relationship is recognisable between the calcite fraction and the ductility-ratio D of a quartz vein.

In order to test whether there is a relationship between the initial calcite content in the veins and their $D$-ratio, thin sections of quartz vein chips from the vein parts external to their sheared zones were prepared for 29 samples from Crawford Knob and 25 samples from Chancellor Ridge. We used an optical microscope to estimate the approximate calcite fraction in $2 \mathrm{D}$ section by eye (estimated precision of $\pm 5 \%$ ). 
Fig. $4.19 \mathrm{~b}$ is a scatter plot of $D$-ratios versus calcite fractions in the veins. Since there is a positive scaling relationship between original vein thickness and the ductility ratio $D$, we only compared veins of similar thickness. Quartz veins with undeformed thicknesses ranging from $1.5 \mathrm{~cm}$ to $2.5 \mathrm{~cm}$ (average $t h_{\text {orig }}=2.0 \mathrm{~cm}$ ) are plotted as black diamonds, whereas the ones that were originally thicker or thinner than this are plotted as grey diamonds.

The plot shows that while some veins contain up to $40 \%$ calcite, the calcite fraction for most of the veins is $<25 \%$. The most important observation here is that there is no clear relationship between $D$ and the calcite fraction of an individual vein. This suggests that the main part of the deformation was taken up by the quartz matrix and that the overall flow behaviour of the sheared veins was solely controlled by quartz rheology. We infer that the pre-deformational calcite-content in the quartz veins does not control the $D$ values of those veins.

4.6.6 Influence of precursory embrittlement, water-content and water-species in the quartz veins on the deformation type

The incorporation of "water" into quartz has long been known to significantly decrease the viscous flow strength of quartz (e.g., Griggs, 1967, 1974; Jones, 1975; Kekulawala et al., 1978; Paterson, 1989; Kronenberg et al., 1990; Post and Tullis, 1998). Water can be incorporated into quartz in the form of hydroxyl-groups $\left(\mathrm{OH}^{-}-\right.$ ions), leading to hydrolytic weakening of the $\mathrm{Si}-\mathrm{O}-\mathrm{Si}$ bonds in the quartz lattice (e.g., Kronenberg and Wolf, 1990). Water can also be present as molecular water, usually in the form of fluid inclusions within the quartz crystal, e.g., in healed microfractures or lining grain boundaries (e.g., Roedder, 1984).

We used fluid inclusion microscopy and FTIR spectroscopy to investigate a) whether there is evidence for precursory embrittlement of the veins followed by fluid infiltration (e.g., through microcracks), b) how water was incorporated into the quartz veins and c) whether local differences in initial pre-deformational water content, or water species in those veins could have been responsible for the variable degree of ductility $(D)$ observed for the sheared veins. If water was the chief weakening agent in the quartz veins, one would expect to see a positive correlation between water content and the observed vein ductility $D$. 
4.6.6.1 Optical microscopic evidence for precursory embrittlement in the sheared quartz veins

Following Roedder (1984, pp. 343-346) all the fluid inclusions in the sheared veins are interpreted to be secondary. One type of fluid inclusions occurs as abundant, isolated very small inclusions $(<2 \mu \mathrm{m})$ that are randomly dispersed in the quartz veins and are only recognisable as tiny spots under an optical microscope (orange arrows in Fig. 4.20a, 4.20b). Based on the resemblance of these small fluid inclusions in our samples with the results of static recrystallisation experiments of wet quartz, we infer that these fluid inclusions may have been derived from $\mathrm{OH}^{-}$-point defects in the quartz crystals by the reaction $\mathrm{Si}(\mathrm{OH})_{4} \rightarrow \mathrm{SiO}_{2}+2 \mathrm{H}_{2} \mathrm{O}$ during the pervasive static recrystallisation of the quartz veins subsequent to their deformation (e.g., Griggs, 1967; Kerrich, 1976). These $\mu \mathrm{m}$-sized fluid inclusions occur both in the sheared and the unsheared parts of the deformed quartz veins. Additionally, both outside and inside of the shear zones in the quartz veins, water occurs as large fluid inclusions (up to $\sim 10$ $\mu \mathrm{m})$. These fluid inclusions are typically arranged along grain- and subgrain-boundaries or in curved arrays (Figs. 4.20c, 4.20d). The curved arrays are interpreted to represent healed microfractures. Some of the larger fluid inclusions in these microfractures contain bubbles, probably of water vapor. The decrease in size of fluid inclusions from the centre to the edge of the healed microfractures indicates that the originally large fluid inclusions that infilled the open microfractures have undergone necking down resulting in several smaller inclusions (Fig. 4.20e, I-IV; Bodnar, 2003). The occurrence of bubbles of different sizes in the fluid inclusions in Figs. 4.20a and 4.20b indicates that the rocks have undergone cooling during necking down and healing of the microcracks (Fig. 4.20f; Roedder, 1984, pp. 59-61; Bodnar, 2003).

During static recrystallisation, fluid inclusions are generally inferred to be swept out of quartz grains and into grain boundaries (e.g., Kerrich, 1976). However, a recent study of the interaction between grain boundary migration and ethanol fluid inclusions in the rock analogue camphor has shown that under certain conditions, fluid inclusions may actually hardly be influenced by passing grain boundaries (Schmatz and Urai, 2010). These authors report that whether or not a fluid inclusion will be affected by a migrating grain boundary depends to a great extent on the fluid inclusion size and on the grain boundary velocity. In general, the larger an original inclusion is and the slower a grain boundary moves the more likely it is that fluid inclusions are affected by the 
sweeping grain boundary (Schmatz and Urai, 2010). A grain boundary that migrates with an intermediate velocity can drag a fluid inclusion and later drop it at a different location. Consequentially, the shape of the affected fluid inclusion may change from spherical to elliptical pointed perpendicular to the moving grain boundary (Schmatz and Urai, 2010). Most of the larger fluid inclusions in Fig. 4.20d are slightly elliptical in shape with the long axes of the individual fluid inclusions being parallel to each other, possibly indicating that these fluid inclusions may have been dragged, stretched and then dropped by a relatively fast migrating grain boundary. This would mean that the healed microfracture must have existed before the onset of static recrystallisation and grain growth. Also, most of the healed microfractures are curved, indicating that they were affected by the migrating grain boundaries during static recrystallisation and therefore suggesting their development prior to that static grain growth.

Healed microfractures are abundant in both the undeformed and the deformed parts of the sheared (ductilely deflected) quartz veins. If focused brittle deformation at the site of the future ductile shear zones was a necessary precursor to their inception, and played a key role in the subsequent localisation of ductile strain in the fluid infiltrated quartz, one would expect to observe an increase in the density of microfractures, or a difference in their width and interconnectivity in the shear zone relative to outside it (e.g., Fusseis and Handy, 2008). However, the appearance and the density of the healed microfractures in the statically recrystallised quartz grains are very similar in both the external, unsheared part and the internal, sheared parts of those same veins (Fig. 4.20c, 20d). We therefore conclude that brittle precursory fracturing may have been important in leading to the introduction of water into the quartz veins, and could have made them weaker than the surrounding schist host rocks. Precursory embrittlement and associated water infiltration, however, did not localise strain within the quartz veins, because there is no microstructural evidence for enhanced microcracking or secondary fluid inclusions in the sheared parts of the veins relative to the undeformed parts of the same veins. Evenly distributed microfracturing has apparently taken place within both the sheared and unsheared parts of the quartz veins. We cannot, however, exclude the possibility that evidence for differential microcracking could have been removed during the static recrystallisation of the quartz veins post-shearing. Under the microscope, we were not able to find any differences in microfracture density or character between fully ductilely deformed quartz veins and those veins with $D<1.0$. 

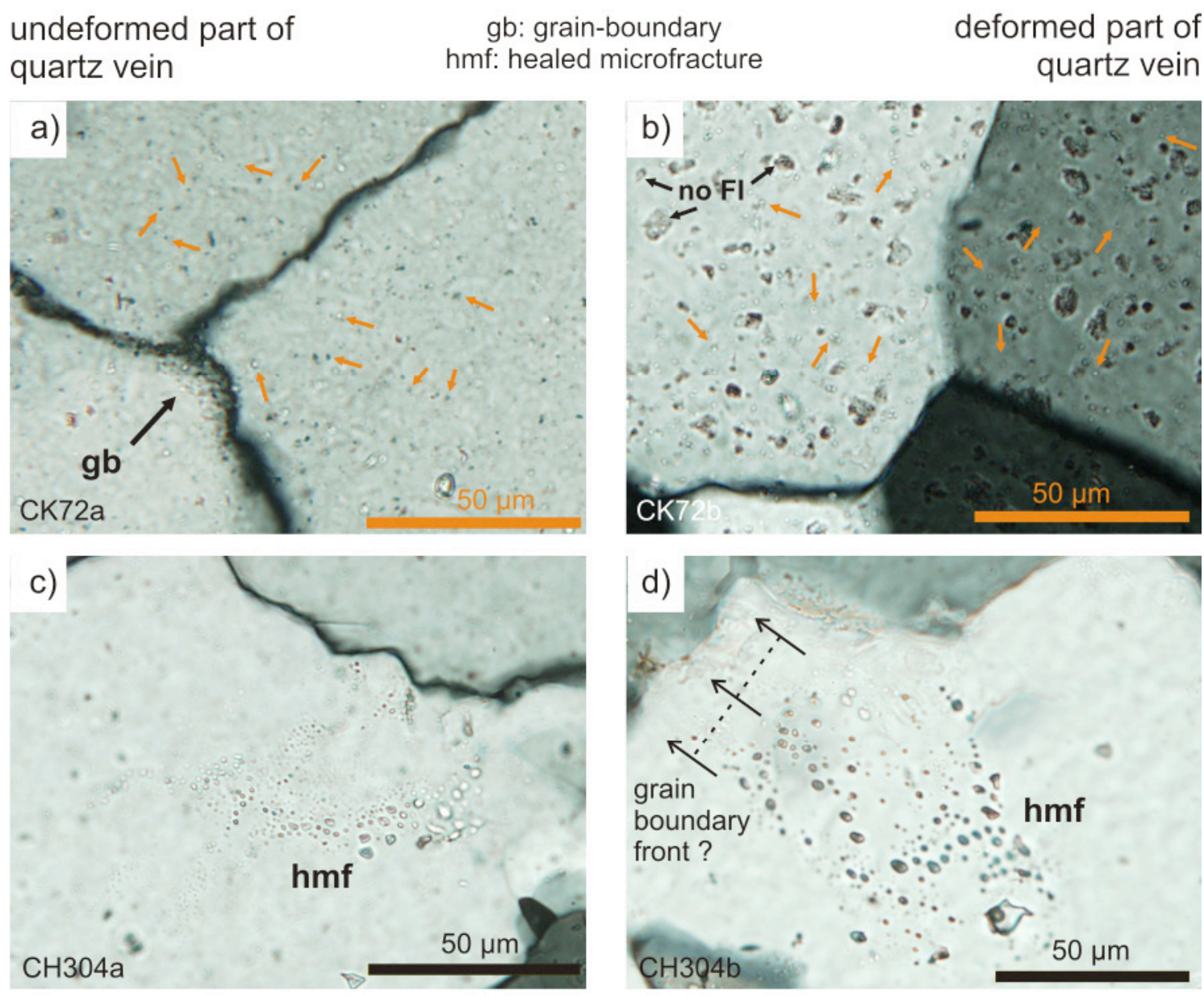
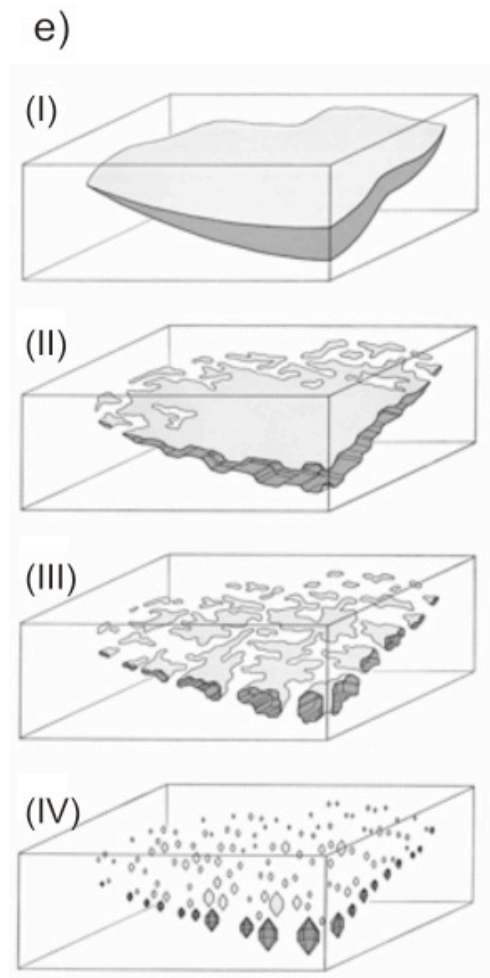

fluid filled fracture + dissolution of material from crack wall

reprecipitation of new material + isolation of small pockets of fluid

continued healing irregularly shaped fluid inclusions become more regular

evolution of fluid inclusions through maturation results in negative crystal shaped fluid inclusions f) Time

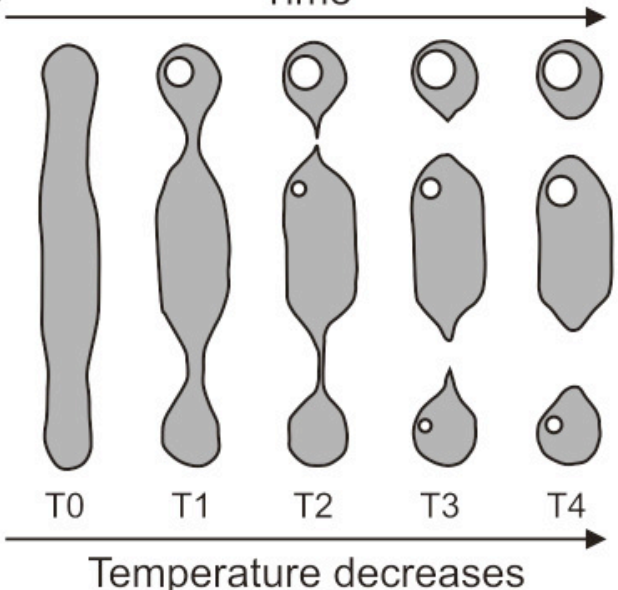

T0: original fluid inclusion; only liquid

T1: vapour bubble evolves during cooling

T2: necking down forms two fluid inclusions with smaller bubble in larger inclusion

T3: larger inclusion undergoes necking down again

T4: at room temperature, all three inclusions show very different liquid-to-vapour ratios 
Fig. 4.20 (previous page): Microphotographs of secondary fluid inclusions in quartz grains from the undeformed (left) and deformed (right) parts of two veins. For sample locations see Fig. 4.5a. a) Sample CK72a, undeformed part of a quartz vein. Polygonised grain-boundary ( $g b)$ is decorated by small $(<2$ $\mu \mathrm{m}$ ) fluid inclusions. Orange arrows point to some of the very small fluid inclusions that are distributed throughout the vein. b) Sample CK72b, deformed part of the same quartz vein. Orange arrows mark some of the abundant small $(<2 \mu \mathrm{m})$ fluid inclusions that could only just be resolved with an optical microscope. Note the similar size and density of fluid inclusions in both sample parts (undeformed and deformed). The bigger, dark irregularities are not fluid inclusions ("no FI") but are due to thin section preparation. c) Sample CH304a, undeformed part of the quartz vein. Healed microfracture (hmf) in quartz grain. The microfracture is decorated by fluid inclusions that are $>1 \mu \mathrm{m}$. Note the curved nature of the healed microfracture. d) Sample CH304b, deformed part of the same quartz vein. Healed microfracture plane, decorated by large (up to $\sim 10 \mu \mathrm{m}$ ) fluid inclusions. View is onto the healed microfracture plane. Note slightly elliptical shape of the medium sized fluid inclusions. e) Schematic illustration of necking down of a fluid-filled fracture at a constant temperature (modified from Bodnar, 2003) and f) during cooling (modified from Bodnar, 2003). The fact that the fluid inclusions in (a) and (b) contain bubbles indicates that these fluid inclusions underwent necking down during cooling.

\subsubsection{Determination of water species and water content in the quartz veins}

Water species and water content in quartz are the main controlling factors on hydrolytic weakening in quartz (e.g., Kronenberg and Wolf, 1990). We conducted FTIR spectroscopy in order to quantify any differences in water content or species between brittlely versus ductilely deformed quartz vein samples.

\subsection{FTIR - Sampling philosophy and analysis}

In order to find out whether the water content or species in a quartz vein was an important influence on the resulting $D$-ratio of a deforming quartz vein, we chose the samples for the FTIR analysis so that we could compare the $D$-values of those veins with either similar $t h_{\text {orig }}$ and $y_{\text {tot }}$ or veins that do not follow the scaling relationships between $D$ and $t h_{\text {orig }}$ and/or $y_{\text {tot }}$ as described at the start of section 4.6.2; e.g.,, sample CK326 was derived from a vein that is originally $1.7 \mathrm{~cm}$ thick and displaced by $3.6 \mathrm{~cm}$, whereas $\mathrm{CH} 330$ has an original thickness of $0.8 \mathrm{~cm}$ and a total displacement of $4.3 \mathrm{~cm}$ (Table 4.2). The $D$-value for CK326 is 0.1 and for CH330 it is 1.0 (Table 4.2), despite CH330 being only about half as thick as CK326 and having been displaced $0.7 \mathrm{~cm}$ more. The original thicknesses and the total displacements of the sheared quartz veins are given in Table 4.2 for comparison. We measured samples of the non-sheared parts of four veins and of the sheared parts of two quartz veins from Chancellor Ridge, as well as samples of six undeformed vein parts from Crawford Knob. The water contents of the deformed vein samples were measured and compared to those of the unsheared parts of the two veins in order to determine whether there is a difference in water 
content in the quartz veins before and after deformation and whether this could be consistent with initial strain hardening in the shear zones as inferred in section 4.5.2.

The samples were prepared at Ruhr-University Bochum and measured with their FTIR spectrometer Bruker IFS 48. Selected areas of polished slabs with a thickness of 0.6 to $0.8 \mathrm{~mm}$ were measured with a nominal spot size of $0.08 \mathrm{~mm}$. These parameters represent a compromise between sensitivity and spatial resolution. For the FTIR measurements the most suitable samples were selected, but unfortunately these are still of limited quality, mainly due to second phase particles (carbonate) and discontinuities leading to reduced transparency. Some impregnation of the samples with glue was unavoidable due to fractures and fissures that formed during sampling of the rock chips; this glue could not be completely removed and remnants can give rise to weak $\mathrm{CH}$ absorption bands. Under these circumstances, measurements were necessarily restricted to spots providing the required degree of transparency. Ten to fifteen spots were measured per vein sample and the mean water concentration of those spots is taken as the representative minimum concentration for that sample.

Table 4.2 Original thicknesses $\left(t h_{\text {orig }}\right)$ and total displacement $\left(y_{t o t}\right)$ of the veins that were chosen for FTIR analyses (Figs. 4.21 and 4.22)

\begin{tabular}{ccc}
\hline Sample name & $t_{\text {orig }}$ & $y_{\text {tot }}$ \\
\hline CK326 & $1.7 \mathrm{~cm}$ & $3.6 \mathrm{~cm}$ \\
CH302 & $2.0 \mathrm{~cm}$ & $6.3 \mathrm{~cm}$ \\
CH304 & $3.0 \mathrm{~cm}$ & $10.8 \mathrm{~cm}$ \\
CK309 & $1.6 \mathrm{~cm}$ & $11.9 \mathrm{~cm}$ \\
CH326 & $2.0 \mathrm{~cm}$ & $7.5 \mathrm{~cm}$ \\
CK308 & $1.6 \mathrm{~cm}$ & $11.2 \mathrm{~cm}$ \\
CK330 & $2.5 \mathrm{~cm}$ & $3.1 \mathrm{~cm}$ \\
CK324 & $3.3 \mathrm{~cm}$ & $11.2 \mathrm{~cm}$ \\
CH330 & $0.8 \mathrm{~cm}$ & $4.3 \mathrm{~cm}$ \\
CK315 & $1.1 \mathrm{~cm}$ & $4.8 \mathrm{~cm}$ \\
\hline
\end{tabular}

\subsection{FTIR - Results}

All twelve samples show broad band absorption, indicating the presence of molecular water. We have plotted the FTIR-spectra for an example vein (CH326; Fig. 4.21a) in Fig. 4.21b. Low temperature measurements $\left(-190^{\circ} \mathrm{C}\right.$; liquid nitrogen) reveal the broad band absorption with the characteristics of ice (Fig. 4.21c). This means that 
the molecular water is freezable and present as fluid inclusions, with a size large enough to form ice. According to experience gained from similar material in other studies, the typical inclusion size may vary between about 0.05 and $0.5 \mu \mathrm{m}$ (Bohren and Huffman, 1983). The concentration of point defects and non-freezable water is below the limit of detection.
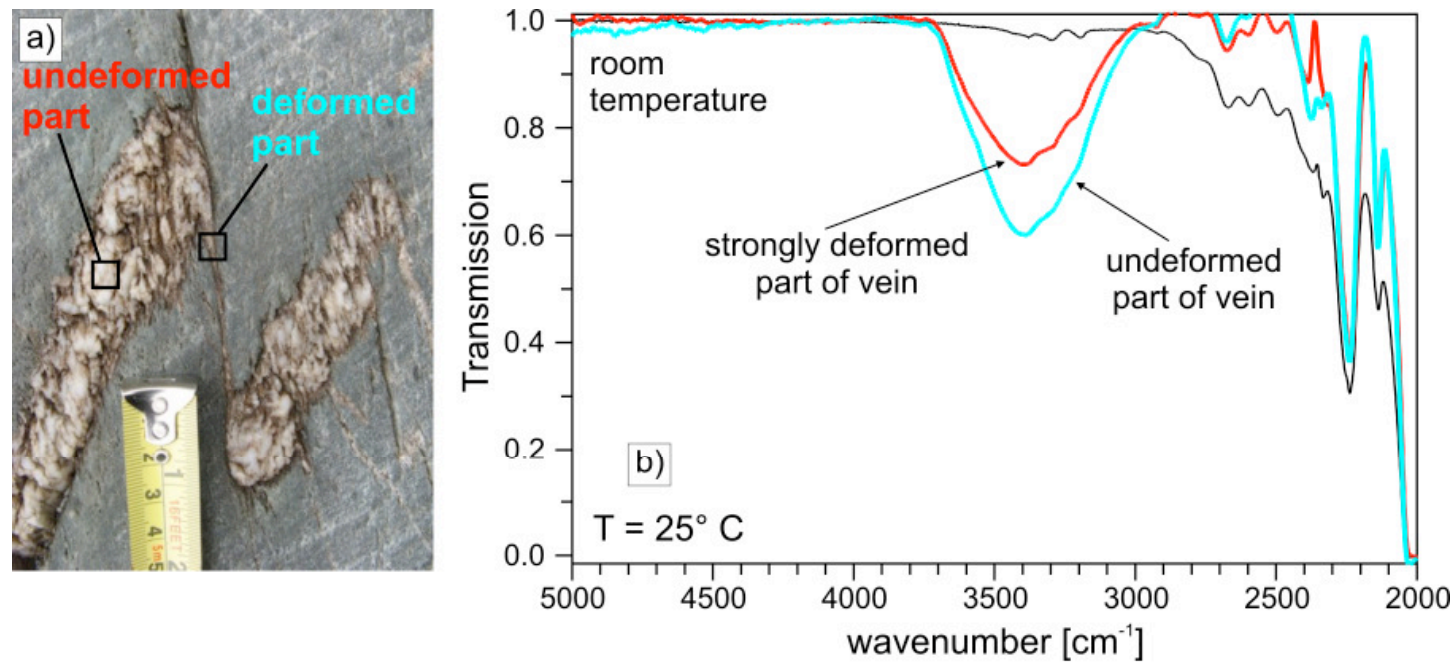

sample $\mathrm{CH} 326 \mathrm{a}$ - undeformed section $0.753 \mathrm{~mm}$ thick

sample $\mathrm{CH} 326 \mathrm{~b}$ - deformed section $0.779 \mathrm{~mm}$ thick

pure "dry" quartz

- parallel $<\mathrm{c}>$ section $0.8 \mathrm{~mm}$ thick

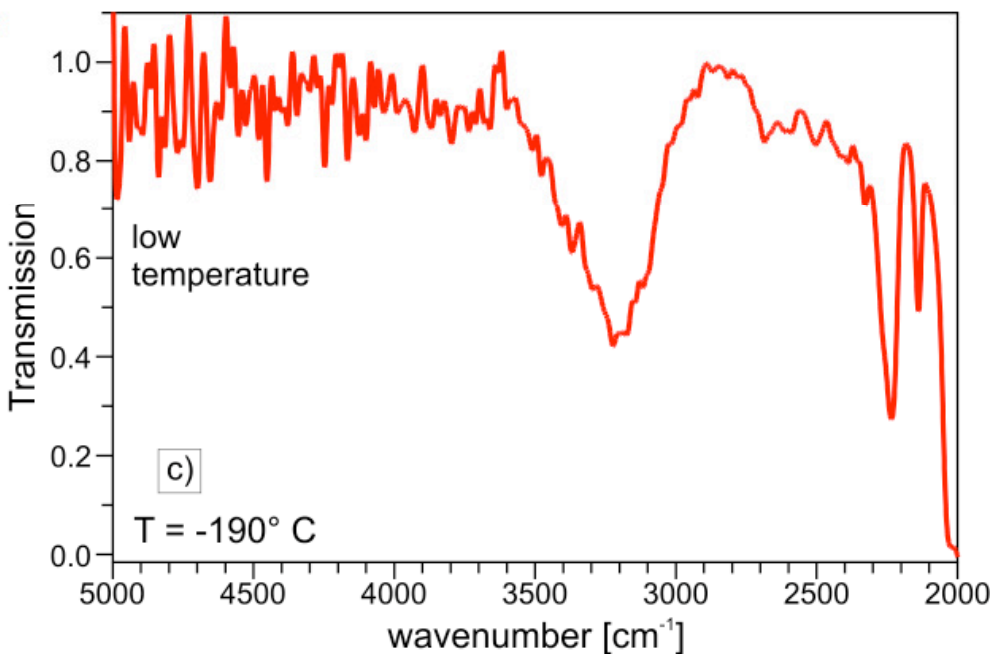

Fig. 4.21: FTIR results for vein sample CH326 $(D=1.0)$ from Chancellor Ridge. For sample location cf. Fig. 4.5a. a) Photograph of sampled vein with approximate sampling locations in vein. b) Transmission spectra for the two different samples of $\mathrm{CH} 326$ at room temperature. Red line: undeformed sample external to shear zone; blue line: deformed sample internal to shear zone. We have plotted a FTIR spectrum for 'dry' quartz for comparison (black line). c) Transmission spectrum for the undeformed part of vein $\mathrm{CH} 326$ from low temperature measurements. The sample shows broad-band transmission for wavelengths between $\sim 3000$ and $3700 \mathrm{~cm}^{-1}$ for room temperature and for $\sim 2900-3600 \mathrm{~cm}^{-1}$ for the low temperature measurements. This is indicative for molecular water $\left(\mathrm{H}_{2} \mathrm{O}\right)$. Low-T measurements reveal the broad band transmission characteristic for ice. This means that the water is freezable and present as fluid inclusions, large enough to form ice. There are no "peaks" in the FTIR spectrum between 3000$3700 \mathrm{~cm}^{-1}$ which means that the concentration of point defects is too low to be detected by FTIR. 
We present the results of the FTIR analyses in Fig. 4.22a, where we plotted the mean water concentration (green and orange diamonds) for each sample of the external vein parts on the left vertical axis and the $D$-ratio (black diamonds) of the corresponding samples on the right axis. The horizontal axis contains the sample labels (CK: Crawford Knob; $\mathrm{CH}$ : Chancellor Ridge). The samples along that axis are ordered such that $D$ is increasing from left to right.

As shown in Fig. 4.22a, the water concentrations appear relatively uniform at a given locality (e.g., Chancellor Ridge, Crawford Knob). The water concentrations for the samples from Crawford Knob (orange diamonds) range from $443 \pm 136 \mathrm{ppm} \mathrm{H} / \mathrm{Si}$ $(1 \sigma)$ to $802 \pm 236 \mathrm{ppm} \mathrm{H/Si}(1 \sigma)$ with a mean of $550 \pm 135 \mathrm{ppm} \mathrm{H} / \mathrm{Si}$. The Chancellor Ridge samples (green diamonds) yield an average concentration of $1198 \pm 267$ ppm $\mathrm{H} / \mathrm{Si}$, ranging from $922 \pm 208 \mathrm{ppm} \mathrm{H/Si}$ to $1499 \pm 485 \mathrm{ppm} \mathrm{H} / \mathrm{Si}$.

The inset in Fig. 4.22a shows that there is no correlation of the molecular water concentration with the deformation type (brittle or ductile) in the individual quartz veins. This becomes particularly obvious in a comparison of samples CK308 and CK326 (cf. Fig. 4.17a, 4.17b). For both veins, we measured water contents of $~ 500 \mathrm{ppm}$ H/Si (Fig. 4.22a). Both veins have similar thicknesses and CK308 is displaced $7.6 \mathrm{~cm}$ more than CK326. Because of the higher displacement, one would expect vein CK308 to have a higher brittle slip component than CK326. However, the opposite is the case: CK326 was displaced in an almost entirely brittle fashion $(D=0.1)$ whereas the shearing of CK308 was entirely ductile, despite both veins having similar water contents and similar initial vein thicknesses. Thus there is now evidence that the difference in flow stress or relative ductility of different quartz veins was not caused by differences in molecular water contents (at least as preserved today).

There is, however, an apparent difference in water content between the undeformed part of a quartz vein relative to the sheared part of the same quartz vein (Fig. 4.22b). In sample CH304, the water concentration in the deformed part of the vein is $200 \mathrm{ppm}$ $\mathrm{H} / \mathrm{Si}$ lower than in the undeformed part of the vein. In sample $\mathrm{CH} 326$ the deformed part of the vein has nearly $400 \mathrm{ppm} \mathrm{H/Si} \mathrm{less} \mathrm{than} \mathrm{the} \mathrm{undeformed} \mathrm{part.} \mathrm{This} \mathrm{relationship}$ (sheared parts of the vein are drier than unsheared parts) is exactly opposite to the simple idea of hydrolytic weakening controlled shear zone localisation in quartz. It is unclear how reliable those results are, since only two examples were measured and the 
errors are very large. If these differences are real, perhaps it reflects water leakage from the sheared parts of the veins either during vein deformation or during static recrystallisation after vein deformation. If so, loss of water within the shear zones during the shearing process could explain the observed initial hardening behaviour of the deforming quartz veins (Fig. 4.13).

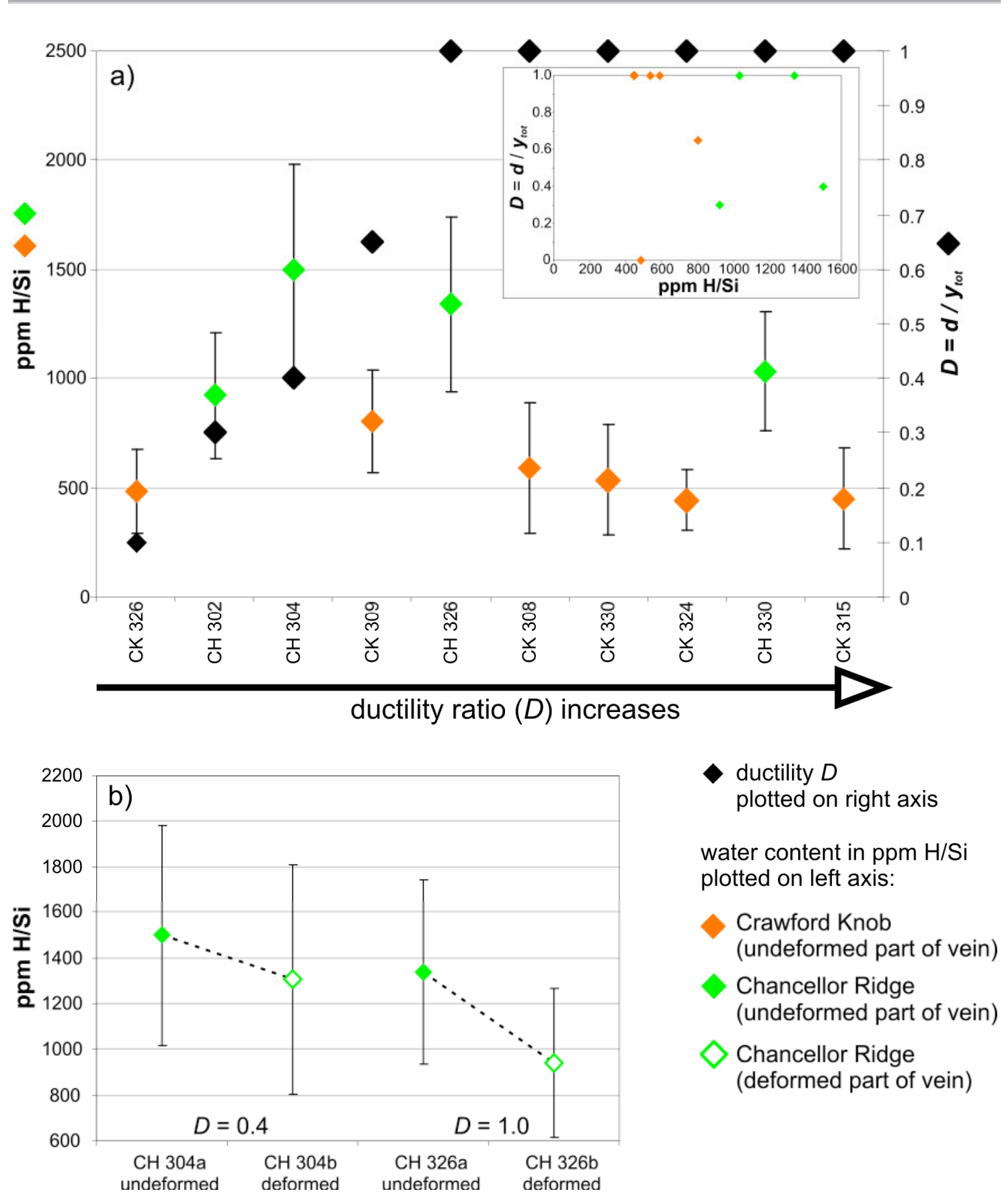


Fig. 4.22 (previous page): FTIR analysis results. For sample locations see Fig. 4.5a. a) Water concentration (left axis) in 10 samples of external (undeformed) vein compared to $D$-ratio (right axis, black diamonds). Orange diamonds: samples from Crawford Knob; Green diamonds: samples from Chancellor Ridge. Errors are $( \pm 2 \sigma)$. The water concentration in the samples from Chancellor Ridge is 23 times higher than the concentration for Crawford Knob. The inset shows $D$-values of the same 10 veins plotted directly against water concentration. Water concentrations cannot be correlated to the $D$-ratios. b) Plot of water concentration for samples $\mathrm{CH} 304$ and $\mathrm{CH} 326$ that compares the deformed to the undeformed part of the same vein. $\mathrm{CH} 304$ shows a water content that is 194 ppm less in the deformed part of the vein $(\mathrm{CH} 304 \mathrm{~b})$ than in the undeformed part $(\mathrm{CH} 304 \mathrm{a})$. For sample $\mathrm{CH} 326$, this difference in water content between the undeformed and deformed parts (again less in the latter) of the vein is $~ 398$

\subsubsection{Influence of locally variable conditions of deformation on the vein ductility $D$}

In this section, we examine whether possible variations in deformation temperature or stress conditions could have caused the variable $D$-values in the sheared quartz veins.

\subsubsection{Temperature}

Temperature is a key factor in the transition between brittle and ductile deformation. In the quartz flow law (Eq. 4.1), temperature is a variable in the exponential part of that dislocation creep law. Temperature strongly influences the flow strain rate and therefore the effective viscosity ("strength") of rocks. Local variations in temperature could potentially have influenced the ductility $(D)$ of a given quartz vein. For that reason, it is important to determine the deformation temperature of the rocks as accurately as possible. The temperature range under which the quartz veins may have been ductilely deformed is here derived by quartz-calcite oxygen isotope exchange thermometry in the shear-infilling quartz-carbonate veins and by Titanium-in-Quartz geothermometry in the older, strongly sheared quartz veins.

\subsection{Quartz-calcite oxygen isotope exchange thermometry on shear-infilling veins}

Wightman (2005) conducted quartz-calcite oxygen isotope exchange thermometry on six shear-infilling vein samples from the area around Crawford Knob and Chancellor Ridge (Appendix 4.A). After having established isotopic equilibrium between the quartz and the calcite through cathodoluminescence imaging of the shear-infilling veins, she calculated a quartz-calcite fractionation factor of $\Delta_{\text {qtz-cal }}=1.51 \pm 0.07 \%$. Using this fractionation factor with an oxygen isotope exchange thermometer that was calibrated by Sharp and Kirschner (1994) $\left(\Delta_{q t z-c a l}=0.87( \pm 0.06) \times 10^{6} / T^{2}\right)$ she calculated an average temperature of $486 \pm 34^{\circ} \mathrm{C}$ for the crystallisation of the infilling veins. This 
temperature was interpreted by Wightman (2005) to be the temperature during deposition of the shear-infilling, syntectonic (fibrous) quartz-carbonate veins. In Appendix 4.A, we present these results and outline the analytical procedures that she used.

\subsection{Titanium-in-Quartz geothermometry ("TitaniQ”)}

For the TitaniQ-analysis, we have collected and prepared 20 samples from within the sheared part of the quartz veins from Chancellor Ridge and 8 from Crawford Knob. The samples were derived from different paleo-structural depths in order to evaluate whether local (1-100 m scale) high temperature gradients could have resulted in the variable $D$-ratios that were measured in the sheared quartz veins. We have also prepared samples from one fault-infilling vein from Chancellor Ridge and two from Crawford Knob in order to compare those temperatures with the ones that were derived from quartz-calcite oxygen isotope thermometry (section 4.6.1.1, Appendix 4.A). For both Crawford Knob and Chancellor Ridge, we also prepared one sample of undeformed vein material to determine whether there is a difference in apparent recrystallisation temperature external and internal to the shear zones in the quartz veins.

The Titanium-in-Quartz geothermometer ("TitaniQ") is based on the isovalent substitution of $\mathrm{Si}^{4+}$ by $\mathrm{Ti}^{4+}$ ions in the quartz crystal lattice. If quartz is in equilibrium with a Ti-bearing mineral (e.g., rutile, illmenite, titanite), the $\mathrm{TiO}_{2}$-activity $\left(a_{\mathrm{TiO}_{2}}\right)$ is fixed. In this case, the ion substitution increases exponentially with temperature (Wark and Watson, 2006). Wark and Watson (2006) calibrated the TitaniQ geothermometer with experiments on (mostly) igneous rocks in the $600-1000^{\circ} \mathrm{C}$ range. They derived the following relationship between Ti-concentration in quartz and crystallisation temperature:

$$
T\left({ }^{\circ} \mathrm{C}\right)=\frac{-(3765 \pm 24)}{\log \left(X_{T i}^{q t z}\right)-(5.69 \pm 0.02)}-273
$$

where $X_{T i}^{q t z}$ is the Ti concentration in [ppm] by weight and $T$ is the quartz crystallisation temperature in $\left[{ }^{\circ} \mathrm{C}\right]$.

If no rutile is present, the $\mathrm{TiO}_{2}$ activity $\left(a_{\mathrm{TiO}_{2}}\right)$ will be less than 1 . For that case, the geothermometer needs to be slightly modified (Wark and Watson, 2006): 


$$
T\left({ }^{\circ} \mathrm{C}\right)=\frac{-(3765 \pm 24)}{\log \left(\frac{X_{T i}^{q t z}}{a_{T i O_{2}}}\right)-(5.69 \pm 0.02)}-273
$$

where $a_{\mathrm{TiO}_{2}}$ is Titanium-activity.

Ghent and Stout (1984) measured $\mathrm{TiO}_{2}$ activities for metamorphic rocks. They report $a_{\mathrm{TiO}_{2}}=0.8-1.0$ for metapelites. Using $a_{\mathrm{TiO}_{2}}=1.0$ in Eq. 4.3 therefore results in a minimum temperature for rutile-undersaturated rocks (Wark and Watson, 2006).

We used the electron microprobe in order to check for the presence of Ti-bearing minerals like rutile $\left(\mathrm{TiO}_{2}\right)$, ilmenite $\left(\mathrm{FeTiO}_{3}\right)$, or titanite $\left(\mathrm{CaTiSiO}_{5}\right)$ in any part of a representative vein (CK75, sample location in Fig. 4.5a). We also checked for those minerals in the vein that has infilled the fault across which vein CK75 was displaced. We could not confirm the presence of any Ti-bearing minerals in sample CK75. Since a Ti-bearing phase is absent, we assume $a_{\mathrm{TiO}_{2}}=1.0$ for the following analyses, which results in the calculation of minimum recrystallisation temperatures. Cathodoluminescence (CL)-imaging of different locations in both undeformed and deformed parts of CK75 showed that there was no Ti-diffusion-related zoning present in the measured quartz veins (Fig. 4.23). The lack of Ti-related zoning could indicate either homogeneous, continuous grain growth at a constant temperature or homogenisation of the quartz grains after recrystallisation. We infer that the temperatures that are recorded by the Ti-concentration in the quartz veins are the temperatures that prevailed during static recrystallisation and grain growth (Kohn and Northrup, 2009; Spear and Wark, 2009; also refer to Appendix 4.B) and are thus a minimum estimate of the deformation temperature.

Titanium concentrations in all samples were measured by LA ICP-MS (for analytical details see Appendix 4.B). The minimum temperatures under which the quartz veins deformed and recrystallised were calculated using Eq. 4.3, with $a_{\mathrm{TiO}_{2}}=1.0$. We have summarised all calculated recrystallisation temperatures with their individual errors $(2 \sigma)$ in Table 4.3. The errors contain both the analytical errors as well as the calibration errors from Wark and Watson's geothermometer. Temperatures calculated for $a_{T_{i O_{2}}}=0.8$ are $\sim 13 \pm 1^{\circ} \mathrm{C}$ higher than for $a_{\mathrm{TiO}_{2}}=1.0$ for all samples. The calculated minimum $\left(a_{\mathrm{TiO}_{2}}=1.0\right)$ mean recrystallisation temperature is $425 \pm 38^{\circ} \mathrm{C}(2 \sigma)$ for the 
veins from Chancellor Ridge and $400 \pm 21^{\circ} \mathrm{C}(2 \sigma)$ for the Crawford Knob veins (Table 4.3).

\section{Backscatter images (BS)}
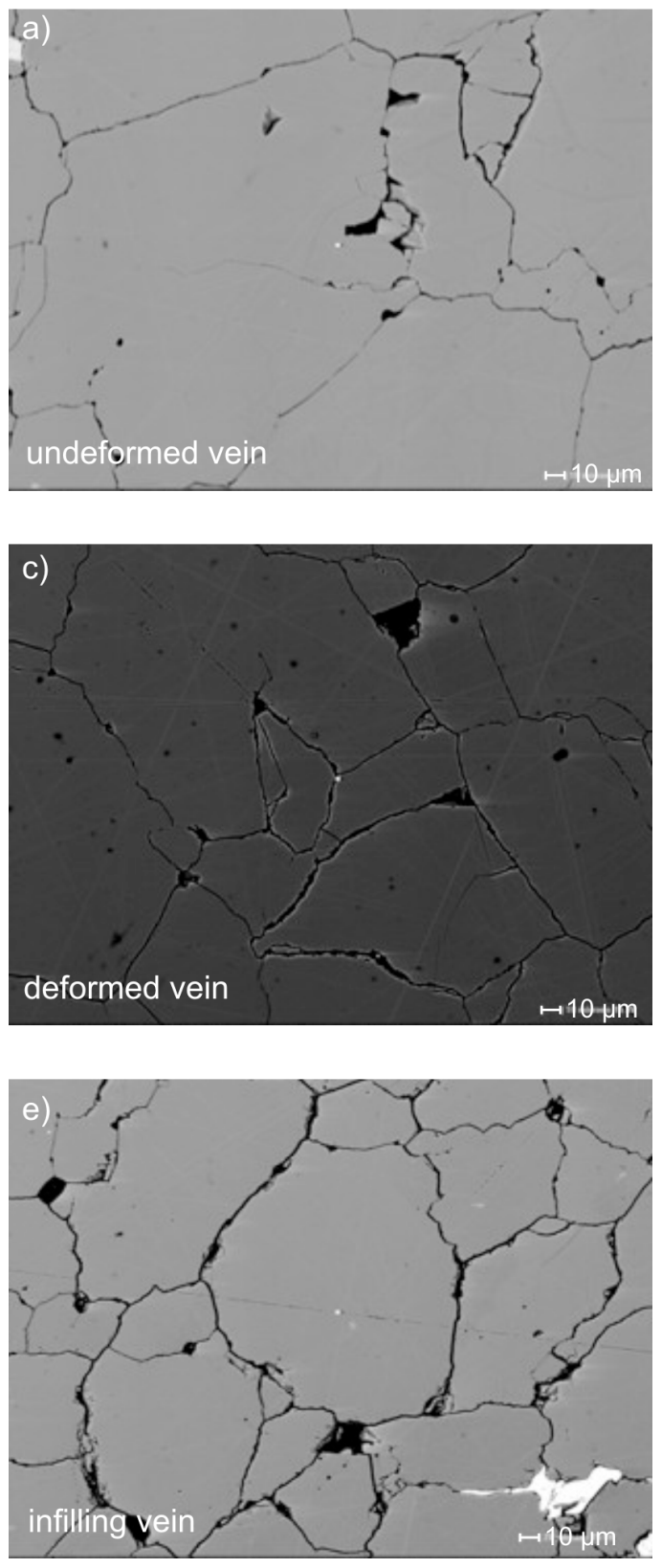

Cathodoluminescence images $(\mathrm{CL})$
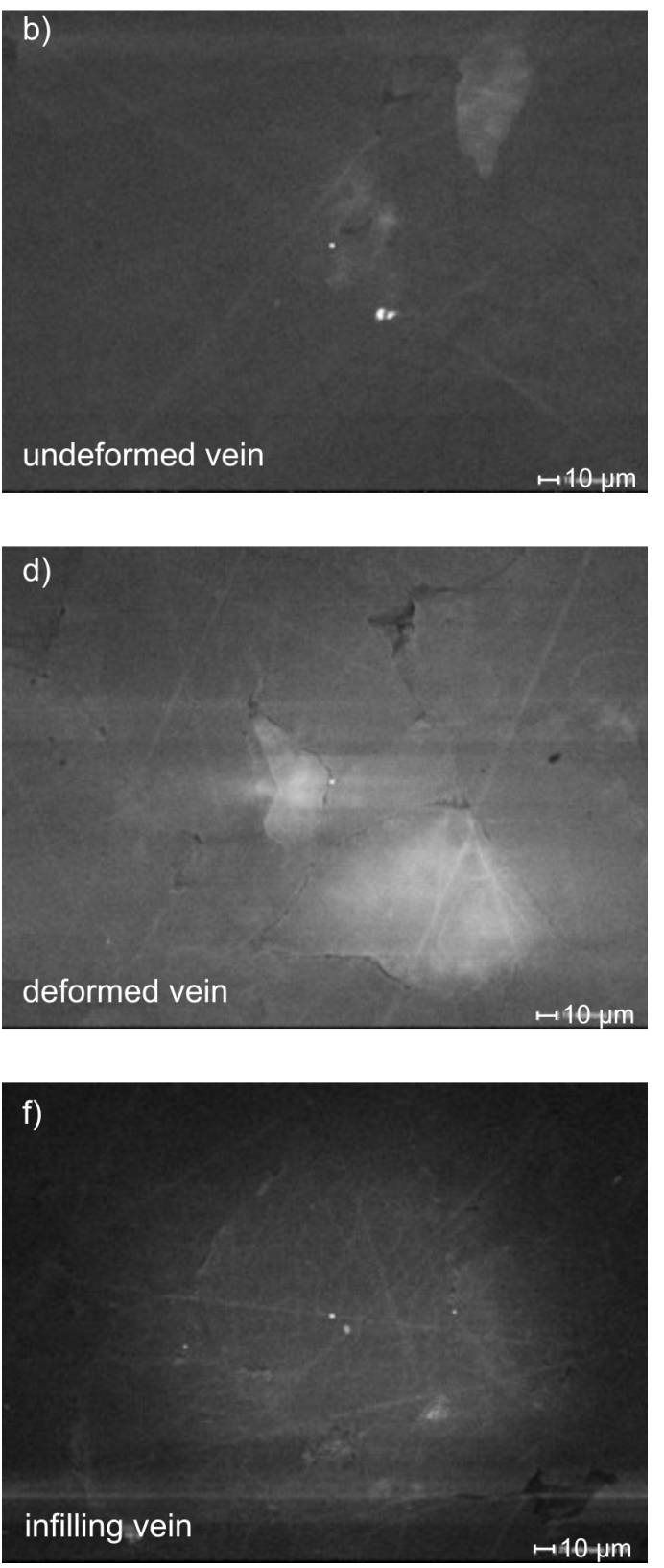

Fig. 4.23: Backscatter (BS) and cathodoluminescence (CL) images of ductilely sheared quartz vein sample CK75, and of adjacent shear-infilling vein. The CL-images illustrate the lack of Ti-diffusion zoning. This suggests isotropic, homogeneous grain growth during static recrystallisation in those veins. a) BS-image of undeformed part of sheared vein; b) CL-image of undeformed part of sheared vein; c) BS-image of deformed part of sheared vein; d) CL-image of deformed part of sheared vein; e) BS-image of shear-infilling vein; f) CL-image of shear-infilling vein. The CL-images for both the undeformed and the deformed parts of the quartz vein are very similar. No Ti-zoning is recognisable in (b) or (d). No Tizoning is recognisable in the shear-infilling vein in (f) either. The bright small spots under CL-light are probably diamonds that are left over from polishing of the mounts. CL-images were taken at $223 \mathrm{nA}, 15$ $\mathrm{kV}$ excitation voltage. 
Table 4.3 Ti-in-Quartz analyses results $\left(a_{\mathrm{TiO}_{2}}=1.0\right)$

\begin{tabular}{|c|c|c|}
\hline Sample & $X_{T i}^{q t z}(\mathrm{ppm}, \pm 1 \sigma)$ & $\mathrm{T}_{\min }\left({ }^{\circ} \mathrm{C}, \pm 2 \sigma\right)$ \\
\hline \multicolumn{3}{|l|}{ Chancellor Ridge } \\
\hline $\mathrm{CH} 301 \mathrm{~b}$ & $5.00 \pm 0.80$ & $481 \pm 26$ \\
\hline $\mathrm{CH} 302 \mathrm{~b}$ & $2.40 \pm 0.28$ & $436 \pm 19$ \\
\hline $\mathrm{CH} 303 \mathrm{~b}$ & $1.90 \pm 0.31$ & $423 \pm 23$ \\
\hline $\mathrm{CH} 304 \mathrm{~b}$ & $1.50 \pm 0.27$ & $410 \pm 23$ \\
\hline CH305b & $1.70 \pm 0.20$ & $417 \pm 19$ \\
\hline CH306b & $1.90 \pm 0.22$ & $423 \pm 19$ \\
\hline $\mathrm{CH} 307 \mathrm{~b}$ & $4.00 \pm 0.20$ & $467 \pm 16$ \\
\hline $\mathrm{CH} 308 \mathrm{~b}$ & $2.50 \pm 0.87$ & $426 \pm 37$ \\
\hline $\mathrm{CH} 310 \mathrm{~b}$ & $2.40 \pm 0.36$ & $436 \pm 22$ \\
\hline $\mathrm{CH} 311 \mathrm{~b}$ & $1.50 \pm 0.23$ & $410 \pm 21$ \\
\hline $\mathrm{CH} 312 \mathrm{~b}$ & $1.60 \pm 0.19$ & $413 \pm 19$ \\
\hline $\mathrm{CH} 313 \mathrm{~b}$ & $1.50 \pm 0.22$ & $410 \pm 21$ \\
\hline CH314b & $1.60 \pm 0.33$ & $413 \pm 26$ \\
\hline CH315b & $1.40 \pm 0.14$ & $406 \pm 17$ \\
\hline CH316b & $1.50 \pm 0.20$ & $410 \pm 19$ \\
\hline $\mathrm{CH} 323 \mathrm{~b}$ & $1.50 \pm 0.61$ & $410 \pm 47$ \\
\hline $\mathrm{CH} 324 \mathrm{~b}$ & $1.90 \pm 0.57$ & $423 \pm 36$ \\
\hline CH325b & $2.10 \pm 0.48$ & $428 \pm 29$ \\
\hline $\mathrm{CH} 329 \mathrm{~b}$ & $2.00 \pm 0.42$ & $426 \pm 27$ \\
\hline $\mathrm{CH} 330 \mathrm{~b}$ & $2.40 \pm 0.21$ & $436 \pm 17$ \\
\hline \multicolumn{2}{|c|}{ AVERAGE TEMPERATURE } & $425 \pm 38$ \\
\hline CH307a (undeformed) & $8.00 \pm 1.70$ & $514 \pm 34$ \\
\hline CH308c (infilling) & $3.80 \pm 0.39$ & $464 \pm 19$ \\
\hline \multicolumn{3}{|l|}{ Crawford Knob } \\
\hline CK303b & $1.10 \pm 0.12$ & $394 \pm 34$ \\
\hline CK306b & $1.90 \pm 0.65$ & $423 \pm 21$ \\
\hline CK307b & $1.10 \pm 0.22$ & $394 \pm 17$ \\
\hline CK308b & $1.20 \pm 0.23$ & $398 \pm 24$ \\
\hline CK309b & $1.20 \pm 0.17$ & $398 \pm 20$ \\
\hline CK310b & $1.30 \pm 0.49$ & $402 \pm 24$ \\
\hline CK324b & $1.00 \pm 0.31$ & $389 \pm 20$ \\
\hline CK330b & $1.40 \pm 0.59$ & $406 \pm 43$ \\
\hline \multicolumn{2}{|c|}{ AVERAGE TEMPERATURE } & $400 \pm 21$ \\
\hline CK75a (undeformed) & $10.70 \pm 1.10$ & $535 \pm 23$ \\
\hline CK309c (infilling) & $1.20 \pm 0.18$ & $398 \pm 41$ \\
\hline CK310c (infilling) & $1.00 \pm 0.17$ & $389 \pm 48$ \\
\hline
\end{tabular}


Since there could have been a difference in deformation temperature between the structural top (SE-side) and bottom (NW-side) of the NE-striking and SE-dipping shear array, and since this temperature difference could also have led to variable observed $D$ values, we plotted the calculated temperatures against a paleo-structural depth relative to a reference height (Fig. 4.24). We chose an elevation of $1755 \mathrm{~m}$ as reference height because that is the highest point at which a sample was taken in that area (sample TL116 (E2283812; N5746771) for oxygen isotope thermometry, Appendix 4.A). For example, a data point that plots at a paleo-depth of $300 \mathrm{~m}$ in Fig. 4.24 was taken at an elevation of $1455 \mathrm{~m}$, i.e., $300 \mathrm{~m}$ below sample TL116. This approach implies of course, that relative depth differences during the time of brittle-ductile shear formation were maintained during exhumation and are reflected in the current topography. We used different patterns and grey scales for the data points in Fig. 4.24 in order to differentiate between sample location, deformed vein part, undeformed vein part, and infilling vein. In the grey shaded area of Fig. 4.24, we also plotted the temperature range that was determined from quartz-calcite $\delta^{18} \mathrm{O}$-exchange thermometry in section 4.6.1.1.1. Fig. 4.24 shows that the quartz in most of the sheared veins has been statically recrystallised at minimum temperatures between $390^{\circ} \mathrm{C}$ and $450^{\circ} \mathrm{C}$, with the Chancellor Ridge veins showing slightly higher apparent temperatures than those from Crawford Knob.

For comparison with the above results in the deformed veins, we also calculated the recrystallisation temperatures for an undeformed part of a quartz vein from Chancellor Ridge $\left(514 \pm 23^{\circ} \mathrm{C}(2 \sigma)\right)$ and at Crawford Knob $\left(535 \pm 34^{\circ} \mathrm{C}(2 \sigma)\right)$ (Table 4.3; Fig. 4.24). When compared to the average recrystallisation temperature that we calculated for the sheared parts of the same quartz veins in both locations, the data indicate that the quartz recrystallisation temperature of the original, unsheared vein part was $c .100^{\circ} \mathrm{C}$ hotter than that in the sheared part of the vein $\left(\Delta T=135^{\circ} \mathrm{C}\right.$ for Crawford Knob and $\Delta T=89^{\circ} \mathrm{C}$ for Chancellor Ridge). From this, we infer that the undeformed parts of the quartz veins had already been fully recrystallised (at higher temperature) before the onset of the Cenozoic shearing. The measured static recrystallisation temperatures in the undeformed vein parts could therefore provide an upper boundary on the temperatures during the subsequent shear zone formation. These maximum temperature estimates together with the minimum recrystallisation temperatures measured inside the sheared parts and the oxygen isotope temperatures in the infilling 
veins, result in an inferred temperature range for the Cenozoic deformation of the quartz veins of $400-530^{\circ} \mathrm{C}$.

Fig. 4.24 also shows that, within error, the minimum recrystallisation temperature of the fault-infilling veins $\left(\sim 400^{\circ} \mathrm{C}\right.$ for the two Crawford Knob veins and $\sim 460^{\circ} \mathrm{C}$ for the Chancellor Ridge vein, cf. Table 4.3) was similar to that for the sheared marker veins (cf. Table 4.3). This agrees with the interpretation of Wightman and Little (2007) that the shearing and infilling of the shears were penecontemporary events.

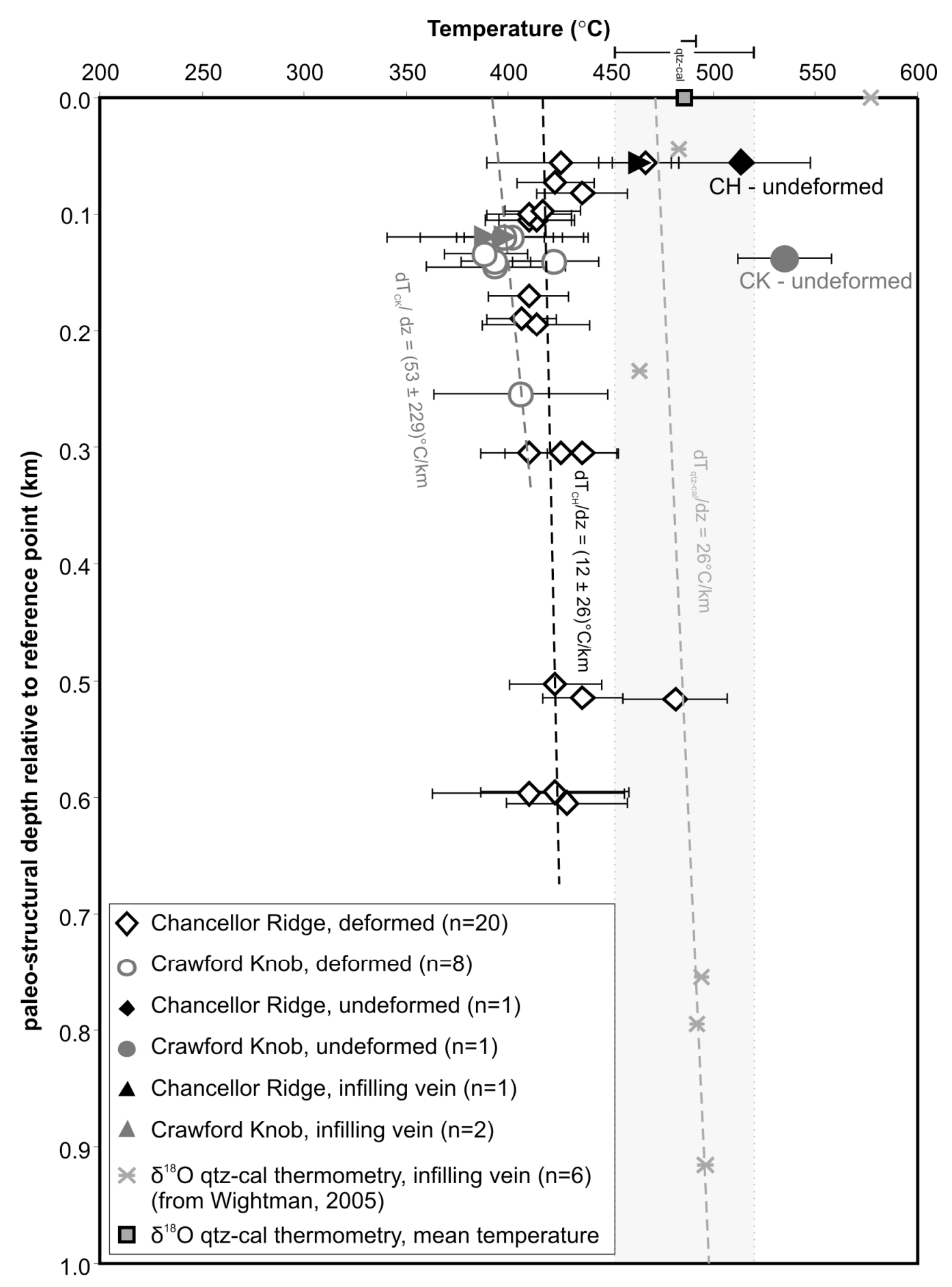


Fig. 4.24 (previous page): Scatter plot of TitaniQ-determined minimum temperatures for quartz recrystallisation as well as temperatures calculated from quartz-calcite $\delta^{18} \mathrm{O}$-exchange thermometry versus relative paleo-structural depth. This plot shows that higher temperatures determined with TitaniQ were measured in the undeformed vein parts than for the deformed parts of the same sheared veins. Temperatures determined by Ti-in-Quartz thermometry in the sheared veins are within error of oxygenisotope temperatures for recrystallisation of the shear-infilling veins, indicating similar recrystallisation temperatures for both types of adjacent veins. The dashed lines are linear regression lines that could indicate geothermal gradients, however, the uncertainties of those lines are too high to use in the calculation of paleo-geothermal gradients. The grey-shaded temperature was derived from qtz-cal oxygen isotope geothermometry by Wightman (2005).

Since the temperatures that were measured for individual deformed veins are temperatures that prevailed during static grain growth and recovery of the previously deformed quartz veins, single temperature measurements do not reflect the actual deformation temperature and cannot be used to directly explain the variable values of $D$ for those veins (again, they are minima). The temperatures that were measured via Tiin-Quartz thermometry are not precise enough to resolve any vertical temperature gradient (see large errors on temperature gradients in Fig. 4.24). For that reason we were not able to determine whether temperature had a major influence on the $D$-ratio of individual veins, but infer that all quartz veins were deformed in the estimated temperature range $\left(400-530^{\circ} \mathrm{C}\right)$. This temperature range together with Wightman's estimate of $486 \pm 50^{\circ} \mathrm{C}$ based on oxygen isotopes at an inferred paleodepth of $25 \mathrm{~km}$ implies a paleo-geothermal gradient of $16-21^{\circ} \mathrm{C} / \mathrm{km}$. The lack of any evidence for an abnormally high perturbed paleo-geothermal gradient for the shear array is consistent with the escalator model, because this requires that the shears formed above the toe of the orogenic ramp well to the east of the Alpine Fault. There, isotherms were assumed to have remained subhorizontal since the Mesozoic and not been advected upwards due to high uplift rates closer to the Alpine Fault (Fig. 4.4).

\subsubsection{Depth and differential stress during shearing}

The depth at which the brittle-ductile shears formed is the most difficult factor to obtain. It is also one of the most important factors because the overburden stress and brittle shear resistance is proportional to that depth (e.g., Kohlstedt et al., 1995). Several depth estimates have been made for the detachment and the deformation depth of the mylonites adjacent to the Alpine Fault. Stern et al. (2001) have used seismic imaging (megashot gathers) to estimate the depth of the crustal detachment to the east of the SEdipping Alpine Fault ramp to $\sim 35 \mathrm{~km}$. Based on the overgrowth textures of garnet in a 
mylonitised garnet-oligoclase zone Alpine schist sample that was taken $\sim 100 \mathrm{~m}$ to the east of the Alpine Fault and using garnet-biotite geothermometry and garnet-biotiteplagioclase-quartz geobarometry Vry et al. (2004) estimate that mylonitisation took place in the Cenozoic at peak temperatures of $c .600^{\circ} \mathrm{C}$ at pressures of $c .1 .1 \mathrm{GPa}$, corresponding to $c .40 \mathrm{~km}$ depth. Toy (2007) reports that deformation temperatures in the Alpine Fault mylonites did not exceed $\sim 650^{\circ} \mathrm{C}$ at $\geq 700-850 \pm 150 \mathrm{MPa}$, i.e., mylonitisation took place at $26-33 \mathrm{~km}$ depth. Her P-T values are based on feldspar thermobarometry, Ti-in-Biotite thermometry, and the absence of prism<c>-slip quartz CPO fabrics in the Alpine Fault mylonites. From these above mentioned depth estimates, we will here assume that during the brittle-ductile shear formation that the basal detachment was located at a depth of $\sim 32 \pm 5 \mathrm{~km}$ (Fig. 4.3). Since the rocks in the brittle-ductile shear array have been tilted east and are now exposed 5-7 km to the east of the Alpine Fault and that fault has a mean dip of $\sim 45^{\circ}$ (Fig. 4.4), we infer that they have been exhumed from a minimum depth of $(32 \mathrm{~km}-7 \mathrm{~km})=25 \mathrm{~km}$. This calculation implies that the rocks to the east of the Alpine Fault were transported up that inclined plane as rigid blocks (e.g., Little, 2004), and ignores the effect of any viscous deformation on the geometry of the underlying rocks, e.g., a possible thinning of the mylonite zone towards the surface (Toy, 2007).

Wightman (2005) measured fluid inclusion densities of aqueous fluids $\left(\mathrm{H}_{2} \mathrm{O}-\mathrm{NaCl}\right)$ in what appear to be primary inclusions (Fig. 4.8d) of four infilling vein samples from different locations in the shear array (one SW of Franz Josef Glacier, two from Baumann Glacier, one from Sam Peak; for localities see Fig. 4.3b). The analytical procedure is detailed in Appendix 4.C. The results of the analysis are summarised in Table 4.C-1. Homogenisation temperatures were $T_{h}=234 \pm 15^{\circ} \mathrm{C}$ implying fluid densities of $\rho_{f} \approx 0.84 \mathrm{~g} / \mathrm{cm}^{3}$. We determined the fluid pressure at the time of fluid inclusion entrapment in the infilling veins by combining fluid inclusion isochors with the temperature range that was derived in sections 4.6.6.1.1 and 4.6.6.1.2 from quartzcalcite ${ }^{18} \mathrm{O} /{ }^{16} \mathrm{O}$ exchange thermometry and Titanium-in-Quartz geothermometry. Fig. 4.25 illustrates this: the average fluid inclusion isochore (based on $\rho_{f}=0.84 \mathrm{~g} / \mathrm{cm}^{3}$ ) intersects the lines of the minimum and maximum temperature estimate $\left(400-530^{\circ} \mathrm{C}\right)$ at the fluid pressure $P_{f}=310 \pm 90 \mathrm{MPa}$. This $P_{f}$ is inferred to have been the fluid pressure 
during growth of the fluid-entrapping infilling veins after development of the fractures and during their passive infilling as a result of fluid flow along these fractures.

The minimum depth estimate of $\sim 25 \mathrm{~km}$ leads us to infer an overburden pressure of $P_{\text {lith }} \geq 660 \mathrm{MPa}$ (assuming a rock density $\rho=2700 \mathrm{~kg} / \mathrm{m}^{3}$ and $P_{\text {lith }}=\rho g z$ ). This suggests a ratio of fluid pressure to lithostatic pressure at the time of vein growth and fluid inclusion entrapment of $\lambda=P_{f} / P_{\text {lith }} \approx 0.47$, which is slightly above the theoretical hydrostatic ratio of $\lambda \approx 0.37-0.4$. Simple Mohr-Coulomb analyses (Fig. 4.26) indicate that to allow brittle failure of the Alpine Schist at such depths in the lower crust, would require fluid pressures that were probably near-lithostatic (i.e., fluid pressure ratio $\left.\lambda=P_{f} / P_{\text {lith }} \approx 0.98\right)$, an observation that is consistent with geophysical data interpreted to represent enhanced (near-lithostatic) fluid pressures in the hanging wall of the Alpine Fault (Stern et al. 2001, 2007). The different fluid pressure ratios indicate that the fluid pressure in the shears must have been cycling from near-lithostatic during fracturing of the Alpine schist host to near-hydrostatic during deposition of the shearinfilling quartz-calcite veins (cf. Wightman, 2005; Wightman et al., 2006; Wightman and Little, 2007).

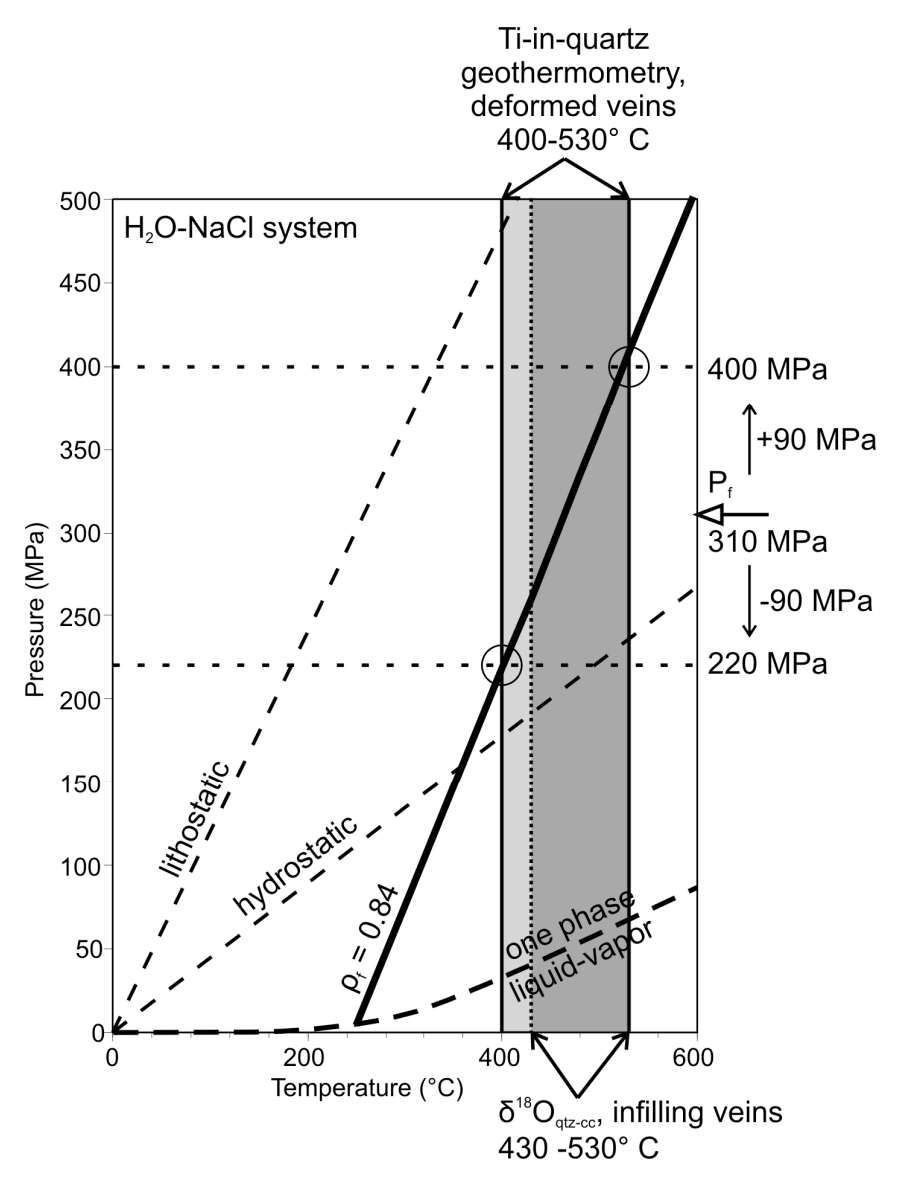


Fig. 4.25 (previous page): Pressure-temperature diagram for the determination of the fluid pressure $P_{f}$ at the time of fluid inclusion entrapment in the fault-infilling quartz-carbonate veins from primary fluid inclusions in quartz and two different estimates for deformation temperature. The fluid pressure at the time of fluid inclusion entrapment is determined by the intersection between the average fluid inclusion isochor $\left(\rho_{f}=0.84 \mathrm{~g} / \mathrm{cm} 3\right)$ with the lines of the maximum and minimum estimates for deformation temperature. The resulting inferred fluid pressure is $310 \pm 90 \mathrm{MPa}$. Quartz-calcite $\delta^{18} \mathrm{O}$-geothermometry by Wightman (2005), Appendix 4.A. Ti-in-Quartz (TitaniQ) geothermometry, this study. Hydrostatic and lithostatic pressure gradients (stippled lines) are based on $\rho_{\text {hydro }}=1.0 \mathrm{~g} / \mathrm{cm} 3$ and $\rho_{\text {rock }}=2.7 \mathrm{~g} / \mathrm{cm} 3$ respectively. The average temperature gradient is $22^{\circ} \mathrm{C} / \mathrm{km}$.

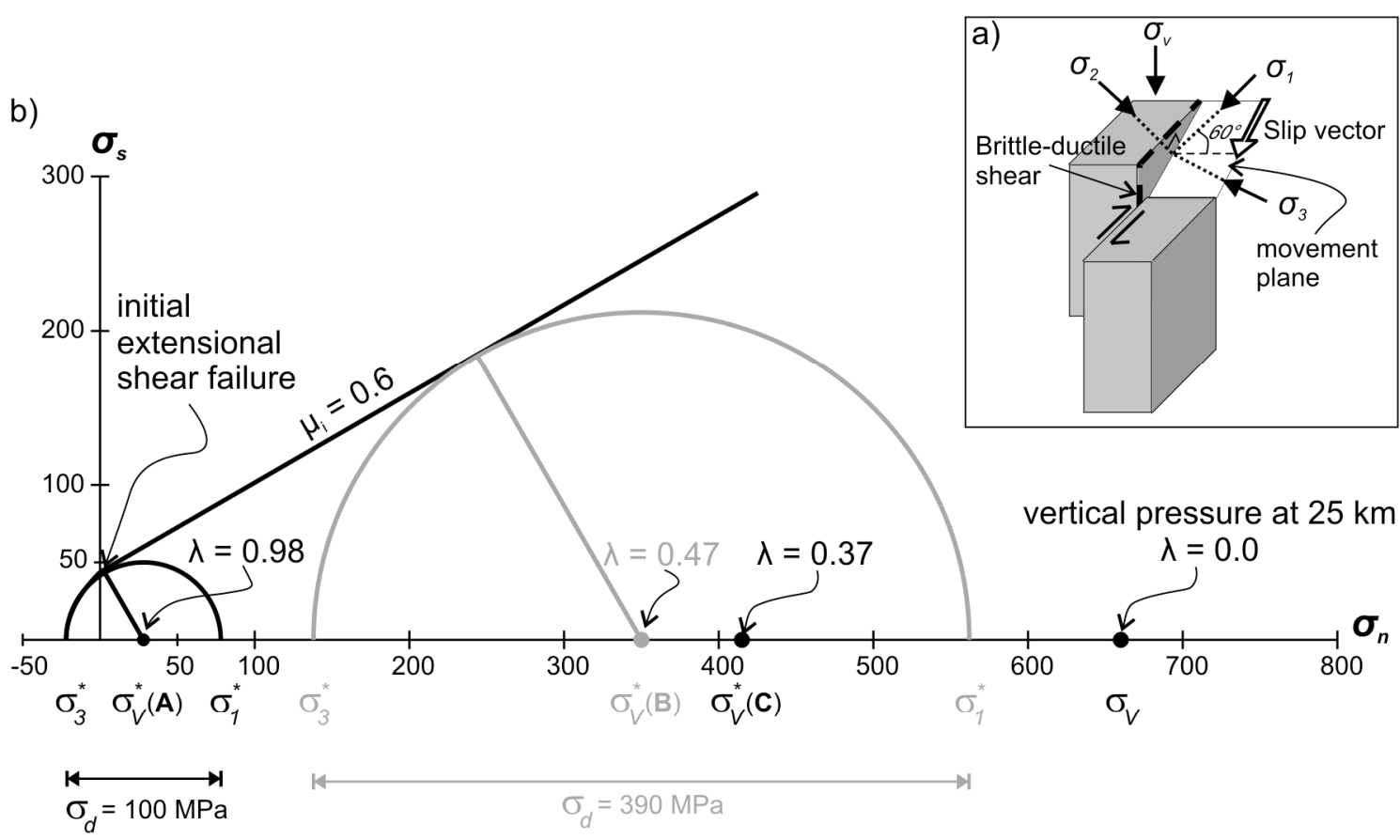

Three different fluid pressures at $25 \mathrm{~km}$ depth:
(A) $\quad \lambda=0.98$
$P_{f}=645 \mathrm{MPa}$
pre-failure
(B) $\lambda=0.47$
$P_{f}=310 \mathrm{MPa}$
syn-trapping, post-failure
(C) $\quad \lambda=0.37$
$P_{f}=245 \mathrm{MPa}$
post-failure, hydrostatic

Fig. 4.26: a) Block diagram of near-vertical brittle-ductile shear (after Wightman, 2005), schematically indicating principal stress directions assuming Andersonian faulting behaviour. $\sigma_{v}$ is the vertical overburden stress. $\sigma_{1}, \sigma_{2}$ and $\sigma_{3}$ are maximum, intermediate and minimum principal stresses. The slip vector is indicated by the bold white arrow. The movement plane is perpendicular to the shear surface and contains the slip vector. $\sigma_{1}$ and $\sigma_{3}$ lie in the movement plane. b) Mohr-Coulomb-Griffith failure envelope for intact rock illustrating stresses during initial brittle-ductile shear zone formation at a depth of $25 \mathrm{~km}$. $\mu_{i}=$ coefficient of internal friction; $\sigma_{n}=$ normal stress; $\sigma_{s}=$ shear stress; $\sigma_{v}=$ overburden lithostatic pressure; $P_{f}=$ fluid pressure; $\sigma_{v}{ }^{*}=\sigma_{n}-P_{f}$, effective normal stress. In this diagram, we inferred $\sigma_{v}=\sigma_{2}$. Effective stresses are marked with (*). $\sigma_{d}$ is differential stress.

Point (A): effective normal stress for $\lambda=0.98$. This fluid pressure ratio is necessary to fracture intact rock at $25 \mathrm{~km}$ depth. At (A), the maximum differential stress can be $\sim 100 \mathrm{MPa}$ without inducing brittle failure. This means that $\sigma_{d} \geq 100 \mathrm{MPa}$ is a minimum estimate for shear failure at near lithostatic fluid pressures. Point (B): effective normal stress for $\lambda=0.47$, as calculated from the entrapment $P_{f}$ in fluid inclusions in the infilling veins (see text for detail) after brittle failure of the intact schist.

Point $(C)$ : effective normal stress at hydrostatic conditions $(\lambda=0.37)$. 
Considering the near-vertical attitude of the brittle faults, which strike subparallel to the plate margin in this transpressive plate boundary setting, we inferred that the intermediate principal stress was nearly vertical and hence equal to the overburden lithostatic pressure at $25 \mathrm{~km}$ depth, i.e., $\sigma_{V}=P_{\text {lith }}=660 \mathrm{MPa}$.

Wightman (2005) interpreted microstructures in the shear-infilling veins (relict quartz grains with elongate shape and crystallographic preferred orientations at high angles to the faults) as indicators of emplacement of the infilling veins through crackseal processes into hybrid extensional-shear fractures in the quartzofeldspathic rocks although the relative timing of fracture dilation and shearing is unclear. For example, the initial fracturing may have been by shear failure requiring a larger differential stress than if the cracks nucleated as mode I structures. Assuming a depth of $\geq 25 \mathrm{~km}$, and using a combined Mohr-Coulomb-Griffith analysis of brittle fracture for intact rock, we derived a minimum estimate for the differential stress at the time of brittle failure of the host schist of $\sigma_{d}=\left(\sigma_{1}-\sigma_{3}\right)=100 \mathrm{MPa}$ (Fig. 4.26b, Point A). For this differential stress, the fluid pressure must have been near-lithostatic $\left(P_{f} \approx 645 \mathrm{MPa}\right)$. Considering that fluid pressures were $\sim 310 \pm 90 \mathrm{MPa}$ (i.e., $\lambda=0.33-0.61$ ) at the time of the fluid inclusion entrapment in the infilling veins, one infers that the fluid pressure must have fallen as the infilling veins began to grow post-failure. At this $P_{f}$, the expected differential stress for conditions of brittle failure would have been $\sim 390 \mathrm{MPa}$ (Fig. 4.26b, Point B).

The cycling fluid pressures could have led to variations in the relative stability or the rate of fault slip that could in turn have led to local strain rate variations in a given quartz vein and thus to a partitioning of brittle to ductile deformation in a different way between the high $P_{f}$ and low $P_{f}$ area on an individual fault. 


\subsection{Discussion}

In the following, we discuss what could have led to the formation of well localised ductile shear zones in some veins and to brittle shear zones in others.

\subsubsection{Was precursory brittle deformation necessary for the localisation of the ductile} shear zones?

Gleason and DeSisto (2008) document a greenschist facies ductile shear zone that apparently developed without the aid of a brittle precursor. The shear zone formed in a pegmatitic dike cross-cutting granitic gneisses in the Adirondacks, New York. This example leads to the question whether a brittle precursor is a necessary precondition to form a ductile shear zone (as introduced in Fig. 4.1), even in already layered and lithologically inhomogeneous rocks. For example, Simpson (1986) reported that high fluid pressure had induced fracturing in diorites from southern California and in Striped Rock granite from Virginia. This fracturing was followed by hydrolytic weakening of the rocks to trigger crystal-plastic creep of quartz and feldspar and ductile strain localisation. Tourigny and Tremblay (1997) described a shear zone from Québec, where brittle fractures and joints have been ductilely reactivated multiple times after reaction softening and hydraulic weakening of wall rocks had taken place adjacent to the fractures. Similar processes (weakening through precursory embrittlement) have recently been described by Pennacchioni (2005) in Adamello tonalites in the Italian Alps, where joints in en-échelon arrangement were reactivated as "fault-like" shear zones under water-deficient conditions with ductile deformation only occurring in the overlapping region between adjacent joints, where strain rates were presumably lower and therefore facilitated ductile flow. Mancktelow and Pennacchioni (2005) and Pennacchioni and Mancktelow (2007) investigated the influence of fluid-alteration in metagranodiorites in the Tauern window, eastern Alps on the formation of paired ductile shear zones versus single shear zones. Their evolutionary shear zone model predicts that the observed paired ductile shear zones could only form along the relatively weaker rims of chemically hardened halos in the wall rocks, where fluids had been introduced through precursory brittle fractures and had led to the fluid-altered halos in the wall rocks surrounding the fractures. Single shear zones only formed where precursory brittle fracturing had taken place, but without obvious fluid-alteration effects. Shear zones and shear zone terminations in particular in foliated metasediments 
at the Cap de Creus, Spain were investigated by Fusseis et al. (2006) and Fusseis and Handy (2008) among others. They concluded that the formation and propagation of ductile shear zones was induced by initial microfracturing that facilitated fluid ingress and subsequent hydrolytic weakening.

In section 4.6.5 we have shown that there is evidence for microfracturing of the quartz veins in the form of healed microfractures before the shearing of the veins initiated. We also showed that the microfracture density is apparently similar in both the deformed and the undeformed parts of the veins. It is unclear what caused the microfracturing in the quartz veins. We interpret the homogeneously distributed microfracture array throughout the veins as having been an avenue of water introduction into them. Later, this could have led to a decrease in viscosity of those veins. In that sense, brittle precursory fracturing may have been a contributor to weakening of the quartz veins with respect to the schist. Our data suggest, however, that it did not control the place of shear localisation inside those veins. In the quartz veins from the Southern Alps, precursory microfracturing and water infiltration was probably not important for the subsequent localisation of the ductile shear zones at particular sites in those veins during the late Cenozoic.

\subsubsection{Was local softening or hardening of the quartz veins necessary to form the ductile} shear zones?

We could not find any evidence for a focused (intra-vein) softening process in the deformed quartz veins in the Southern Alps. In fact, the increase of the ductilely sheared width $(d s w)$ with the ductile displacement $(d)$ (Fig. 4.13, section 4.5.2) led us to infer that those quartz veins have actually locally hardened during the initiation of shear zone formation. Local hardening could also be supported by lower water concentrations in the deformed parts of the sheared veins than in their undeformed parts (FTIR; section 4.6.5.2). Syndeformational water leakage in the quartz veins would be in agreement with a hardening behaviour of the quartz veins. Still, today we observe mainly ductile shear zones in most of the quartz veins. We infer therefore, that the faults in the adjacent schist controlled the formation of the ductile shear zones in the quartz veins ahead of their tips. Due to the water that may already have been introduced into the quartz veins via their older microfracture arrays either by late Cenozoic fluid flow along the brittleductile shear faults (Wightman and Little, 2007) or by some previous event, the veins were already weak enough to not fail brittlely but to transform into ductile shear zones 
when the brittle fault tips propagated through the schist to impinge on the veins. We argue that although the quartz veins are approximately homogeneous, it was not necessary to introduce a smaller scale rheological contrast into the quartz. This contrasts with the shear zone examples presented in the studies cited in section 4.7.1. Whatever controlled the spacing of the brittle faults in the host schist also controlled the location of ductile shear zone formation in the rheologically weaker quartz veins. In a similar way, but on a much larger scale Ellis and Stöckhert (2004) proposed that localisation of ductile strain in the viscous mid-lower crust can be achieved by seismic rupture of an overlying fault in the brittle upper crust and the transfer of the high stress from the down-dip fault tip into the ductilely deforming lower crust.

\subsubsection{What has caused the different degrees of ductility in the quartz veins?}

Variable degrees of ductile behaviour of the shear zones in the quartz veins raise the question as to what caused this differential behaviour. We have eliminated the calcite fraction as a weakening agent, as well as differences in fluid content or species (at least as preserved today). $D$ - $x$-plots along five separate shears revealed that $D$ varies along-strike of those shears and scales mainly with the original vein thickness and to a certain degree inversely with the total displacement (Fig. 4.16). In cases where these scaling relationships are clearly violated, we infer that variations of slip rates at the decimetre-scale along the shears may have been responsible for variable creep strain rates and therefore different effective viscosities in the sheared quartz veins along individual faults. From the results of this study, we could not determine what may have caused these variable slip rates. In the following, we present some possible explanations.

The faults may seem like straight, planar, through-going structures, but as can be seen from detailed outcrop maps, in reality, these faults interact with each other and with lithologically different layers (Figs. 4.9 and 4.10). They bend around the older quartz veins and pelite layers, they merge, they terminate, and they create step-over zones between overlapping fault strand terminations. These interactions do not only take place in two dimensions, but also in 3D-space. Variable slip rates may therefore have been caused by fault-fault-interaction in the third dimension, which is mostly not exposed.

Fluid pressure may have varied along the brittle faults and led to patches on the fault surface that may have moved by stable sliding and others that may have only 
moved by semi-stable sliding. Applying a combined Mohr-Coulomb-Griffith brittle failure criterion for intact rock, we inferred that at the calculated depth of $25 \mathrm{~km}$ for the shear array formation, a minimum differential stress of $\sim 100 \mathrm{MPa}$ would have been necessary to fracture the Alpine schist host to the quartz veins by hybrid shearextensional failure. Fluid pressures were probably cycling between near-lithostatic at or just before the time of brittle failure of the metagreywacke schist and supra-hydrostatic after that brittle failure during emplacement of the syntectonic fibrous shear-infilling quartz-calcite veins. Along some (metre-scale) sections of individual brittle faults in the schist, fluid pressure could have been higher than along other sections. Hypothetically, variable fluid pressures could have been caused by different permeabilities of the Alpine schist host depending on whether it had, e.g., pelitic or psammitic grain sizes. The differential fluid pressures could in return have led to local spatial differences in shear resistance. Enhanced slip rates may have occurred where fluid pressures were high and decreased slip rates, where $P_{f}$ was lower. More separation-length data perhaps in combination with schist permeability studies is needed to reliably and directly confirm an apparent link between the variability of the $D$-values to the cycling fluid pressures.

Another possible reason for different shear resistances along the faults could be locally different fault roughness due to the incrementally grown fibrous shear-infilling veins. For example, Voisin et al. (2007) have performed experiments with a salt slider that developed striae due to dissolution-precipitation creep on the salt surface with progressive sliding. A decrease in fault roughness due to the striae development in their experiments led to the transition from stick-slip behaviour to episodic stable sliding. Since slip in the quartzofeldspathic host rocks was partly accommodated by dissolutionprecipitation creep (Wightman, 2005), we could also expect that differences in the Alpine schist lithology played a role in slip rate variations along the faults. Dissolutionprecipitation creep is a grain size sensitive deformation mechanism with $\dot{\varepsilon} \propto 1 / d^{3}$ (e.g., Rutter, 1983), meaning that an increase in grain size of only one order of magnitude (e.g., from 10 to $100 \mu \mathrm{m}$ ) could result in a decrease in strain rate of 3 orders of magnitude. Since slip rate is strain rate multiplied by shear zone or fault width, and since the average fault width is relatively constant $(\sim 2 \mathrm{~mm})$ throughout the studied fault array, this would result in a decrease in slip rate by 3 orders of magnitude. A change in slip rate of three orders of magnitude is sufficient to achieve brittle yielding in some veins and ductile deformation in others. However, more data is needed to confirm that 
e.g., quartz veins in psammitic (coarse grained) layers are more likely to deform ductilely than quartz veins in pelitic (finer grained) layers (e.g., Mair et al., 2002).

Also, the fault planes in the brittle-ductile shear array are not entirely planar but can be undulose. An undulose fault surface has been shown to have an influence on the friction coefficient and therefore the type and velocity of sliding along that fault (Chester and Chester, 2000). Fault movement was probably not only accommodated by stable sliding as we originally assumed but might be better described by a rate-and-state dependent frictional sliding law (e.g., Scholz, 2002; pp. 81-94). Such a law includes changes of the fault friction coefficient that does not only depend on the properties of the fault surface (e.g., fault roughness, asperities density) but also on the elastic properties of the host rocks. The development of the rate-and-state dependent friction coefficient controls whether a fault undergoes stable or unstable sliding (Scholz, 2002). Frictional sliding on the faults that were investigated here might have been of the unstable type especially during the initial stages of shearing, because the smoothness of the fault planes as observed today yet had to develop. Unstable sliding may have led to accelerated movement on some fault sections. The accelerated shearing may have induced locally higher shear strain rates at the quartz veins ahead of that sliding segment and therefore to local embrittlement in those particular quartz veins that were cross-cut by that section of the fault. We cannot directly confirm whether any of the processes mentioned above or if a combination thereof was responsible for the variable fault slip rates. We conclude however that variable slip rates along separate shears were probably the main factor leading to differential effective viscosities and therefore $D$-values between the different quartz veins.

\subsection{Conclusions}

In order to contribute to the understanding of ductile shear zone localisation processes in quartzose rocks with homogeneous but variably strong layers in the mid to lower crust, we have conducted a detailed examination of narrow $(2-3 \mathrm{~cm}$ wide) brittleductile shear zones that formed in quartz veins as a result of late Cenozoic transient embrittlement in the hangingwall of the Alpine Fault. The shearing took place above the foot of the Alpine Fault ramp at $\geq 20 \mathrm{~km}$ depth at temperatures between $400-530^{\circ} \mathrm{C}$, a minimum differential stress of $100 \mathrm{MPa}$ and fluid pressures that cycled between lithostatic and near-hydrostatic in the failure/post-failure period. 


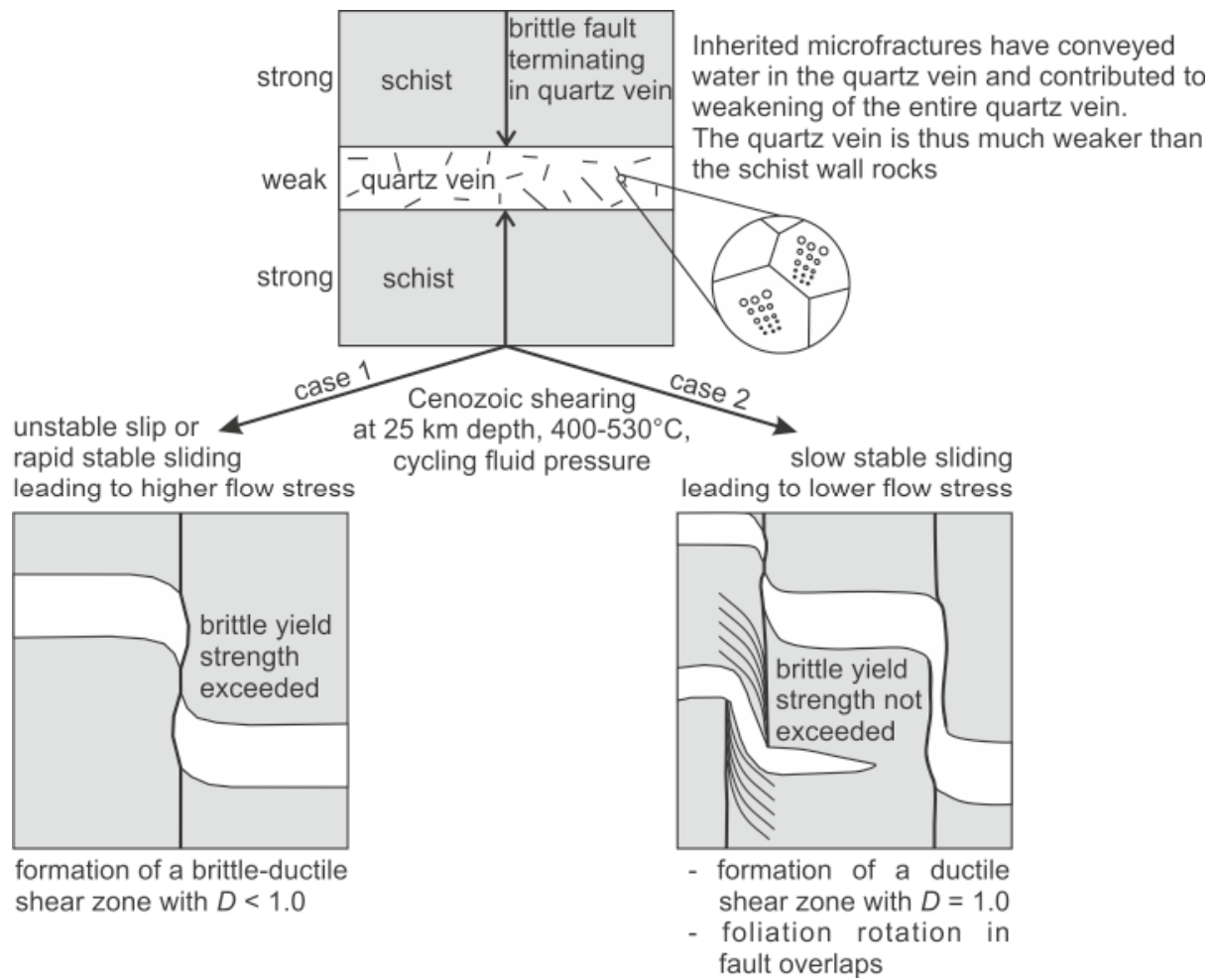

Fig. 4.27: Schematic diagram showing proposed model for ductile shear zone formation in rocks with layers that are homogeneous but of different strengths. The flow diagram illustrates two ways to form localised ductile shear zones in a quartz vein that is hosted by metagreywacke schist. Inherited microfractures have led to fluid ingress in the quartz veins and has left the vein rheologically weaker than the surrounding schist. No rheological contrast had to be introduced in order to form those shear zones. The quartz vein was already weaker than the surrounding schist. The resulting type of shear zone in the quartz vein depends on the local slip rate. A high slip rate (case1) would lead to high strain rate and high flow stress possibly followed by brittle yielding in the quartz vein, whereas a low slip rate (case 2) invokes low strain rates and a fully ductile shear zone in the quartz vein.

From the results of this study we conclude that:

- $\quad$ in layered sequences of rocks, formation of a ductile shear zone in a weak layer that is surrounded by strong material is possible without focused local precursory embrittlement or focused local weakening of that layer;

- $\quad$ in the investigated shear zones, the rheological contrast that was necessary to form a ductile shear zone can be pervasive microfracturing with subsequent water ingress through those microfractures; if so,

- the location of shear zone formation in the sheared quartz veins can be determined by the location of the brittle fault tips impinging onto those veins, and not by any vein-scale weakening processes or inhomogeneities in the veins; 
- the shear zones that were investigated in this paper actually hardened, not softened; at least in the initial stages of shearing;

- the locally variable styles of rock deformation (brittle vs. ductile) in the investigated shear zones and variable ratios of ductile to total displacement ( $D$-value) were probably controlled by variable slip rates along segments of individual faults that were experiencing different types of frictional instability or slip leading to variable local strain rates and effective viscosities of those shear zones.

In Fig. 4.27 we present a simple model that shows how the shear zones with variable ductilities could have formed. 


\section{Appendix 4.A - Analytical details of quartz-calcite ${ }^{18} \mathrm{O} /{ }^{16} \mathrm{O}$ exchange thermometry}

Quartz-calcite ${ }^{18} \mathrm{O} /{ }^{16} \mathrm{O}$ exchange thermometry was conducted on 6 samples from the brittle-ductile shear array by R. Wightman during the course of her $\mathrm{PhD}$ thesis. The following analyses results (Table 4.A-1) are taken from her $\mathrm{PhD}$ work (Wightman, 2005) that resulted in a manuscript on the conditions during the formation of the brittleductile shear array (Wightman et al., in prep.). We have adapted figure and table numbers to fit this paper.

"For mineral separate oxygen isotopic data (Table 4.A-1), thick sections of the fault infilling veins were made $\sim 500 \mu \mathrm{m}$ thick, then prepared using the thin sawblade technique (Elsenheimer and Valley, 1993; Kohn et al., 1993). Approximately 1-2 mg of each mineral sample was selected from the centre and rim of the veins to test for isotopic homogeneity across the vein, before further sample was crushed. Quartz analyses were collected using a laser probe extraction system at University of Wisconsin-Madison using a $\mathrm{CO}_{2}$ laser, $\mathrm{BrF}_{5}$ reagent and a Finnigan-MAT 251 mass spectrometer following procedures described in Valley et al. (1995) and Spicuzza et al. (1998). Calcite samples were reacted with anhydrous $\mathrm{H}_{3} \mathrm{PO}_{4}$ following the methods of McCrea (1950). Calcite-acid mixtures were maintained at $50^{\circ} \mathrm{C}$ overnight, then $\mathrm{CO}_{2}$ extracted under vacuum and cryogenically purified. Values of $\delta^{18} \mathrm{O}$ were then measured on the mass spectrometer.

Table 4.A-1 Oxygen isotope composition and mineral fractionations from infilling veins

\begin{tabular}{cccccc}
\hline & Quartz & \multicolumn{3}{c}{ Calcite } & \\
\cline { 2 - 4 } Sample & size & $\delta^{18} \mathrm{O}_{\text {qtz }}$ & size & $\delta^{18} \mathrm{O}_{\text {cal }}$ & $\Delta$ (qtz-cal) \\
\hline IA43 -1 & 19.6 & 13.21 & 6 & 11.78 & 1.43 \\
IA43 -2 & 17.7 & 13.17 & 29 & 11.60 & 1.57 \\
IA44 -1 & 16.6 & 12.98 & 12 & 11.51 & 1.47 \\
IA44 -2 & 20.9 & 13.11 & 25 & 11.57 & 1.54 \\
IA46 - & 16.5 & 12.82 & 24 & 11.38 & 1.44 \\
IA46 -2 & 18.6 & 12.88 & 27 & 11.34 & 1.54 \\
I102 & 20.0 & 13.30 & 16 & 11.76 & 1.54 \\
TL27 & 12.9 & 12.56 & 12 & 10.94 & 1.62 \\
TL116 -1 & 24.4 & 12.99 & 25 & 11.94 & 1.05 \\
TL116 -2 & 19.7 & 13.05 & 15 & 11.62 & 1.43 \\
\hline
\end{tabular}

Note: compositions of quartz are corrected to UWG-2=5.8\%o, and all values normalised to \%o V-SMOW. Sizes are in $\mu$ moles $\mathrm{CO}_{2}$. 
Oxygen isotope analyses are precise to within $\pm 0.06 \%$ ( 1 standard deviation) based on analysis of the standards NBS-28 quartz $\left(\delta^{18} \mathrm{O}=9.44 \pm 0.06 \%\right.$ ) and UW Gore Mountain Garnet $\# 2\left(\delta^{18} \mathrm{O}=5.76 \pm 0.05 \%\right.$ ). These standards were periodically run during data collection in order to continuously check the integrity of the collection system. All isotopic values are reported in standard $\delta$-notation, normalised to V-SMOW.

Six samples of fault-infilling veins from the Franz Josef and Fox glaciers area (Fig. 4.1) were analysed for $\delta^{18} \mathrm{O}$ in both quartz and calcite (Table 4.A-1). In four of the samples where the vein was $>1 \mathrm{~cm}$ thick, several analyses were made, one in the centre of the vein and one at the rim of the vein. This was to evaluate isotopic homogeneity across the vein in order to ascertain mineral equilibrium so that stable isotope geothermometry could be used. Only one analysis pair was made on samples TL27 and I102 due to the limited thickness of the vein $(<1$ $\mathrm{cm})$ and the difficulty in extracting sufficient size calcite mineral splits $(>1 \mathrm{mg})$ from discrete areas of the veins.

Oxygen isotope values for both quartz and calcite fall within previously determined $\delta^{18} \mathrm{O}$ values for the Alpine Schist (e.g., Vry et al., 2001). Sample analyses from the different areas of the veins are within $0.07 \%$ for quartz and $0.14 \%$ for calcite. These differences are only just larger than the analytical uncertainties for the laboratory standards $( \pm 0.06 \%$ ). Cathodoluminescence $(\mathrm{CL})$ imaging of the veins reveals only one microtexturally distinct set of quartz and calcite mineral phases. This suggests that the veins were deposited in one event and that the quartz and calcite grains analysed are likely to be in isotopic equilibrium with one another.

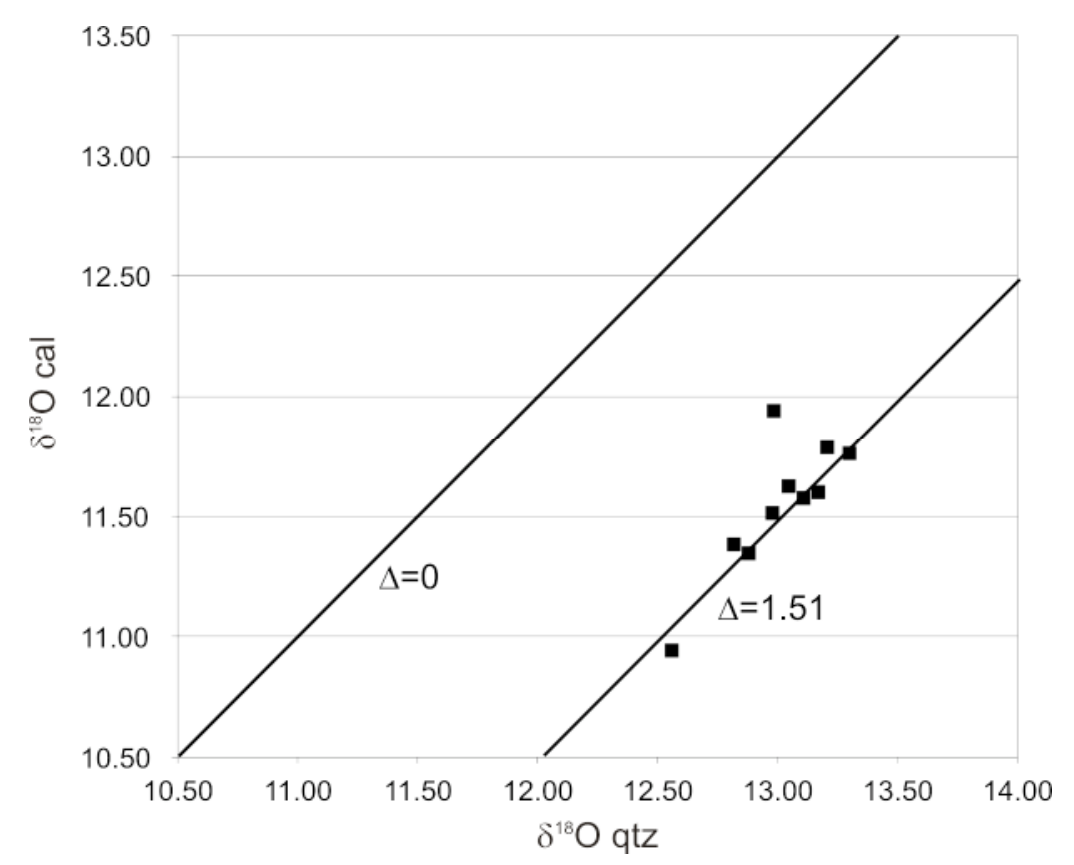

Fig. 4.A1 (Wightman, 2005, her Fig. 3.7): Plot of $\delta^{18} \mathrm{O}$ in quartz against $\delta^{18} \mathrm{O}$ in calcite from same infilling vein samples. Line of no ${ }^{18} \mathrm{O} /{ }^{16} \mathrm{O}$ fractionation is shown $(\Delta=0)$, and also line of best fit with data set $(\Delta=1.51)$. All values are normalised to V-SMOW. 
A plot of $\delta^{18} \mathrm{O}_{\mathrm{qtz}}$ against $\delta^{18} \mathrm{O}_{\text {cal }}$ from the same vein sample (Fig. 4.A1) allows the degree of isotopic equilibrium between the phases to be assessed. With one exception, the samples plot within analytical uncertainty of a straight line, demonstrating a constant fractionation factor between the two minerals, which is in agreement with the textural evidence that the two phases were deposited contemporaneously. Fractionation between the quartz-calcite mineral pairs from the centre and rims of the veins yields a consistent value of $\Delta_{\text {qtz-cal }}=1.51 \pm 0.07 \%$ o $(n=9)$. The quartz-calcite fractionation factor of Sharp and Kirschner (1994) yields temperature estimates of $486 \pm 34^{\circ} \mathrm{C}$ for deposition of these veins (uncertainties reflect the $2 \sigma$ error on the calibration of Sharp and Kirschner (1994) in combination with the uncertainty in our fractionation value). Another calibration for the fractionation of oxygen between quartz and calcite by Clayton et al. (1989) yield significantly lower temperatures (e.g., $229 \pm 50^{\circ} \mathrm{C}$ for $\Delta_{\text {qtz-cal }}=1.51$ ). This calibration was determined experimentally at temperatures between 600 and $1300^{\circ} \mathrm{C}$ (Clayton et al., 1989), and we consider the temperature estimate made using this calibration to be unreasonable given the greenschist facies vein mineral assemblage, and the minor ductile deformation that occurred post-deposition in quartz in these veins (indicative of temperatures $>\sim 300^{\circ} \mathrm{C}$ )."

\section{Appendix 4.B - Analytical details of Titanium-in-Quartz geothermometry}

We took cathodoluminescence (CL) images of different locations in the deformed, and undeformed parts of CK75 in order to test for Ti-diffusion-related zoning in the measured quartz grains (Fig. 4.21). The CL-images were taken at Victoria University of Wellington with a JEOL Superprobe 733 (at 223 nA beam current, $15 \mathrm{kV}$ excitation voltage). As Fig. 4.21 shows, the deformed and undeformed parts of the quartz veins lack Ti-zoning. The infilling vein does not show any zoning in the quartz grains either.

All samples $(n=33)$ that were measured by Titanium-in-Quartz geothermometry are mm-sized unoriented rock chips that were mounted in polished epoxy briquettes. Ticoncentrations were measured for all 33 samples by laser ablation inductively coupled plasma mass spectrometry (LA-ICP-MS) at Victoria University of Wellington. We measured mass peaks for the following isotopes: ${ }^{29} \mathrm{Si},{ }^{43} \mathrm{Ca},{ }^{47} \mathrm{Ti},{ }^{48} \mathrm{Ti}$. The standard we used was NIST-612.

The low variation in the temperatures that were measured with the TitaniQ geothermometer as well as the lack of Ti-zoning in the CL-images could be due to homogenisation of the Ti-concentrations after the static recrystallisation of the veins that took place after their deformation. The application of the Titanium-in-Quartz thermometer depends on the assumption that Ti-concentrations in the measured quartz grains did not change significantly through diffusion after the static recrystallisation 
process had finished. We calculated Ti-diffusion rates $D_{T i}$ via Eq. 4.B-1 (Cherniak et al., 2007):

$$
D_{T i}=7 \times 10^{-8} \exp \left(\frac{-237 \mathrm{~kJ} \cdot \mathrm{mol}^{-1}}{R T}\right) \text { in }\left[\mathrm{m}^{2} \mathrm{~s}^{-1}\right]
$$

The characteristic transport distance $d_{c}$ over which Ti may diffuse through the quartz lattice in two dimensions is given by

$$
d_{c}=\sqrt{4 D_{T i} t}
$$

where $D_{T i}$ is diffusion rate in $\left[\mathrm{m}^{2} \mathrm{~s}^{-1}\right]$ and $t$ is time in [s], and $d_{c}$ in $[\mathrm{m}]$ is the characteristic transport distance over which Ti may diffuse through the quartz grains. We can calculate the time for exhumation of the brittle-ductile shear array from $25 \mathrm{~km}$ depth at a dip-slip rate of $10 \mathrm{~mm} / \mathrm{yr}$ on the Alpine Fault and a dip of the fault ramp of $45^{\circ}$ at that depth to be 3.5 Myrs. For this maximum time period, Eq. 4.B-2 predicts that at $\sim 425^{\circ} \mathrm{C}$ (Chancellor Ridge) Ti will diffuse $\sim 0.34 \mu \mathrm{m}$ and at $\sim 400^{\circ} \mathrm{C}$ (Crawford Knob) Ti will diffuse $\sim 0.14 \mu \mathrm{m}$. Since the diameters of the quartz grains that were chosen for LA-ICP-MS analyses were in the order of $>50 \mu \mathrm{m}$, we conclude that Ti-diffusion can be neglected at these low temperatures and cannot be responsible for sample homogenisation. We infer that the temperatures that were measured in the quartz vein samples are actual minimum static recrystallisation temperatures (e.g., Kohn and Northrup, 2009; Spear and Wark, 2009).

\section{Appendix 4.C - Fluid inclusions analyses on shear-infilling quartz-calcite veins}

Fluid inclusion analyses were conducted on 4 samples of the shear-infilling quartzcalcite veins from the brittle-ductile shear array by R. Wightman during the course of her $\mathrm{PhD}$ thesis. The following analyses results (Table 4.C-1) are taken from her $\mathrm{PhD}$ work (Wightman, 2005) that resulted in a manuscript on the conditions during the formation of the brittle-ductile shear array (Wightman et al., in prep.). We have adapted figure and table numbers to fit this manuscript.

"Four samples of the veins that infill brittle-ductile faults around the Franz Josef Glacier and Sam Peak areas (Fig. 4.3b) were analysed for fluid inclusions. Thick sections, $60 \mu \mathrm{m}$ thick, were prepared and doubly polished. Initial petrography of the veins and inclusions was done on a standard petrographic microscope and the fluid inclusion analyses were undertaken on a Linkham heating-freezing stage at Victoria University of Wellington. Slow heating rates were used $\left(\sim 1-2^{\circ} \mathrm{C} /\right.$ minute) and results were reproducible to $\pm 0.2^{\circ} \mathrm{C}$ (Table 4.C-1). 
Fluid inclusions in the infilling veins occur as part of two distinct petrographic textures: as isolated primary inclusions in both quartz and calcite (Fig. 4.8d, and as trails in texturally secondary, healed microfractures (Fig. 4.8c). Most analyses were done on what appeared to be texturally primary inclusions in quartz, as these were larger than the $2-5 \mu \mathrm{m}$ secondary inclusions that define the inclusion trails. Texturally primary inclusions in sample TJFA44 were measured in both quartz and calcite hosts to ensure consistency of the trapped fluid between the mineral phases. The primary inclusions in three of the samples analysed (IA28, IA31 and TJFA44) were large (10-20 $\mu \mathrm{m})$, while the primary inclusions in IA44 were smaller (2-10 $\mu \mathrm{m})$. All the inclusions analysed consist of two phases at room temperature (liquid and vapour $\mathrm{H}_{2} \mathrm{O}$; Fig. 4.8d), and results are summarised in Table 4.C-1.

Table 4.C-1 Fluid inclusion data from infilling veins

\begin{tabular}{llllllll} 
Sample & Mineral & No. inclusions & Inclusion type & $\mathrm{T}(\mathrm{m})^{\mathrm{a}}$ & $\mathrm{T}(\mathrm{h})^{\mathrm{b}}$ & wt\% salt & Fluid density \\
\hline IA28 & Quartz & 28 & Primary & $-2.2 \pm 0.2$ & $244 \pm 6$ & 3.55 & 0.83 \\
IA31 & Quartz & 100 & Primary & $-1.1 \pm 0.1$ & $230 \pm 3$ & 1.89 & 0.84 \\
IA44 & Quartz & 26 & Primary & $-1.3 \pm 0.1$ & $229 \pm 3$ & 2.19 & 0.84 \\
TJFA44 & Quartz & 22 & Primary & $-3.0 \pm 0.6$ & $242 \pm 5$ & 5.2 & 0.85 \\
TJFA44 & Calcite & 18 & Primary & $-1.9 \pm 0.1$ & $243 \pm 4$ & 3.2 & 0.83 \\
\hline
\end{tabular}

${ }^{\mathrm{a}} \mathrm{T}(\mathrm{m})=$ melting temperature of ice

${ }^{\mathrm{b}} \mathrm{T}(\mathrm{h})=$ homogenisation temperature (to liquid)

The primary inclusions in both mineral phases melt at $-1.6 \pm 0.9^{\circ} \mathrm{C}$, indicating the presence of dissolved salts, averaging $3.2 \mathrm{wt} \%$ (equivalent) $\mathrm{NaCl}$, in an aqueous fluid. The inclusions trapped in calcite hosts in sample TJFA44 show little variation in salinity or melting temperature from the inclusions trapped in quartz from other samples. Little to no $\mathrm{CO}_{2}$ is observed optically in the measured inclusions, but small amounts of dissolved $\mathrm{CO}_{2}$ (up to $\mathrm{X}_{\mathrm{CO} 2}=0.01$ ), if present, could account for up to $1.5^{\circ} \mathrm{C}$ of the observed freezing-point depression (Hedenquist and Henley, 1985) without being optically detectable. All the inclusions homogenise to a single liquid phase at temperatures of $234 \pm 15^{\circ} \mathrm{C}$, implying fluid densities of $\sim 0.84 \mathrm{~g} / \mathrm{cm}^{3}$. The isochores determined from these densities are shown in Figure 4.23." 


\section{Chapter 5}

\section{Summary of results and conclusions}

\subsection{Summary of results}

In order to contribute to the understanding of the deformation behaviour and the rheology of quartz and quartzofeldspathic rocks under natural conditions, we have investigated an array of neotectonically formed, dextral-oblique faults that have displaced biotite-zone quartzofeldspathic Alpine Schist and quartz veins embedded in that schist in the Southern Alps of New Zealand. Fault slip is generally brittle in the quartzofeldspathic host schist, but exhibits variable degrees of fully ductile to fully brittle deformation in a set of foliation-discordant quartz veins that are cross-cut by the faults. In this geological study we tried to extract rheological information from these naturally formed, brittle-ductile shear zones in the quartz veins. The main goals of the study were to determine whether we can extrapolate laboratory derived flow laws for quartz to geological conditions, and to find a set of flow law parameters, such as the stress exponent $n$ and the pre-exponential factor $A$, that would be applicable to the deformed quartz veins. Building on these results, we make inferences about deformation mechanisms operating during ductile-to-brittle deformation of quartz. Another aim was to determine whether softening or hardening mechanisms were operating during the formation of the well-localised ductile shear zones in the quartz veins. We also try to understand what may have led to differential ductile and brittle behaviour from one quartz vein to another.

\subsubsection{Geometry of the brittle-ductile shears and slip rate estimates}

The shears are inferred to have formed in an escalator-like fashion in the late Cenozoic during a period of transient deep embrittlement during their tilting and upramping onto the Alpine Fault ramp (Little et al., 2002a). The array of shear zones was exhumed in the past few Myrs and is now exposed in the central part of the Southern Alps, New Zealand, west of the Main Divide and approximately 5-7 km to the southeast of the Alpine Fault. The faults strike subparallel to the Alpine Fault. They are near-vertical and are spaced $37 \pm 54 \mathrm{~cm}(\mathrm{n}=72)$ apart. We measured a mean slip of $7.2 \pm$ $5.8 \mathrm{~cm}(\mathrm{n}=72)$ per shear across mostly ductile shear zones that are $2 \pm 1 \mathrm{~cm}(\mathrm{n}=72)$ wide 
(Chapter 3; Table 3.1). The average ductile component of slip is $4.8 \pm 3.4 \mathrm{~cm}(\mathrm{n}=72)$ resulting in a mean finite ductile shear strain of $2.4 \pm 2.16$. The slip data have been corrected for the deviation of the measurement plane from the movement plane using a sequence of algebraic steps that are described in Chapter 2 (Grigull and Little, 2008). Based on the model for sequential shear activation by Little et al. (2002a), an estimate of the minimum time of shear activity per shear is $34 \pm 49 \mathrm{yrs}$, resulting in a maximum slip rate of $2.0 \pm 3.3 \mathrm{~mm} \mathrm{yr}^{-1}$ (Table 3.1). If all shears in the shear array had been active simultaneously across the entire width of the shear array $(\sim 2 \mathrm{~km})$, a minimum slip rate estimate would be in the order of $\sim 10^{-4} \mathrm{~mm} \mathrm{yr}^{-1}$ (section 3.3.4).

\subsubsection{Deformation conditions during shear zone formation in the quartz veins}

From studies on the depth of mylonitisation at the base of the Alpine Fault (e.g. Vry et al., 2001; Toy, 2007), we assume that the shears formed at a minimum depth of $\sim 25 \mathrm{~km}$, i.e., $\sim 5-7 \mathrm{~km}$ structurally above the Alpine Fault mylonites. Assuming a depth of $25 \mathrm{~km}$ and using a Mohr-Coulomb analysis of brittle failure of the host rocks, we infer that minimum differential stresses during embrittlement and shearing of the quartz veins were $\sim 100 \mathrm{MPa}$. For this differential stress, near-lithostatic fluid pressures are required to induce hybrid shear-extensional brittle failure in the quartzofeldspathic Alpine schist at $25 \mathrm{~km}$ depth. The fluid pressure ratio $\lambda$ is inferred to have been $\sim 0.98$ at the time of brittle failure (section 4.6.6.2).

Based on Titanium-in-Quartz geothermometry (section 4.6.6.1) in the deformed quartz veins and quartz-calcite oxygen-isotope thermometry in syntectonic faultinfilling quartz-calcite veins (Wightman, 2005), the temperature during deformation of the quartz veins is inferred to have been $400-530^{\circ} \mathrm{C}$. Fluid inclusion analyses on primary inclusions in remnant quartz grains of the fault-infilling veins resulted in a fluid density of $\sim 0.84$ (Wightman, 2005; see also Appendix 4.C in this study). Combining the fluid inclusion isochor for that fluid density with the temperature range above, we could estimate a pore fluid pressure of $310 \pm 90 \mathrm{MPa}$ at the time of fluid inclusion entrapment (Fig. 4.25). This fluid pressure would result in a near-hydrostatic fluid pressure ratio, indicating that fluid pressures were probably cycling from near-lithostatic to suprahydrostatic. After brittle failure of the host schist, differential stresses in the quartz veins could have been as high as $\sim 390 \mathrm{MPa}$ (section 4.6.6.2). 


\subsubsection{Can laboratory-derived flow laws be extrapolated to natural conditions?}

In Chapter 3, we addressed the question whether experimentally derived flow laws could be used to describe the flow behaviour of the naturally deformed quartz veins. A key tool in this study is a set of geometrical scaling parameters expressed in the deformed quartz veins. Fig. 3.6 shows that the ductile shear zone width $(d s w)$ scales roughly with the ductile amount of slip $(d)$ and with the original quartz vein thickness $\left(t h_{\text {orig }}\right)$. This figure also shows that the ductile-to-total slip ratio in the quartz veins ('ductility' $D$ ) depends to a first order on $t h_{\text {orig }}$ and to some degree on the total fault slip $\left(y_{t o t}\right)$. Through finite-element modelling with a 'home-grown' code (SULEC, Chapter 3 ), we tried to reproduce these observed scaling relationships. For that, we varied original vein thicknesses as well as flow law parameters in the computer models. All of our models included a water fugacity that was calculated to be $\sim 200 \mathrm{MPa}$ for the pressure and temperature conditions mentioned above. The scaling relationships and the field observation that the brittle faults are always well localised where they impinge on the quartz veins were used to distinguish between successful and unsuccessful models.

We observed interesting interactions between the (mostly) ductile quartz vein and the surrounding brittle schist material in the numerical models. Fig. 3.10 shows that the propagation behaviour of the brittle fault through the schist towards the quartz vein is controlled by the effective viscosity of the quartz vein. For very stiff quartz veins, the fault bifurcates or even forms two separate faults. For very soft quartz veins, the fault forms rotational cross-shears in the strain-softening, much stiffer schist. The model that fits our field observation is the model where the viscous flow strength of the quartz vein and the frictional strength in the schist are nearly equal (model P2, Fig. 3.10). In model $\mathrm{P} 2$, the brittle fault stays well-localised and bends around the quartz vein. In that model, frictional and viscous energy dissipation must therefore have been relatively equal. The fault propagation also seems to depend on the stress exponent that was chosen for the quartz vein. Our results indicate that the fault stays localised when $n$ is closer to 4 than to 1 .

We tried to further constrain the stress exponent in the quartz veins by setting up experiments with varying values for $n$ in the quartz veins. We observed that as long as the ductilely deforming quartz vein is surrounded by the brittlely deforming schist, the resulting quartz vein shapes were indistinguishable from each other. The shape of the deformed quartz veins was controlled by the brittlely deforming quartzofeldspathic schist. The resulting shape depends on the viscosity ratio between quartz and schist. The 
schist should be approximately twice as strong as the quartz in order to match the geometrical scaling relationship between $d s w$ and $d$ (Fig. 3.16a).

We infer from the results of Chapter 3 that we can extrapolate laboratory derived flow laws to natural conditions as long as the range of the above mentioned strength ratios is adhered to and as long as water fugacity is included in the flow law. We predict a pre-exponential factor of $A_{E}=10^{-10 \pm 2} \mathrm{MPa}^{-\mathrm{n}} \mathrm{s}^{-1}$ for our quartz veins, using a water fugacity of $200 \mathrm{MPa}$, and a stress exponent $n$ that is closer to 4 than to 1 . These results indicate that the shearing of the quartz veins was primarily accommodated by a dislocation creep process rather than a diffusional process. In Fig. 5.1, we compare our derived flow law with a range of published flow laws in a plot of temperature versus differential stress (see also Fig. 1.1).

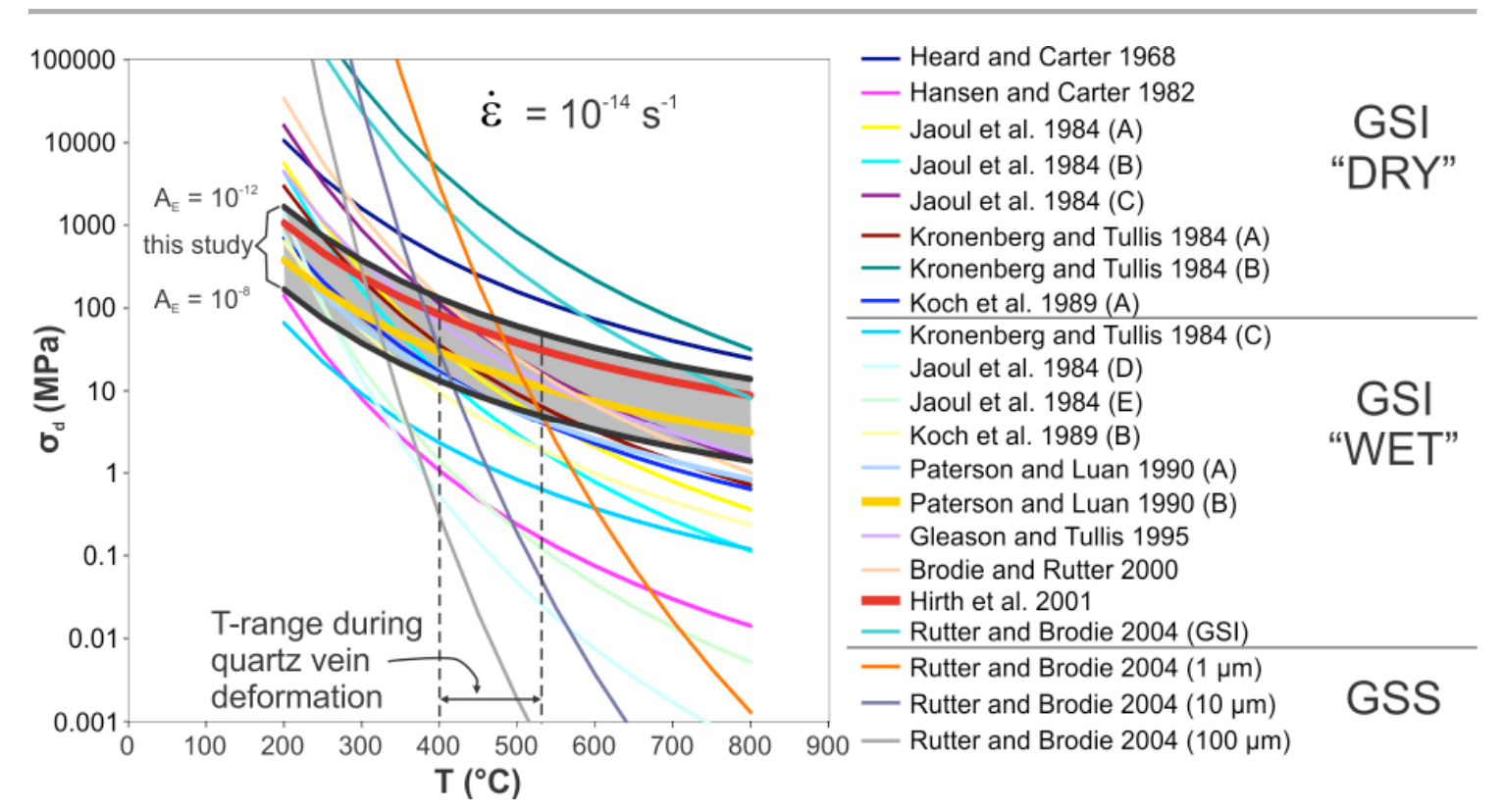

Fig. 5.1: Temperature-strength diagram illustrating range of flow stresses predicted by some published flow laws for quartz in comparison to the flow law derived in this study at a fixed strain rate of $10^{-14} \mathrm{~s}^{-1}$. The grey shaded area covers the range of strengths predicted by the flow law of this study. $A_{E}$ is the preexponential factor in $\left[\mathrm{MPa}^{-\mathrm{n}} \mathrm{s}^{-1}\right]$. GSI: grain-size insensitive creep; GSS: grain-size sensitive creep. When compared at $400-530^{\circ} \mathrm{C}$ (quartz vein deformation temperature), only some published flow laws result in differential stresses that are in the range of the flow strengths predicted by 'our' flow law (see main text).

In order to make the flow laws comparable, here, no water fugacity was included. When compared at the temperature range that was determined for the deformation of the quartz veins $\left(400-530^{\circ} \mathrm{C}\right)$, Fig. 5.1 shows that the following flow laws result in flow strengths that are similar to the ones calculated with our flow law: Jaoul et al. (1984, A, C), Kronenberg and Tullis (1984, A), Paterson and Luan (1990, B), Gleason and Tullis 
(1995), and Brodie and Rutter (2000), Hirth et al. (2001). We predict that all other flow laws do not represent the rheology of the naturally deformed quartz veins in the Southern Alps.

As a suggestion for future work, (deca)metre-scale modelling of the formation and evolution of brittle-ductile shears across several quartz veins (as opposed to only one vein like in this study) may provide insight into what rheological factors or processes may have controlled the spacing of these shears and the strength of the entire shear array.

5.1.4 Reasons for differences in ductility of the quartz veins and implications for shear zone localisation

In Chapter 4, we evaluated factors that could have introduced differences in the rheology of the quartz veins prior to their shearing and therefore led to the variable ductility $(D)$ of the quartz veins. These factors were calcite fraction in the quartz veins, molecular water content, differences in fault slip rate, and potentially variable deformation conditions (temperature, stress). We also investigated whether any softening or hardening processes had preceded the localisation of the ductile shear zones in the quartz veins.

Using optical microscopy, we measured calcite contents of individual quartz veins between 0 and $40 \%$. We could however not determine a systematic scaling of the ductile-to-total slip ratio $(D)$ with the calcite fraction of a vein (section 4.6.5). We could also not find any evidence for a localisation partitioning into the calcite layers that occur in some of the quartz veins. Calcite was therefore discarded as a potential softening agent.

No primary fluid inclusions were observed in the sheared quartz veins via optical microscopy. Secondary fluid inclusions occur mostly in form of healed microcracks or decorating grain boundaries (Fig. 4.20). The observation of healed microcracks in both the deformed and the undeformed part of the sheared veins, led us to infer that embrittlement and subsequent healing by fluid ingress had taken place throughout the entire veins prior to their ductile shearing and prior to static grain growth. This may have led to an inherited weakness of the entire quartz vein with respect to the schist.

FTIR-analyses of the undeformed parts of 10 quartz veins indicate that water contents in the quartz veins ranged from $\sim 440$ to $\sim 1500 \mathrm{ppm} \mathrm{H/Si}$ on average. There was no significant difference in molecular water content between ductilely and brittlely 
deformed quartz veins, at least as preserved today. However, water is abundant and we infer that the veins were wet enough and therefore weak enough for the brittle faults to blunt into them and transform into ductile shear zones. The deformed part of the veins seems to contain less molecular water, which would be consistent with an initial hardening process that we infer from the non-linear relationship between $d$ and $d s w$.

We could not confirm changes or differences in the deformation temperatures during deformation of the quartz veins, since the resolution of the temperature data was not high enough (section 4.6.6.1).

The results of the laboratory analyses indicate that the rheological composition of the quartz veins prior to deformation was very similar and that the quartz veins were deformed under similar conditions. We therefore inferred that none of the listed factors contributed to the variable D-values from one quartz vein to the next. We could not find any evidence for inherited or induced softening or hardening processes that would have been necessary for the formation of the ductile shear zones in the quartz veins. We conclude that the localisation of the shear zones was imposed by the brittle faults impinging on the quartz veins.

Plots of $D$-values, $t h_{\text {orig }}$, and $y_{\text {tot }}$ measured along 5 individual faults revealed that $\mathrm{D}$ strongly correlates with $t h_{\text {orig }}$ and that there is an inverse correlation between $D$ and $y_{t o t}$. Sometimes these relationships are violated. Displacement-profiles along five individual faults revealed that $y_{\text {tot }}$ is fluctuating rapidly across short distances along a shear (Fig. 4.16). This fluctuation was interpreted to indicate that some fault segments moved at higher or lower slip rates than others. This may in turn have led to differences in creep strain rates in the cross-cutting quartz veins and therefore to variable differential stresses from one vein to another and the observed differential $D$-values.

Despite the smooth and straight appearance of the faults, slip rates may have varied significantly along the faults. The faults may have moved via some kind of rate-andstate dependent frictional sliding process, thereby affecting the quartz veins through varying strain rates. Sliding on the faults, especially at the initiation of shearing, was probably not of the stable type. We therefore concluded that fault slip rate was the chief controlling factor on the ductility of the quartz veins.

Although we infer that fault slip rate was a major control on the ductility of the quartz veins, we were not able to provide much evidence as to how slip rate may have varied from one fault segment of the same fault to another. More mapping with special consideration of the composition of the surrounding quartzofeldspathic schist could be 
useful to determine if, for example, quartz veins in pelitic layers are more or less ductilely deformed than in the psammitic layers.

\subsection{Conclusions}

From the analysis of macroscopic field observations, microstructural observations, FTIR-results, geothermometry, as well as from geological mapping and numerical modelling of variably ductilely to brittlely sheared quartz veins embedded in quartzofeldspathic host rock exhumed in the central Southern Alps of New Zealand, we conclude that:

a) The deformed shape of a viscous geological marker may only contain information on the stress exponent of a viscous flow law if this marker is not surrounded by a stronger, brittlely deforming material.

b) In layered rocks, the shape of a viscously deformed geological marker allows to determine viscous-to-frictional strength ratios between the weak and the strong material; c) In the presence of a viscously deforming layer, the propagation and bifurcation behaviour of a brittle fault across that layer is controlled by the effective viscosity of that layer.

d) Laboratory-derived flow laws can be used to describe the ductile deformation behaviour of quartz if the boundary conditions that prevailed during deformation are well constrained and if water fugacity is included in the flow law.

e) The dominant deformation mechanism operative during the deformation of the quartz veins investigated in this study was probably power law dislocation creep with a stress exponent $n \geq 3$.

f) Slip rate along metre-scale faults can vary rapidly along the faults. These variations can lead to differences in strain rate and effective viscosity between individual geological markers that are cross-cut by the faults. At high strain rates this may lead to the brittle failure of the otherwise viscously deforming markers.

g) A ductile shear zone can form in a homogeneous rock layer without the aid of a softening or hardening process. As long as the rock is surrounded by viscously stronger or entirely brittle material, the location of ductile shear zone formation is predetermined by a propagating brittle fault in that stronger material.

h) Shear zone width is controlled by the viscous strength ratio between strong and weak material and the original thickness of the deformed layer. 


\section{References}

Adams, C.J. 1980. Contemporary Uplift and Erosion of the Southern Alps, NewZealand - Summary. Geological Society of America Bulletin 91(1), 2-4.

Adams, C. J. 1981. Uplift rates and thermal structure in the Alpine Fault zone and Alpine schists, Southern Alps, New Zealand. Geological Society, London, Special Publications 9, 211-222.

Batt, G. E. 2001. The approach to steady-state thermochronological distribution following orogenic development in the Southern Alps of New Zealand. American Journal Of Science 301(4-5), 374-384.

Batt, G. E., Baldwin, S. L., Cottam, M. A., Fitzgerald, P. G., Brandon, M. T. and Spell, T. L. 2004. Cenozoic plate boundary evolution in the South Island of New Zealand: New thermochronological constraints. Tectonics 23(4).

Batt, G. E. and Braun, J. 1999. The tectonic evolution of the Southern Alps, New Zealand: insights from fully thermally coupled dynamical modelling. Geophysical J. Int. 136, 403-420.

Beavan, J., Tregoning, P., Bevis, M., Kato, T. and Meertens, C. 2002. The motion and rigidity of the Pacific Plate and implications for plate boundary deformation. Journal of Geophysical Research 107(B10), 2261.

Beavan, J., Ellis, S., Wallace, L. M. and Denys, P. 2007. Kinematic constraints from GPS on oblique convergence of Pacific and Australian plates, Central South Island, New Zealand. In: A continental plate boundary - Tectonics at South Island, New Zealand (edited by Okaya, D., Stern, T. \& Davey, F.). Geophysical Monograph 175. American Geophysical Union, Washington, D.C., 75-94.

Berryman, K., Beanland, S., Cooper, A. F., Cutten, H. N., Norris, R. J. and Wood, P. R. 1992. The Alpine Fault, New Zealand: variation in Quaternary structural style and geomorphic expression. Ann. Tecton., Spec Issue - Suppl. 6, 126-163.

Bodnar, R. J. 2003. Reequilibration of fluid inclusions. In: Fluid Inclusions: Analysis and Interpretation (edited by Samson, I., Anderson, A. \& Marshall, D.). Short Course 32. Mineralogical Association of Canada, 213-230.

Bohren, C. F. and Huffman, D. R. 1983. Absorption and Scattering of Light by Small Particles. Wiley VCH.

Bons, P. D. and Urai, J. L. 1992. Syndeformational grain growth: microstructures and kinetics. Journal of Structural Geology 14(8/9), 1101-1109.

Bons, P. D. and den Brok, S. W. J. 2000. Crystallographic preferred orientation development by dissolution-precipition creep. Journal of Structural Geology 22, 1713-1722.

Bourguignon, S., Savage, M. K. and Stern, T. 2007. Crustal thickness and Pn anisotropy beneath the Southern Alps Oblique Collision, New Zealand. In: A Continental Plate Boundary: Tectonics at South Island, New Zealand (edited by Okaya, D., Stern, T. \& Davey, F.). AGU monograph 157.

Brace, W. F. and Kohlstedt, D. L. 1980. Limits on lithospheric stress imposed by laboratory experiments. Journal of Geophysical Research 85(B11), 6248-6252.

Brodie, K. H. and Rutter, E. H. 2000. Deformation mechanisms and rheology: why marble is weaker than quartzite. Journal of the Geological Society, London 157, 1093-1096.

Bruhn, D. F., Olgaard, D. L. and Dell'Angelo, L. N. 1999. Evidence for enhanced deformation in two-phase rocks: Experiments on the rheology of calcite- 
anhydrite aggregates. Journal of Geophysical Research-Solid Earth 104(B1), 707-724.

Buergmann, R. and Dresen, G. 2008. Rheology of the lower crust and upper mantle: Evidence from rock mechanics, geodesy, and field observations. Annu. Rev. Earth Planet. Sci. 36, 531-567.

Bull, W. B. and Cooper, A. F. 1986. Uplifted Marine Terraces Along the Alpine Fault, New-Zealand. Science 234(4781), 1225-1228.

Burkhard, M. 1993. Calcite twins, their geometry, appearance and significance as stressstrain markers and indicators of tectonic regime: a review. Journal of Structural Geology 15(3-5), 351-368.

Burlini, L. and Bruhn, D. 2005. High-strain zones: laboratory perspectives on strain softening during ductile deformation. Geological Society, London, Special Publications 245, 1-24.

Byerlee, J. 1978. Friction of rocks. Pure and Applied Geophysics 116(4-5), 615-626.

Cande, S. C. and Stock, J. M. 2004. Pacific-Antarctic-Australia motion and the formation of the Macquarie Plate. Geophysical J. Int. 157, 399-414.

Cherniak, D. J., Watson, E. B. and Wark, D. A. 2007. Ti diffusion in quartz. Chemical Geology 236, 65-74.

Chester, F. M. and Chester, J. S. 2000. Stress and deformation along wavy frictional faults. Journal of Geophysical Research-Solid Earth 105(B10), 23421-23430.

Christiansen, P. P. and Pollard, D. D. 1997. Nucleation, growth and structural development of mylonitic shear zones in granitic rock. Journal of Structural Geology 19(9), 1159-1172.

Christie, J. M. and Ord, A. 1980. Flow stress from microstructures of mylonites: example and current assessment. Journal of Geophysical Research 85(B11), 6253-6262.

Clayton, R. N., Goldsmith, J. R. and Mayeda, T. K. 1989. Oxygen isotope fractionation in quartz, albite, anorthite and calcite. Geochimica et Cosmochimica Acta 53(3), $725-733$.

Cooper, A. F. and Norris, R. J. 1994. Anatomy, structural evolution and slip rate of a plate-boundary thrust: The Alpine Fault at Gaunt Creek, New Zealand. Geological Society of America Bulletin 106, 627-633.

Cooper, M. A. and Bamford, M. L. F. 1987. A note on photography in structural geology. Journal of Structural Geology 9(1), 121-126.

Cowie, P. A. and Scholz, C. H. 1992. Physical Explanation for the Displacement Length Relationship of Faults Using a Post-Yield Fracture-Mechanics Model. Journal of Structural Geology 14(10), 1133-1148.

Cox, S. and Sutherland, R. 2007. Regional geological framework of South Island, New Zealand, and its Significance for understanding the active plate boundary. In: $A$ continental Plate Boundary: Tectotnics at South Island, New Zealand (edited by Okaya, D., Stern, T. \& Davey, F.). Geophysical monograph 175. American Geophysical Union, Washington, 369.

Cox, S. C. and Barrell, D. J. A. 2007. Geology of the Aoraki area: scale 1:250,000. Institute of Geological and Nuclear Sciences 1:250,000 geological map 15, 71 p. +1 folded map.

Craw, D. 1997. Fluid inclusion evidence for geothermal structure beneath the Southern Alps, New Zealand. New Zealand Journal of Geology and Geophysics 40, 4352 . 
Craw, D. and Campbell, J. R. 2004. Tectonic and structural setting for active mesothermal gold vein systems, Southern Alps, New Zealand. Journal of Structural Geology 26, 995-1005.

Dahlen, F. A. 1984. Noncohesive Critical Coulomb Wedges: An Exact Solution. Journal of Geophysical Research 89(B12), 10125-10133.

De Bresser, J. H. P. and Spiers, C. J. 1990. High-temperature deformation of calcite single-crystals by $\mathrm{r}+$ and $\mathrm{f}+\mathrm{slip}$. In: Deformation Mechanisms, Rheology and Tectonics (edited by Knipe, R. J. \& Rutter, E. H.). Geological Society Special Publication 54, 285-298.

De Bresser, J. H. P., ter Heege, J. H. and Spiers, C. J. 2001. Grain size reduction by dynamic recrystallization: can it result in major rheological weakening? Int. J. Earth Sciences (Geol. Rundschau) 90, 28-45.

De Mets, C., Gordon, R. G., Argus, D. F. and Stein, S. 1990. Current plate motions. Geophysical J. Int. 101, 425-478.

De Mets, C., Gordon, R. G., Argus, D. F. and Stein, S. 1994. Effect of recent revisions to the geomagnetic reversal time scale on estimates of current plate motions. Geophysical Research Letters 21, 2191-2194.

DellAngelo, L. N. and Tullis, J. 1996. Textural and mechanical evolution with progressive strain in experimentally deformed aplite. Tectonophysics 256(1-4), 57-82.

Dresen, G., Evans, B. and Olgaard, D. L. 1998. Effect of quartz inclusions on plastic flow in marble. Geophysical Research Letters 25(8), 1245-1248.

Dunlap, W. J., Hirth, G. and Teyssier, C. 1997. Thermomechanical evolution of a ductile duplex. Tectonics 16(6), 983-1000.

Ellis, S., Beavan, J. and Eberhart-Phillips, D. 2006a. Bounds on the width of mantle lithosphere flow derived from surface geodetic measurements: application to the central Southern Alps, New Zealand. Geophysical J. Int. 166(1), 403-417.

Ellis, S., Beavan, J., Eberhart-Phillips, D. and Stöckhert, B. 2006b. Simplified models of the Alpine Fault seismic cycle: Stress transfer in the mid crust. Geophysical J. Int. 166(1), 386-402.

Ellis, S. and Stöckhert, B. 2004a. Imposed strain localization in the lower crust on seismic timescales. Earth Planets Space 56, 1103-1109.

Ellis, S. M. and Stöckhert, B. 2004b. Elevated stresses and creep rates beneath the brittle-ductile transition caused by seismic faulting in the upper crust. Journal of Geophysical Research 109(B05407), 10.

Elsenheimer, D. and Valley, J. W. 1993. Submillimeter scale zonation of $\delta^{18} \mathrm{O}$ in quartz and feldspar, Isle of Skye, Scotland. Geochimica et Cosmochimica Acta 57(15), 3669-3676.

Evans, B. and Kohlstedt, D. L. 1995. Rheology of Rocks. In: Rock Physics and Phase Relations - A Handbook of Physical Constants (edited by Ahrens, T. J.). American Geophysical Union, Washington, 148-165.

Fletcher, R. C. 2001. Ductile shear zones as counterflow boundaries in pseudoplastic fluids: Discussion. Journal of Structural Geology 23, 155-156.

Fullsack, P. 1995. An arbitrary Lagrangian-Eulerian formulation for creeping flows and its application in tectonic models. Geophysical J. Int. 120, 1-23.

Fusseis, F. and Handy, M. R. 2008. Micromechanisms of shear zone propagation at the brittle-viscous transition. Journal of Structural Geology 30(10), 1242-1253.

Fusseis, F., Handy, M. R. and Schrank, C. 2006. Networking of shear zones at the brittle-to-viscous transition (Cap de Creus, NE Spain). Journal of Structural Geology 28, 1228-1234. 
Ghent, E. D. and Stout, M. Z. 1984. $\mathrm{TiO}_{2}$ activity in metamorphosed pelitic and basic rocks - principles and applications to metamorphism in southeastern Canadian Cordillera. Contributions to Mineralogy and Petrology 86(3), 248-255.

Gleason, G. C. and DeSisto, S. 2008. A natural example of crystal-plastic deformation enhancing the incorporation of water into quartz. Tectonophysics 44, 16-30.

Gleason, G. C. and Tullis, J. 1995. A flow law for dislocation creep of quartz aggregates determined with the molten salt cell. Tectonophysics 247, 1-23.

Grapes, R. and Watanabe, T. 1992. Metamorphism and Uplift of Alpine Schist in the Franz Josef-Fox Glacier Area of the Southern Alps, New-Zealand. Journal of Metamorphic Geology 10(2), 171-180.

Grapes, R. H. 1995. Uplift and exhumation of Alpine Schist, Southern Alps, New Zealand: thermobarometric constraints. New Zealand Journal of Geology and Geophysics 38, 525-533.

Gratier, J. P. and Gamond, J. F. 1990. Transition between seismic and aseismic deformation in the upper crust. Geological Society, London, Special Publications 54, 461-473.

Griggs, D. 1967. Hydrolytic Weakening of Quartz and Other Silicates. Geophysical Journal of the Royal Astronomical Society 14(1-4), 19-\&.

Griggs, D. 1974. Model of Hydrolytic Weakening in Quartz. Journal of Geophysical Research 79(11), 1653-1661.

Grigull, S. this study. Rheological constraints on quartz derived from scaling relationships and numerical models of sheared brittle-ductile quartz veins, central Southern Alps, New Zealand. Chapter 3.

Grigull, S. and Little, T. A. 2008. A graphical-algebraic method for analysing shear zone displacements from observations on arbitrarily oriented outcrop surfaces. Journal of Structural Geology 30, 868-875.

Handy, M. R. 1989. Deformation regimes and the rheological evolution of fault zones in the lithosphere - The effects of pressure, temperature, grainsize and time. Tectonophysics 163(1-2), 119-152.

Handy, M. R. 1990. The solid-state flow of polymineralic rocks. Journal of Geophysical Research 95(B6), 8647-8661.

Handy, M. R. 1994. Flow laws for rocks containing two non-linear viscous phases: a phenomenological approach. Journal of Structural Geology 16(3), 287-301.

Hansen, F. D. and Carter, N. L. 1982. Creep of selected crustal rocks at $1000 \mathrm{MPa}$. Eos Trans. 63, 437.

Heard, H. C. and Carter, N. L. 1968. Experimentally Induced Natural Intragranular Flow In Quartz And Quartzite. American Journal Of Science 266(1), 1-\&.

Hedenquist, J. W. and Henley, R. W. 1985. The importance of CO2 on freezing point measurements of fluid inclusions: Evidence from active geothermal systems and implications for epithermal ore deposition. Economic Geology 80(5), 13791406.

Herman, F., Braun, J. and Dunlap, W. J. 2007. Tectonomorphic scenarios in the Southern Alps of New Zealand. Journal of Geophysical Research 112(B04201), 25.

Hill, M. P. 2005. Evolution of quartz and calcite microstructures exhumed from deep brittle-ductile shear zones in the Southern Alps of New Zealand. Unpublished MSc thesis, Victoria University of Wellington.

Hirth, G., Teyssier, C. and Dunlap, W. J. 2001. An evaluation of quartzite flow laws based on comparisons between experimentally and naturally deformed rocks. Int. J. Earth Sciences (Geol. Rundschau) 90, 77-87. 
Hirth, G. and Tullis, J. 1992. Dislocation creep regimes in quartz aggregates. Journal of Structural Geology 14(2), 145-159.

Hirth, G. and Tullis, J. 1994. The brittle-plastic transition in experimentally deformed quartz aggregates. Journal of Geophysical Research 99(B6), 11731-11747.

Hobbs, B. E., Muehlhaus, H.-B. and Ord, A. 1990. Instability, softening and localization of deformation. Geological Society, London, Special Publications 54, 143-165.

Holm, D. K., Norris, R. J. and Craw, D. 1989. Brittle and ductile deformation in a zone of rapid uplift: central Southern Alps, New Zealand. Tectonics 8(153-168).

Holyoke, C. W. and Tullis, J. 2006. Formation and maintenance of shear zones. Geology 34(2), 105-108.

Hudleston, P. J. and Lan, L. 1993. Information from fold shapes. Journal of Structural Geology 15(3-5), 253-264.

Hudleston, P. J. and Lan, L. 1994. Rheological controls on the shapes of single-layer folds. Journal of Structural Geology 16(7), 1007-1021.

Hudleston, P. J. and Lan, L. 1995. Rheological Information from Geological Structures. Pure and Applied Geophysics 145(3/4), 605-620.

Huismans, R. S., Buiter, S. J. H. and Beaumont, C. 2005. Effect of plastic-viscous layering and strain softening on mode selection during lithospheric extension. Journal of Geophysical Research 110(B02406), 17.

Hull, J. 1988. Thickness-displacement relationships for deformation zones. Journal of Structural Geology 10(4), 431-435.

Jaoul, O., Tullis, J. and Kronenberg, A. 1984. The effect of varying water contents on the creep behaviour of Heavitree Quartzite. Journal of Geophysical Research 89(B6), 4298-4312.

Jessell, M. W., Bons, P. D., Evans, L., Barr, T. and Stüwe, K. 2001. Elle: a microprocess approach to the simulation of microstructures. Computers and Geosciences 27, 17-30.

Jessell, M. W., Kostenko, O. and Jamtveit, B. 2003. The preservation potential of microstructures during static grain growth. J. metamorphic Geol. 21, 481-491.

Ji, S. and Xia, B. 2002. Rheology of polyphase Earth Materials. Polytech. Int. Press, Montreal, Que.

Ji, S. and Zhao, P. 1993. Flow laws of multiphase rocks calculated from experimental data on the constituent phases. Earth and Planetary Science Letters 117(1-2), 181-187.

Jin, D. H., Karato, S. and Obata, M. 1998. Mechanisms of shear localization in the continental lithosphere: Inference from the deformation microstructures of peridotites from the Ivrea zone, northwestern Italy. Journal of Structural Geology 20(2-3), 195-209.

Jones, M. E. 1975. Water weakening of quartz, and its application to natural rock deformation. Journal of the Geological Society, London 131, 429-432.

Kaus, B. J. P. and Podladchikov, Y. Y. 2006. Initiation of localized shear zones in viscoelastic rocks. Journal of Geophysical Research 111(B04412), 18.

Kekulawala, K. R. S. S., Paterson, M. S. and Boland, J. N. 1978. Hydrolytic weakening in quartz. Tectonophysics 46, T1-T6.

Kenis, I., Urai, J. L., van der Zee, W. and Sintubin, M. 2004. Mullions in the HighArdenne Slate Belt (Belgium): numerical model and parameter sensitivity analysis. Journal of Structural Geology 26, 1677-1692.

Kenis, I., Urai, J. L., Zee, W. v. d., Hilgers, C. and Sintubin, M. 2005. Rheology of finegrained siliciclastic rocks in the middle crust - evidence from structural an numerical analysis. Earth and Planetary Science Letters 233, 351-360. 
Kerrich, R. 1976. Some effects of tectonic recrystallisation on fluid inclusions in vein quartz. Contrib. Mineral. Petrol. 59, 195-202.

Kerrich, R., Beckinsale, R. D. and Durham, J. J. 1977. The transition between deformation regimes dominated by intercrystalline diffusion and intracrystalline creep evaluated by oxygen isotope thermometry. Tectonophysics 38(3-4), 241257.

Kirby, S. H. 1980. Tectonic Stresses In The Lithosphere - Constraints Provided By The Experimental Deformation Of Rocks. Journal Of Geophysical Research 85(NB11), 6353-6363.

Kleffmann, S., Davey, F., Melhuish, A., Okaya, D., Stern, T. and Team, S. 1998. Crustal structure in the central South Island, New Zealand, from the Lake Pukaki seismic experiment. New Zealand Journal of Geology and Geophysics 41(1), 39-49.

Koch, P. S., Christie, J. M., Ord, A. and George, R. P., Jr. 1989. Effect of water on the rheology of experimentally deformed quartzite. Journal of Geophysical Research 94(B10), 13975-13996.

Kohlstedt, D. L., Evans, B. and Mackwell, S. J. 1995. Strength of the lithosphere Constraints imposed by laboratory experiments. Journal of Geophysical Research-Solid Earth 100(B9), 17587-17602.

Kohn, M. J. and Northrup, C. J. 2009. Taking mylonites' temperatures. Geology 37(1), 47-50.

Kohn, M. J., Valley, J. W., Elsenheimer, D. and Spicuzza, M. J. 1993. Oxygen isotope zoning in garnet and staurolite - Evidence for closed-system mineral growth during regional metamorphism. American Mineralogist 78(9-10), 988-1001.

Koons, P. O. 1987. Some thermal and mechanical consequences of rapid uplift: an example from the Southern Alps, New Zealand. Earth and Planetary Science Letters 86(2-4), 307-319.

Koons, P. O. 1990. 2-Sided Orogen - Collision and Erosion from the Sandbox to the Southern Alps, New-Zealand. Geology 18(8), 679-682.

Koons, P. O., Craw, D., Cox, S. C., Upton, P., Templeton, A. S. and Chamberlain, C. P. 1998. Fluid flow during active oblique convergence: A Southern Alps model from mechanical and geochemical observations. Geology 26(2), 159-162.

Kronenberg, A., Segall, P. and Wolf, G. H. 1990. Hydrolytic weakening and penetrative deformation within a natural shear zone. In: The brittle-ductile transition in rocks - The Heard volume (edited by Duba, A. G., Durham, W. B., Handin, J. W. \& Wang, H. F.). Geophysical Monograph 56. American Geophysical Union, Washigton, DC, 21-36.

Kronenberg, A. K. and Tullis, J. 1984. Flow Strengths Of Quartz Aggregates - GrainSize And Pressure Effects Due To Hydrolytic Weakening. Journal Of Geophysical Research 89(NB6), 4281-4297.

Kronenberg, A. K. and Wolf, G. H. 1990. Fourier-Transform Infrared-Spectroscopy Determinations of Intragranular Water-Content in Quartz-Bearing Rocks Implications for Hydrolytic Weakening in the Laboratory and within the Earth. Tectonophysics 172(3-4), 255-271.

Lan, L. and Hudleston, P. J. 1995a. The effects of rheology on the strain distribution in single layer buckle folds. Journal of Structural Geology 17(5), 727-738.

Lan, L. and Hudleston, P. J. 1995b. A method of estimating the stress exponent in the flow law for rocks using fold shape. Pure and Applied Geophysics 145(3-4), 605-620. 
Lan, L. and Hudleston, P. J. 1996. Rock rheology and sharpness of folds in single layers. Journal of Structural Geology 18(7), 925-931.

Leitner, B., Eberhart-Phillips, D., Anderson, H. and Nabelek, J. L. 2001. A focused look at the Alpine fault, New Zealand: Seismicity, focal mechanisms, and stress observations. Journal of Geophysical Research-Solid Earth 106(B2), 21932220.

Little, T. A. 2004. Transpressive ductile flow and oblique ramping of lower crust in a two-sided orogen: Insight from quartz grain-shape fabrics near the Alpine fault, New Zealand. Tectonics 23(TC2013).

Little, T. A., Cox, S., Vry, J. K. and Batt, G. 2005. Variations in exhumation level and uplift rate along the oblique-slip Alpine fault, central Southern Alps, New Zealand. Geological Society of America Bulletin 117(5-6), 707-723.

Little, T. A., Holcombe, R. J. and Ilg, B. R. 2002a. Ductile fabrics in the zone of active oblique convergence near the Alpine Fault, New Zealand: identifying the neotectonic overprint. Journal of Structural Geology 24(1), 193-217.

Little, T. A., Holcombe, R. J. and Ilg, B. R. 2002b. Kinematics of oblique collision and ramping inferred from microstructures and strain in middle crustal rocks, central Southern Alps, New Zealand. Journal of Structural Geology 24(1), 219-239.

Little, T. A., Savage, M. K. and Tikoff, B. 2002c. Relationship between crustal finite strain and seismic anisotropy in the mantle, Pacific-Australia plate boundary zone, South Island, New Zealand. Geophysical Journal International 151(1), 106-116.

Little, T. A., Wightman, R., Holcombe, R. J. and Hill, M. P. 2007. Transpression models and ductile deformation of the lower crust of the Pacific Plate in the central Southern Alps, a perspective from field geology. In: A continental plate boundary - Tectonics at South Island, New Zealand (edited by Okaya, D., Stern, T. \& Davey, F.). Geophysical Monograph 175. American Geophysical Union, Washington, D.C., 271-288.

Luan, F. C. and Paterson, M. S. 1992. Preparation and Deformation of Synthetic Aggregates of Quartz. Journal of Geophysical Research 97(B1), 301-320.

Mair, K., Frye, K. M. and Marone, C. 2002. Influence of grain characteristics on the friction of granular shear zones. Journal of Geophysical Research-Solid Earth 107(B10).

Malvern, L. E. 1969. Introduction to the mechanics of a continuous medium. PrenticeHall, Inc., Englewood Cliffs, New Jersey.

Mancktelow, N. S. 2006. How ductile are ductile shear zones? Geology 34(5), 345-348.

Mancktelow, N. S. and Pennacchioni, G. 2005. The control of precursor brittle fracture and fluid-rock interaction on the development of single and paired ductile shear zones. Journal of structural Geology 27, 645-661.

Mancktelow, N. S. and Pennacchioni, G. 2010. Why calcite can be stronger than quartz. Journal Of Geophysical Research-Solid Earth 115(B01402).

McCrea, J. M. 1950. On the isotopic chemistry of carbonates and a paleotemperatures scale. Journal of Chemical Physics 18(6), 849-857.

Means, W. D. 1984. Shear zones of types I and II and their significance for reconstruction of rock history. Geological Society of America Abstract Programs 16:50.

Means, W. D. 1995. Shear zones and rock history. Tectonophysics 247, 157-160.

Montési, L. G. J. 2004. Controls of shear zone rheology and tectonic loading on postseismic creep. Journal of Geophysical Research 109(B10404), 18. 
Montési, L. G. J. and Zuber, M. T. 2002. A unified description of localization for application to large-scale tectonics. Journal of Geophysical Research 107(B3), ECV1 (1-21).

Moresi, L., Dufour, F. and Muehlhaus, H.-B. 2003. A Lagrangian integration point finite element method for large deformation modeling of viscoelastic geomaterials. Journal of Computational Physics 184, 476-497.

Nagel, T. J. and Buck, W. R. 2006. Channel flow and the development of paralleldipping normal faults. Journal of Geophysical Research 111(B08407), 14.

Norris, R. J. and Cooper, A. F. 1995. Origin of Small-Scale Segmentation and Transpressional Thrusting Along the Alpine Fault, New-Zealand. Geological Society of America Bulletin 107(2), 231-240.

Norris, R. J. and Cooper, A. F. 2001. Late Quarternary slip rates and slip partitioning on the Alpine Fault, New Zealand. Journal of Structural Geology 23, 507-520.

Norris, R. J. and Cooper, A. F. 2003. Very high strains recorded in mylonites along the Alpine Fault, New Zealand: implications for the deep structure of plate boundary faults. Journal of Structural Geology 25, 2141-2157.

Norris, R. J. and Cooper, A. F. 2007. The Alpine Fault, New Zealand: Surface geology and field relationships. In: A continental plate boundary: Tectonics at South Island, New Zealand (edited by Okaya, D., Stern, T. \& Davey, F.). Geophysical Monograph 175. American Geophysical Union, Washington, D.C., 157-174.

Nüchter, J.-A. and Stöckhert, B. 2007. Vein quartz microfabrics indicating progressive evolution of fractures into cavities during postseismic creep in the middle crust. Journal of Structural Geology 29, 1445-1462.

Ohlmacher, G. C. and Aydin, A. 1997. Mechanics of vein, fault and solution surface formation in the Appalachian Valley and Ridge, northeastern Tennessee, U.S.A.: implications for fault friction, state of stress and fluid pressure. Journal of Structural Geology 19(7), 927-944.

Passchier, C. W. and Trouw, R. A. J. 2005. Microtectonics. Springer, Berlin Heidelberg New York.

Paterson, M. S. 1987. Problems in the extrapolation of laboratory rheological data. Tectonophysics 133, 33.

Paterson, M. and Luan, F. 1990a. Quartzite rheology under geological conditions. In: Deformation Mechanisms, Rheology and Tectonics (edited by Knipe, R. \& Rutter, E. H.). Geological Society Special Publication 54. Geological Society of London, 299-307.

Paterson, M. S. 1989. The interaction of water with quartz and its influence in dislocation flow - an overview. In: Rheology of Solids and of the Earth (edited by Karato, S.-i. \& Toriumi, M.). Oxford University press.

Paterson, M. S. 2005. Experimental rock deformation - The brittle field. Springer, Berlin and Heidelberg.

Paterson, M. S. and Luan, F. C. 1990b. Quartzite rheology under geological conditions. In: Deformation Mechanisms, Rheology and Tectonics (edited by Knipe, R. J. \& Rutter, E. H.). Geological Society Special Publication 54. Geological Society of London, 299-307.

Paterson, W. S. B. 1981. The Physics of Glaciers. Pergamon, Oxford.

Pennacchioni, G. 2005. Control of the geometry of precursor brittle structures on the type of ductile shear zone in the Adamello tonalites, Southern Alps (Italy). Journal of Structural Geology 27, 627-644.

Pennacchioni, G. and Mancktelow, N. S. 2007. Nucleation and initial growth of a shear zone network within compositionally and structurally heterogeneous granitoids 
under amphibolite facies conditions. Journal of Structural Geology 29, 17571780 .

Piazolo, S., Jessell, M. W., Bons, P. D. and Evans, L. 2001. Animations of dynamic recrystallization with the numerical modelling system Elle. In: Animations in Geology. Journal of the Virtual Explorer (edited by Rawling, T. \& Aillères, L.) 4, 45-49.

Piazolo, S., Bons, P. D., Jessell, M. W., Evans, L. and Passchier, C. W. 2002. Dominance of Microstructural Processes and their effect on microstructural development: Insights from Numerical MOdelling of dynamic recrystallisation. In: Deformation Mechanisms, Rheology and Tectonics: Current Status and Future Perspectives (edited by De Meer, S., Drury, M. R., De Bresser, J. H. P. \& Pennock, G. M.). Special Publications 200. Geological Society, London, 149170.

Piazolo, S. C. 2000. Shape Fabric Development During Progressive Deformation. Unpublished PhD thesis, Johannes Gutenberg-Universität Mainz.

Pitzer, K. S. and Sterner, S. M. 1994. Equations of state valid continuously from zero to extreme pressures for $\mathrm{H} 2 \mathrm{O}$ and $\mathrm{CO} 2$. Journal of Chemical Physics 101(4), 6.

Post, A. and Tullis, J. 1998. The rate of water penetration in experimentally deformed quartzite, implications for hydrolytic weakening. Tectonophysics 295(1-2), 117137.

Ramsay, J. G. and Huber, M. I. 1987. The techniques of modern structural geology. Volume 2: Folds and Fractures. Academic Press, San Diego.

Ranalli, G. 1987. Rheology of the Earth. Allen and Unwin, Boston.

Renner, J. and Evans, B. 2002. Do calcite rocks obey the power-law creep equation? Geological Society, London, Special Publications 200, 293-307.

Roedder, E. 1984. Fluid Inclusions. Reviews in Mineralogy 12, 644 p.

Rutter, E. H. 1983. Pressure solution in nature, theory and experiment. Journal of the Geological Society, London 140, 725-740.

Rutter, E. H. 1986. On the nomenclature of mode of failure transition in rocks. Tectonophysics 122, 381-387.

Rutter, E. H. and Brodie, K. H. 2004a. Experimental grain size-sensitive flow of hotpressed Brazilian quartz aggregates. Journal of Structural Geology 26, 20112023.

Rutter, E. H. and Brodie, K. H. 2004b. Experimental intracrystalline plastic flow in hotpressed synthetic quartzite prepared from Brazilian quartz crystals. Journal of Structural Geology 26, 259-270.

Rybacki, E., Paterson, M. S., Wirth, R. and Dresen, G. 2003. Rheology of calcite-quartz aggregates deformed to large strain in torsion. Journal of Geophysical Research 108(B2), 2089.

Saha, D. 1997. Flow laws in polymineralic aggregates deformed by a combination of diffusion creep and dislocation creep. Proceedings of the Indian Academy of Sciences-Earth and Planetary Sciences 106(4), 221-224.

Schmatz, J. and Urai, J. L. 2010. The interaction of fluid inclusions and migrating grain boundaries in a rock analogue: deformation and annealing of polycrystalline camphor-ethanol mixtures. Journal of Metamorphic Geology 28(1), 1-18.

Schmid, S. M. and Handy, M. R. 1991. Towards a genetic classification of fault rocks: Geological usage of tectonophysical implications. In: Controversies in Modern Geology (edited by Müller, D. W., McKenzie, J. A. \& Weissert, H.). Academic Press, London, 339-361. 
Scholz, C. H. 1988. The brittle-plastic transition and the depth of seismic faulting. International Journal of Earth Sciences (Geologische Rundschau) 77(1), 319328.

Scholz, C. H. 2002. The mechanics of earthquakes and faulting. Cambridge University Press, Cambridge.

Schrank, C. E., Handy, M. R. and Fusseis, F. 2008. Multiscaling of shear zones and the evolution of the brittle-to-viscous transition in continental crust. Journal of Geophysical Research-Solid Earth 113(B1), -.

Schueller, S., Gueydan, F. and Davy, P. 2005. Brittle-ductile coupling: Role of ductile viscosity on brittle fracturing. Geophysical Research Letters 32, L10308.

Schueller, S., Gueydan, F. and Davy, P. 2009. Mechanics of the transition from localized to distributed fracturing in layered brittle-ductile systems. Tectonophysics in print.

Sharp, Z. D. and Kirschner, D. L. 1994. Quartz-calcite oxygen-isotope thermometry - a calibration based on natural isotopic variations. Geochimica et Cosmochimica Acta 58(20), 4491-4501.

Shi, Y., Allis, R. and Davey, F. 1996. Thermal modeling of the Southern Alps, New Zealand. Pure and Applied Geophysics 146(3-4), 469-501.

Sibson, R. H. 1982. Fault zone models, heat flow and the depth distribution of earthquakes in the continental crust of the United States. Bulletin of the Seismological Society of America 72, 151-163.

Sibson, R. H. 1983. Continental Fault Structure and the Shallow Earthquake Source. Journal of the Geological Society 140(Sep), 741-767.

Sibson, R. H., White, S. H. and Atkinson, B. K. 1981. Structure and distribution of fault rocks in the Alpine Fault zone, New Zealand. In: Thrust and Nappe Tectonics (edited by McClay, K. R.). Special Publications 9. Geological Society of London, 197-210.

Simpson, C. 1986. Fabric development in Brittle-to-Ductile Shear Zones. Pure and Applied Geophysics 124(1/2), 271-288.

Sonder, L. J. 2001. Ductile shear zones as counterflow boundaries in pseudoplastic fluids: Discussion and theory. Journal of Structural Geology 23, 149-153.

Spear, F. S. 1993. Metamorphic Phase Equilibria and Pressure-Temperature-Time Paths. Mineralogical Society of America Monograph, 799.

Spear, F. S. and Wark, D. A. 2009. Cathodoluminescence imaging and titanium thermometry in metamorphic quartz. Journal of Metamorphic Geology 27(3), 187-205.

Spicuzza, M. J., Valley, J. W., Kohn, M. J., Girard, J. P. and Fouillac, A. M. 1998. The rapid heating, defocused beam technique: a CO2-laser-based method for highly precise and accurate determination of delta O-18 values of quartz. Chemical Geology 144(3-4), 195-203.

Stern, T., Kleffmann, S., Okaya, D., Scherwath, M. and Bannister, S. 2001. Low seismic-wave speeds and enhanced fluid pressure beneath the Southern Alps of New Zealand. Geology 29(8), 679-682.

Stern, T., Okaya, D., Kleffmann, S., Scherwath, M., Henrys, S. and Davey, F. 2007. Geophysical Exploration and Dynamics of the Alpine Fault Zone. In: $A$ Continental Plate Boundary - Tectonics at South Island, New Zealand (edited by Okaya, D., Stern, T. \& Davey, F.). Geophysical Monograph 175. American Geophysical Union, Washington, D.C., 207-232. 
Stern, T., Okaya, D. and Scherwath, M. 2002. Structure and strength of a continental transform from onshore-offshore seismic profiling of South Island, New Zealand. Earth Planets and Space 54(11), 1011-1019.

Stipp, M., Stünitz, H., Heilbronner, R. and Schmid, S. M. 2002. Dynamic recrystallization of quartz: correlation between natural and experimental conditions. In: Deformation Mechanisms, Rheology and Tectonics: Current Status and Future Perspectives (edited by de Meer, S., Drury, M. R., de Bresser, J. H. P. \& Pennock, G. M.) 200. Geological Society of London, Special Publications, London, 171-190.

Stipp, M. and Tullis, J. 2003. The recrystallized grain size piezometer for quartz. Geophysical Research Letters 30(21), SDE 3 1-5.

Stöckhert, B., Brix, M. R., Kleinschrodt, R., Hurford, A. J. and Wirth, R. 1999. Thermochronometry and microstructures of quartz - a comparison with experimental flow laws and predictions on the temperature of the brittle-plastic transition. Journal of Structural Geology 21, 351-369.

Stunitz, H. and Tullis, J. 2001. Weakening and strain localization produced by syndeformational reaction of plagioclase. International Journal of Earth Sciences 90(1), 136-148.

Sutherland, R. 1996. Magnetic anomalies in the New Zealand region, 1:4,000,000. Geophysical Map 9.

Sutherland, R. 1999a. Basement geology and tectonic development of the greater New Zealand region: an interpretation from regional magnetic data. Tectonophysics 308(3), 341-362.

Sutherland, R. 1999b. Cenozoic bending of New Zealand basement terranes and Alpine Fault displacement: a brief review. New Zealand Journal of Geology and Geophysics 42(2), 295-301.

Sutherland, R., Berryman, K. and Norris, R. 2006. Quaternary slip rate and geomorphology of the Alpine fault: Implications for kinematics and seismic hazard in southwest New Zealand. Geological Society of America Bulletin 118(3-4), 464-474.

Talbot, C. J. 1999. Ductile shear zones as counterflow boundaries in pseudoplastic fluids. Journal of Structural Geology 21, 1535-1551.

Talbot, C. J. 2001. Ductile shear zones as counterflow boundaries in pseudoplastic fluids: Reply. Journal of Structural Geology 23, 157-159.

Tippett, J. M. and Kamp, P. J. J. 1993. Fission-Track Analysis of the Late Cenozoic Vertical Kinematics of Continental Pacific Crust, South Island, New-Zealand. Journal of Geophysical Research-Solid Earth 98(B9), 16119-16148.

Tourigny, G. and Tremblay, A. 1997. origin and incremental evolution of brittle/ductile shear zones in granitic rocks: natural examples from the southern Abitibi Belt, Canada. Journal of Structural Geology 19(1), 15-27.

Toy, V. G. 2007. Rheology of the Alpine Fault mylonite zone: deformation processes at and below the base of the seismogenic zone in a major plate boundary structure. Unpublished $\mathrm{PhD}$ thesis, University of Otago.

Toy, V. G., Prior, D. J. and Norris, R. J. 2008. Quartz fabrics in the Alpine Fault mylonites: Influence of pre-existing preferred orientations on fabric development during progressive uplift. Journal of Structural Geology 30(5), 602-621.

Treagus, S. H. 1999. Are viscosity ratios of rocks measurable from cleavage refraction? Journal of Structural Geology 21, 895-901. 
Treagus, S. H., Hudleston, P. J. and Lan, L. 1996. Non-ellipsoidal inclusions as geological strain markers and competence indicators. Journal of Structural Geology 18(9), 1167-1172.

Treagus, S. H. and Lan, L. 2000. Pure shear deformation of square objects, and applications to geological strain analysis. Journal of Structural Geology 22(1), 105-122.

Treagus, S. H. and Lan, L. 2003. Simple shear of deformable quare objects. Journal of Structural Geology 25(12), 1993-2003.

Treagus, S. H. and Lan, L. 2004. Deformation of square objects and boudins. Journal of Structural Geology 26, 1361-1376.

Treagus, S. H. and Treagus, J. E. 2002. Studies of strain and rheology of conglomerates. Journal of Structural Geology 24, 1541-1567.

Trepmann, C. A. and Stoeckhert, B. 2003. Quartz microstructures developed during non-steady state plastic flow at rapidly decaying stress and strain rate. Journal of Structural Geology 25, 2035-2051.

Tse, S. T. and Rice, J. A. 1986. Crustal earthquake instability in relation to the depth variation of frictional slip properties. Journal of Geophysical Research 91(B9), 9452-9472.

Twiss, R. J. and Moores, E. M. 2007. Structural Geology. W. H. Freeman and Company, New York.

Valley, J. W., Kitchen, N., Kohn, M. J., Niendorf, C. R. and Spicuzza, M. J. 1995. UWG-2, a garnet standard for oxygen isotope ratios: Strategies for high precision and accuracy with laser heating. Geochimica et Cosmochimica Acta 59(24), 5223-5231.

Voisin, C., Renard, F. and Grasso, J.-R. 2007. Long term friction: From stick-slip to stable sliding. Geophysical Research Letters 34(L13301), 5 p.

Voll, G. 1976. Recrystallization of quartz, bitotie and feldspars from Erstfeld to the Lenetina Nappe, Swiss Alps, and its geological significance. Schweizerische Mineralogische und Petrographische Mitteilungen 56, 641-647.

Vry, J., Powell, R., Golden, K. M. and Petersen, K. 2009. The role of exhumation in metamorphic dehydration and fluid production. Nature geoscience (published online 29 November 2009) doi:10.1038/ngeo699 Letter.

Vry, J. K., Baker, J., Maas, R., Little, T. A., Grapes, R. and Dixon, M. 2004. Zoned (Cretaceous and Cenozoic) garnet and the timing of high grade metamorphism, Southern Alps, New Zealand. Journal of Metamorphic Geology 22(3), 137-157.

Vry, J. K., Storkey, A. C. and Harris, C. 2001. Role of fluids in the metamorphism of the Alpine Fault Zone, New Zealand. Journal of Metamorphic Geology 19(1), 21-31.

Walcott, R. I. 1998. Modes of oblique compression: late Cenozoic tectonics of the South Island of New Zealand. Reviews of Geophysics 36(1), 1-26.

Wannamaker, P. E., Jiracek, G. R., Stodt, J. A., Caldwell, T. G., Gonzalez, V. M., McKnight, J. D. and Porter, A. D. 2002. Fluid generation and pathways beneath an active compressional orogen, the New Zealand Southern Alps, inferred from magnetotelluric data. Journal of Geophysical Research 107(B6), 20.

Wark, D. A. and Watson, E. B. 2006. TitaniQ: a titanium-in-quartz geothermometer. Contrib. Mineral. Petrol. 152, 743-754.

Wellman, H. M. 1955. New Zealand Quaternary Tectonics. Geologische Rundschau 43(1), 248-257. 
Wellman, H. W. 1979. An uplift map for the South Island of New Zealand and a model for the uplift of the Southern Alps. Royal Society of New Zealand Bulletin 18, 13-20.

White, S. 1976. The effects of strain on the microstructures, fabrics, and deformation mechanisms in quartzites. Philosophical Transactions of the Royal Society of London. Series A, Mathematical and Physical Sciences 283(1312), 69-86.

Wightman, R. 2005. Deformation and Orogenesis: the Geodynamic Significance of a Brittle-Ductile Fault Array in the Central Southern Alps, New Zealand. Unpublished $\mathrm{PhD}$ thesis, Victoria University of Wellington.

Wightman, R. and Little, T. A. 2007. Deformation of the Pacific Plate above the Alpine Fault ramp and its relationship to expulsion of metamorphic fluids: an array of backshears. Geophysical Monograph Series AGU 175, 177-205.

Wightman, R., Little, T. A., Baldwin, S. L. and Valley, J. W. Conditions of transient deep embrittlement in the lower crust of central Southern Alps, New Zealand. Journal of Geophysical Research in prep.

Wightman, R., Prior, D. J. and Little, T. A. 2006. Quartz veins deformed by diffusion creep-accomodated grain boundary sliding during a transient, high strain-rate event in the Southern Alps, New Zealand. Journal of Structural Geology 28, 902-918. 


\section{Appendix A - MATLAB ${ }^{\circledR}$ script for Chapter 2}

This appendix contains the MATLAB ${ }^{\circledR}$ script that enables one to project outcrop coordinates of deformed geological markers into the movement plane. The script consists of two separate M-files ('projection.m' and 'dircosA.m'). 'projection.m' automatically calls 'dircosA.m'. To run the code, type projection in the MATLAB ${ }^{\circledR}$ command window. The program will open a window which lets the user choose the file that contains $x_{o c}-y_{o c}$ data from the outcrop. The chosen file must be a tab-separated *.txt file with the $x_{o c}$ coordinates in the first column and the $y_{o c}$ coordinates in the second column. Once the script has read the *.txt file, it prompts the user to input the geological attitudes (right-hand-rule) necessary for the conversion of the outcrop data into the movement plane of the fault. It then asks the user to save the projected coordinates in a *.txt file and creates a figure with the new coordinates.

\section{Script 'projection.m':}

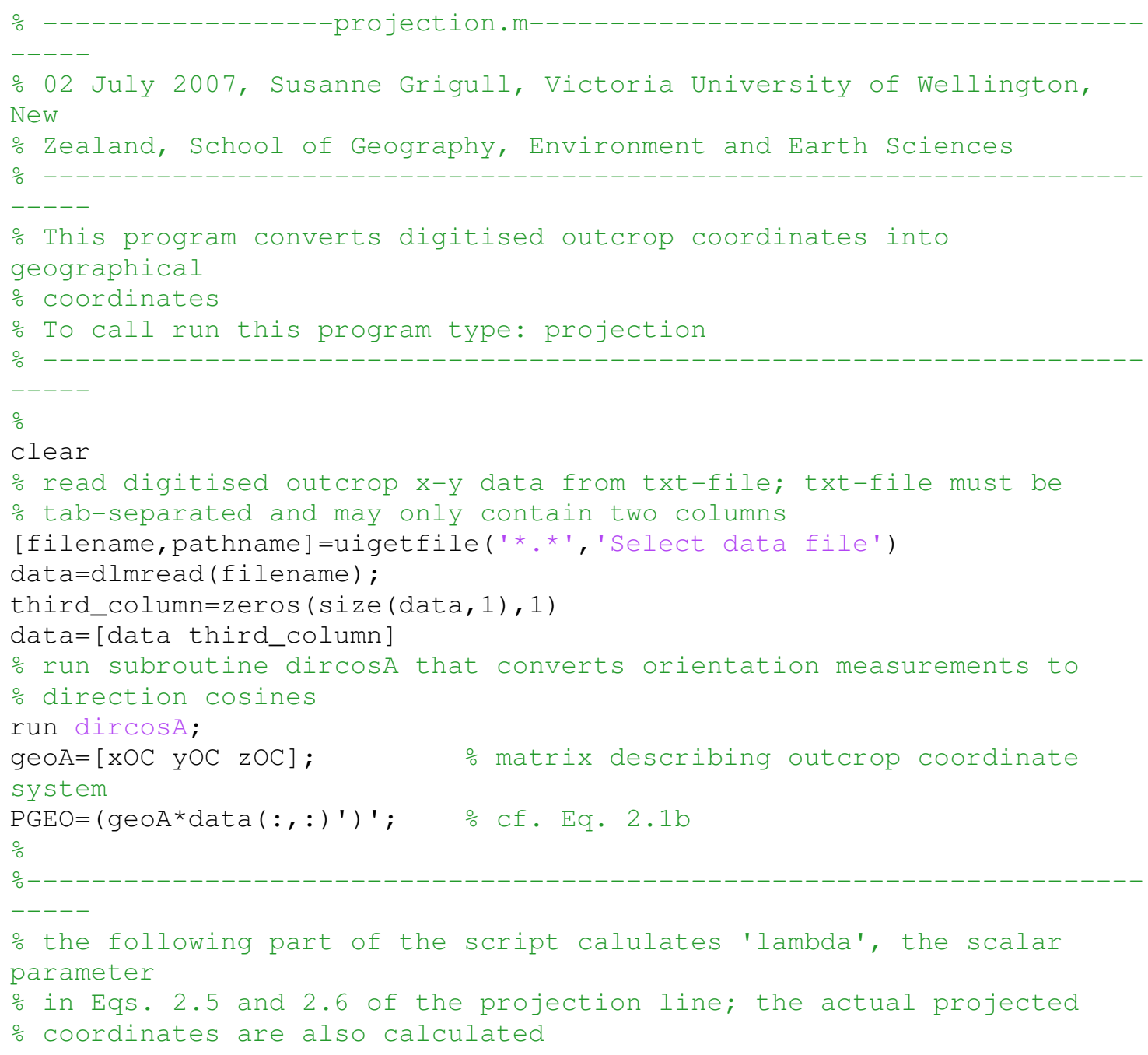




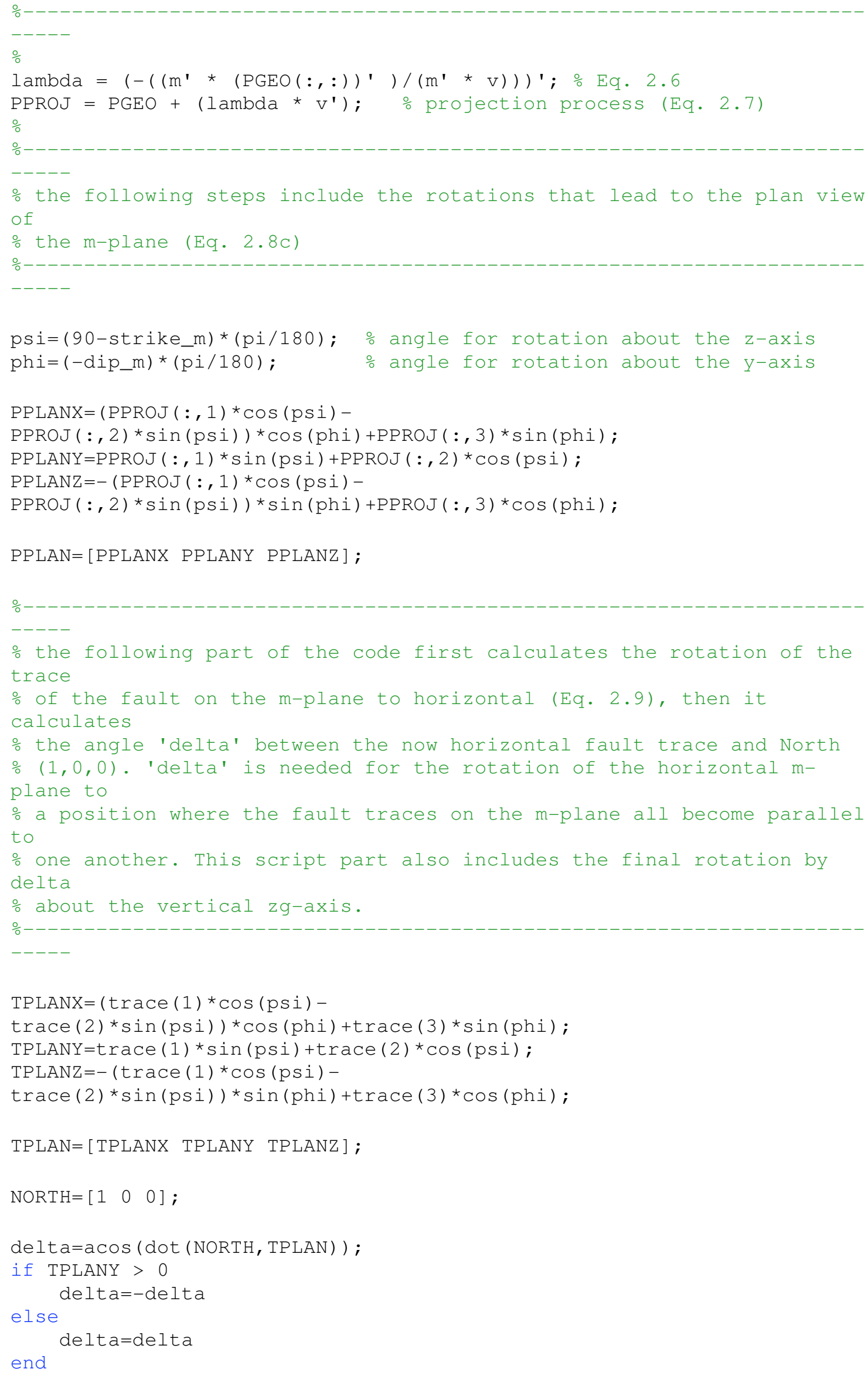




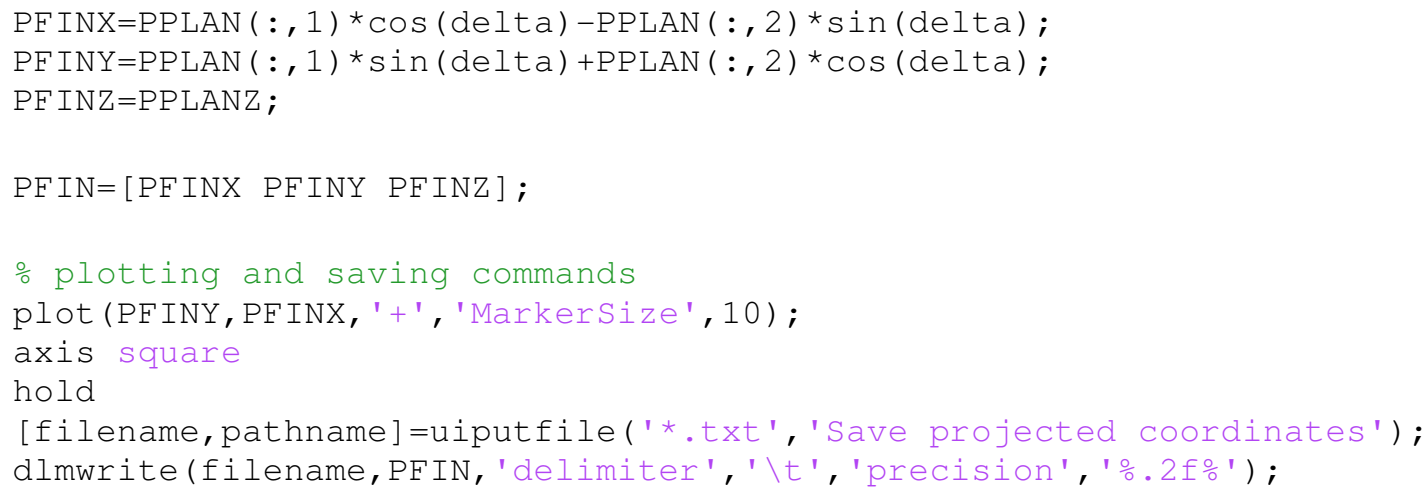

\section{Script 'dircosA.m':}

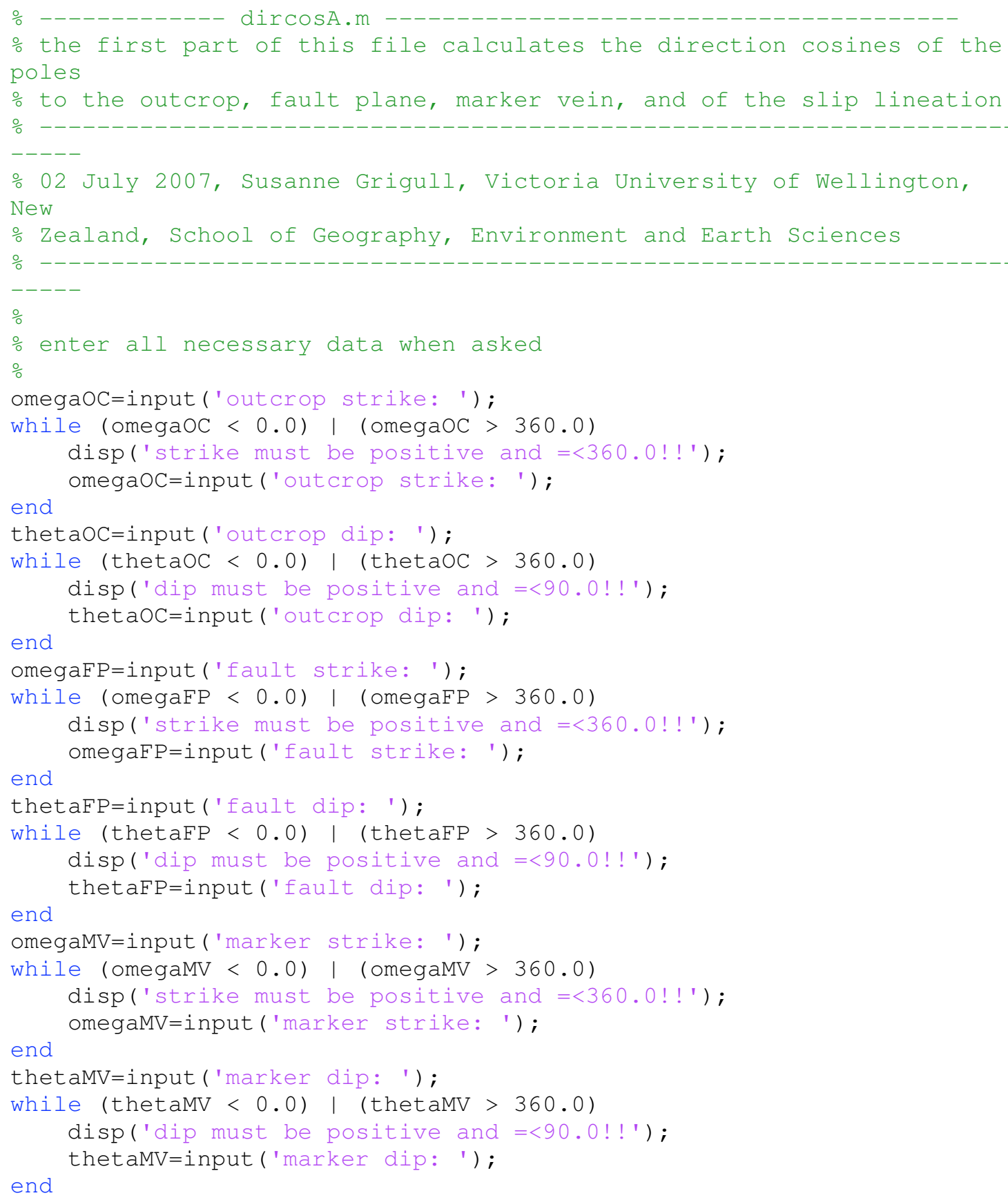




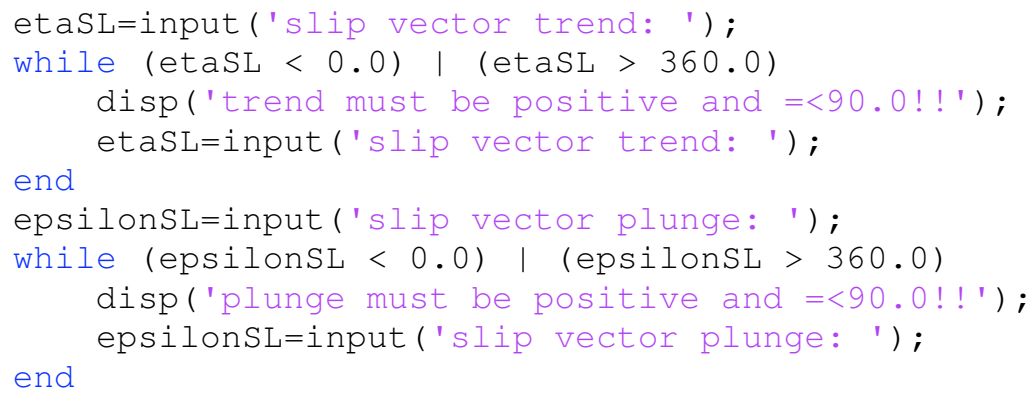




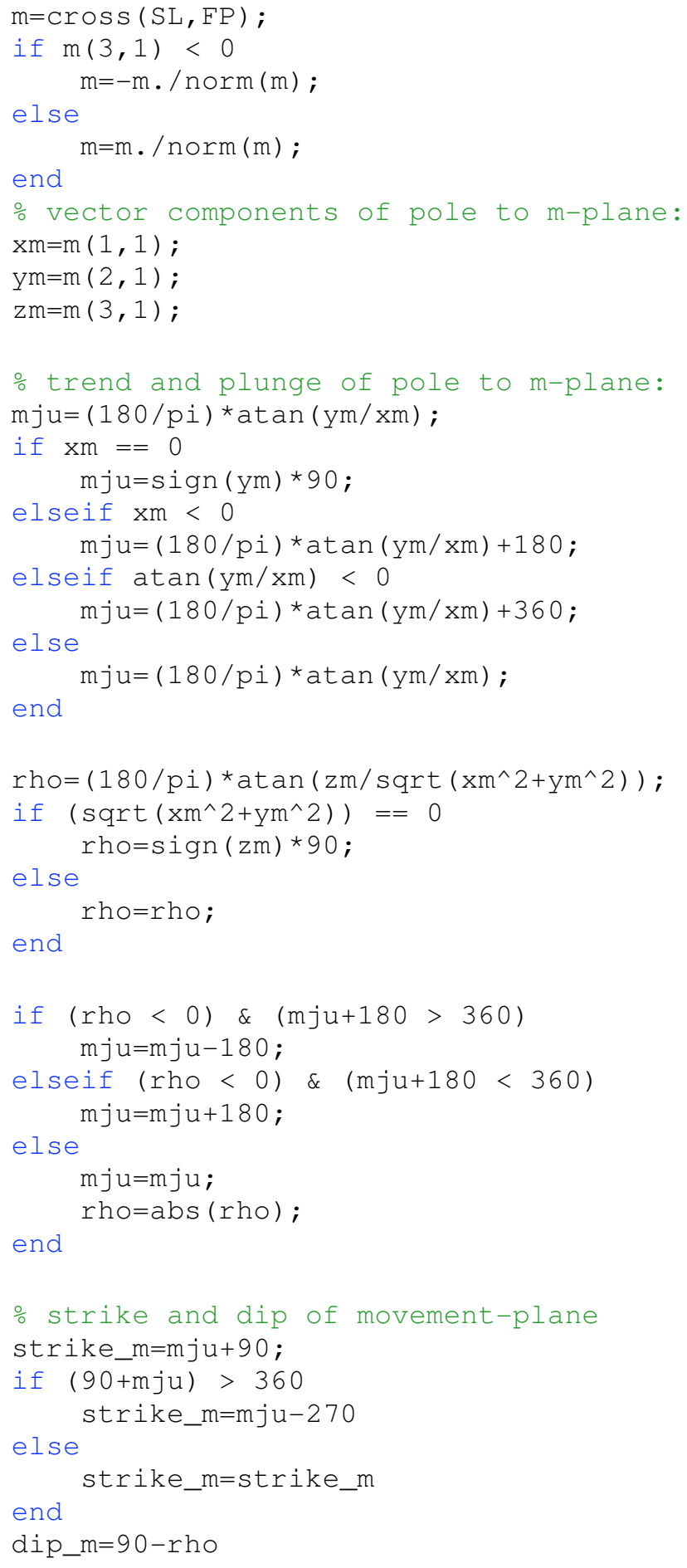




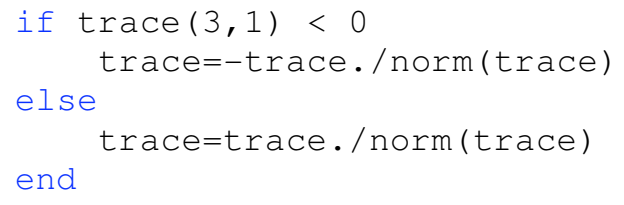




\section{Appendix B - Benchmark our code vs. Abaqus/Standard}

Our code has been tested against several standard visco-plastic benchmark problems. In addition, we have tested vein deformation problems using our code against the commercial code Abaqus (version 6.7, Simulia). Since Abaqus/Standard is a Lagrangian code with limited remeshing facilities, it is unable to handle the extremely large strains generated by the deforming quartz veins in an accurate fashion. Despite this limitation, Abaqus incorporates elastic as well as visco-plastic rheologies and has been rigorously tested against many engineering and analytical problems, and so provides a useful benchmark for the initial stages of deformation.

\section{Appendix B.1 - Model setup}

We set up the same model in both codes (see also model setup in Chapter 3). The model dimensions are $10 \times 10 \mathrm{~cm}$ and a $1 \mathrm{~cm}$ thick horizontal quartz vein is embedded in the model. For both codes, we choose initially square elements with side dimensions of $1 \mathrm{~mm}$, giving a total mesh of $100 \times 100$ elements. We imposed four tracers per element in the visco-plastic code leading to a total of 40,000 tracers in the model. For the Abaqus models, we used plane strain elements with four integration points.

Velocity boundary conditions are prescribed on all edges of the model, so that the left half is moving upwards and the right half downwards. We prescribed a $2 \mathrm{~mm}$ wide zone (initial fault) in the middle of the top and bottom edges in which the displacement rates change from left to right via a sinusoidal function, in order to prevent the build-up of sharp corners and hence avoid convergence problems in Abaqus/Standard. We used the flow law for viscous creep from Hirth et al. (2001) with a water fugacity of 200 $\mathrm{MPa}$. We translated the experimental pre-exponential factors into our model parameters according to Appendices 3.C. The frictional yield stress is defined in terms of the maximum differential stress and is set to $150 \mathrm{MPa}$ (giving a maximum shear stress $\tau_{\max }$ of $75 \mathrm{MPa}$ ) in both materials. Plastic strain softening is included in the schist in order to achieve strain localisation (Appendix 3.B). We used a competence contrast of 10 in the models, meaning that the effective viscosity of the schist is an order of magnitude higher than the effective viscosity of the quartz. Since the Abaqus models also require elastic material properties, we chose a Young's modulus of $30 \mathrm{GPa}$ and a Poisson's ratio of 0.26 for both materials. 
We ran the models at two different velocities: a) $7.9 \times 10^{-12} \mathrm{~m} / \mathrm{sec}(0.25 \mathrm{~mm} / \mathrm{yr})$, and b) $7.9 \times 10^{-14} \mathrm{~m} / \mathrm{sec}(0.0025 \mathrm{~mm} / \mathrm{yr})$ on either side of the model. At the same amount of offset, we then compared the following output results: vein shape, differential stress, frictional yield, shear strain rate, accumulated plastic strain, and accumulated creep strain.

a) Vein shape after deformation

We compared the resulting vein shapes of both codes at a total offset of $25 \mathrm{~mm}$. For both velocities, the resulting vein shapes for the two codes are reasonably similar (Fig. B.1a). For the fastest high velocity (Fig. B.1a) both codes predict a sharply displaced quartz vein localised on the shear zone. Our visco-plastic code shows some "granularity" resulting from the limited tracer resolution. In our code, the vein loses coherence in the middle, whereas in the Lagrangian Abaqus models, it is continuous. At the slow displacement rate (Fig. B.1a), both codes predict a less localised shear zone and a smooth vein shape. In both codes, the quartz vein is strongly thinned out in the middle of the shear zone, but is still coherent.

\section{b) Differential stress}

At a total offset of $25 \mathrm{~mm}$, the overall contour pattern of the differential stress is similar for both codes (Fig B.1b). Within the fault zone in the model schist, the stress values of our code match those of the Abaqus model.

In the models with the fast velocity, there is a difference in the stress contours in the "brittlely" sheared part of the quartz vein: the Abaqus models still show stress values of $150 \mathrm{MPa}$, whereas the stresses in an equivalent location in our code have lower values. This is due to our code averaging material properties in each element to reflect dominant tracer properties, whereas the material properties in Abaqus are advected with the deforming finite elements. This means that once a material property has been assigned to an element in Abaqus, it will not change, i.e. if the assigned yield strength of the quartz elements has been reached, the differential yield stress will stay at the yield value (150 MPa), since there is no strain softening in the quartz. In contrast, since the tracer densities can vary in our code, the quartz tracers become thinned out and eventually overwhelmed. Once the frictional yield for the quartz vein has been reached, the quartz in our code does not flow ductilely any more in this area, and if shearing 
continues, quartz tracers are dispersed, the vein rips off, and the Eulerian elements adopt schist material properties.

c) Frictional yield

The frictional yield flag shows where elements in the model have reached the assigned plastic yield strength (although, this does not necessarily mean that these elements are accumulating plastic strain). Both models in both codes yield along the fault in the schist (Fig. B.1c). In the faster model, the quartz yields as well, i.e. the vein deforms brittlely. The fast displacement case shows a widening of the "yielding zone" in both codes. However, the zone widens slightly more in the Abaqus models, possibly due to the high distortion of the elements at $25 \mathrm{~mm}$ offset. When compared at an offset of $2.5 \mathrm{~mm}$, both codes show approximately the same frictional yield width (Fig. B.1c).

d) Shear strain rates

At $2.5 \mathrm{~mm}$ offset within or near the quartz vein, both codes show the same values for the shear strain rates for both model velocities.

In the schist material, at an offset of $2.5 \mathrm{~mm}$, our code seems to produce slightly slower strain rates than Abaqus/Standard (factor of less than 2). This is due to the Abaqus models localising onto a slightly narrower fault zone in the schist compared to our models at this stage, so that the strain rates are more concentrated on fewer elements. If compared at $25 \mathrm{~mm}$, the strain rates in both the schist and the quartz material are almost the same (Fig. B.1d).

e) Accumulated strains

Due to the slightly more localised strain rates in the Abaqus models, they accumulate slightly higher strains over the same amount of time compared to our code. However, the plastic strain values for the faster model are very similar for both codes (Fig. B.1e).

For the accumulated creep strain, the slow model provides the best match (Fig. B.1f). Here, both quartz and schist creep viscously. Agreement at faster velocities is not so good; this is because the elements in Abaqus can both fail plastically and creep viscously at the same time, whereas our code only features either plastic or viscous behaviour. 


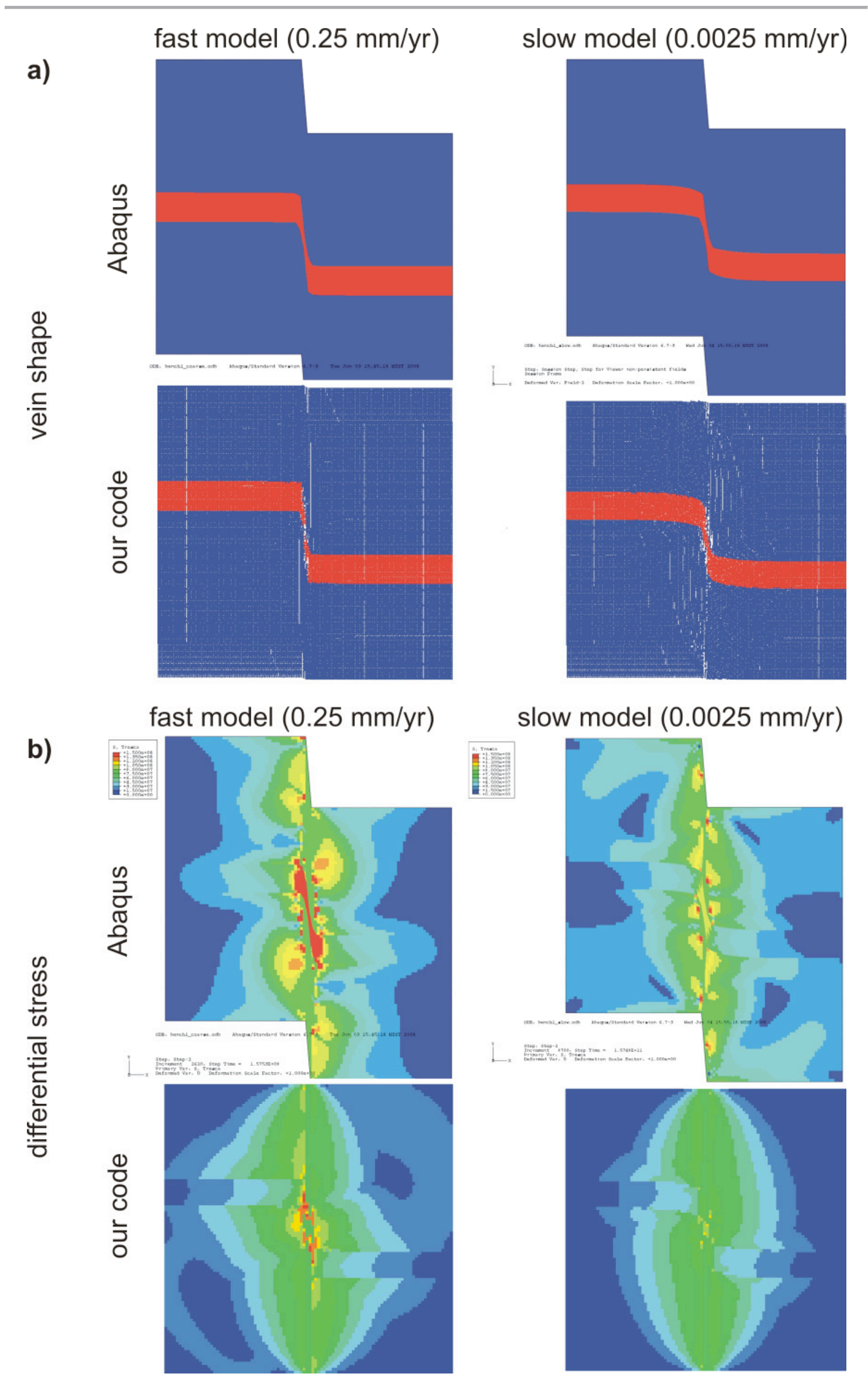




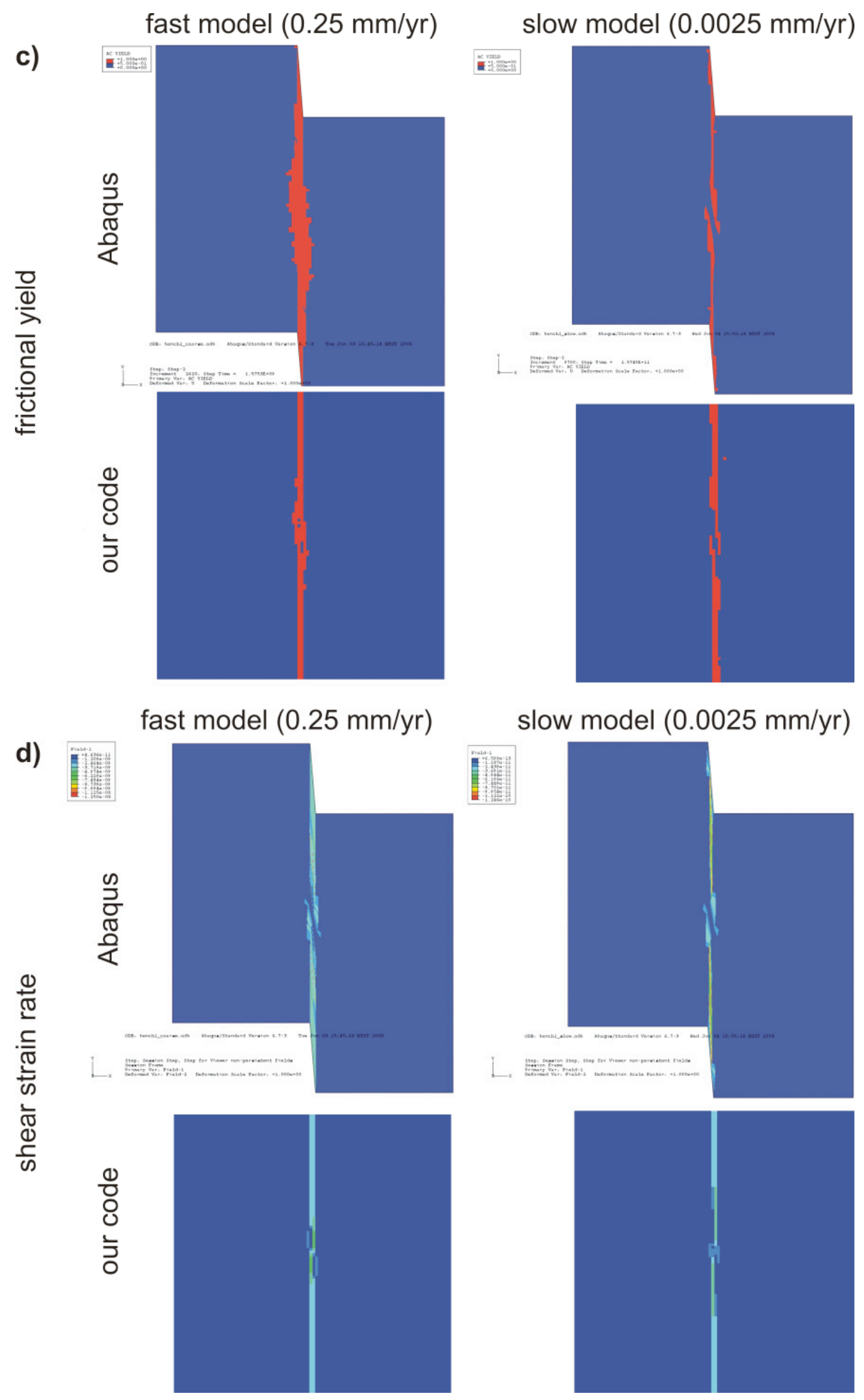




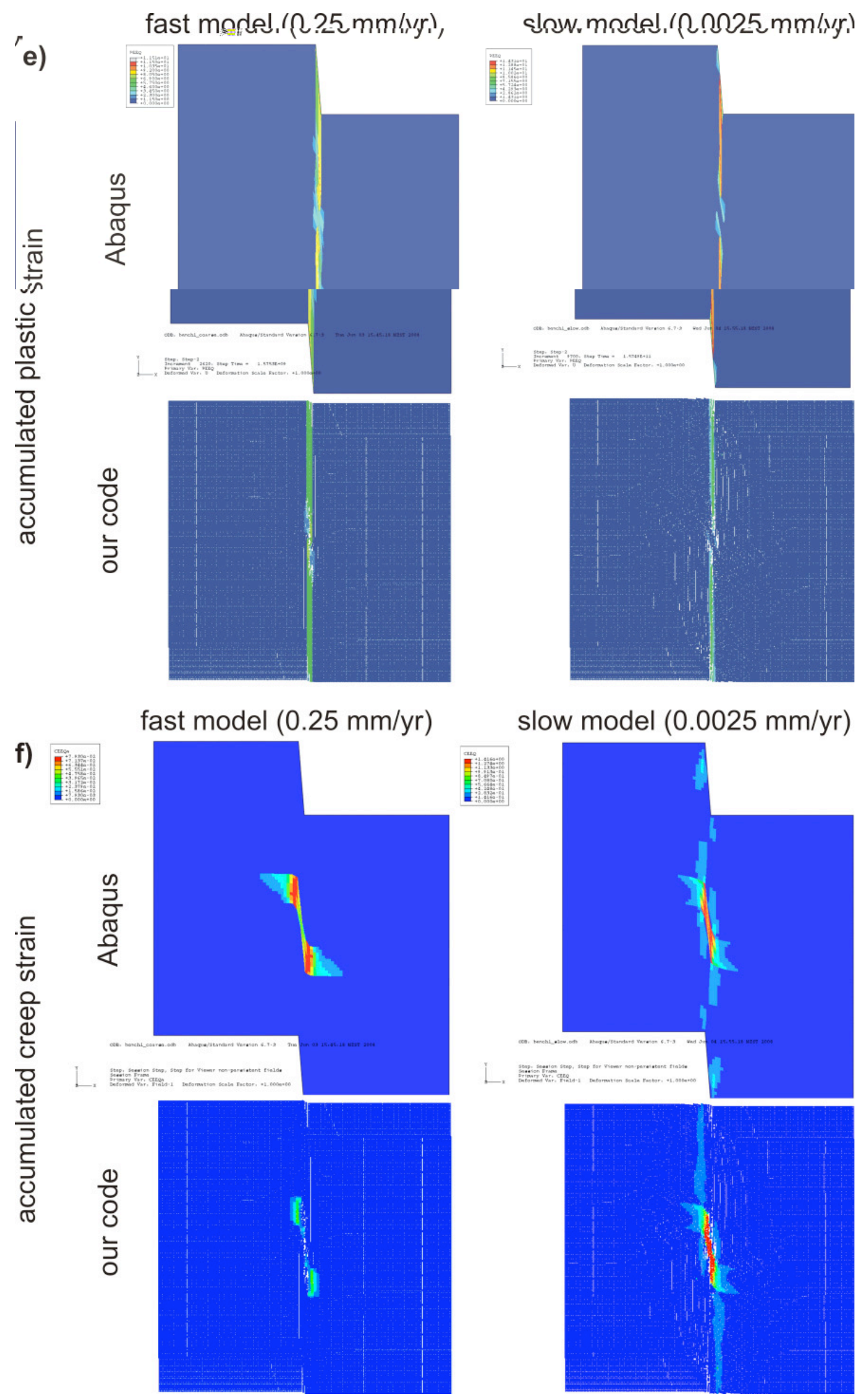


Fig. B.1 (previous page): Benchmark comparison of our code with the commercial code Abaqus (Simulia) and at a fast velocity $(0.25 \mathrm{~mm} / \mathrm{yr})$ and a slow velocity $(0.0025 \mathrm{~mm} / \mathrm{yr})$ at $25 \mathrm{~mm}$ displacement. a) resulting vein shape; b) differential stress; c) frictional yield (red: yielding, blue: not yielding); d) shear strain rate; e) accumulated plastic strain; f) accumulated creep strain.

Despite minor discrepancies, based on this small benchmark, we conclude that our code is very suitable for the modelling purposes of this paper. It produces modelling results that are very similar to the ones produced by Abaqus/Standard. In addition, our code significantly reduces CPU time (Abaqus: days, our code: hours). 